
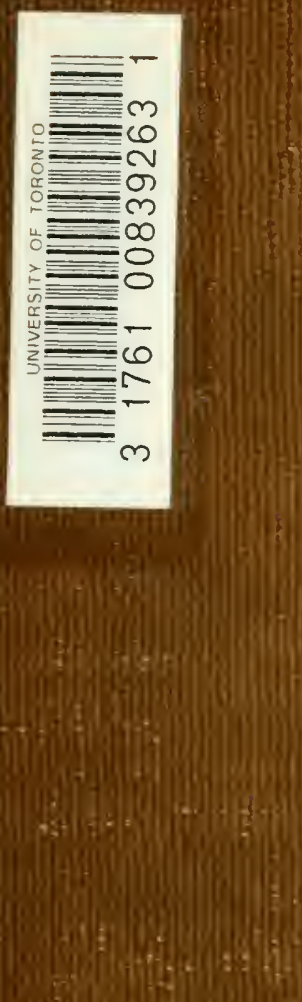

8
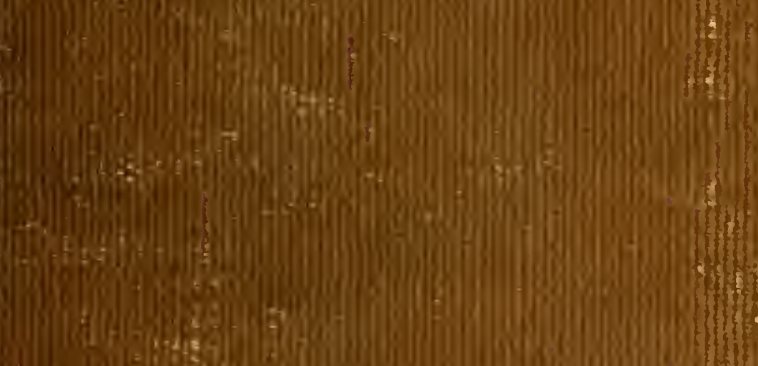

UNiv. OF TOROHTO 







\section{BODY-BUILD AND ITS INHERITANCE}

BY

\section{CHARLES BENEDICT DAVENPORT}

DiRECTOR OF DEPARTMENT OF GENETICS, CARNEGIE INSTITUTION OF WASHINGTON
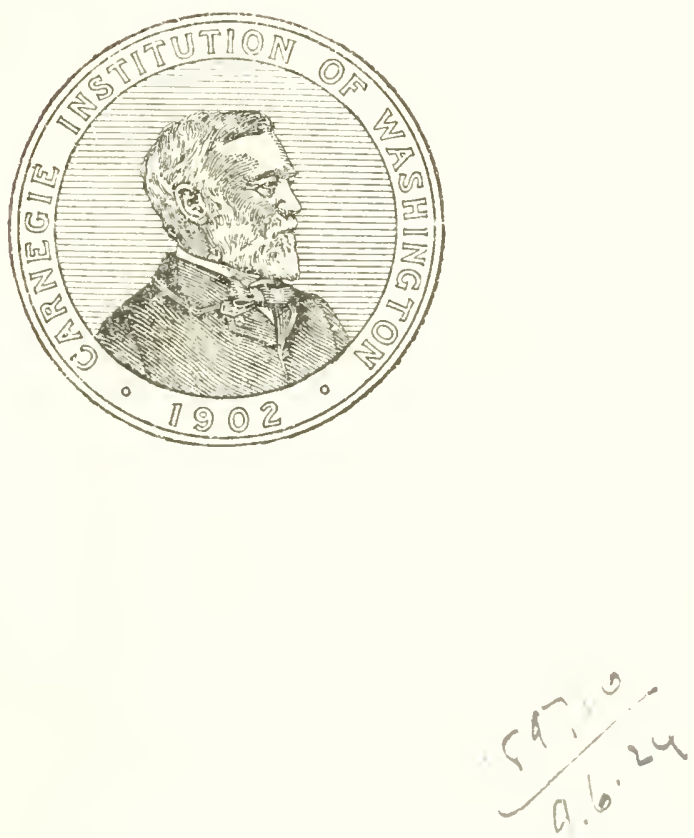

Published by the Carnegile Institution of Wasmington

Washington, Deceuber 1923 


\section{CARNEGIF INSTITUTION OF WASHINGTON}

Publication No. 329

\section{Paper No. 35 of the Departuent of Genertos}

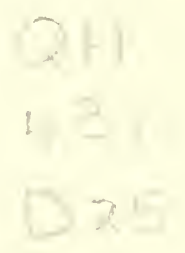




\section{PREFACE.}

This study of the hereditary factors of body-build is an outgrowth of the author's activities in the office of the Surgeon-General of the Army during the World War, where he was in charge of anthropology. In the examination of thousands of young men the extraordinary diversity of build was a striking fact. The question of its genetic basis arose and the desire was stimulated to find out if those physiologists are correct who account for variations from average build solely on the ground of special conditions of food intake and activity, and generally disregard the possibility that factors of heredity are involved. It was anticipated that the study would be a minor one. But, on account of the wealth of family data at the Eugenics Record Office, the task assumed unexpectedly large proportions. Much correspondence had to be undertaken to secure confirmation or correction of the records, and the period of analysis of the materials grew from months into years, while the manuscript of the text and tables accumulated.

Though it has added much to the bulk of the volume, it has seemed desirable to print full details about the more critical cases. Geographical location, race, occupation, and diseases have been generally given because they all bear upon build. The height and weight are of course given, and these are usually in English measurements, since they were first reported in that system. They are given in brief form thus: " $120 / 63$ inches"; which means that the subject weighed 120 pounds (usually including clothing) and was 63 inches tall (without shoes). The word "inches" is added as an indicator of the system of measurement employed. In other cases English measures, or indices based on them, are placed in parenthesis in accordance with scientific custom. Net relative chest-girths, where given, are based on measurements taken just below the axilla. are reduced to "on skin" measurements by subtracting 3 centimeters for summer clothing and 6 centimeters for indoor winter clothing, and are divided by net stature.

To this book many persons have contributed. Hundreds have furnished data on the Records of Family Traits. Dr. Bret Ratner kindly responded to my request by having daily measurements made on 11 infants during the first 10 days of life. The photographs of men of standard build were contributed by Dr. George L. Meylan; the photographs of boys on plate 3 were obtained for me by Dr. William Burdick, of the Playground Association of Baltimore. Through the 
kindness of Mr. Carle O. Warren, of the Marquand School, Brooklyn, the photographs of boys of various ages shown on plates 4 to 6 were secured. Dr. Harvey G. Beck and Dr. L. F. Barker gave permission for the republication from Barker's "Endoerinology and Metabolism" of the photographs at the bottom of plate $S$. The families who have, on request, furnished special data are too numerous to mention. To all of the foregoing $\mathrm{I}$ desire to express sincerest thanks. 


\section{TABLE OF CONTENTS.}

Preface... PAGE

Part I. Build, its defnition and its ontogeny $\ldots \ldots \ldots \ldots \ldots \ldots \ldots \ldots \ldots \ldots \ldots \ldots$

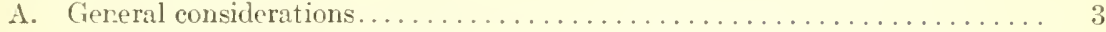

Types of variation in build. . . . . . . . . . . . . . . . . . . . . 4

The measurement of build . . . . . . . . . . . . . . . . . . . . 4

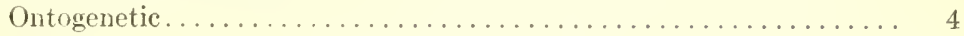

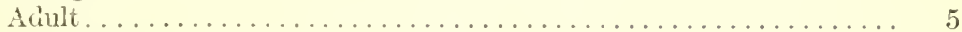

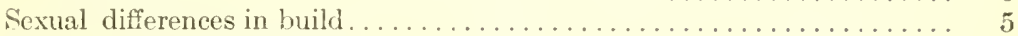

Racial differences in build . . . . . . . . . . . . . . . . . . . . . 7

Geographical differences in build . . . . . . . . . . . . . . . 7

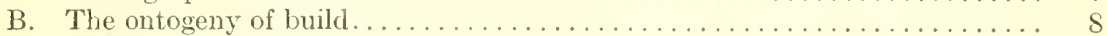

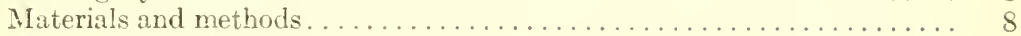

The ontogenetic curve of build . . . . . . . . . . . . . 11

Later ontogenetie changes in individual build . . . . . . . . . . . . 16

Relation of juvenile to adult build . . . . . . . . . . . . . . . . . 19

Part II. Mass studies in heredity of adult build. . . . . . . . . . . . . . . 22

Methods and materials........................... 23

The adult index of build. . . . . . . . . . . . . . . . . . . . . . . . . 24

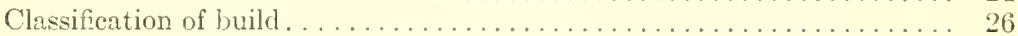

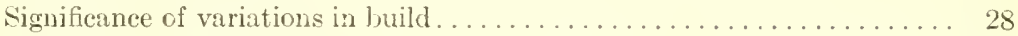

Diseases in relation to build.......................... 29

Mass study of variation and heredity in build................ 36

Regression of progeny toward mediocrity................. 37

IIypothesis. . . . . . . . . . . . . . . . . . . . . . 40

Mate selection in build. . . . . . . . . . . . . . . . . . . . 44

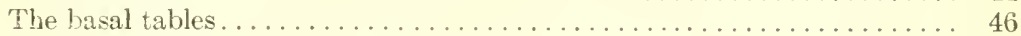

Part III. Family studies in heredity of build $\ldots \ldots \ldots \ldots \ldots \ldots \ldots \ldots \ldots \ldots \ldots \ldots$

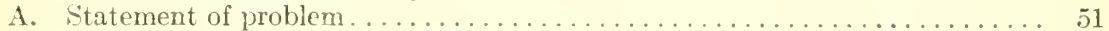

B. Discussion of special matings. . . . . . . . . . . . . . . . 51

CLass I. Both parents slender..................... 51

Mating 1 . One parent is very slender of slender stock; the other slender 51

Mating 2. Both parents are slender, of slender stock........... 53

Mating 3 . Other slender $\times$ very slender matings . . . . . . . . . . . 54

Mating 4 . Other slender $\times$ slender matings. . . . . . . . . . . . 56

Summary of slender $\times$ slender matings . . . . . . . . . . . . . . . 68

Class II. Both parents fleshy . . . . . . . . . . . . . . . . . 69

Mating 1. One parent is very fleshy, the other fleshy of fleshy stoek... 69

Mating 2. Both parents fleshy of fleshy stock .............. 77

Mating 3 . Other very fieshy $x$ very fleshy matings . . . . . . . . . . so

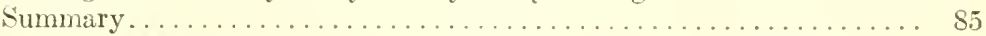

Class III. Mating of slender with fleshy stock. The F generation..... 86

Mating 1. One parent slender, of slender stoek, the other fleshy of

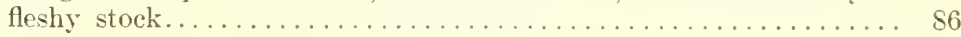

Mating 2. Other slender $\times$ fleshy matings............... 93

Mating 3 . Very slender $\times$ very fieshy. . . . . . . . . . . . . . . . 97

Mating 4 . Slender $\times$ very fleshy matings. . . . . . . . . . . 98

Summary................................ 105

CLass IV. Matings of probably heterozygous parents. The $\mathrm{F}_{2}$ genera-

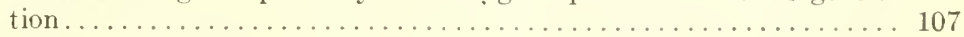

Mating 1. Both parents either medium or fleshy, and probably earrying gametes for slenderness as well as fleshiness. . . . . . . . . . . 107

Mating 2 . Other medium $\times$ medium matings . . . . . . . . . . . . . . . 118

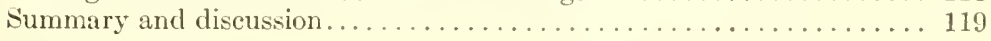


PArT 111. Family studies of luild-Continued.

B. Diselssions of special matings-Cortinued.

Class V. The back eross........................... 119

Mating 1. Heterozygous medium or fleshy $\times$ slender........... 119

Mating 2. Floshy $\times$ heterozygous fleshy parents............. 132

Summary and diseussion........................ 140

C. General discussion ................................ 141

Heredity and environment in build ...................... 141

Eudoerine glands as links between ehromosomes and somatic qualities. . . 145

Evidence of segregation in the heredity of build................. 146

(In the mumber of factors involved in fleshy huild............... 149

D. Summary of conelusions.............................. 152

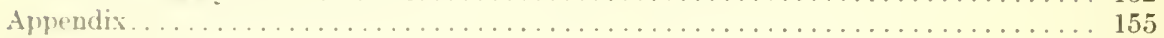

Literature eited. . . . . . . . . . . . . . . . . . . . . . . . . . . . . . 175

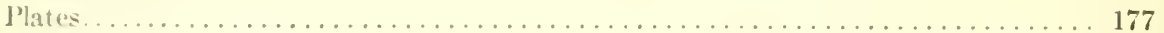




\title{
BODY-BUILD AND ITS INHERITANCE
}

\author{
BY
}

Charles Benedict Davenport

Dircctor of Department of Genetics, Carnegie Institution of Washington 



\section{PART I. \\ BUILD, ITS DEFINITION AND ITS ONTOGENY.}

A. GENERAL CONSIDERATIONS.

If a hundred men of about the same stature be compared, it is seen that they vary greatly in weight. At the same time they vary in form, and especially in bulk. This variation is popularly recognized by the variety of terms applied to build. It may be of interest to pause a moment to consider popular terminology relating to build. We have, first, terms expressing a marked deviation below the normal build. We speak of persons as "slender," "thin," "gaunt," "slim," "slight," "spare," "lank," and "spindling." These terms are not exactly synonyms. "Lank" implies angularity; "gaunt" connotes the ravage of disease; "thin" connotes a loss of weight; "slight" connotes lightness and smallness of bone; "spindling" is used especially of youth in the period of rapid growth preceding adolescence; "slim" has a faint connotation of insufficiency; "slender" best expresses the idea which we shall want to use in this work where we have a relatively small interest in stature and where we wish to avoid connotation of disease, developmental changes, etc. In other languages there exists a series of terms which similarly differ slightly in connotation. Thus, in French, there is "maigre," in German "mager," which often connote a loss of weight through disease, "duinn," which connotes loss of a former more nearly average weight, and "schlank," which is close to the English "slender." On the other hand, the English language contains a variety of terms applicable to deviation in build above the average. Thus we have the words "stout," "portly," "fleshy," "corpulent," "thick-set," "obese," "chubby," and "fat." The word "stout" usually carries a connotation of vigor. The term "portly" connotes large size with a tendency to excessively great circumference. "Fleshy" is nearly synonymous with "portly" but has less connotation of majesty of size. "Corpulent" usually carries a connotation of abdominal enlargement. "Thick-set" implies a large bony frame. "Obese" frequently connotes excessive, strictly pathological, increase of build. "Chubby" is applied especially to infants. "Fat" connotes excessive production of fat in the body, as opposed to an unusually large muscular development. Perhaps of all of these terms "fleshy" is as satisfactory as any as an expression for build without connotation in respect to degree or source of great weight, whether due to fat, muscle, or bone. In the German language there are the terms, "plump," and "schwerfällig," which serve to express large build. In the French language there are the terms, "gros," "obese," and "embonpoint," which is near to the English equivalent 
"stout" or "fleshy." In the present work the term "fleshy" is used, despite its slight suggestion of muscular development merely, largely because it begins with a different letter from slender. The word "slender" will be used for the other extreme of build. It has been found convenient to indicate those terms by their initial letters " $\mathrm{S}$ " and " $F$ " respectively.

Our main problem is, in how far does this difference in build between slender and fleshy persons depend on constitutional factors?

\section{Trpes of Yariation in Build.}

Two types of rariation in build have to be distinguished: $(a)$ the ontogenetic change in normal build during development with increasing stature, and (b) the change in weight in adults of relatively invariable stature. In type $a$, stature and other proportions are rapidly changing, but in type $b$, stature remains constant, and, throughout the race, stature does not differ as much in mature persons as it does from birth to maturity. These two types follow different laws and must be studied by different methods. Consequently they are considered in distinct parts of the present paper.

\section{Tife Measurement of Build.}

It is now necessary to consider how build may best be expressed quantitatively. The subject of the best index of build has been much discussed, but without sufficiently differentiating between the two types of variation in build, the ontogenetic and the adult. One of the latest authors to consider the matter is Bardeen (1920, p. 486), who mentions the desirability of recording the volume of the body as a whole, notes its impracticability, and concludes that we may estimate volume from weight. It may, however, be doubted if volume is really inrolved in the popular notion of build. At least, it is equally probable that the idea of build, as popularly conceived, is a relation of transverse to vertical diameters. When I look at a man, or a photograph of one as in plate 1, and think, "he is slender." it is because I make a mental comparison of his breadth (of shoulders or ehest) with his height and find that his breadth in comparison with that of most men I know of that height is small; or if he is stout the diameter of the chest is large in relation to stature (plate 2). It seems probable that breadth in relation to height gives the best expression of the popular idea of build. By the use of this relation, build can be easily expressed for any age, since chest eireumference (which bears a nearly constant relation to chest diameter) has been recorded for many persoms of all agres.

Untogcnetic. - Since in so many children and young people the stature and chest circumference have been measured, it is possible to use these data in finding the law of normal ontogenetic changes in 
build from birth to maturity. This ratio, chest-girth $\div$ stature, has thus been used in discussing this law, as more fully described in section $B$. This relation can be used for tracing the change in build of the same developing child or for tracing the average change of build.

Adult.-In the study of adult changes of build we start with the condition that in the individual the stature is fixed. Consequently, in an individual whose weight is changing, the relation of the build at $a$ years is to that at another period $n$ years later as chest-girth at $a$ years: chest-girth at $a+n$ years. Thus, in the adult period, changes of build are proportional to chest-girth. In different persons, of differing stature, the stature has to be taken into account, and the differences in build are measured by the relation of relative chestgirth as in children. Unfortunately, in our study of heredity in adult build, we usually do not know the chest-girth of the different members of the family, but only their stature and weight. Our problem is, then, to find a relation between chest-girth and weight that will enable us to infer the one from the other. This problem will be further consiciered in a later section (p. 24).

\section{Sexual Differences in Build.}

Sex influences the body so profoundly that we have, first of all, to consider its influence on build, either in early or in adult stages. At birth there is, on the average, a difference between the sexes in weight. The male is about 2.5 per cent heavier than the female (3,310 : 3.230 grams in German children. Daffner, 1902, p. 125, quoting Hecker: 3,606 : 3,485 grams in American children, Benedict and Talbot, 1915). But this does not imply that the boy baby is the chubbier, since the boy baby is longer by about 1.7 per cent than the girl baby. There is no obvious difference in the chubbiness of the sexes at birth. Likewise, in later infancy no obvious difference has been detected, though no thoroughgoing studies have been made on this subject. In childhood and youth children of different sex differ in build on the average, but this is because the form of the ontogenetic curve of build is very different. After maturity and cessation of growth, there is a marked difference in form between the sexes. The female has more subcutaneous fat and appears plumper. If the criterion of weight be applied, the complication arises that the specific gravity of the female seems to be less than that of the male (Bardeen, 1920, p. 485, following Meeh, 1895). As found by Medico-Actuarial Mortality investigations of the Associated Life Insurance Medical Directors of the Actuarial Society of America, 1912, volume I, p. 251: "The difference in weight between men and women of the same height is slight under the age of 20 , but above that age young men are distinctly heavier than young women, the difference becoming less marked as they grow older. The tall women are markedly lighter 
than men of the same height." The main reason for the greater weight of young men is their relatively much greater chest circumference.

T'+BLE: 1. - The distribution of frequencies of the various classes of build of ofspring derived from the various types of matings.

Semmation Table, Males only. Based on Table 11.

\begin{tabular}{|c|c|c|c|c|c|c|c|c|}
\hline \multirow{2}{*}{$\begin{array}{l}\text { Type of } \\
\text { inating. }\end{array}$} & \multirow{2}{*}{$\begin{array}{l}\text { No. of } \\
\text { matings. }\end{array}$} & \multirow{2}{*}{$\begin{array}{l}\text { No. of } \\
\text { children. }\end{array}$} & \multicolumn{5}{|c|}{ Build of male offspring. } & \multirow{2}{*}{$\begin{array}{l}\text { Total } \\
\text { No. } \\
\text { male and } \\
\text { female } \\
\text { children. }\end{array}$} \\
\hline & & & is & $S$ & II & $F$ & $V F$ & \\
\hline $1 \leq \times s$ & 4 & $\overline{5}$ & 1 & 2 & 1 & 1 & 0 & 11 \\
\hline $13 \times M$ & $s$ & 11 & 0 & 2 & 7 & 2 & 0 & 28 \\
\hline$V S \times F$ & 5 & 12 & 0 & 1 & 4 & 6 & 1 & 25 \\
\hline$S \times S$ & 23 & 29 & 1 & 21 & 7 & 0 & 0 & 47 \\
\hline SXM & 101 & 172 & 0 & 12 & 116 & 38 & 6 & 306 \\
\hline $\mathrm{s} \times \mathrm{F}$ & 49 & SS & 1 & 5 & $5 \mathrm{I}$ & 30 & 1 & 155 \\
\hline$\therefore \times V F$ & 11 & 23 & 0 & 3 & 8 & 10 & 2 & 34 \\
\hline$M \times M$ & 92 & 175 & 0 & is & 117 & 40 & 3 & 327 \\
\hline$M \times F$ & 114 & 194 & 0 & 9 & 118 & 58 & 9 & 340 \\
\hline $\mathrm{MI} \times \mathrm{VF}$ & 30 & 59 & 1 & 3 & 21 & 24 & 10 & 112 \\
\hline$F \times F$ & 33 & 77 & 3 & 30 & 34 & 6 & 4 & 156 \\
\hline$F \times V F$ & 30 & 57 & 0 & 0 & 22 & 28 & 7 & 100 \\
\hline $\mathrm{VF} \times \mathrm{VF}$ & 7 & 21 & 0 & 0 & 9 & 3 & 9 & 30 \\
\hline Total... & 507 & 926 & 7 & 106 & 515 & 246 & 52 & $1,6 \pi 1$ \\
\hline \multicolumn{3}{|c|}{ Average build. } & 25.00 & 29.03 & 33.64 & 39.15 & 49.09 & \\
\hline
\end{tabular}

Average male index of build, $35.81 \pm .12$. Standard deviation, $5.33 \pm .084$.

TABLE 2.-The distribution of frequencies of the various classes of build of offspring derived from the various types of matings.

Sumation Table, Females oxly. Based on Table 11a.

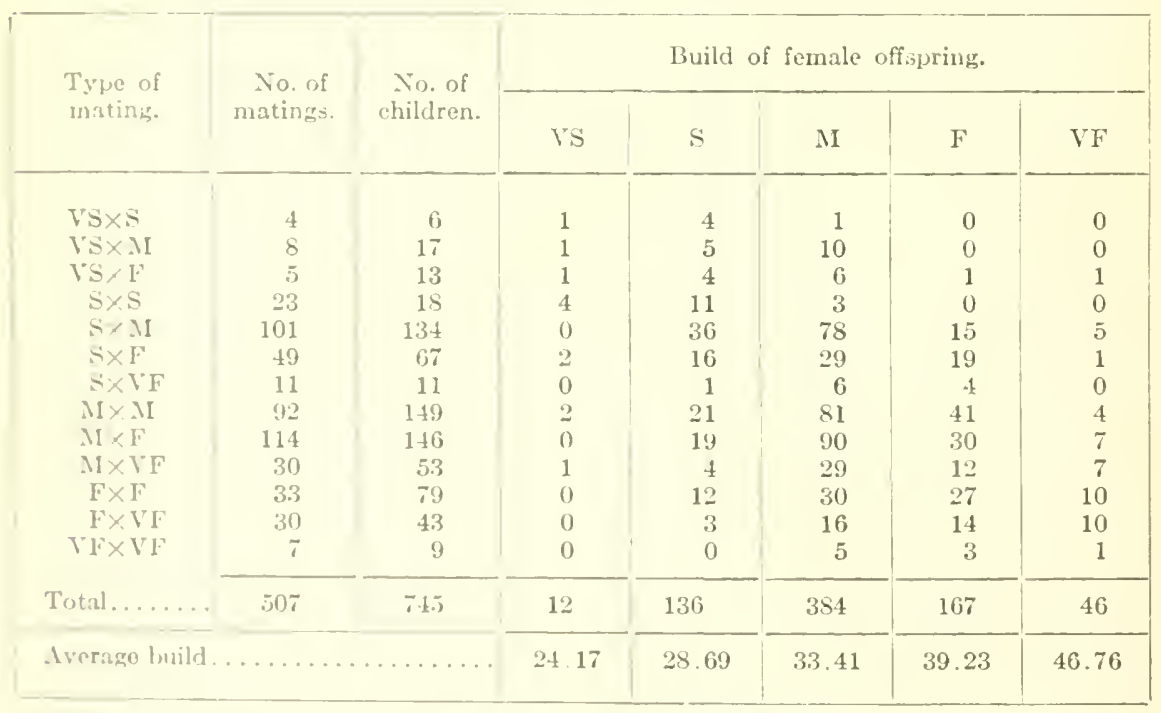

Average female in lex of build, $34.51 \pm .13$. Standard deviation, $5.13 \pm .09$. 
Proceeding by a method to be developed later, I have divided adult build into five classes, and counted for the various matings the number of children falling into each. (See tables 1 and 2.) The average index of build, obtained from the individual indices of huild, is 2.52 (metric system) or $35.81 \pm 0.12$ (English system) for males, and 2.43 $(34.54 \pm 0.13)$ for females, a difference of only 3.7 per cent in favor of the males, a difference that for our purposes can be neglected. A separation of the sexes in our studies will therefore be, ordinarily, not attempted, and this has the advantage in giving us larger frequencies in our tables.

\section{Racial Differences in Build.}

That there are marked racial differences in build is notorious. The slender Scotchman (plate 1, fig. 3) is in striking contrast with the South Italian, Greek, or Russian Jew (plate 2, fig. 3). The Eskimo are noted for their fleshiness, but Aretic conditions seem to favor large build. (See Davenport and Love, 1921, p. 165.) Martin (1914, p. 248) gives an average body-build of 1.42 (2.3 our system) for South Russian Jews and 1.07 (1.7 our system) for Bushmen. Probably the Nilotic negroes are the slenderest race on earth (Martin, 191, p. 254; for photograph see Martin, p. 263, or Davenport, 1917, p. 347). The racial differences in body-build are so great that, when feasible, race should be taken into account in studies on body-build.

\section{Geographical Differences ix Build.}

Apart from race, it seems probable that climate influences build. The races that live in the north polar region are of stout build, but this may be a racial trait. On the other hand. the whites who come to live near the pole are heavier than those who live near the equator. This may be due to relative freedom in the subpolar area from certain diseases which reduce weight. There may, however, be a physiological response of the body to the long, cold winters. Whatever the explanation, men from Alaska were found, at mobilization of the United States Army in 1917-18, to have a much higher index of build than those from any other region, i. e., 2.28 (32.41) $;^{a}$ North Dakota and South Dakota came next, with indices of 2.24 (31.85) and 2.23 (31.73) respectively. These were followed by Montana, Minnesota, and Wisconsin. Contrariwise, the recruits from the Gulf States had a low index of build. Whatever the determining causes, geographical differences in build do exist. Consequently, in studies of build, it is desirable to consider the residences of the persons studied.

\footnotetext{
a The method of measuring build is discussed at page 24. The smaller index (usually lying between 1.5 and 4.5) is the metric index. The larger index (2o un to 100) is the English system index, and is usually expressed without decimals.
} 


\section{B. THE ONTOGENY OF BUILD.}

From the time of fertilization of the egg it proceeds on its course of development directed by its "hereditary factors," but modifiable by the conditions offered by the environment. Thus is determined the weight of the baby at birth, and thus the build of the later stages to maturity are directed. It has seemed useful to measure the changes in build from birth to maturity, using the method of measuring build durine development described in an earlier section (p. 4).

\section{Materials and Metiods.}

The materials arailable for such a study are considerable and may be drawn from a large number of different nationalities. A selection had to be made from this material; there were chosen the best available series from those nationalities most representative of the population of the United States, considering the diversity of its European origin. Two sets of data were utilized: first, collections of measurements made on males from 1 year to 21 years; second. some collections from children of both sexes from birth to 1 year of age.

The first collection of data is gathered from nine sources, listed below. The data used are given in detail in table 3, which shows the number of individuals measured by each observer at each age, the average relative chest-girth at that age, and the average, for each age, of the different averages of the relative chest-girths formed by each observer. These averages are not weighted, since the racial stocks measured by the different observers differed. The average of each observer has therefore to be considered as a unit of nearly equal value with that of any other (table 3 ).

1. Quetelet (1870) data. As Quetelet's original book was not available, the data reprinted in Bardeen (1920, p. 544) were used. Quetelet measured 10 persons at each age from 1 to 20 years (and older). He selected his subjects with good judgment and the resulting eurve of varying build is remarkably smooth. The subjects were doubtless Belgians.

2. Weissenberg (1911) data. These were gathered by observations on South Russian Jews. The numbers observed ranged from 15 males at birth to about 40 to 100 at later ages. This series is of especial value because such large numbers of individuals of each age were measured and because in it are considered only children as near as possible to their birthdays; that is, as 2 or 3 year old children were taken those of exactly 2 or 3 years \pm 2 months; as 4,5 , and 6 year olds, 4,5 , and 6 years \pm 3 months; as 7 and 8 years, 7 or 8 years \pm 4 months. For older children the even year \pm 5 months was taken. The measurement was taken at the line of the nipples and below the lower apex of the scapulæ; chest apparently at rest.

3. Benedict and Talbot (1920) data. These were gathered from healthy children of Boston, Massachusetts. Girth was taken at the nipples, in a quiescent condition. The number of individuals considered at each age is small (1 to 9), but the (ata are preeious, because so few have been published for the period 2 to 5 years. 
ONTOGENY OF BCILD.

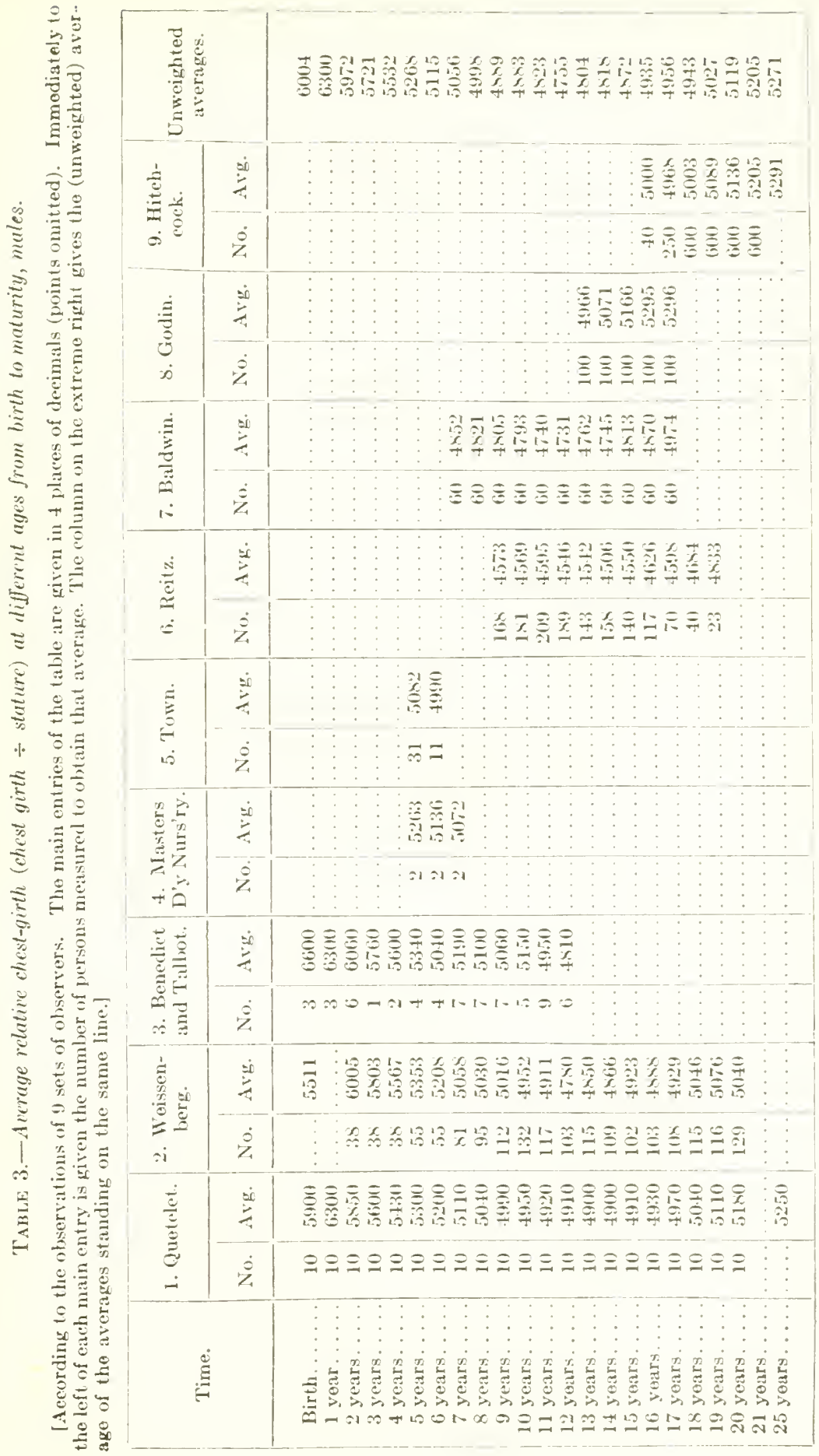


4. Masters Day Nursery data. Original, from measurements made upon health children in New York City. The rlest was measured at the line of the nipples in at quiescent conclition. The nmbers are small, 2 per year.

5. Tow (1922) diata. A sperial study of 5 and 6 year old children of Cedar Rapids. Iowa. There were 31 and 11 dhildren respectively".

6. Reitz (1904) data. A study of school children of Berlin, Germany. Chest-girth measured "at rest." From 23 to 209 at the respective ages from 6 to 19 years, inclusive.

7. Baldwin (1921) data. A group of 60 boys of the rell-to-do class at the Horace Mann Schnol. New York City, were measured repeatedly in succesive vears from 7 to 17 years of age inclusive. Chest at "normal" condition.

S. Godin (1903) data. Measurements taken annually on the same 100 boys in a French military school at St. Hippolyte-du-Fort, Gard. Chestgirth below pectoralis in repose. Ages $131 / 2$ to 17 years inclusive.

9. Hitchcock. Sceler, and Phillips (1900) data. Measurements made on about 40 to 600 students at Amherst College at each age from 16 to 26 years inclusive. The chest-girth is made at the level of the nipples and embraces the scapulx.

Owing to the complex nature of the curve of build during the first year of development, special collections of data were made for this portion of the curve (table 4). They are listed as follows:

1. Original data contributed by Dr. Bret Ratner, pediatrician, of New York, being measurements made in May and June, 1922, of weight, length, and chest circumference on 11 babies at the Manhattan Maternity Hospital during each of the first 10 days after birth. There were 9 boys and 2 girls. Judging alone by the surnames, there were apparently of British stock 6, of German stock 2, of Italian stoek 2, and of Spanish stock 1 . It is very difficult to measure length and chest-girth of infants. Length "on birthday" was generally taken with the child suspended by its feet, chestgirth with the chest as quiet as possible. The first measurement was taken ats soon as the baby was born, and each morning thereafter at $8^{\mathrm{h}} 30^{\mathrm{m}}$ a. m. The liter lengths were measured on a grarluated board.

2. New York Milk Station data collected by Miss Louise A. Nelson and Miss Margaret R. Babcock, of the Eugenies Record Office staff. They were made during May and June 1922, on healthy babies, without elothing. The length was measured with the aid of a graduated board. Boys and girls were both included, as at this age their build is not very different, on the average. The numbers ranged from 4 to 52 for the various months from 0.5 month to 13 montlis by 0.5 -month intervals.

3. Ratner adranced data. Original data secured by Dr. Bret Ratner lat Manhattan Maternity Hospital, New York City, on healthy children whose parents brought them repeatedly to the hospital) and kindly given to the writer for this study. In this series, observations are especially abundant at $1,1.5$, and 2 months $(47,170$, and 30 cases respectively).

4. Grover (1915) data. Boys only among out-patients of the Children's Ifospital, Bo-ton, and risitors at milk stations. No clothing. Chest measured at level of nipples, milway between inspiration and expiration. Length measured on graduated hoard. From 2 to $\overline{5}$ at each month of age.

j. Benerlict and Talbot (1920) data. (See No. 3, p. 9.) One to 6 individuals at the various months. 
6. Schmid-Monnard (1892) data. Copiel from Bardeen (1920, page 542). Boys and girls measured at Frankfort am Main, Germany. 8 to 67 in respective months. Ages 1 to 13 months and up to 30 months.

7. Crum (1915) data. Average measurements of babies without regard to sex, 193 to 264 per month, mostly baby-show babies and hence strongly selected. Various parts of the United States.

From the foregoing collections of data, tables 3, 4, and 5 were drawn up, giving for each age the mean relative chest-girth found by each observer. Also, the number of individuals upon which the measurement is based, necessary for weighting the mean. The mean of all measurements was weighted in table 4 , but not in table 3 for the reasons stated on page 8 .

TABLE 4.-Average relative chest-girth of infants from birth to 19 months.

lObtained from 6 series of observations, described on pages 12, 13. The main entries of the table are given in 4 places of decimals (point omitted). Immediately to the left of each main entry is given the number of persons measured to obtain that average. The column at the extreme right gives the weighted averages of the averages standing in the same line.]

\begin{tabular}{|c|c|c|c|c|c|c|c|c|c|c|c|c|c|}
\hline \multirow{2}{*}{ Time. } & \multicolumn{2}{|c|}{ 3. Ratner. } & \multicolumn{2}{|c|}{$\begin{array}{c}\text { 2. N. Y. } \\
\text { Milk } \\
\left(\sigma^{7} \text { and } q\right) .\end{array}$} & \multicolumn{2}{|c|}{ 4. Grover. } & \multicolumn{2}{|c|}{$\begin{array}{l}\text { 5. Benedict } \\
\text { and Talbot }\end{array}$} & \multicolumn{2}{|c|}{$\begin{array}{l}\text { 6. Schmid } \\
\text { and } \\
\text { Monnard. }\end{array}$} & \multicolumn{2}{|c|}{ 7. Crum. } & \multirow{2}{*}{ Aver. } \\
\hline & No. & Avg. & No. & Avg. & No. & Avg. & No. & Avg. & No. & Avg. & No. & Avg. & \\
\hline 2 weeks & 32 & 6641 & 4 & 6533 & & & 3 & 6599 & & & & & 6627 \\
\hline 1 month & 47 & 6602 & 26 & 6504 & 2 & 5861 & 2 & 6249 & 67 & 6280 & & & 6419 \\
\hline 1.5 months & 170 & 6772 & 36 & 6639 & & $\ldots \ldots$ & 4 & 6574 & . & 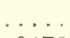 & & & 6745 \\
\hline 2 months & 30 & 6670 & 52 & 6623 & 4 & 6661 & 3 & 6765 & 44 & 6470 & & & 6512 \\
\hline 3 months & 11 & 6700 & 49 & 6566 & 3 & 6220 & 4 & 6529 & 37 & 6040 & & & 6382 \\
\hline 4 months & 12 & 6542 & 39 & 6542 & 3 & 6157 & 4 & 6304 & 30 & 6510 & & & 6507 \\
\hline 5 months & 10 & 6492 & 26 & 6522 & 3 & 6278 & 3 & 6455 & 37 & 6230 & & $\ldots$ & 6368 \\
\hline 6 months & 8 & 6500 & 39 & 6542 & 5 & 6278 & 6 & 6117 & 27 & 6540 & 259 & 6556 & 6540 \\
\hline 7 months & 10 & 6720 & 27 & 6424 & 3 & 6203 & 3 & 6500 & 19 & 6240 & 256 & 6468 & 6456 \\
\hline 8 months & 3 & 6267 & 23 & 6317 & 4 & 6464 & 1 & 6308 & 16 & 6400 & 232 & 6470 & 6450 \\
\hline 9 months & 3 & 6550 & 26 & 6364 & 3 & 6060 & 4 & 6352 & 29 & 6160 & 211 & 6355 & 6333 \\
\hline 10 months & 2 & 6200 & 18 & 6431 & 2 & 6237 & 2 & 6110 & 17 & 6400 & 209 & 6404 & 6400 \\
\hline 11 months & 1 & 6600 & 13 & 6354 & 2 & 5868 & 1 & 6174 & 15 & 6120 & 193 & 6336 & 6318 \\
\hline 12 months & 1 & 5800 & 8 & 6271 & 1 & 5691 & 1 & 6383 & 22 & 6090 & 289 & 6298 & 6280 \\
\hline 13 months & & $\ldots$ & 11 & 6186 & & $\ldots \ldots$ & 1 & 6026 & 19 & 6080 & 264 & 6235 & 6222 \\
\hline
\end{tabular}

It will be observed that the means of build differ, for the constant age, more than do the differences between successive ages. That is to say, the absolute difference between races at any given age is greater than the average differences between one year and the next.

The mean relative chest circumferences for the different ages are plotted in figure 2.

\section{The Ontogenetic Curve of Build.}

The resulting curve of build from birth to maturity is given in figure 1. This curve shows that build in males is greatest at birth, or at about 1 month, and that it then steadily diminishes to 12 years 
of age. It then slowly increases to maturity, and indeed to 30 years, after which it increases with extreme slowness, probably to 55 years.

From table $4 \mathrm{~A}$ and the curve of build, figure 2, we see that the infant at birth has a chest-girth which is somewhat over two-thirds of stature $(0.6685)$. It falls rapidly to one month after birth, and then begins to rise. This minimum is connected with the loss of weight which follows birth, and is due to the difficulty of making adjustments to the new conditions which the organism has to ineet. This adjustment is soon thereafter completed and within 2 months chest-girth and weight are not only recovered, but have caught up with increasing length of body. At 6 weeks the body has reached its maximum post-natal chubbiness. Another temporary loss in chubbiness occurs

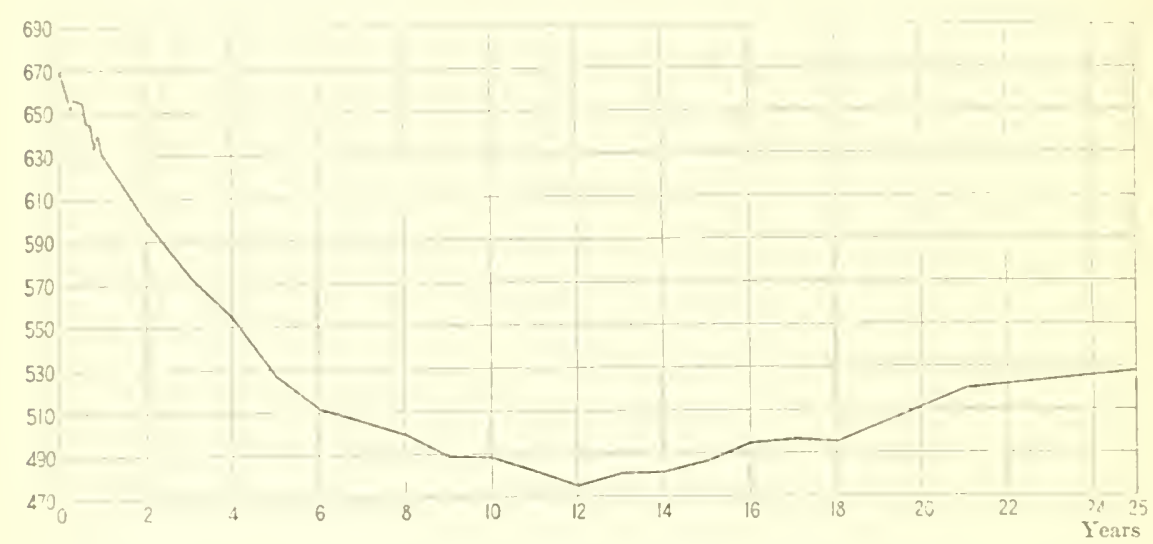

Fis. 1.-Polygon of development of relative chest-girth, male.

Abseisse: Age in rears. Ordiuates (chest-girth $\div$ stature) $\times 1000$. Bused on arerages of the measurements of Quetelet (Belgians), Weissenberg (Russian Jews). Benediet and Talbot (U. S. 1.), Masters Day Nursery, N. Y. City, Town (Iowa children), Gray and Jacolss (school byss, well-to-do), Reitz (Germans), Godin (French), Hitcheock (L. S. A. eollege men), Baldwin ( $\mathrm{N}$. Y. ('ity schools).

at about 8 months, due perhaps to the cutting of the incisors. The decline which subsequently ensues is prevailingly due to the rapid growth of the legs without corresponding increase in transverse diameter (plates 3 and 4 ). At about 12 years the boy enters the awkward age when, his legs and arms having grown from 5 to $10 \mathrm{~cm}$. in a single year, he has not yet acquired muscular control of them (plate 7, fig. 2). At the same time his trunk retains childish proportions (plate 5, fig. 12). A little earlier than the boy, the girl enters the "Backfisch" stage of similar slenderness and awkwardness (plate 7, fig. 3, from Stratz, 1922, p. 258). It is commonly believed that this rapid growth of the appendages and their long bones is controlled by the secretions of the pituitary gland. Gradually in the boy, at 14 years, as the gonads begin to ripen, the growth of the legs is retarded and the transverse chest diameter begins to increase rapidly; 
the lad is quickly transformed into a broat-shomldered. broad-chested, stocky man (plate 3, fig. 3, plate 5, fig. 8) and accordingly the curve of build rises much more in the youme man than in the voung woman (plate 7, figs. 4 and 5). Consequently tho adult fomale build, as measured by relative chest circumforences, is relatively small. It

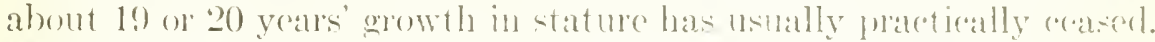
Meanwhile chest-girth increases slowly by the onlargenent of trunk muscles and deposition of fat. Wrowht is, indeed, stated to increase, on the average, until the age of 55 years (tablos 6 and 7 ).

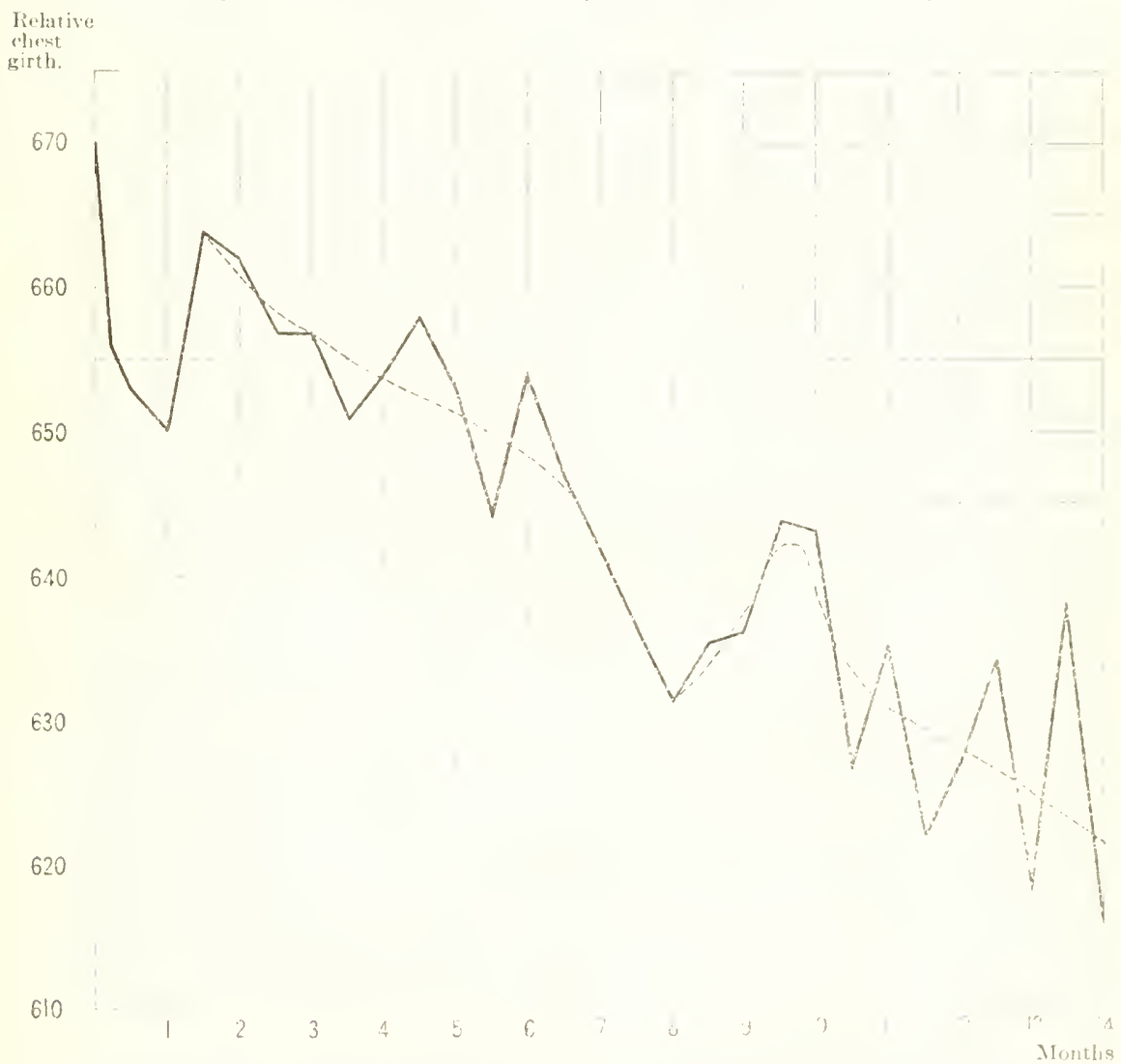

Fre. 2.-Polygon of relative chest-eirth in infants, from lirth to fourtemen months, with

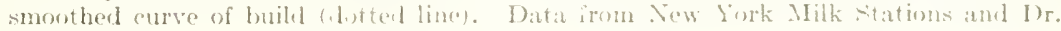
13. Ratner.

It may be well to consider briefly, necesarily somewhat speeulatively, the signifieance of this ontogenetic change in huilet. First of all, the high relative chest circumference of infancy is due chicfly to the extremely short legs of the infant. Leg-length constitutes only about 40 per cent of stalure at birth, whereas it comes to eonstitute 53 to 55 per cent at maturity. Consequently, the relative leg-length at infancy is only a trifle more than 70 per ecnt of the adult relative 
IBLILD: DEFINITION AND ONTOGENY.

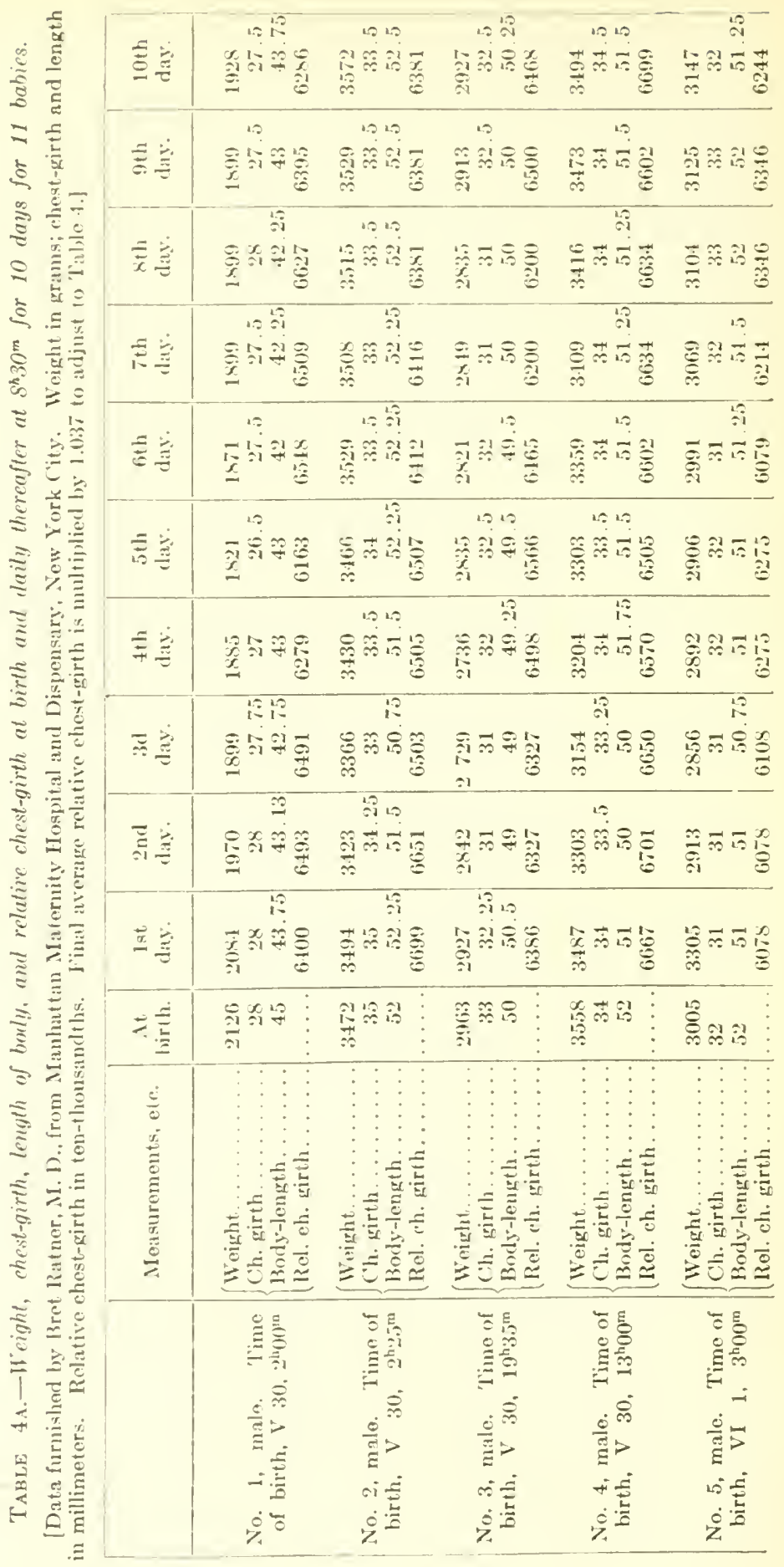




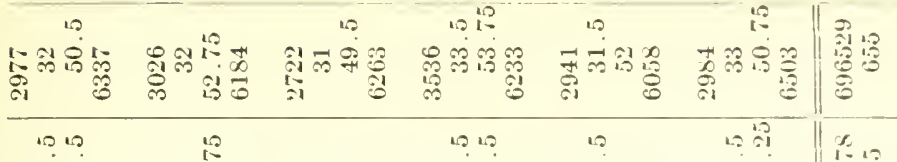

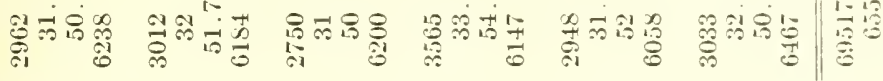

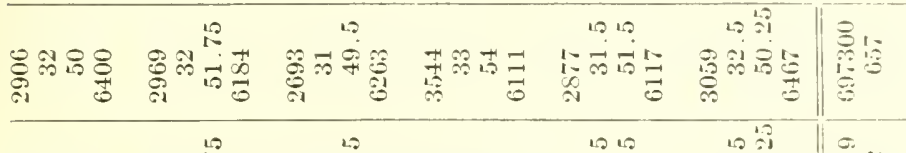

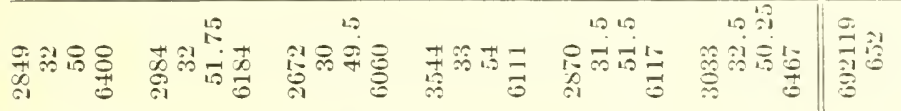

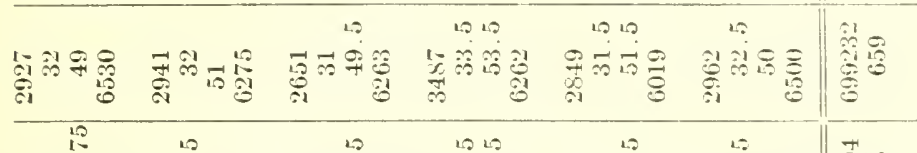

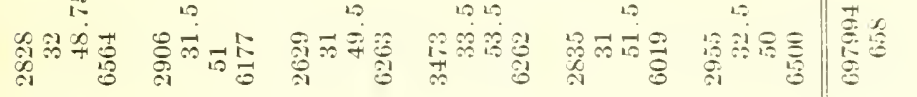
10

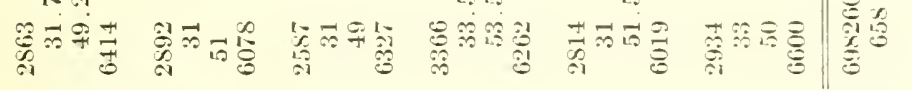

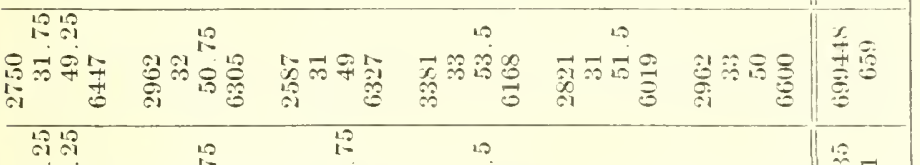

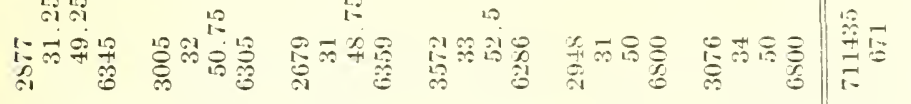

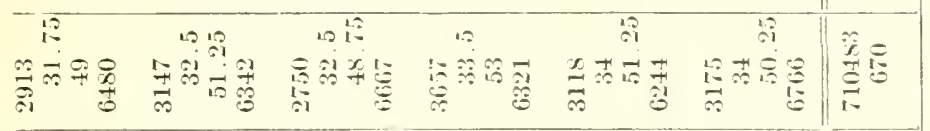

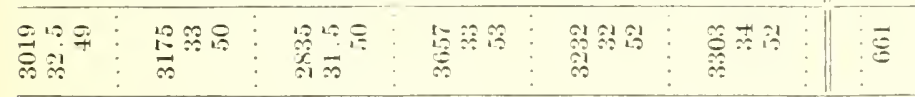

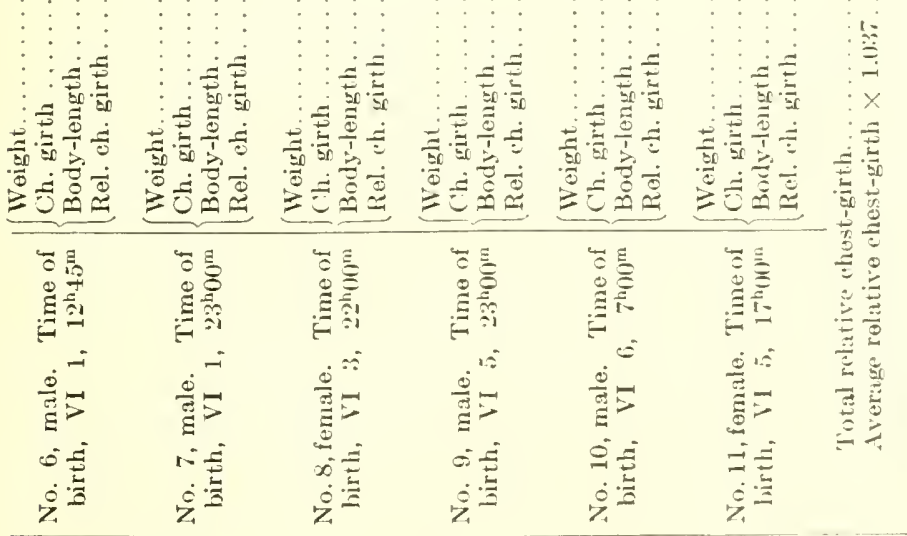


leg-length. Likewise the leg-length of the gorilla is about 70 per cent that of a European man (German, ef. Martin, 1914, p. 308). Consequently the relative leg-length of the infant, at birth, is to that of the adult as the relative leg-length of an anthropoid ape is to the relative leg-length of man. Incidentally, it may be added that the relative length of the arm of the infant is only slightly ( $S$ per cent) less than that of the adult. while in the chimpanzee the relative arm-length is IS per cent greater than that of man.

We have seen that the relative leg-length of the boy inereases to about 12 years and thereafter diminishes to the period of completed growth. The white man has his greatest leg-length shortly before adolescence. We find that among the races of mankind it is the longlegged negro tribes of East Africa, especially the upper Nile (Johnston, 1906. II, p. 932), which are among the lowest races of mankind, and which seem to represent in the adult the physical stage through which the white boy passes at 12 years. Other African tribes have, indeed, relatively shorter legs and thus show a persisting adult stage that is either slightly younger or slightly older than that of the 12 -year-old white boy.

Figure 1 (to return to it after this digression) seems thus adequately to measure the varying build of humans from birth to past maturity. It may, indeed, be regarded as composed of two parts; first, that from birth to the cessation of growth in stature, and seeond, that beyond cessation of growth in stature.

The curve of build thus obtained is. apart from the first period of adjustment that follows birth, a smoothly flowing one, that might indeed be expressed by a formula

$$
y=a x+b x^{2}+c x^{3}+d x^{4} \text {, etc. }
$$

The curve of build of figure 1 seems to be new in this form. It is, however, of the same general shape as the curve of varying "Körperfülle" drawn by Martin (1914. p. 246) from Quetelet's data and based on the relation of weight $\div$ stature ${ }^{3}$. The numbers of children considerert in Martin's figure are inadequate and there is hardly sufficient justification for the use of this formula to express changes of build during ontogeny.

The ontogenetic eurve of build may serve as a graphic representation of the stages of development as listed by Stratz (1922). These stages are shown in table 5 .

Later Ontogenetic Cinanges in Individal. Bulld.

Any investigation of the heredity of build is apt to meet with the difficulty that only the present weights and statures of ehildren, parents, and grandparents are known; that the persons are of different ages and hence the data concerning them are not precisely com- 
parable. Even if we exclude from consideration children of the rapid developmental period, under 18 years of age, still we have the problem of individual change of build in mature life. Since stature is practically immutable at this period, change in build may be measured by change in weight. That ehange in woight docs oceur is notorious. Figures 3 to 6 illustrate graphieally the ehanges in weight in various individuals from records taken almost at random. In figure 3 the curves of increasing weight run rapidly upward; in figure 4 they go up and then fall again; in figure 6 they are more nearly horizontal.

TABLE 5.-Growth-periods: in chiliren.

[Mordified from C. W. Stratz, 192:2, p. . i.]

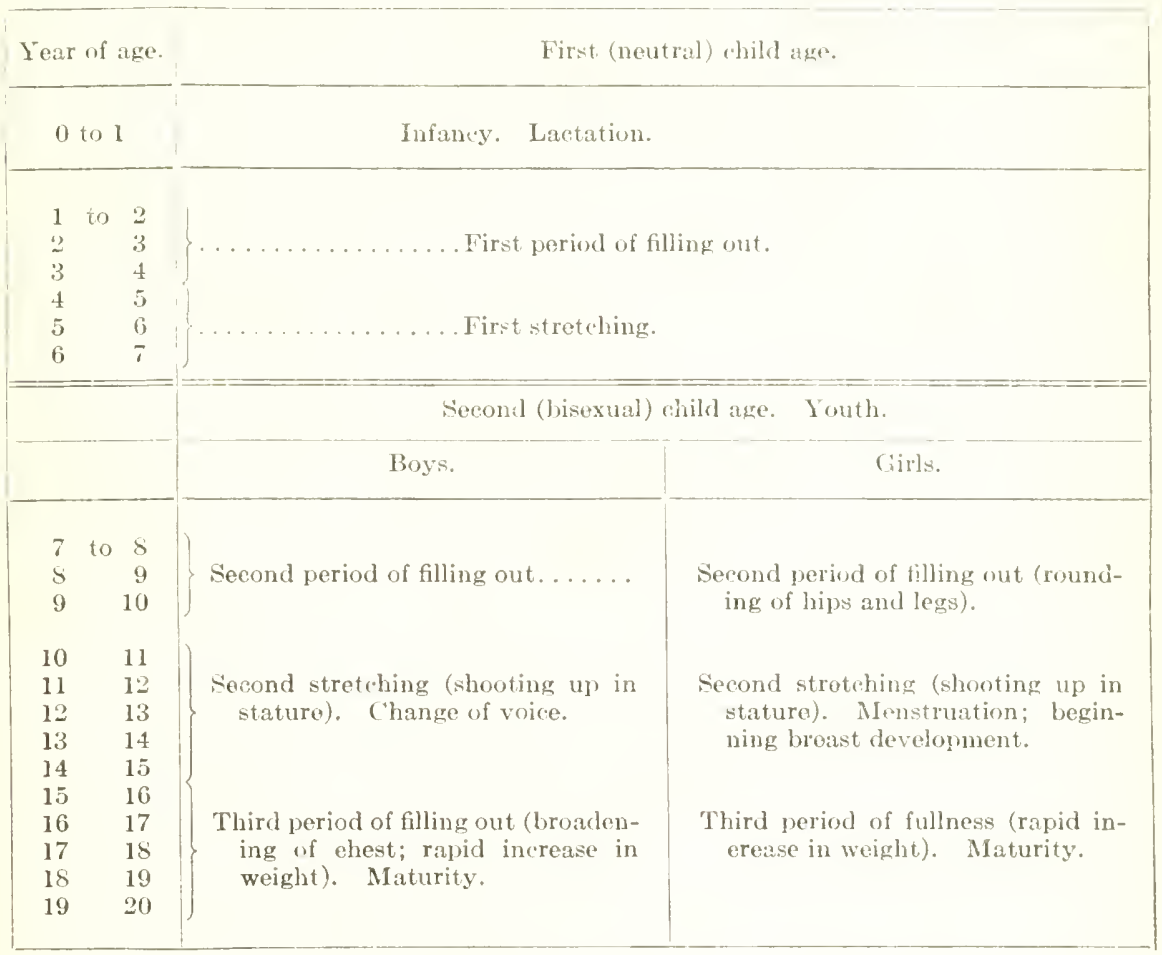

On the whole, the weight tends to increase with age. This is shown by the tables of the "Medico-Actuarial Mortality Investigation" (vol. I, pp. 38 and 67). The tables are reproduced in our tables 6 and 7 . They show that, on the average, weight tends to increase with age up to 50 or 51 years. The fact that there is, on the average, an increase in build, makes necessary an adjustment in some cases of the youthful indices of children to make them comparable with the adult indices of their parents.

The adjustment was made to the weight of the child by finding in the appropriate columm of stature and line of age the expected weight 


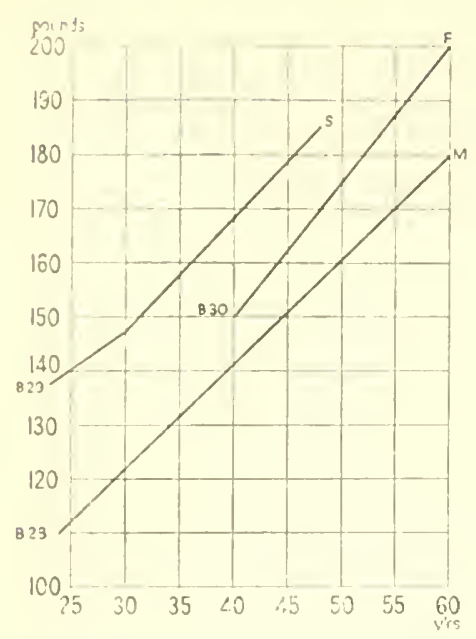

Fti. 3.-Changes in weight from $: 5$ to 50 or 60 years of father (F), mother (M), and son (S) in D: Bot-1 family, showing a consistent history of rapid increase of build with age.

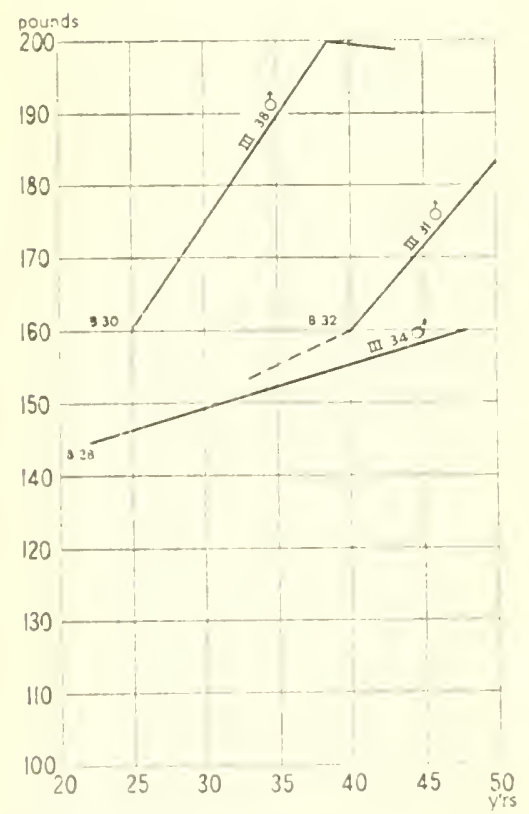

Fici. 5.-Changes in weight from 25 to 45 years of 3 sibs belonging to the D: HAY-1 fanily, showing a slight tendency to increase with age.

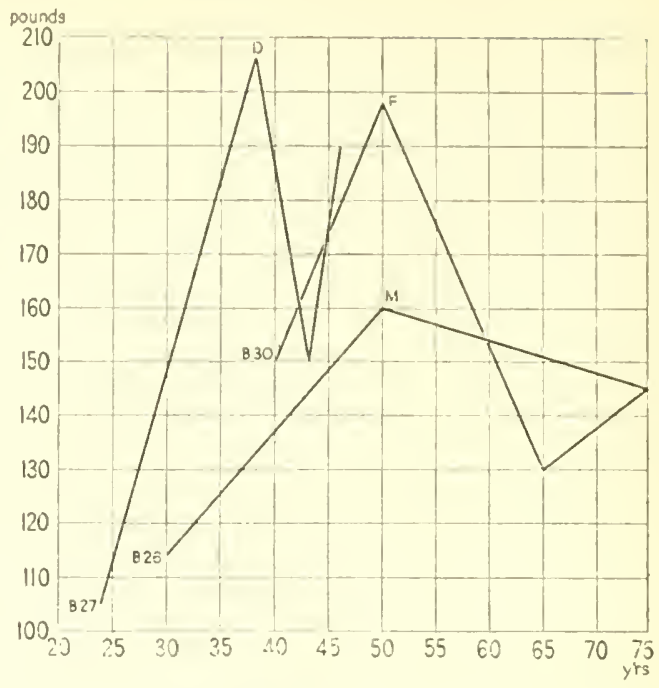

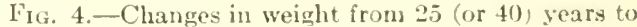
45 (or 75 ) yeirs of father (F), mother (M), and daughter (D) in D: Bol-la family, showing a history of fluctuating build.

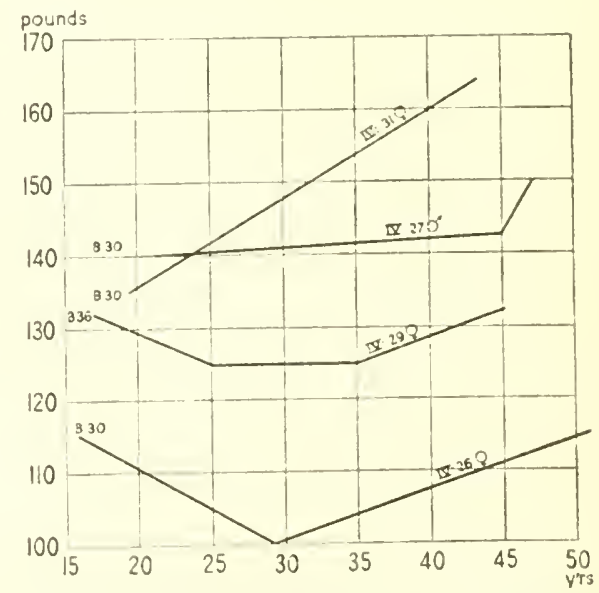

FIG. 6.-Changes in weight from 15 to 50 years in 4 sibs of the D: BAN-1 family, showing no great tendency to change of build during life. 
and adding the difference between this weight and the weight in the same column opposite the mid-parental age to the given weight of the child.

TABLE 6.-Graded average weight of men of different statures at various ages.

[Copied from Table IV of "Medico-actuarial mortality investigations."]

\begin{tabular}{|c|c|c|c|c|c|c|c|c|c|c|c|c|c|c|c|c|c|c|}
\hline $\begin{array}{c}\text { Age, } \\
\text { years. }\end{array}$ & 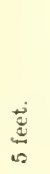 & 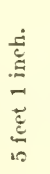 & 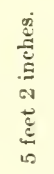 & 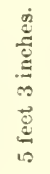 & 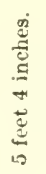 & 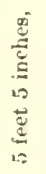 & 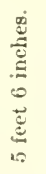 & 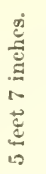 & 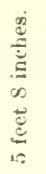 & 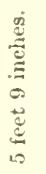 & 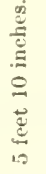 & 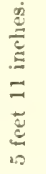 & 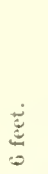 & 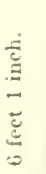 & 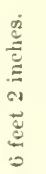 & 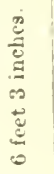 & 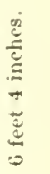 & 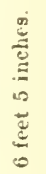 \\
\hline 15 & 107 & 109 & 112 & 115 & 118 & 122 & 126 & 130 & 134 & 135 & 142 & 117 & 152 & 157 & 162 & 167 & 172 & 177 \\
\hline 16 & 109 & 111 & 114 & 117 & 120 & 124 & $12 \mathrm{~S}$ & 132 & 136 & 140 & 144 & 149 & 154 & 150 & 164 & 169 & 174 & 179 \\
\hline 17 & 111 & 113 & 116 & 119 & 122 & 126 & 130 & 134 & 138 & 142 & 146 & 151 & 156 & 161 & 166 & 171 & 176 & 181 \\
\hline 18 & 113 & 115 & 118 & 121 & 124 & 128 & 132 & 136 & 140 & 144 & 148 & 153 & $15 \mathrm{~s}$ & 163 & 168 & 173 & 178 & 183 \\
\hline 19 & 115 & 117 & 120 & 123 & 126 & 130 & 134 & 138 & 142 & 146 & 150 & 155 & 160 & 165 & 170 & 175 & 180 & 185 \\
\hline 20 & 117 & 119 & 122 & 125 & 128 & 132 & 136 & 140 & 144 & 148 & 152 & 156 & $16 \mathrm{I}$ & $166^{\circ}$ & 171 & 176 & 181 & 186 \\
\hline 21 & 118 & 120 & 123 & 126 & 130 & 134 & 138 & 111 & 145 & 149 & 153 & 157 & 162 & 167 & 172 & 177 & 182 & 187 \\
\hline 22 & 119 & 121 & 124 & 127 & 131 & 135 & 139 & 112 & 146 & 150 & 154 & 154 & $16 i 3$ & 168 & 173 & 178 & 183 & 188 \\
\hline 23 & 120 & 122 & 125 & 128 & 132 & 136 & 140 & 143 & 147 & 151 & 155 & 159 & 16.1 & 169 & 175 & 180 & 185 & 190 \\
\hline 24 & 121 & 123 & 126 & 129 & 133 & 137 & 141 & 144 & 115 & 152 & 156 & 160 & 16.5 & 171 & 177 & 182 & 187 & 192 \\
\hline 25 & 122 & 124 & 126 & 129 & 133 & 137 & 111 & 14.5 & 119 & 153 & 157 & 162 & 167 & 173 & 179 & 181 & 189 & 194 \\
\hline 26 & 123 & 125 & 127 & 130 & 134 & 138 & 142 & 146 & 150 & 154 & 158 & 163 & 168 & 174 & 180 & 186 & 191 & 196 \\
\hline 27 & 124 & 126 & 128 & 131 & 134 & 138 & 1.12 & 146 & 150 & 154 & 158 & 1633 & 169 & 175 & $1 S 1$ & 157 & 192 & 197 \\
\hline 28 & 125 & 127 & 129 & 132 & 135 & 139 & 143 & 147 & 151 & 155 & 1.59 & 151 & 170 & 175 & 182 & 188 & 193 & 198 \\
\hline 29 & 126 & 128 & 130 & 133 & 136 & 140 & 144 & 118 & 152 & 156 & 160 & 165 & 171 & 177 & 183 & 189 & 194 & 199 \\
\hline 30 & 126 & 128 & 130 & 133 & 136 & 110 & 1.14 & 145 & 152 & 156 & 161 & 166 & 172 & 178 & 1.84 & 190 & 196 & 201 \\
\hline 31 & 127 & 129 & 131 & 134 & 137 & 141 & 145 & 149 & 153 & $15 \vec{i}$ & 162 & 167 & 173 & 179 & 185 & 191 & 197 & 202 \\
\hline 32 & 127 & 129 & 131 & 134 & 137 & 141 & 145 & 149 & 154 & 158 & 163 & 1038 & 174 & 180 & 186 & 192 & 198 & 203 \\
\hline 33 & 127 & 129 & 131 & 134 & 137 & 141 & $1+5$ & 149 & 154 & 159 & 164 & 169 & 175 & $1 \leqslant 1$ & 197 & 193 & 199 & 204 \\
\hline 34 & 128 & 130 & 132 & 135 & 138 & 142 & 146 & 150 & 155 & 160 & 165 & 170 & 176 & 152 & 158 & 194 & 200 & 206 \\
\hline 35 & 128 & 130 & 132 & 135 & 138 & 142 & 116 & 150 & 155 & 160 & 165 & 170 & $1 \gamma t j$ & 152 & 159 & 195 & 201 & 207 \\
\hline 36 & 129 & 131 & 133 & 136 & 139 & 143 & 1.17 & 151 & 156 & 161 & 166 & 171 & 177 & 183 & 190 & 196 & 202 & 208 \\
\hline 37 & 129 & 131 & 133 & 136 & 140 & 144 & 118 & 152 & $15 \pi$ & 162 & 167 & 172 & 178 & $14 t$ & 191 & 197 & 203 & 209 \\
\hline 38 & 130 & 132 & 134 & 137 & 140 & 144 & 145 & 152 & 157 & 162 & 167 & 173 & 179 & $1>5$ & 192 & 198 & 204 & 210 \\
\hline 39 & 130 & 132 & 134 & 137 & 140 & 144 & 148 & 152 & 157 & 162 & 167 & 173 & 179 & $155^{\circ}$ & 192 & 199 & 205 & 211 \\
\hline 40 & 131 & 133 & 135 & 138 & 141 & 145 & 149 & 153 & 158 & 163 & 168 & 174 & 180 & 156 & 193 & 200 & 206 & 212 \\
\hline 41 & 131 & 133 & 135 & 138 & 141 & 145 & 149 & 153 & $15 \mathrm{~s}$ & 163 & 168 & 174 & 180 & 156 & 193 & 200 & 207 & 213 \\
\hline 42 & 132 & 134 & 136 & 139 & 142 & 146 & 150 & 154 & 159 & 164 & 169 & 175 & $1 \mathrm{si}$ & $1 \times 7$ & 194 & 201 & 208 & 214 \\
\hline 43 & 132 & 134 & 136 & 139 & 142 & 146 & 150 & 154 & 159 & 164 & 169 & 175 & $1 \$ 1$ & 187 & 194 & 201 & 208 & 214 \\
\hline 44 & 133 & 135 & 137 & 140 & 143 & $1: 7$ & 151 & 155 & 160 & 165 & 170 & 176 & 182 & 158 & 195 & 202 & 209 & 215 \\
\hline 45 & 133 & 135 & 137 & 140 & 143 & 147 & 151 & $15 j$ & 160 & 165 & 170 & 176 & 182 & 188 & 195 & 202 & 209 & 21,5 \\
\hline 46 & 134 & 136 & 138 & $1 \neq 1$ & 144 & 148 & 152 & 156 & 161 & 166 & 171 & 177 & 183 & 189 & 196 & 203 & 210 & 216 \\
\hline 47 & 134 & 136 & 138 & 141 & 144 & $1 \pm s$ & 152 & 156 & 161 & 166 & 171 & 177 & 153 & 190 & 197 & 201 & 211 & $21 \%$ \\
\hline 48 & 134 & 136 & 138 & 141 & 144 & 148 & 152 & 156 & 161 & 166 & 171 & 177 & 183 & 190 & 197 & 204 & 211 & 217 \\
\hline 49 & 134 & 136 & 138 & 141 & 144 & 148 & 152 & 156 & 161 & 166 & 171 & 177 & 153 & 190 & 197 & 204 & 211 & 217 \\
\hline 50 & 134 & 136 & 138 & 141 & 144 & $1+8$ & 152 & 156 & 161 & 166 & 171 & 177 & $18: 3$ & 190 & 197 & 204 & 211 & 217 \\
\hline 51 & 135 & 137 & 139 & 142 & 145 & 149 & 153 & 157 & 162 & 167 & 172 & 178 & 184 & 191 & 198 & 205 & 212 & 218 \\
\hline 52 & 135 & 137 & 139 & 142 & 145 & 149 & 153 & 157 & 162 & 167 & 172 & 178 & 181 & 191 & 198 & 205 & 212 & 218 \\
\hline 53 & 135 & 137 & 139 & 142 & 145 & 149 & 153 & 157 & 162 & 167 & 172 & 178 & 181 & 191 & 19.5 & 205 & 212 & 218 \\
\hline 54 & 135 & 137 & 139 & 112 & 145 & 149 & 153 & 158 & 163 & 168 & 173 & 178 & 184 & 191 & 195 & 205 & 212 & 219 \\
\hline 55 and up & 135 & 137 & 139 & 142 & 145 & 149 & 153 & 158 & 163 & 168 & 173 & 178 & 184 & 191 & 193 & 205 & 212 & 219 \\
\hline
\end{tabular}

Relation of Juvenile to Adult Build.

This adjustment was not always necessary, first, because in not a few cases the children were of an adult age and the data for the build of the parents, now dead, were given for the same age; second, exam- 
ination of such developmental curves as are shown in figure 6 strongly indicates that when the parents are of slender build, and the children are of slender build at the age of 25 years younger than the parents,

TABLE 7.-Graled a"crage weight of women of different statures at various ages.

[Copied from Table IX of "Medico-actuarial mortality invostigations."]

\begin{tabular}{|c|c|c|c|c|c|c|c|c|c|c|c|c|c|c|c|c|c|}
\hline $\begin{array}{l}\text { Ager. } \\
\text { years. }\end{array}$ & 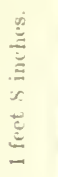 & 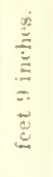 & 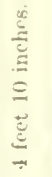 & 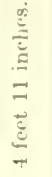 & $\underbrace{\stackrel{E}{E}}_{10}$ & 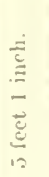 & 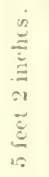 & 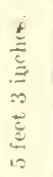 & 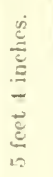 & 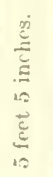 & 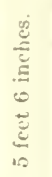 & 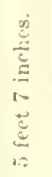 & 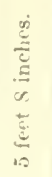 & 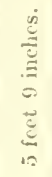 & 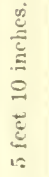 & 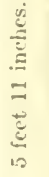 & $\underbrace{\stackrel{\tilde{E}}{c}}_{0}$ \\
\hline 15 & 101 & 103 & 105 & 106 & 107 & 109 & 112 & 115 & $11 \mathrm{~s}$ & 122 & 126 & 130 & 134 & $13 \mathrm{~s}$ & 142 & 147 & 152 \\
\hline If & 102 & 104 & 166 & $10 \mathrm{~s}$ & 109 & 111 & 114 & 117 & 120 & 124 & 128 & 132 & 136 & 139 & 143 & 148 & 153 \\
\hline 17 & 103 & 105 & 107 & 109 & 111 & 113 & 116 & 119 & 122 & 125 & 129 & 133 & 137 & 140 & 144 & 149 & 154 \\
\hline is & 104 & 106 & 108 & 110 & 112 & 11.1 & 117 & 120 & 123 & 126 & 130 & 134 & $13 \mathrm{~S}$ & 141 & 145 & 150 & 155 \\
\hline 19 & 105 & $10 \pi$ & 109 & 111 & 113 & 115 & 118 & 121 & 12.1 & 127 & 131 & 135 & 139 & 1.12 & 146 & 151 & 155 \\
\hline 20 & 106 & $10 \mathrm{~s}$ & 110 & 112 & 114 & 116 & 119 & 122 & 125) & $12 S$ & 132 & 136 & 140 & 143 & 147 & 151 & 156 \\
\hline 21 & 107 & 109 & 111 & 113 & 11.5 & 117 & 120 & 123 & 126 & 129 & 133 & 137 & 141 & 144 & 14.9 & 152 & 1506 \\
\hline 22 & $10 \tau$ & 109 & 111 & 113 & 115 & 117 & 120 & 123 & 126 & 129 & 133 & 137 & 141 & 145 & 119 & 153 & 157 \\
\hline 23 & $10 S$ & 110 & 112 & 114 & 116 & 118 & 121 & 124 & 127 & 130 & 134 & 138 & 142 & 146 & 150 & 153 & 157 \\
\hline 24 & 109 & 111 & 113 & 115 & 117 & 119 & 121 & 124 & 127 & 130 & 134 & $13 \mathrm{~S}$ & 142 & 146 & 150 & 154 & 158 \\
\hline 25 & 109 & 111 & 113 & 115 & 117 & 119 & 121 & 124 & 128 & 131 & 135 & 139 & 143 & 147 & 151 & 154 & 158 \\
\hline 26 & 110 & 112 & 114 & 116 & 118 & 120 & 122 & 125 & 128 & 131 & 135 & 139 & 143 & 147 & 151 & 155 & 159 \\
\hline 27 & 110 & 112 & 114 & 116 & $11 \mathrm{~s}$ & 120 & 122 & 125 & 129 & 132 & 136 & 110 & 144 & 148 & 152 & 155 & 159 \\
\hline 25 & 111 & 113 & 115 & 117 & 119 & 121 & 123 & 126 & 130 & 133 & 137 & 141 & 145 & 1.19 & 153 & 156 & 160 \\
\hline 29 & 111 & 113 & 115 & 117 & 119 & 121 & 123 & 126 & 130 & 133 & 137 & 141 & 145 & 149 & 153 & 156 & 160 \\
\hline 30 & 112 & 114 & 116 & 118 & 120 & 122 & 124 & 127 & 131 & 134 & 138 & 142 & 1.46 & 150 & 151 & 157 & 161 \\
\hline 31 & 113 & 115 & 117 & 119 & 121 & 123 & 125 & 128 & 132 & 135 & 139 & 143 & 147 & 151 & 154 & 157 & 161 \\
\hline 32 & 113 & 115 & 117 & 119 & 121 & 123 & 125 & 128 & 132 & 136 & 140 & 141 & 148 & 152 & 155 & 158 & 162 \\
\hline 33 & 114 & 116 & $11 \mathrm{~s}$ & 120 & 122 & 124 & 126 & 129 & 133 & 137 & 141 & 145 & 149 & 153 & 156 & 159 & 162 \\
\hline 34 & 115 & 117 & 119 & 121 & 123 & 125 & 127 & 130 & 134 & 138 & 142 & 146 & 150 & 154 & 157 & 160 & 163 \\
\hline 35 & 115 & 117 & 119 & 121 & 123 & 125 & 127 & 130 & 134 & $13 \mathrm{~s}$ & 142 & 146 & 150 & 154 & 157 & 160 & 163 \\
\hline 36 & 116 & 118 & 120 & 122 & 12.4 & 126 & 128 & 131 & 135 & 139 & 143 & 147 & 151 & 155 & 158 & 161 & 164 \\
\hline 37 & 116 & 118 & 120 & 122 & 124 & 126 & 129 & 132 & 136 & 140 & 144 & 148 & 152 & 156 & 159 & 162 & 165 \\
\hline $3 s$ & 117 & 119 & 121 & 123 & 125 & 127 & 130 & 133 & 137 & 141 & 145 & 119 & 153 & 157 & 160 & 163 & 166 \\
\hline 39 & $11 S$ & 120 & 122 & 124 & 126 & 128 & 131 & 134 & 138 & 142 & 146 & 150 & 154 & $15 \mathrm{~s}$ & 161 & 164 & 167 \\
\hline 40 & 119 & 121 & 123 & 125 & 127 & 129 & 132 & 135 & 138 & 142 & 146 & 150 & 154 & 158 & 161 & 164 & 167 \\
\hline 41 & 120 & 122 & 124 & 126 & 128 & $130)$ & 133 & 136 & 139 & 1.43 & 147 & 151 & 155 & 159 & 162 & 165 & 168 \\
\hline 42 & 120 & 122 & 124 & 126 & 128 & 130 & 133 & 136 & 139 & 143 & 147 & 151 & 155 & 159 & 162 & 166 & 169 \\
\hline 43 & 121 & 123 & 125 & 127 & 129 & 131 & 134 & 137 & 140 & 14.1 & 1.18 & 152 & 156 & 160 & 163 & 167 & 170 \\
\hline 44 & 122 & 124 & 126 & 128 & 130 & 132 & 135 & 138 & 141 & 145 & 1.19 & 153 & 157 & 161 & 164 & 168 & 171 \\
\hline 45 & 122 & 124 & 126 & 128 & 130 & 132 & 135 & 138 & 141 & 145 & 149 & 153 & 157 & 161 & 164 & 168 & 171 \\
\hline 46 & 123 & 125 & 127 & 129 & 131 & 133 & 136 & 139 & 142 & 146 & 150 & 151 & 158 & 162 & 165 & 169 & 172 \\
\hline 47 & 123 & 125 & 127 & 129 & 131 & 133 & 136 & 139 & 142 & 146 & 151 & 155 & 159 & 163 & 166 & 170 & 173 \\
\hline 48 & 121 & 126 & 128 & 130 & 132 & 134 & 137 & 140 & 143 & 147 & 152 & 156 & 160 & 164 & 167 & 171 & 174 \\
\hline 49 & 12.4 & 126 & 125 & 130 & 132 & 134 & 137 & 140 & 143 & 147 & 152 & 156 & 161 & 165 & $16 \mathrm{~S}$ & 172 & 175 \\
\hline 50 & 125 & 127 & 129 & 131 & 133 & 135 & $13 \mathrm{~s}$ & 141 & 141 & 148 & 152 & 156 & 161 & 165 & 169 & 173 & 176 \\
\hline 5$]$ & 125 & 127 & 120 & 131 & 133 & 135 & 138 & 141 & 14.1 & $14 \mathrm{~S}$ & 152 & 157 & 162 & 166 & 170 & 174 & 177 \\
\hline 52 & 125 & 127 & 129 & 131 & 133 & 135 & 138 & 141 & 144 & $14 \mathrm{~S}$ & 152 & 157 & 162 & 166 & 170 & 174 & 177 \\
\hline 53 & 125 & 127 & 129 & 131 & 133 & 135 & 138 & 141 & 144 & $14 \mathrm{~s}$ & 152 & 157 & 162 & 166 & 170 & 174 & 177 \\
\hline 54 & 125 & 127 & 129 & 131 & 133 & 135 & 138 & 1.11 & 144 & 148 & 153 & 158 & 163 & 167 & 171 & 174 & 177 \\
\hline $5 \overline{5}$ & 125 & 127 & 129 & 131 & 1333 & 135 & 138 & 141 & 14.1 & 148 & 153 & 158 & 163 & 167 & 171 & 174 & 177 \\
\hline
\end{tabular}

the increase in weight of the children will not usually follow the actuarial tables. The actuarial tables, indeed, represent only the average increase, and this average is made of a population that does not increase its weight at all when it grows older (fig. 6) and a popu- 
lation that increases its weight at a much faster rate than indicated in the actuarial tables (fig. 3). Consecquently, no adjustment is marle to the given weights of the children whose parents are slender. In the case where one parent was stender and one fat, the adjustment is still made in the build of all the children. This procedure, undoubtedly, introduces an error which, so far as I see can not be avoided. Baldwin (1921, p. 74) states that "as a general rule heavy children remain relatively heavy during the period sturlied"; and his developmental curves of individual children show that the same persistence of the juvenile build is commonly true for children of slight weight. It is striking how often the children of heavy parents will be heavy even in youth, and conversely, children of exceptionally great weight are apt to retain, and add to, their build.

Chambers (1850, pp. 139-143) cites the following cases of early familial obesity: A boy of 3 years weighs $39.5 \mathrm{~kg}$. ( 87 pounds); his 6 sisters and brothers are obese. A girl of 5 years 5 months weighs 89 kg. (196 pounds); obesity on both sides of the house. A boy of 16 weighs $114 \mathrm{~kg}$. (252 pounds); there is collateral heredity.

A striking case of early obesity persisting to maturity is that of Miss Allen (plate S).

On the other hand, it is often strikingly true that in families with a tendency to fleshy build some of the children will remain slender until 20 or 25 years and then begin to grow fat. The metabolic changes that induce fatness first appear in later life. 


\section{PART II.}

\section{MASS STUDIES IN HEREDITY OF ADULT BUILD.}

It is a matter of common observation that in some families the parents and children are all slender; in others, there may be many examples of obesity. Worthington (187\%, p. 50) cites a number of examples from C. Bouchard. A woman of 45 years weighs $107 \mathrm{~kg}$. ( 236 pounds); her obesity began shortly after marriage; her father is very obese and her mother obese. A woman of 49 years, whose father is a Turk and whose mother is French, weighs $117 \mathrm{~kg}$. or about 258 pounds; her mother was obese. I woman of $115 \mathrm{~kg}$. or about 250 pounds has an obese mother and two sisters who were obese in infancy; also a gouty mother's father and father's father.

The following, from (hambers (1850), show obesity "on both sicles of the house": Male of 28 years, $120 \mathrm{~kg}$. (260 pounds); woman of 48 years, $127 \mathrm{~kg}$. (280 pounds); woman of 52 years, $98.4 \mathrm{~kg}$. (217 pounds); man of 57 years, $227 \mathrm{~kg}$. (500 pounds); woman of 58 years, $104 \mathrm{~kg}$. (231 pounds); woman of 68 years, $118 \mathrm{~kg}$. (260 pounds); woman of 70 years, $107 \mathrm{~kg}$. (23S pounds). In many other cases cited by (hambers, one parent of the obese patient was obese. Howard (1908, p. 54) cites the case of a 7 -year-old girl. 45.5 inches $(115.6 \mathrm{~cm}$. tall. who weighed $40 \mathrm{~kg}$. (SS pounds), had a pendulous abdomen, and was feeble-minded. Her sibs were not abnormal and her parents were of average build. One of her great uncles weighs $127 \mathrm{~kg}$. (280 pounds), an uncle, at 40 years, about $109 \mathrm{~kg}$., and an aunt of 31 years. $95 \mathrm{~kg}$. (210 pounds). This case is instruetive because of the skipping of a generation.

In the elass of obese cases known as adiposis dolorosa, heredity is usually obvious. Price (1909) cites a case of an obese woman of 48 years and weighing $140 \mathrm{~kg}$. (310 pounds) who belongs to a fraternity of 7:1 was a miscarriage, 2 died young of aceident, 1 died at 2:2 of typho-pneumonia, 1 died young of scarlet fever, and 1 brother is large and rheumatic. The father seems to have been of arerage build and the mother is stated to have been "very thin." Of her sibs, 6 were fleshy or very fleshy; 1 medium, and 1 slender"; the children of these fleshy sibs of the mother are "all stout."

Lyon (1910, p. 68) discusses heredity in adiposis dolorosa and lipomatosis and cites a considerable number of cases of family recurrence in his cases and others. Thus he twice treated a father and his son for multiple fatty tumors; also twice a mother and daughter. Lyon's obese ease No. 5 was like her 3 sisters and 1 daughter; a son of her father's brother showed similar fatty deposits. 10 other instances of family recurrence of abnormal fat deposit are cited. 
Maranon and Bonilla (1920) cite the rawe of at gill of 18 years who was slender, like her parents, until after an attack of syphilis, when she came to weigh $157 \mathrm{~kg}$. or 350 pounds. while her height was 160 cm.. her ehest-girth $130 \mathrm{~cm}$., and that of her abtomen 150 (ons. or 90 per cent of her height. She hat a very large brother, and both mother's parents were obese, though the parents were not known to be so.

Such examples might be multiplied indefinitely.

Our problem is not what are all the causes of this diversity of build, but rather in how far do genetical factors play a part in this diversity. We are not oblivious to the fact that there are many factors responsible for the result-deviation from the average build. These we shall consider in detail in a later section, and the consideration will help us to see the limits to the action of the genetical factors. Before going on to that, we shall have to consider more in detail the nature of the facts for which an explanation has to be sought.

\section{METHODS AND MATERIALS.}

The method of analyzing the genetic factors in build is that of tabulating the distribution of aberrant builds in the family network. There is required, first, a large mass of family data which includes many extreme or aberrant types of build, and which is as reliable and as accurately quantitative as possible; secondly, this has to be subjected to the ordinary methods of genetic analysis.

The available material has consisted of data on stature and weight given in the Records of Family Traits which constitute a fair sample of the population; and of quantitative data on special schedules giving stature and weight of a fraternity, its parents, uncles and aunts, and grand-parents. These special schedules had been mailed to an address list of overweight and underweight persons obtained through the kind cooperation of Mr. Arthur Hunter. Those who returned the schedules showed an especial appreciation of the requirements of our study. A third source was the A file of the Eugenics Record Office, where are gathered miscellaneous pedigrees of families showing aberrancy in build. A fourth and especially valuable source was the field work of Miss Louise A. Nelson, of the Eugenies Record Office; this started with selected, usually obese, cases.

After the data had been assembled and tabulated, a certain amount of correspondence and personal visitation was undertaken in order to secure a confirmation or revision of the records in hand. In some cases this brought to light errors in the records. in others, useful details. Naturally, it was not possible to secure a revision of all of the data used, but an attempt was made to select only records that had been compiled with care and conscientiousness, and these traits in the compiler reveal themselves pretty clearly to a person who has 
examined thousands of these records, just as carelessness is revealed also by slipshod speech or posture.

For our study we desire the data of stature and weight for children. parents, and grand-parents. With some exceptions only those families are studied in which all these data are accurately given. Also. only children who are above 18 years of age can be utilized. because stature changes so rapidly until that age. However, sinee it is build and not stature we are studying, the fact of increase of stature from 19 to 21 years of age affects the result very little. Finally, in a certain proportion of the eases the stature and weight of all of the grand-parents are not given quantitatircly. Such families are utilized, nevertheless. with such quantitative data as may have been afforded.

The data were taken from the Records of Family Traits by Miss Miriam Kortright, who long assisted in our statistical work. The computations of index of build were made by Miss Kortright and Mr. William Kraus, Miss Laura Craytor, and Miss Margaret Andrus. who checked one another's work. The tabulation and seriations of the indices were done by Misses Margaret Babcock and Katharine Belzer.

\section{THE ADULT INDEX OF BUILD.}

In an earlier section of this paper the question of the best index of build has been discussed generally. It was pointed out that many regard it as a truism that build is a relation of volume to stature. Since the volume of a person's body is rarely known, and it is difficult to determine it, weight has been substituted for volume. However, this substitution assumes that specific gravity is the same for slender and for fat persons; but this is not at all the case. The specific gravity of a fat person is about that of water $(0.978$ to 1.079 in 4 children 7 to 1.3 years of age, Meeh, 1879 , and 1.014 in a 61 -year-old man of $98 \mathrm{~km}$. weight, Mies, 1899); of a thin person it may be 5 to 8 per cent above that of water (1.049 to 1.082 for thin convicts, Mies, 1899). This variable specific gravity complicates the attempt to infer volume from weight. In view of these difficulties it were better to measure build by a rclation of chest diameter (or circumference) to stature. But this ratio can not be used in our studies, since our data, for the most part, give only weight and stature and not chestgirth. It remains thus to determine the closest relation between weight and chest-girth. This determination I have attempted to make for 100 young men, 20 to 25 years of age, measured at Harvard Iniversity where they were students. It will hardly be worth while to reproduce the detailed tables of measurements and ratios, but they will be found summarized in table $S$. In this table is given the frequency of oecurrence of each of the different ratios (or rather classes of ratios) found using chest-girth in first, second, and third powers as 
a divisor. If weight vated exactly with the chest-girth, they the ratio of the fomer to the lattor should romain comstant. Fuch a strict

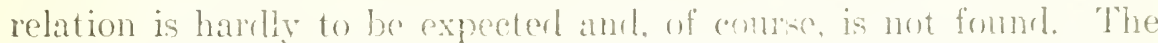

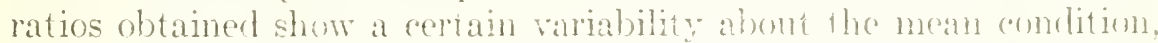
and this variability is measured hy the stanciard feviation. Finilarly. if each weight be divided in turn by the second and thind powers of stature, ant the corresponding rariatility of the latios be considered, we shall have a method of lecirling whether weight varies more closely with the first, second, or third powpr of chest-girth, and which of those powers gives in its fluctuations the best measure of the corresponding fluctuations in weight.

TABLE S.-Thrability of weight in relation to the second and third powers of chest-girth as foimd in Ion Ilarward stuleits.

$[f$, frequeney of necurrence of the given index-rlass.]

\begin{tabular}{|c|c|c|c|c|c|c|c|}
\hline \multicolumn{3}{|c|}{$\frac{\text { Weight }}{\text { chest-girth }}$} & \multicolumn{2}{|c|}{$\begin{array}{c}\text { Neight } \\
\text { chest-rirth² }\end{array}$} & \multicolumn{3}{|c|}{$\begin{array}{c}\text { Weight } \\
\text { rhest-girth }\end{array}$} \\
\hline \multicolumn{3}{|r|}{$f$} & \multicolumn{2}{|r|}{$f$} & \multicolumn{3}{|c|}{$f$} \\
\hline $610 \mathrm{ts}$ & 619 & 1 & bigy to 780 & 1 & $711 \mathrm{to}$ & 720 & 1 \\
\hline $6+10$ & 649 & 3 & $711 \quad 720$ & 1 & 761 & 7711 & 3 \\
\hline 660 & 669 & 2 & $7: 31 \quad 740$ & 1 & $7 ! 1$ & $\rightarrow(i 1)$ & 3 \\
\hline 670 & 679 & $\overline{4}$ & 750 & 1 & $>(0) 1$ & $\therefore 10$ & 3 \\
\hline 680 & $6 \$ 9$ & 6 & $7(60)$ & 5 & $\$ 11$ & $\times 20$ & 3 \\
\hline 690 & 699 & 2 & 70 & 2 & $\therefore 21$ & $(3.30)$ & 3 \\
\hline 700 & 709 & 7 & Tho & 4 & +31 & ati) & 3 \\
\hline 710 & 719 & 6 & 730 & 11 & 841 & $\sin 0$ & 5 \\
\hline 720 & 729 & 4 & 500 & 10 & -5.51 & $\therefore 60$ & 1 \\
\hline 730 & 739 & 10 & $\$ 10$ & 7 & ofil & -70 & 10 \\
\hline $7 \pm 0$ & 749 & 7 & $\therefore 20$ & 9 & 71 & $\rightarrow>0$ & 6 \\
\hline 750 & 759 & 7 & 830 & $\therefore$ & $\sin 1$ & $s \$ 0$ & 3 \\
\hline 760 & 769 & 6 & $(10)$ & j & $x ! 1$ & $(i) 0$ & j) \\
\hline 7.70 & 769 & 4 & 8.50 & 3 & 901 & (11) & $\bar{j}$ \\
\hline $7 \times 0$ & -899 & $\tau$ & $>60$ & 4 & 911 & 920 & 3 \\
\hline 790 & 799 & 5 & 870 & y & 921 & 930 & 2 \\
\hline 800 & $\operatorname{sog}$ & 2 & $8+0$ & 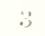 & 031 & $(40)$ & 7 \\
\hline$\$ 10$ & $\$ 19$ & 3 & $\$ 90$ & $t$ & 941 & 9.50 & 1 \\
\hline 820 & $\times 29$ & 3 & $\$ 00$ & 3 & 951 & (siri) & 4 \\
\hline 830 & 8339 & 3 & 910 & 4 & 9 (il & $\$ 170$ & 1 \\
\hline 840 & $\rightarrow+9$ & 1 & 930 & 2 & 971 & I) & ?) \\
\hline s.jo & $\$ 50$ & 1 & 960 & $\overline{1}$ & SN1 & 990 & 1 \\
\hline 870 & 879 & 1 & 970 & 2 & 991 & 1000 & 5 \\
\hline 900 & 909 & 1 & & & 1001 & 1010 & 2 \\
\hline \multirow[t]{4}{*}{920} & 929 & 1 & & & 1031 & 1040 & 1 \\
\hline & & & & & $10 \div 1$ & 1050 & 4 \\
\hline & & & & & $10 \mathrm{fi} 1$ & 107() & 2 \\
\hline & & & & & 1111 & $1: 20$ & 1 \\
\hline \multicolumn{3}{|c|}{$\sigma .35 .32$} & \multicolumn{2}{|l|}{$\sigma ., 51.50$} & \multicolumn{3}{|c|}{$\sigma$, - } \\
\hline
\end{tabular}

A comparison of the standard deviations gives the following results for man:

\begin{tabular}{|c|c|c|c|}
\hline & $\frac{\text { weight }}{\text { chest-girth }}$ & $\frac{\text { woight }}{\text { chest-cirth }}$ & $\begin{array}{c}\text { woight } \\
\text { chest-ririh }{ }^{3}\end{array}$ \\
\hline & a. 553 & 51.5 & 77.0 \\
\hline
\end{tabular}


From these results the conclusion is drawn that since the variability (standard deviation) of weight $\div$ - chest-girth ${ }^{2}$ is least, the square of the ehest-girth varies more closely with weight than either the first or third power of chest-girth; consequently the square of chest-girth is the best measure of weight of the three.

By hypothesis, the chest-girth in persons of the same build varies very elosely or exactly with stature; consequently we could substitute in the foregoing ratios for chest its arerage equivalent, $\frac{\text { stature }}{K}$, in which $K$ is nearly 2, more precisely 1.9. In any case it is thus clearly deducible that a better index of build is got by dividing weight by the square of stature than by its cube, as has been so often done. Accordingly, the ratio of weight to stature ${ }^{2}$ has been adopted in this paper as the standard index of build. The correlation between this index of build and relative chest-girth is found by calculation to be about 0.45 .

In any scale of index of build it is, of course, desirable to use the metric system. Unfortunately, most of our data are in English units, so that our indices were first obtained by the use of these units. We have in many cases transmuted the English into the equivalent metric measures. We have, however, retained the original English index, since a large portion of the more cultured part of the world uses that system in daily life. A table to facilitate transmutation is also given in the Appendix, table XVIII. To facilitate the determination of the index of build when stature and weight (in English or metric units) are known, table XVI has been prepared (pages 169, 170).

To avoid decimals, the ratio, weight in pounds $\div$ (stature in inches $)^{2}$ is multiplied in this book by 1.000 ; this gives a series of ratios running from 20 to 60 and over. To avoid confusion with the English system, the metric equivalents are taken as the ratio of weight in grams $\div$ (stature in centimeters) ${ }^{2}$. This gives a series of index numbers of the order 1.5 to 4.0 ; in this case, at least, one decimal is always expressed. The small integral figure and the decimal at once indicate that the index is from metric units. Since the index of build has often been expressed as the ratio of weight to, respectively, stature, stature ${ }^{2} .5$, and stature ${ }^{3}$, table XVII has been prepared to permit these ratios to be transmuted into weight $\div$ stature $^{2}$, English system.

\section{CLASSIFICATION OF BUILD.}

For the purposes of analysis, it was found necessary to make a small number of classes of build. To decide upon the limits of these classes, a polygon of frequency of all indices of build was made, as shown in figure 7 . It appeared plain at the outset that it is desirable 
to plot the data in this polygon by using as abscisse the logarithms of the index of build rather than the absolute indices, since the range of weight above the mode is, for obvious reasons, very much greater than below the mode. Taking mean weight at $68 \mathrm{~kg}$., or 150 pounds, the minimum weight is about $20 \mathrm{~kg}$. (45 pounds), or $25 \mathrm{~kg}$. ( 55 pounds) below the mean, and the maximum weight is about $150 \mathrm{~kg}$. (330 pounds), or $182 \mathrm{~kg}$. (400 pounds) above the mean. That

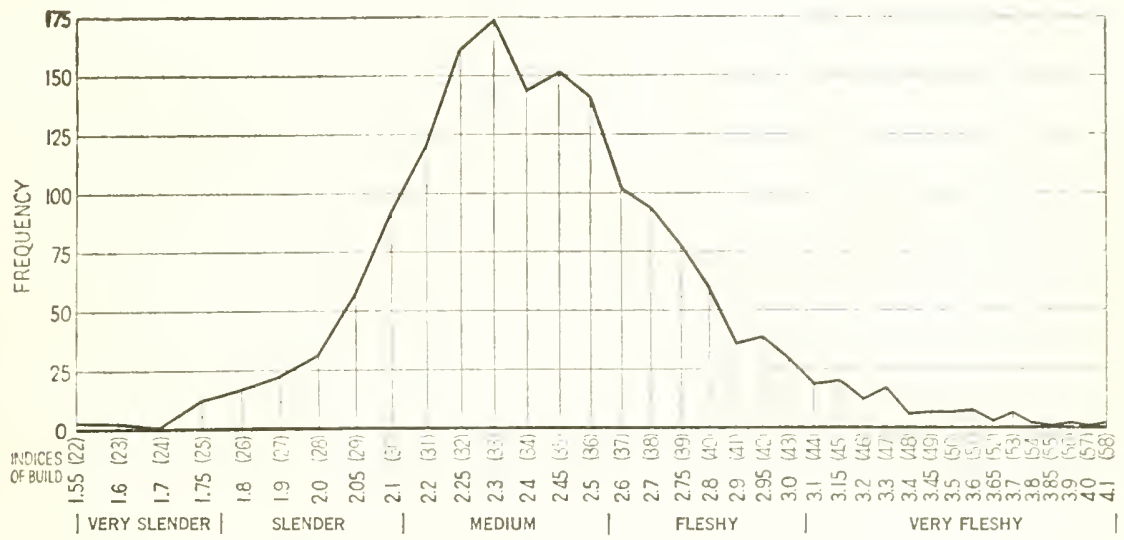

FIG. 7.-Polygon of frequency of the various indices of build (weight $\div$ stature ${ }^{2}$ ). From last column of table 12 , with slight modifications.

is, the range of weight classes is three times as great above as below the mean. Plotting data in logarithmic fashion, as shown in figure 7 , it appears that the modal index of build is 2.3 (33). The range is from $1.4(20)$ to $4.5(64)$. Using the logarithms of abscisse, the curve is more nearly a symmetrical one. It is more irregular above than below the mode, because the classes are more numerous and the frequency of each class smaller. The presence of two modes is suggestive of the hypothesis that the medium class and probably the fleshy classes are not strictly homogeneous, but, on the contrary, comprise groups of individuals whose build is due to dissimilar factors, or sets of factors.

TABLE 9.-The five standard classes of build; limits and middle points of each.

\begin{tabular}{|c|c|c|c|}
\hline \multirow[b]{2}{*}{ Class. } & \multicolumn{3}{|c|}{ Range of indices. } \\
\hline & Metric. & English. & $\begin{array}{l}\text { Middle of class } \\
\text { (English). }\end{array}$ \\
\hline 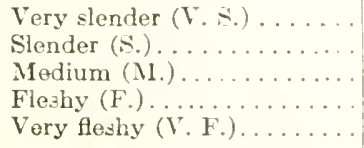 & $\begin{array}{ll}1.40 \text { to } 1.80 \\
1.41 & 2.14 \\
2.15 & 2.56 \\
2.57 & 3.05 \\
3.06 & 4.50+\end{array}$ & $\begin{array}{ll}20 & \text { to } 25.4 \\
25.5 & 30.4 \\
30.5 & 36.4 \\
36.5 & 43.4 \\
43.5 & 64+\end{array}$ & $\begin{array}{l}23.5 \\
28.0 \\
33.5 \\
40.0 \\
48.0\end{array}$ \\
\hline
\end{tabular}


To derive the desired classes from figure 7 , the polygon was somewhat arbitrarily divided into five parts, as indicated. Taking 33.5 as a starting-point, an equal logarithmic distance was laid off, above and below this point, on the base-line. This was taken as the range of middle class. An equal logarithmic range was accorded the classes next above and below the median respectively. All of the remainders were thrown into the extreme classes to which are given, thus, a somewhat greater range than the interior classes. This seemed desirable, since their frequencies were so low. The adjusted classes finally adopted are as shown in table 9 .

\section{SIGNIFICANCE OF VARIATIONS IN BUILD.}

What is the meaning of the great variations of build described in the preceding paragraph? What is known in this matter may here be briefly summarized that it may be held in mind in considering the numerous cases to which we shall have occasion to refer.

In general, it may be stated that variations in build are due to endogenous causes and exogenous causes. In this book we shall have occasion to examine especially the former-the constitutional or hereditary factors. These include idiosyncrasies of metabolism, in part controlled by peculiarities in the functioning of the endocrine glands; in part, probably, by even finer protoplasmic differences. Thus it is known that the thyroid gland greatly influences metabolism; its activity in growing children tends to produce tall and slender form. On the other hand, deficiency in its activity in childhood leads to the type of obesity known as cretinism, and in middle life to inyxedema. The secretions of the pituitary gland cooperate with the thyroid in stimulating growth, especially in the preadolescent stage. When pituitary secretions are deficient there frequently results, it is believed, the adiposogenital syndrome, in which great masses of fat are deposited on breasts, abdomen, hips, and buttocks, and the gonads remain infantile. A case that quite certainly belongs to this category is shown by Beck (1922, p. 881) and reproduced in plate 8, figures $3,4,5$; 3 of this man's 4 sibs are fleshy and have scant beards. This is quite like our standard very fleshy case (plate 2, fig. 5). See, also, the extreme cases falling under this category described by Lyon, 1910 .

Lesions of the pineal gland (Beck, 1922, p. 909) and of the gonads are stated in some cases to induce obesity. Certain it is that, on the other hand, the activity of the gonads tends to slow up growth in stature and to increase the chest circumference (plate 6), and this change is more marked in the male than the female.

The exogenous causes of build are striking, so much so that many physiologists seem to accept the hypothesis that they are of sole importance, that excess of fat is due merely to excess of calories ingested over those concerned in bodily activity. While no one will 
deny the possibility of starving most fleshy persons thin or of increasing the weight of most adults by an excess of food, yet it is also obvious that two persons of the same stature and fed equal amounts of similar food may come to differ enormously, due to internal conditions, sometimes of glandular origin and sometimes dependent upon, or at least associated with, disease.

\section{DISEASES IN RELATION TO BLILD.}

As just stated, it is frequently true that build is influenced permanently by disease. To test the influence of disease on, or association of diseases with, different types of build, a tabulation was made of the diseases recorded (in the Records of Family Traits, Eugenics

TABLE 10-Incidence of disease in relution to build.

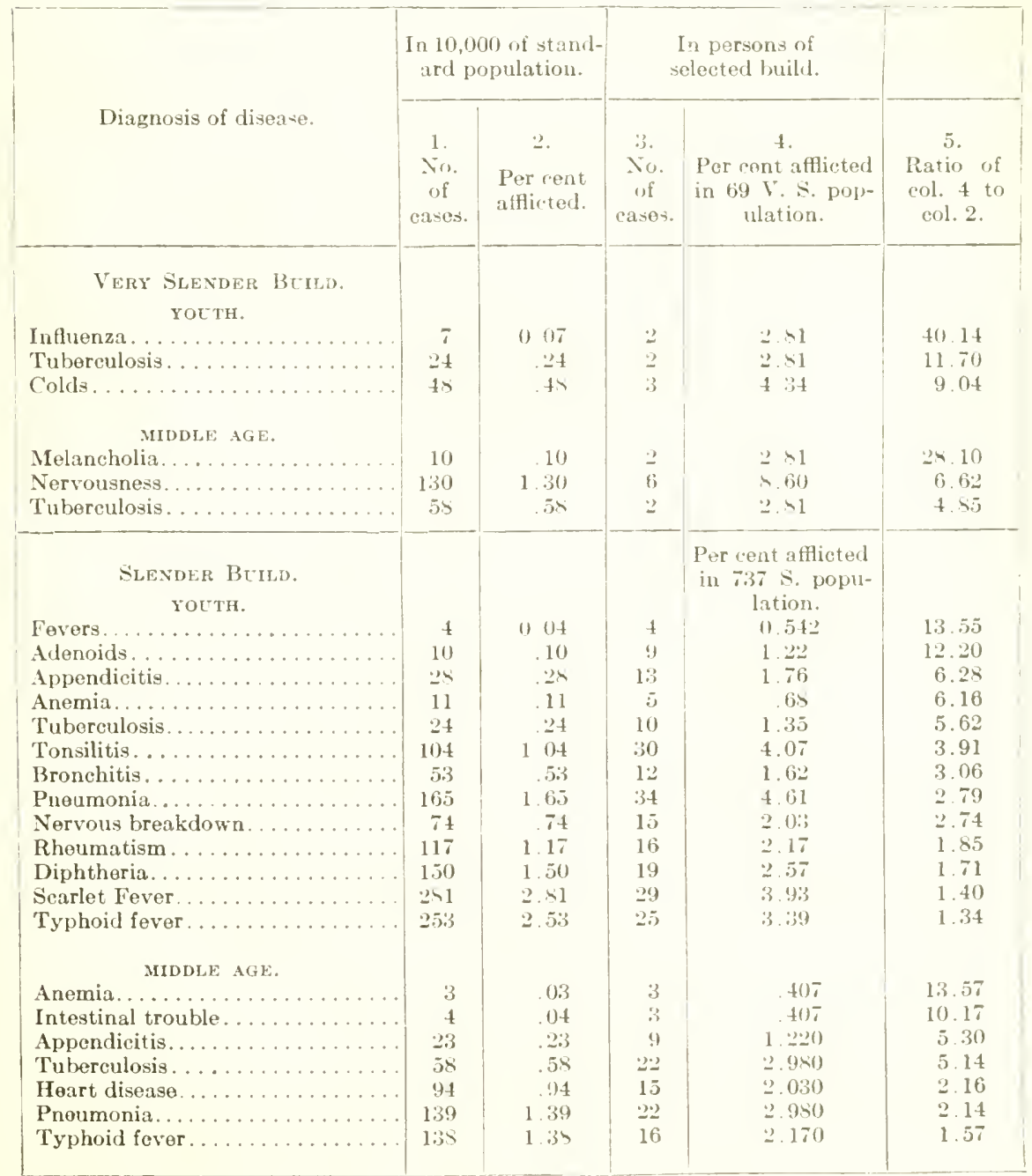


TABLE 10-Incidence of disease in relation to build-Continued.

\begin{tabular}{|c|c|c|c|c|c|}
\hline \multirow[b]{2}{*}{ Diagnosis of disease. } & \multicolumn{2}{|c|}{$\begin{array}{l}\text { In } 10,000 \text { of stand- } \\
\text { ard population. }\end{array}$} & \multicolumn{2}{|c|}{$\begin{array}{l}\text { In persons of } \\
\text { selected build. }\end{array}$} & \multirow[b]{2}{*}{$\begin{array}{l}5 . \\
\text { Ratio of } \\
\text { col. } 4 \text { to } \\
\text { col. } 2 \text {. }\end{array}$} \\
\hline & $\begin{array}{l}\text { 1. } \\
\text { No. } \\
\text { of } \\
\text { easos. }\end{array}$ & $\begin{array}{l}2 . \\
\text { Por cent } \\
\text { afflicted. }\end{array}$ & $\begin{array}{l}3 . \\
\text { No. } \\
\text { of } \\
\text { eases. }\end{array}$ & $\begin{array}{c}4 . \\
\text { Per cent afflicted } \\
\text { in } 543 \mathrm{~F} \text {. popu- } \\
\text { lation. }\end{array}$ & \\
\hline 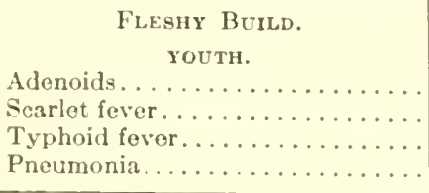 & $\begin{array}{l}10 \\
251 \\
253 \\
165\end{array}$ & $\begin{array}{l}0.10 \\
2.81 \\
2.53 \\
1.65\end{array}$ & $\begin{array}{r}3 \\
36 \\
28 \\
17\end{array}$ & $\begin{array}{l}0.553 \\
6.642 \\
5.166 \\
3.136\end{array}$ & $\begin{array}{r}55.30 \\
2.36 \\
2.04 \\
1.90\end{array}$ \\
\hline 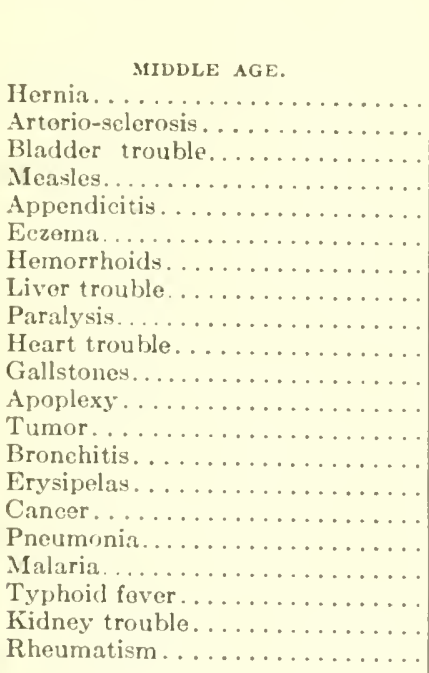 & $\begin{array}{r}8 \\
9 \\
10 \\
10 \\
23 \\
6 \\
13 \\
16 \\
49 \\
94 \\
22 \\
27 \\
18 \\
38 \\
31 \\
51 \\
139 \\
43 \\
138 \\
74 \\
349\end{array}$ & $\begin{array}{r}0.08 \\
.09 \\
.10 \\
.10 \\
.23 \\
.06 \\
.13 \\
.16 \\
.49 \\
.94 \\
.22 \\
.27 \\
.18 \\
.38 \\
.31 \\
.51 \\
1.39 \\
.43 \\
1.38 \\
.74 \\
3.49\end{array}$ & $\begin{array}{r}7 \\
6 \\
6 \\
6 \\
12 \\
3 \\
5 \\
6 \\
18 \\
34 \\
8 \\
8 \\
5 \\
9 \\
7 \\
10 \\
27 \\
8 \\
22 \\
11 \\
37\end{array}$ & $\begin{array}{c}\text { Per cent afflieted } \\
\text { in } 542 \text { F. indi- } \\
\text { viduals. } \\
1.29 \\
1.10 \\
1.10 \\
1.10 \\
2.22 \\
0.55 \\
0.92 \\
1.10 \\
3.35 \\
6.28 \\
1.47 \\
1.47 \\
0.92 \\
1.66 \\
1.29 \\
1.54 \\
4.98 \\
1.47 \\
4.06 \\
2.03 \\
6.52\end{array}$ & $\begin{array}{r}16.00 \\
12.22 \\
11.00 \\
11.00 \\
9.65 \\
9.17 \\
7.11 \\
6.88 \\
6.80 \\
6.69 \\
6.68 \\
5.44 \\
5.13 \\
4.37 \\
4.16 \\
3.61 \\
3.58 \\
3.42 \\
2.95 \\
2.74 \\
1.95\end{array}$ \\
\hline 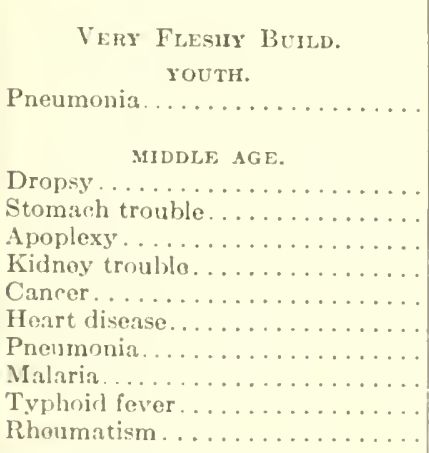 & $\begin{array}{r}14 \\
15 \\
37 \\
74 \\
51 \\
94 \\
139 \\
43 \\
138 \\
349\end{array}$ & $\begin{array}{r}0.14 \\
.15 \\
.37 \\
.74 \\
.51 \\
.94 \\
1.39 \\
.43 \\
1.38 \\
3.49\end{array}$ & $\begin{array}{r}3 \\
3 \\
5 \\
8 \\
4 \\
6 \\
6 \\
2 \\
6 \\
10\end{array}$ & $\begin{array}{c}\text { Per cent afflieted } \\
\text { in } 103 \mathrm{~V} . \mathrm{F} \text {. popu- } \\
\text { lation. } \\
6.79\end{array}$ & $\begin{array}{c}20.80 \\
19.40 \\
11.40 \\
10.60 \\
7.61 \\
6.20 \\
5.6 \\
4.5 \\
4.2 \\
2.8\end{array}$ \\
\hline
\end{tabular}

Very slender build: A. Youth; expectation for eases of measles, 2 ; found, none.

Slender build: A. Youth; expectation for cases of whooping-cough, 7 ; chicken-pox, 4; colds, 4, croup, 3. Cases found, none. 13. Middle Age; expectation for cases of eye trouble, 30, orysipelas, 24, tonsillitis, 23, and apoplexy, 21. Cases found, none.

Fleshy build: A. Youth; expoctation for eases of ear trouble, 19, lung trouble, 18. Cases found, none. B. Niddle age; expectation for eases of throat trouble, 5. Cases found, none. 
Record Office) as occurring during youth and during middle age in 10,000 fairly well described persons. This constituted the control. Then there was determined for our groups of very slender, slender, fleshy, and very fleshy, the incidence of disease. The ratio of the percentage incidence of the latter to the former was then calculated. In table 10 is given in sum many of the results found for the principal diseases. This table may now be briefly discussed.

Persons of very slender build are characterized in youth by an excess of respiratory diseases-influenza, tuberculosis, and colds. In middle age they show an excess of melancholia, nervousness, and tuberculosis.

In 737 persons of slender build there are found in youth many diseases in excess of normal incidence. These comprise diseases of the respiratory tract-tuberculosis, tonsillitis, bronchitis, pneumonia; some nervous diseases, "nervous breakdown"; various general infections, such as "fevers," appendicitis, anemia, "rheumatism," diphtheria, scarlet and typhoid fevers. One might conclude that slender youth are relatively nonresistant to infections. In slender persons there is found in middle age an excess of tuberculosis and pneumonia, much appendicitis and intestinal trouble, and (as also in youth) anemia.

These associations of slender build and disease are not always easy to interpret. The common idea of the tubercular diathesis comprises slender form. On the other hand, a person who has, or has recovered from, active pulmonary tuberculosis is apt to remain underweight, partly because the respiratory apparatus is damaged. The association of "nervousness" with slenderness is probably due to the double effect of some glandular dystrophy, as, for example, of the thyroid gland. Hyperthyroid individuals are usually tall, slender, and "nervous" or irritable.

In 103 persons of very fleshy build, the only outstanding disease of youth is pneumonia. In middle age occur "kidney trouble," "dropsy" (which often accompanies chronic nephritis), and apoplexy, which is sometimes caused by extra pressure on the blood-vessels resulting from impeded elimination from the kidney or to a diabetic tendency which puts extra work on the vessels. "Heart disease" is also commoner than usual.

In 542 persons of fleshy build, "bladder trouble" (probably including diabetes) and kidney trouble are exceptionally frequent, also arterio-sclerosis and its accompaniments, apoplexy and paralysis. Hernia is frequent, as are various diseases of the digestive tract, such as appendicitis, hemorrhoids, liver trouble, and gallstones. These are doubtless not the cause of, but a consequence or concomitant of, overweight. Sibilant bronchitis, lithiasis (uric and biliare), and diabetes mellitus are mentioned, in addition to the above, by Heckel (1920, p. 31) as especially apt to be associated with obesity. 
TABLE 11.-Distribution of progeny of the different matings according to index of build; males and females tabulated separately.

[From Appendix tables, omitting starred families.]

\begin{tabular}{|c|c|c|c|c|c|c|c|c|c|c|c|c|c|c|}
\hline \multirow{2}{*}{ 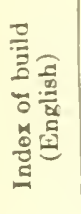 } & \multicolumn{14}{|c|}{ Distribution of male progeny. } \\
\hline & $\begin{array}{l}\infty \\
x \\
x \\
x=1 \\
=\end{array}$ & $\begin{array}{l}z \\
x= \\
x= \\
y\end{array}$ & $\begin{array}{l}1 \\
x \\
3 \\
3 \\
z\end{array}$ & $\begin{array}{l}2 \\
\times= \\
\infty\end{array}$ & $\begin{array}{l}\vec{z}= \\
x= \\
\text { us }\end{array}$ & $\begin{array}{l}x_{0} \Xi \\
x= \\
v_{0}=\end{array}$ & $\frac{1}{x}$ & $\begin{array}{l}z \\
x y \\
z\end{array}$ & $\frac{x}{x}$ & $\frac{1}{x}=$ & 跑 & $\begin{array}{l}5 \\
\times 2\end{array}$ & $\begin{array}{l}2 \\
x>7 \\
2 \\
2\end{array}$ & $\begin{array}{l}{ }^{\circ} 0 \\
\frac{5}{0} \\
0 \\
0\end{array}$ \\
\hline $\begin{array}{l}22 \\
23\end{array}$ & & & & & & & & & & & & & & $\ldots$ \\
\hline 24 & & & & & & & & & & & & & & \\
\hline $\begin{array}{l}25 \\
26\end{array}$ & $\begin{array}{l}1 \\
1\end{array}$ & & & 1 & 1 & $\begin{array}{c}1 \\
\ldots\end{array}$ & & & & $\begin{array}{c}1 \\
\ldots\end{array}$ & & & & $\begin{array}{l}4 \\
2\end{array}$ \\
\hline 27 & 1 & & i & $i$ & & & & 1 & & 1 & & & & 11 \\
\hline 28 & & 1 & $\ldots .$. & 5 & & 1 & 1 & 1 & & & & $\ldots \ldots$ & & 9 \\
\hline 29 & $\cdots$ & 1 & $\ldots \ldots$ & 4 & 3 & 2 & & 3 & 2 & 1 & 2 & & & 18 \\
\hline 30 & & $\ldots \ldots$ & $\ldots \ldots$ & 5 & $\mathrm{~s}$ & 2 & 2 & 13 & 7 & 1 & 1 & & & 39 \\
\hline 31 & 1 & & & 2 & 17 & 5 & 1 & 10 & 6 & 2 & 2 & 1 & 1 & 48 \\
\hline 32 & & 2 & 2 & 3 & 21 & 7 & 2 & 18 & 25 & 3 & 4 & 4 & 3 & 94 \\
\hline 33 & & 2 & 1 & 2 & 23 & 13 & 2 & 23 & 26 & 4 & 3 & 7 & 1 & 107 \\
\hline 34 & & 2 & 1 & $\ldots \ldots$ & 17 & 14 & 1 & 16 & 21 & 3 & 4 & 3 & 1 & 83 \\
\hline 35 & & & & & 24 & 8 & 2 & 25 & 20 & 8 & 8 & 5 & 2 & 102 \\
\hline 36 & & 1 & & $\ldots$ & 14 & 4 & & 25 & 20 & 1 & 9 & 2 & 1 & 77 \\
\hline 37 & & 1 & 1 & $\ldots$ & 12 & 10 & 1 & 8 & 14 & 5 & 6 & 1 & 1 & 60 \\
\hline 38 & & & 1 & & 9 & 9 & 2 & 10 & 16 & 3 & 9 & 3 & & 62 \\
\hline 39 & 1 & & & $\ldots$ & 6 & 4 & 5 & 8 & 5 & 9 & $\tau$ & 7 & 1 & 53 \\
\hline 40 & & & 1 & & 4 & 2 & 1 & 6 & 6 & 5 & 4 & 5 & 1 & 35 \\
\hline 41 & & & 2 & $\ldots$ & 4 & 1 & $\cdots$ & 4 & 10 & & 1 & 2 & $\ldots \ldots$ & 24 \\
\hline 42 & & & $\cdots$ & $\ldots$ & 1 & 2 & 1 & 1 & 5 & 1 & 4 & 6 & & 21 \\
\hline 43 & & 1 & 1 & $\ldots$ & 2 & 2 & & 3 & 2 & 1 & 3 & 4 & & 19 \\
\hline 44 & & & & & 1 & & 1 & $\ldots$ & 1 & 1 & & 2 & 1 & 7 \\
\hline 45 & & & & $\ldots$ & 1 & 1 & & & 2 & 4 & 2 & & 2 & 12 \\
\hline 46 & & & & & & $\ldots \ldots$ & 1 & 1 & & 2 & & 2 & 1 & 7 \\
\hline 47 & & & & $\cdots$ & 1 & & & 1 & 2 & $\ldots$ & 4 & & 2 & 10 \\
\hline 48 & & & & & 1 & & & & & & & 2 & & 3 \\
\hline 49 & & & & & & & & 1 & & $\ldots$ & & & & 1 \\
\hline 50 & & & & & 1 & & & $\ldots \ldots$ & . & 1 & & & 2 & 4 \\
\hline 51 & & & 1 & & 1 & & & & & & 2 & & 1 & 5 \\
\hline 52 & & & . & & $\cdots$ & & $\ldots$ & $\cdots$ & & $\ldots$ & & & $\cdots \cdots$ & 0 \\
\hline 53 & . & & . & $\ldots$ & . & $\ldots$ & $\ldots$ & $\cdots$ & 2 & $\ldots$ & 2 & 1 & $\cdots \cdots$ & 5 \\
\hline 54 & & & - & $\cdots$ & $\cdots$ & $\cdots$ & $\ldots$ & .... & 1 & & $\cdots \cdots$ & $\cdots$ & … & 1 \\
\hline $\begin{array}{l}55 \\
56\end{array}$ & & & & & & & & & . & & & . & $\cdots$ & 0 \\
\hline $\begin{array}{l}56 \\
57\end{array}$ & & & & & & & & $\ldots$ & & & & & .... & 0 \\
\hline 58 & & & & & & & . & & 1 & & & & $\ldots \ldots$ & 1 \\
\hline 79 & & & & & & & & & & 1 & $\cdots$ & $\cdots$ & … & 0 \\
\hline 103 & & & & & & & & $\cdots$ & $\cdots$ & 1 & & & & 1 \\
\hline & $\cdots$ & & $\cdots$ & ..... & $\cdots \cdots$ & $\cdots$ & $\ldots$ & ..... & $\ldots$ & ..... & $\cdots \cdots$ & $\cdots$ & $\cdots$ & $\cdots$ \\
\hline$\sigma^{\pi}$ & 5 & 11 & 12 & 29 & 172 & 8.8 & 23 & 178 & 194 & 59 & 77 & 57 & 21 & 926 \\
\hline 9 & 6 & 17 & 13 & 18 & 134 & 67 & 11 & 149 & 146 & 53 & 79 & 43 & 9 & 745 \\
\hline $\begin{array}{c}\text { Total } \\
\sigma^{7} \\
\text { and } 9\end{array}$ & 11 & 28 & 25 & 47 & 306 & 15.5 & 34 & 327 & 340 & 112 & 156 & 100 & 30 & 1671 \\
\hline
\end{tabular}

Avg. ఠ’, 35.81 $\pm 0.12 \quad 6 \quad \sigma^{7}, 5.325 \pm 0.084$ 
TABLE $11 \mathrm{~A}$-Distribution of progeny of the diffcrent matings according to andex of build; males and females tabulated separately-Continued.

[From Appendix tables, omitting starred families.]

\begin{tabular}{|c|c|c|c|c|c|c|c|c|c|c|c|c|c|c|c|}
\hline \multirow{2}{*}{ 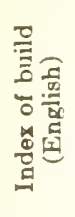 } & \multicolumn{14}{|c|}{ Distribution of female progeny. } & \multirow{2}{*}{ 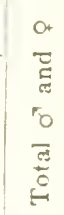 } \\
\hline & $\begin{array}{l}n \\
\times \\
0\end{array}$ & $\begin{array}{l}5 \\
\times \equiv \\
5 \\
>\end{array}$ & $\begin{array}{l}a \\
x> \\
0 \\
2\end{array}$ & $\begin{array}{l}v_{2}= \\
\times=r \\
w_{2}\end{array}$ & $\begin{array}{c}\bar{z}= \\
x= \\
x=\end{array}$ & $\begin{array}{l}\Xi \Xi \\
\times=\end{array}$ & $\sum_{-\infty}^{2}$ & $\begin{array}{l}z \\
x y \\
z\end{array}$ & $\begin{array}{l}=2 \\
x=1 \\
=\end{array}$ & $\begin{array}{l}5= \\
\times=5\end{array}$ & 回吕 & 侌云 & $\frac{5}{x}$ & $\frac{5}{5}$ & \\
\hline 22 & & 1 & & 1 & & & & & & & & & & 2 & 2 \\
\hline 23 & 1 & $\ldots$ & & $\ldots$. & $\cdots$ & 1 & & & & & & & & 2 & 2 \\
\hline 24 & & & & & & & & & & & & & & () & 0 \\
\hline 25 & & & 1 & 3 & & 1 & & 2 & & 1 & & & & $x$ & 12 \\
\hline 26 & 2 & 1 & & 3 & 3 & 3 & & & 1 & $\cdots$ & 1 & & . & 14 & 16 \\
\hline 27 & $\ldots$. & 1 & 1 & 4 & 2 & 1 & & 3 & & $\ldots$ & $\ldots$ & 1 & $\ldots$ & 13 & 24 \\
\hline 28 & & & 1 & 1 & 11 & 1 & & 1 & 4 & . . & 2 & $\ldots$ & & 21 & 30 \\
\hline 29 & 1 & 1 & 1 & 2 & 10 & 5 & 1 & 7 & 5 & 2 & 6 & & $\ldots$ & 41 & 59 \\
\hline 30 & 1 & 2 & 1 & 1 & 10 & 6 & $\ldots \ldots$ & 10 & $y$ & 2 & 3 & 2 & $\ldots$ & 47 & 86 \\
\hline 31 & $\ldots$ & 4 & & 1 & 22 & 8 & 2 & 15 & 9 & 4 & $\underline{2}$ & 3 & 1 & 71 & 119 \\
\hline 32 & 1 & 1 & 1 & 2 & 18 & 2 & 2 & 12 & 15 & 6 & 2 & 2 & 1 & 65 & 159 \\
\hline 33 & $\ldots \ldots$ & 4 & 2 & $\ldots \ldots$ & 12 & 11 & 1 & 14 & 20 & 4 & 1 & 2 & & 71 & 178 \\
\hline 34 & $\ldots$ & $\ldots \ldots$ & 1 & $\ldots \ldots$ & 9 & 4 & & 12 & 13 & 9 & $B$ & 2 & 2 & 60 & 143 \\
\hline 35 & $\ldots$ & $\ldots \ldots$ & 2 & $\ldots \ldots$ & 10 & 2 & & 9 & 13 & 4 & 9 & 3 & $\ldots$ & 52 & 154 \\
\hline 36 & $\ldots \ldots$ & 1 & $\ldots \ldots$ & $\ldots$. & 7 & 2 & 1 & 19 & 20 & 2 & $\delta$ & 4 & 1 & 65 & 142 \\
\hline 37 & & & $\ldots$ & $\ldots \ldots$ & 3 & 3 & 1 & 14 & 8 & 4 & 7 & 2 & $\ldots$ & 42 & 102 \\
\hline 38 & & & $\ldots$ & $\ldots \ldots$ & 2 & 5 & 1 & 7 & 7 & 2 & 2 & 5 & $\ldots$ & 31 & 93 \\
\hline 39 & & & $\ldots \ldots$ & $\ldots$ & 2 & 5 & & 10 & 5 & 2 & $\ldots$ & 1 & 1 & 26 & 79 \\
\hline 40 & $\ldots \ldots$ & $\ldots \ldots$ & 1 & $\ldots$ & 3 & 1 & 1 & 3 & 6 & $\cdots$ & 6 & 1 & 1 & 23 & 58 \\
\hline 41 & $\ldots \ldots$ & $\ldots$ & $\ldots \ldots$ & $\ldots \ldots$ & 2 & 1 & 1 & 5 & 1 & 2 & 2 & 1 & $\ldots$ & 14 & 38 \\
\hline 42 & $\ldots \ldots$ & 1 & $\ldots \ldots$ & $\ldots$. & 1 & 3 & $\ldots \ldots$ & 2 & 2 & $\ldots$ & 7 & 3 & 1 & 21 & 42 \\
\hline 43 & $\ldots \ldots$ & $\ldots \ldots$ & $\ldots \ldots$ & $\ldots \ldots$ & 2 & 1 & $\ldots \ldots$ & $\ldots$ & 1 & 2 & 3 & 1 & $\ldots$ & 10 & 29 \\
\hline 44 & $\ldots \ldots$ & $\ldots \ldots$ & $\ldots \ldots$ & $\ldots$ & 1 & 1 & & $\ldots$. & 2 & $\ldots$ & 6 & 1 & & 11 & 18 \\
\hline 45 & $\ldots \ldots$ & $\ldots \ldots$ & $\ldots \ldots$ & $\ldots$. & 2 & $\ldots \ldots$ & $\ldots \ldots$ & 1 & $\ldots \ldots$ & 2 & $\ldots$ & 3 & $\ldots$ & $\gamma$ & 20 \\
\hline 46 & $\ldots \ldots$ & $\ldots \ldots$ & 1 & $\ldots$ & 1 & $\ldots$ & $\ldots \ldots$ & $\ldots$ & 1 & 1 & & 1 & & 5 & 12 \\
\hline 47 & $\cdots$ & $\ldots \ldots$ & $\ldots$ & $\ldots \ldots$ & $\ldots$ & & & $\ldots \ldots$ & 2 & & 1 & 2 & 1 & 6 & 16 \\
\hline 48 & $\ldots \ldots$ & $\ldots$ & $\ldots$ & $\ldots \ldots$ & & $\ldots$ & $\ldots$. & $\ldots$ & & 1 & . & 1 & $\ldots$ & 2 & 5 \\
\hline 49 & $\ldots \ldots$ & $\ldots \ldots$ & $\ldots \ldots$ & $\ldots \ldots$ & 1 & & $\ldots \ldots$ & 1 & 1 & 1 & 2 & $\ldots$ & $\ldots$ & 6 & 7 \\
\hline 50 & $\ldots$ & & $\ldots$ & $\ldots$ & $\cdots$ & $\cdots$ & ..... & $\ldots \ldots$ & 1 & 1 & $\ldots$ & $\ldots$ & $\ldots$ & 2 & 6 \\
\hline 51 & $\ldots$ & $\ldots \ldots$ & $\ldots$ & $\ldots \ldots$ & . & $\ldots$ & $\ldots$. & 1 & $\cdots$ & & $\ldots$ & 1 & $\ldots$ & 2 & 7 \\
\hline 52 & $\ldots$ & & & $\ldots \ldots$ & $\ldots$ & & ..... & $\ldots \ldots$ & $\ldots \ldots$ & 1 & 1 & & $\ldots$ & 2 & 2 \\
\hline 53 & $\ldots$ & $\ldots \ldots$ & $\ldots$ & $\ldots \ldots$ & $\ldots \ldots$ & & $\ldots$ & $\ldots$. & $\ldots$ & & & 1 & & 1 & 6 \\
\hline 54 & . & $\ldots \ldots$ & $\ldots$ & & $\ldots \ldots$ & & $\ldots$ & $\ldots$. & $\cdots$ & & $\ldots$ & $\ldots$ & $\cdots$ & & 1 \\
\hline 55 & & & & . & $\ldots$ & & $\ldots$. & & $\ldots$ & & $\ldots$ & $\ldots$ & . & & 0 \\
\hline 56 & & & & $\ldots \ldots$ & $\ldots \ldots$ & $\cdots$ & $\ldots \ldots$ & 1 & . . & $\ldots$ & $\ldots$ & $\ldots$ & $\ldots$ & 1 & 1 \\
\hline 57 & & $\cdots$ & & $\ldots \ldots$ & . . & . & . & $\ldots$ & $\ldots \ldots$ & . & $\ldots$ & $\ldots$ & & $\ldots$ & 0 \\
\hline 58 & . & $\cdots$ & & $\ldots \ldots$ & $\cdots$ & . & & & $\ldots$ & & $\ldots$ & $\ldots$ & $\ldots$ & $\ldots$ & 1 \\
\hline 79 & & . & & $\cdots$ & & $\cdots$ & $\because$ & & & $\ldots$ & $\ldots$ & $\cdots$ & $\ldots$ & & 1 \\
\hline 103 & $\cdots$ & & & $\ldots$ & & & & & & $\ldots$ & $\ldots$ & $\ldots$ & $\ldots$ & $\ldots$ & 1 \\
\hline \& & e & 7 & 13 & 15 & 134 & 67 & 11 & 190 & 716 & 53 & 79 & 43 & 0 & -45 & 167 \\
\hline & 0 & 18 & 15 & 10 & 134 & 08 & 11 & $1+9$ & 140 & & & & & & 1081 \\
\hline
\end{tabular}

Avg. $9.34 .54 \pm 0.17$

S. D. $\&, 5.133 \pm 0.089$

The one clear conclusion from this study is that 110 single discase and no special single collection of diseases is exclusivcly responsible for exceptionally slender or exceptionally fleshy build. The variations in build are due primarily rather to various idiosyncrasies of development and metabolism which have largely an hereditary basis, upon which may be superimposed modifications by various types of disease. 


\begin{tabular}{|c|c|c|c|c|c|c|c|}
\hline & 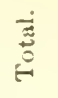 & & $\mathscr{L}_{0}^{\circ}$ & अ & 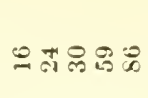 & 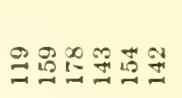 & 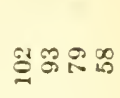 \\
\hline 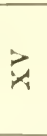 & $\begin{array}{l}5 \\
5 \\
x \\
5 \\
5\end{array}$ & 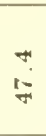 & n & & $\begin{array}{l}\vdots \\
\vdots \\
\vdots\end{array}$ & 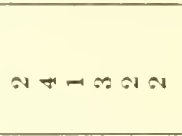 & $-\vdots a^{2101}$ \\
\hline 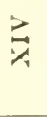 & $\begin{array}{c}5 \\
x \\
x \\
5\end{array}$ & $\begin{array}{l}0 \\
\infty\end{array}$ & 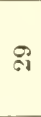 & & 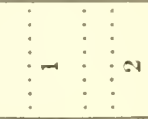 & Hod 0000 & $n \infty \infty 0$ \\
\hline$\Xi$ & $\begin{array}{l}x \\
x \\
x\end{array}$ & $\stackrel{\leftrightarrow}{\circ}$ & $\ddot{m}$ & & $-\vdots \vdots \infty \infty+$ & $+\infty+1=$ & $\cong ニ ッ$ \\
\hline 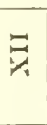 & $\begin{array}{l}\frac{5}{x} \\
x \\
z\end{array}$ & $\dddot{0}$ & $\vec{m}$ & $\vdots \vdots \vdots \vdots$ & $\begin{array}{l}\vdots \\
\vdots \\
\vdots\end{array}-\infty$ & $00 x \cong$ & $0 \times=\infty$ \\
\hline$\ddot{F}$ & $\begin{array}{l}5 \\
\times \\
=\end{array}$ & 施 & $\Xi$ & & $-\vdots+1-0$ & 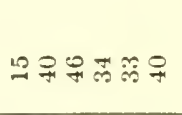 & 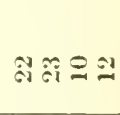 \\
\hline$\%$ & $\begin{array}{l}z \\
x \\
x \\
z\end{array}$ & $\begin{array}{l}\because \\
\dot{\infty}\end{array}$ & $\dot{\mathrm{b}}$ & $\begin{array}{l}\vdots \\
\vdots \\
\vdots \\
\vdots\end{array}$ & 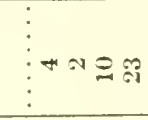 & 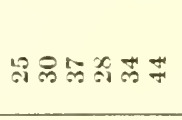 & $\hat{A}=\infty 0$ \\
\hline 至 & \begin{tabular}{l|} 
\\
5 \\
$x$ \\
$n$ \\
$n$
\end{tabular} & $\stackrel{0}{0}$ & $=$ & $\begin{array}{c}\vdots \vdots \\
\vdots \\
\vdots\end{array}$ & 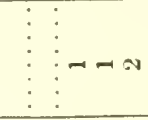 & $n+n-1-1$ & Nos \\
\hline$\Xi$ & $\begin{array}{l} \\
x \\
\infty\end{array}$ & $\infty$ & 马 & $\vdots-1$ & $\therefore-x+\infty$ & $20 ; \infty 00$ & $\because コ の$ \\
\hline 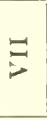 & $\begin{array}{l}z \\
x \\
n \\
n\end{array}$ & $\stackrel{0}{0}$ & $\vec{\Xi}$ & $\begin{array}{c} \\
\vdots \\
\vdots\end{array}$ & $* N \equiv \cong \infty$ & คి. & $22=\infty n$ \\
\hline$\Xi$ & $\begin{array}{l}n \\
\times \\
n\end{array}$ & $\infty$ & $\tilde{i}$ & $-\vdots \vdots$ & $r=000$ & 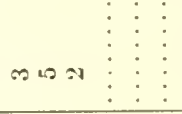 & \\
\hline 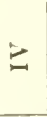 & 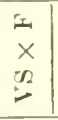 & $\begin{array}{l}0 \\
\text { ले }\end{array}$ & 10 & $\begin{array}{c}\vdots \\
\vdots \\
\vdots \\
\vdots\end{array}$ & 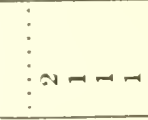 & 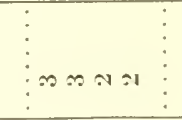 & $\begin{array}{r}\vdots \\
\vdots \\
-\infty\end{array}$ \\
\hline$\Xi$ & $\begin{array}{l}z \\
x \\
0 \\
2\end{array}$ & $\vec{a}$ & $\infty$ & $-\vdots$ & $-\pi-\infty \mathrm{a}$ & $+\infty \infty: 1 \vdots \vdots$ & \\
\hline$\Xi$ & $\begin{array}{l}\infty 2 \\
\times \\
n \\
=\end{array}$ & $\ddot{\infty}$ & + & $\vdots \vdots-$ & s- $\vdots-1$ & $--\vdots \vdots \vdots \vdots$ & $\vdots-$ \\
\hline 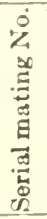 & 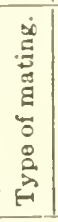 & 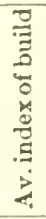 & 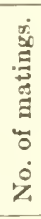 & 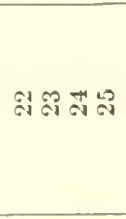 & 오요 & అే & 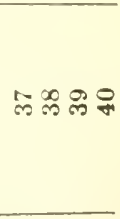 \\
\hline
\end{tabular}




\begin{tabular}{|c|c|c|c|}
\hline 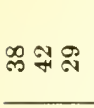 & 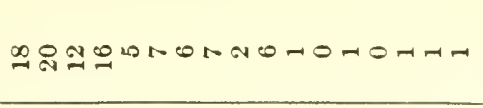 & 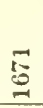 & 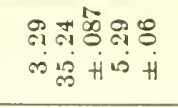 \\
\hline $\begin{array}{c}\vdots \\
\vdots \\
\vdots \\
\vdots\end{array}$ & 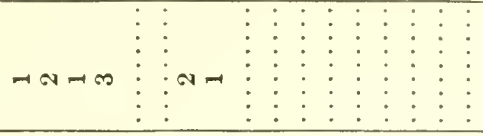 & ? & 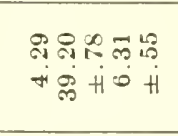 \\
\hline ת & 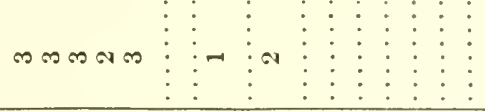 & $\S$ & 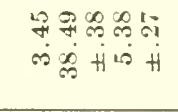 \\
\hline$n=0$ & 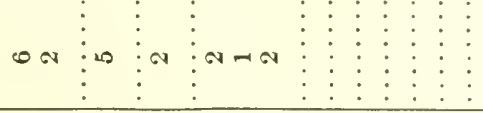 & $\stackrel{5}{-10}$ & 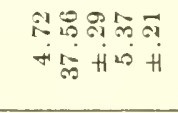 \\
\hline$N-\infty$ & 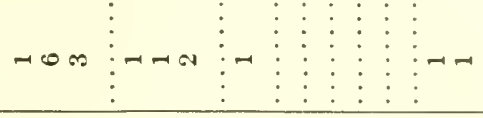 & $\stackrel{92}{\exists}$ & 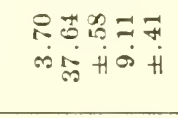 \\
\hline$\exists+\infty$ & 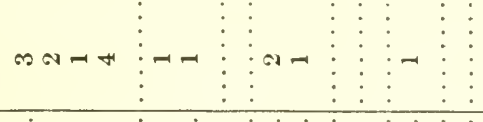 & $\frac{\rho}{\infty}$ & 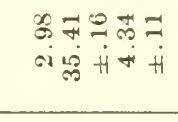 \\
\hline$\infty n$ & 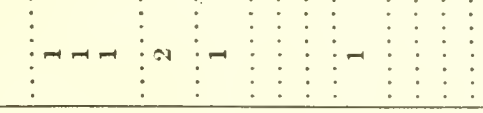 & تi & 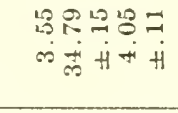 \\
\hline $\begin{array}{r}-1 \\
\vdots \\
\end{array}$ & 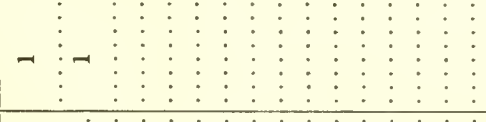 & $\vec{m}$ & 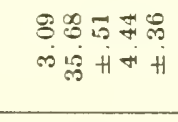 \\
\hline $\cos x$ & 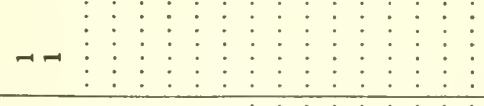 & ํㅗㄱ & 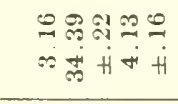 \\
\hline מ & 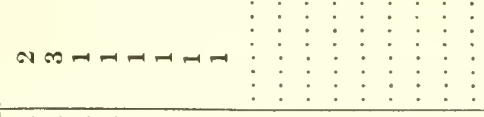 & $\underset{8}{8}$ & 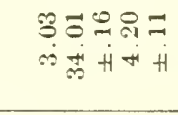 \\
\hline $\begin{array}{c}\vdots \\
\vdots \\
\vdots \\
\vdots \\
\vdots\end{array}$ & 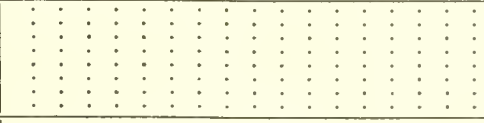 & trits & 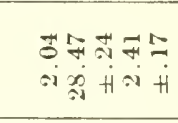 \\
\hline$\infty \quad \vdots$ & 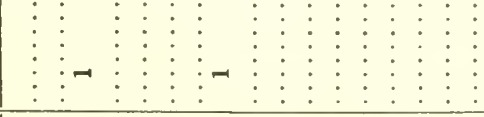 & 28 & 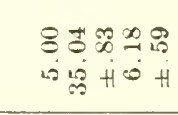 \\
\hline$\vdots \vdots$ & 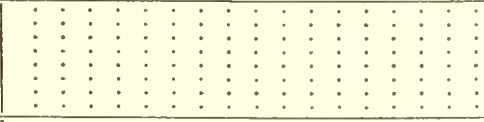 & $\stackrel{\infty}{\infty}$ & 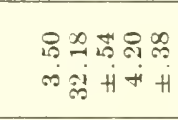 \\
\hline$\vdots \vdots \vdots \vdots$ & 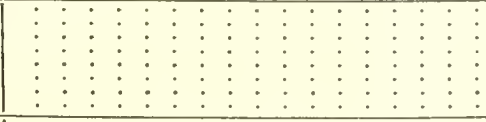 & $=$ & 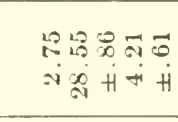 \\
\hline 굮 & 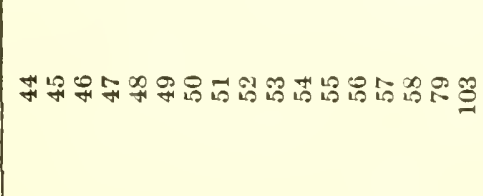 & 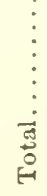 & 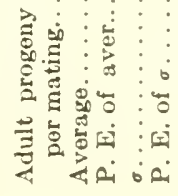 \\
\hline
\end{tabular}


MASS STLDY OF VARIATION AND HEREDITY IN BUILD.

Having considered the classification and something of the causes of variation in build, we have now to consider the relation between the build of the parents and that of the progeny. This is the mass treatment of the data of "heredity" which was the prevailing method 25 years ago and earlier. It is still a useful method in the case of traits due to multiple factors, such as the present one.

The distribution of build in the children of the different matings is given in tables $11,11 \mathrm{~A}$, and 12 . There are 15 possible different combinations of matings of the five grades. The first of these (VS $\times$ VS) is not represented in our data, and the fifth, $\mathrm{VS} \times \mathrm{VF}$, is represented by only one mating and no column is devoted to it. The frequencies are given separately for male and female offspring (table 11), and again for both sexes together (table 12). Table 13 shows that there is a considerable correlation between the average build of the parentage and that of the progeny. From the matings of the fleshier parents the progeny are fleshier; from those of slender parents, slenderer. This relation may conceivably be due to family tradition handed down from parents to children. We shall see later that this hypothesis mects with formidable difficulties to acceptance. The most reasonable hypothesis is that there are, above all, hereditary family tendencies that help determine build.

Comparing the tables for male and female offspring, it appears, first, that there are, for some reason, more males than females about whom data of build are given, probably because more males than females know their stature and weight, or willingly record it; second, there are relatively more females than males of very slender build (grades 22 to 31 ); there are recorded relatively more very fleshy males than females (grades of 50 and above); third, there are relatively more recorded daughters than sons derived from one very slender parent, and from the $\mathrm{F} \times \mathrm{F}$ and $\mathrm{M} \times \mathrm{M}$ matings. The male progeny are more variable than the female as $5.325 \pm 0.084$ is to $5.133 \pm 0.089$; but the difference is less than three times the probable error, and is, consequently, not very significant.

Considering next the table of total progeny of the various matings, it appears that the average number of children with recorded build from the recorded matings is variable. In descending order the fecundity of the matings is shown in table 14. This table shows that larger families, on the average, were derived from fleshy parents than from slender parents. Thus the $\mathrm{F} \times \mathrm{F}$ matings yield 2.3 times as many children, on the average, per mating as the $\mathrm{S} \times \mathrm{S}$ matings. 


\section{REGRESSION OF PROGENY TOWARD MEDIOCRITY.}

Galton pointed out, in the case of stature, that, since correlation between parents and progeny is not perfect, the progeny of selected parents will tend to be less extremely selected and hence more nearly mediocre than their parents. It has, indeed, been shown in my studies on stature $(1917, \mathrm{p} .341)$ that the progeny of tall parents do not show this regression to mediocrity as much as the progeny of short parents. This was regarded as evidence that the gametes of tall parents carried fewer recessive allelomorphs than those of short parents; hence were genetically "purer" and comprise more recessive factors. What is the condition in respect to the varying indices of build?

TABLE 13.-Distribution of progeny of the various matings, according to classes of build, absolute numbers, and proportions, based on A ppendix table, including starred families.

\begin{tabular}{|c|c|c|c|c|c|c|c|c|c|c|c|c|}
\hline \multirow{2}{*}{\multicolumn{2}{|c|}{ Type of mating. }} & \multirow{2}{*}{$\begin{array}{l}\text { Total No. } \\
\text { of children. }\end{array}$} & \multicolumn{5}{|c|}{ Absolute numbers. } & \multicolumn{5}{|c|}{$\begin{array}{l}\text { Proportional frequencies } \\
\text { (per mille). }\end{array}$} \\
\hline & & & VS. & S. & M. & F. & VF. & VS. & s. & M. & F. & VF. \\
\hline \multirow{8}{*}{ No. } & $\mathbf{V S} \times \mathbf{S}$ & 20 & 4 & 12 & 2 & 2 & $\ldots$ & 200 & 600 & 100 & 100 & \\
\hline & $\mathrm{VS} \times \mathbf{M}$ & 28 & 1 & 7 & 17 & 3 & & 36 & 250 & 607 & 107 & \\
\hline & $\mathrm{VS} \times \mathrm{F}$ & 25 & 1 & 5 & 10 & 7 & 2 & 40 & 200 & 400 & 280 & 80 \\
\hline & $\mathrm{S} \times \mathrm{S}$ & 51 & 5 & 35 & 11 & & $\ldots$ & 98 & 686 & 215 & $\ldots \ldots$ & $\ldots$. \\
\hline & $\mathrm{S} \times \mathrm{M}$ & 313 & & 49 & 200 & 53 & 11 & & 157 & 639 & 169 & 35 \\
\hline & $\mathbf{S} \times \mathbf{F}$ & 179 & 5 & 25 & 85 & 57 & 7 & 28 & 140 & 475 & 318 & 39 \\
\hline & $\mathrm{S} \times \mathrm{VF}$ & 50 & & 7 & 18 & 17 & 8 & & 140 & 360 & 340 & 160 \\
\hline & $\mathbf{M} \times \mathbf{M}$ & 332 & 2 & 40 & 201 & 82 & 7 & 6 & 121 & 605 & 247 & 21 \\
\hline $\mathrm{XI}$ & $M \times F$ & 346 & & 31 & 210 & 88 & 17 & $\ldots$. & 90 & 606 & 255 & 49 \\
\hline XII & $\mathbf{M} \times \mathbf{V F}$ & 112 & 2 & 7 & 50 & 36 & 17 & 18 & 63 & 446 & 321 & 152 \\
\hline XIII & $F \times F$ & 159 & & 15 & 62 & 61 & 21 & & 94 & 390 & 384 & 132 \\
\hline XIV & $F \times V F$ & 146 & 1 & 7 & 52 & 51 & 35 & 7 & 48 & 356 & 349 & 240 \\
\hline XV & $\mathrm{VF} \times \mathrm{VF}$ & 37 & & & 12 & $\mathrm{~S}$ & 10 & & $\cdots \cdots$ & 400 & 267 & 333 \\
\hline \multicolumn{2}{|c|}{ Total. } & 1798 & & & & & & & & & & \\
\hline
\end{tabular}

TAELE 14.-Average number of progeny yielded by each type of mating (based on table 1:).

\begin{tabular}{|c|c|c|c|}
\hline Mating. & $\begin{array}{c}\text { No. of } \\
\text { children. }\end{array}$ & Mating. & $\begin{array}{c}\text { No. of } \\
\text { children. }\end{array}$ \\
\cline { 1 - 2 } & & & \\
$\mathrm{VS} \times \mathrm{F}$ & 5.00 & $\mathrm{~S} \times \mathrm{F}$ & 3.16 \\
$\mathrm{~F} \times \mathrm{F}$ & 4.72 & $\mathrm{~S} \times \mathrm{VF}$ & 3.09 \\
$\mathrm{VF} \times \mathrm{VF}$ & 4.29 & $\mathrm{~S} \times \mathrm{M}$ & 3.03 \\
$\mathrm{M} \times \mathrm{VF}$ & 3.70 & $\mathrm{M} \times \mathrm{F}$ & 2.98 \\
$\mathrm{M} \times \mathrm{M}$ & 3.55 & $\mathrm{VS} \times \mathrm{S}$ & 2.75 \\
$\mathrm{VS} \times \mathrm{M}$ & 3.50 & $\mathrm{~S} \times \mathrm{S}$ & 2.04 \\
$\mathrm{~F} \times \mathrm{VF}$ & 3.45 & & \\
\hline
\end{tabular}

The answer to this question is given in table 15, which in turn is based on table 12. This table shows for each of the 13 matings the average departure of the parents from mediocre build (which for the 
parents is 34.86) and the corresponding departure of their offspring from mediocre build (which for the progeny is 35.24). In the righthand column of the table is given the difference between these two departures, which measures the amount of regression toward mediocrity on the part of the progeny. The results of the last column are shown graphically in figure 8 .

TABLE 15.- Average build and regression from parental average of the progeny of the tarious types of mating. Also matings arranged in order of regression. Sexes combined (based on table 12).

\begin{tabular}{|c|c|c|c|c|c|c|c|}
\hline $\begin{array}{l}\text { Type of } \\
\text { mating. }\end{array}$ & $\begin{array}{l}\text { No. of } \\
\text { matings. }\end{array}$ & $\begin{array}{l}\text { No. of } \\
\text { progeny. }\end{array}$ & $\begin{array}{l}\text { Avg. build } \\
\text { of parents. }\end{array}$ & $\begin{array}{l}\text { Avg. build } \\
\text { of progeny. }\end{array}$ & $\begin{array}{l}\text { Departure } \\
\text { of parents } \\
\text { from } \\
\text { mediocrity. }\end{array}$ & $\begin{array}{l}\text { Departure } \\
\text { of progeny } \\
\text { from } \\
\text { mediocrity. }\end{array}$ & Regression. \\
\hline $\mathrm{VS} \times \mathrm{S}$ & 4 & 11 & 26.13 & $28.55 \pm .86$ & -8.73 & -6.69 & +2.04 \\
\hline $\mathrm{VS} \times \mathrm{M}$ & 8 & 28 & 28.38 & $32.15 \pm .54$ & -6.48 & -3.06 & +3.42 \\
\hline$V S \times F$ & 5 & 25 & 32.00 & $35.04 \pm .83$ & -2.86 & -0.20 & +2.66 \\
\hline $\mathrm{S} \times \mathrm{S}$ & 23 & 47 & 29.77 & $28.47 \pm .24$ & $-\quad 5.09$ & -6.77 & -1.68 \\
\hline $\mathrm{S} \times \mathrm{M}$ & 101 & 306 & 30.90 & $34.01 \pm .16$ & -3.96 & -1.23 & +2.73 \\
\hline $\mathrm{S} \times \mathrm{F}$ & 49 & 155 & 33.85 & $34.39 \pm .22$ & -1.01 & -0.85 & +0.16 \\
\hline $\mathrm{S} \times \mathrm{VF}$ & 11 & 34 & 37.91 & $35.48 \pm .51$ & +3.05 & +0.24 & +2.81 \\
\hline $\mathbf{M} \times \mathbf{M}$ & 92 & 327 & 33.23 & $34.79 \pm .15$ & -1.63 & -0.45 & +1.18 \\
\hline $\mathbf{M} \times \mathbf{F}$ & 114 & 340 & 36.45 & $35.41 \pm .16$ & $+\quad 1.59$ & +0.17 & +1.42 \\
\hline$M \times V F$ & 30 & 112 & 40.68 & $36.53 \pm .38$ & +5.82 & +1.29 & +4.53 \\
\hline $\mathbf{F} \times \mathbf{F}$ & 33 & 156 & 39.21 & $37.56 \pm .29$ & +4.35 & +2.32 & +2.03 \\
\hline$F \times V F$ & 30 & 100 & 42.97 & $38.49 \pm .36$ & +8.11 & +3.25 & +4.86 \\
\hline$V F \times V F$ & 7 & 30 & 47.43 & $39.20 \pm .78$ & +12.57 & +3.96 & +8.61 \\
\hline Total. & 507 & 1671 & 34.86 & 35.24 & & & \\
\hline
\end{tabular}

Mediocrity for parents, 34.86. Mediocrity for progeny, 35.24..

Matings Arranged in Order of Regresgion.

\begin{tabular}{|c|r|r|}
\hline $\mathrm{S} \times \mathrm{S}-1.6 \mathrm{~S}$ & $\mathrm{~F} \times \mathrm{F}+2.03$ & $\mathrm{VS} \times \mathrm{M}+3.42$ \\
$\mathrm{~S} \times \mathrm{F}+0.16$ & $\mathrm{VS} \times \mathrm{S}+2.04$ & $\mathrm{M} \times \mathrm{VF}+4.53$ \\
$\mathrm{M} \times \mathrm{M}+1.18$ & $\mathrm{~V} \times \mathrm{F}+2.66$ & $\mathrm{~F} \times \mathrm{VF}+4.86$ \\
$\mathrm{M} \times \mathrm{F}+1.42$ & $\mathrm{~S} \times \mathrm{M}+2.73$ & $\mathrm{VF} \times \mathrm{VF}+8.61$ \\
$\cdots \ldots \ldots \ldots \ldots \ldots \ldots \ldots \ldots$ \\
\hline
\end{tabular}

Figure 8 shows clearly that, in spite of considerable irregularities, the line of regression descends from the matings of two very fleshy parents at the left, and in general from matings in which the average parental departure from the mean build of parents is positive, to the mating of two slender parents (or, less strikingly the VS $\times \mathrm{S}$ mating) or in general to the matings in which the average parental departure is extremely negative. This result is most easily explained on the ground that whereas fleshy parents carry all sorts of gametes for build, slender parents carry a preponderance of gametes of their own kind; hence the progeny do not regress so much from the selected parental condition. This suggests that the slender parents are more nearly homozygous than the fleshy parents. 
Still another test of the gametic composition of the parents is the variability of their offspring. The facts regarding such variability are given in table 16. From this table it appears that the mating that

TABLE 16.-Progeny of the various types of matings arranged in order of variability or standard deviation (S. D.), together with the probable errors (P.E.) of the means and deviations; also the coefficients of variation (based on table 12).

\begin{tabular}{|c|c|c|c|c|}
\hline Type of mating. & $\begin{array}{l}\text { No. of } \\
\text { progeny. }\end{array}$ & $\begin{array}{l}\text { Mean build of pre- } \\
\text { geny and (P. E.) }\end{array}$ & $\begin{array}{l}\text { Standard devia- } \\
\text { tion and (P. E.). }\end{array}$ & $\begin{array}{l}\text { Coefficient of } \\
\text { variability. }\end{array}$ \\
\hline $\mathrm{s} \times \mathrm{s} \ldots \ldots \ldots \ldots$ & 47 & $28.47 \pm 0.24$ & $2.41 \pm 0.17$ & 8.97 \\
\hline $\mathbf{M} \times \mathbf{M} \ldots \ldots \ldots \ldots$ & 327 & $34.79 \pm 0.15$ & $4.06 \pm 0.11$ & 11.67 \\
\hline $\mathrm{S} \times \mathrm{F} \ldots \ldots \ldots$ & 155 & $34.39 \pm 0.22$ & $4.13 \pm 0.16$ & 12.01 \\
\hline $\mathbf{S} \times \mathbf{M}$ & 306 & $34.01 \pm 0.16$ & $4.20 \pm 0.11$ & 12.35 \\
\hline $\mathrm{VS} \times \mathrm{S} \ldots \ldots$ & 11 & $28.55 \pm 0.86$ & $4.21 \pm 0.61$ & 14.75 \\
\hline $\mathrm{VS} \times \mathrm{M} \ldots \ldots$ & 28 & $32.18 \pm 0.54$ & $4.22 \pm 0.38$ & 13.11 \\
\hline $\mathbf{M} \times \mathbf{F} \ldots$ & 340 & $35.41 \pm 0.16$ & $4.27 \pm 0.11$ & 12.06 \\
\hline $\mathrm{S} \times \mathrm{VF} \ldots$ & 34 & $35.68 \pm 0.51$ & $4.44 \pm 0.36$ & 12.44 \\
\hline $\mathbf{F} \times \mathrm{F} \ldots$ & 157 & $37.56 \pm 0.29$ & $5.37 \pm 0.20$ & 14.30 \\
\hline $\mathrm{F} \times \mathrm{VF}$. & 100 & $38.49 \pm 0.36$ & $5.38 \pm 0.27$ & 13.98 \\
\hline$V S \times F \ldots$ & 25 & $35.04 \pm 0.83$ & $6.18 \pm 0.59$ & 17.64 \\
\hline$V F \times V F$ & 30 & $39.20 \pm 0.78$ & $6.31 \pm 0.55$ & 16.10 \\
\hline $\mathrm{M} \times \mathrm{VF}$. & 112 & $37.64 \pm 0.58$ & $9.11 \pm 0.41$ & 24.17 \\
\hline
\end{tabular}

yields the least variable progeny is that of two slender consorts. The variability in their progeny is measured by $2.41 \pm 0.17$. The variability of the progeny of the VS $\times \mathrm{S}$ mating is greater, $4.21 \pm 0.61$,

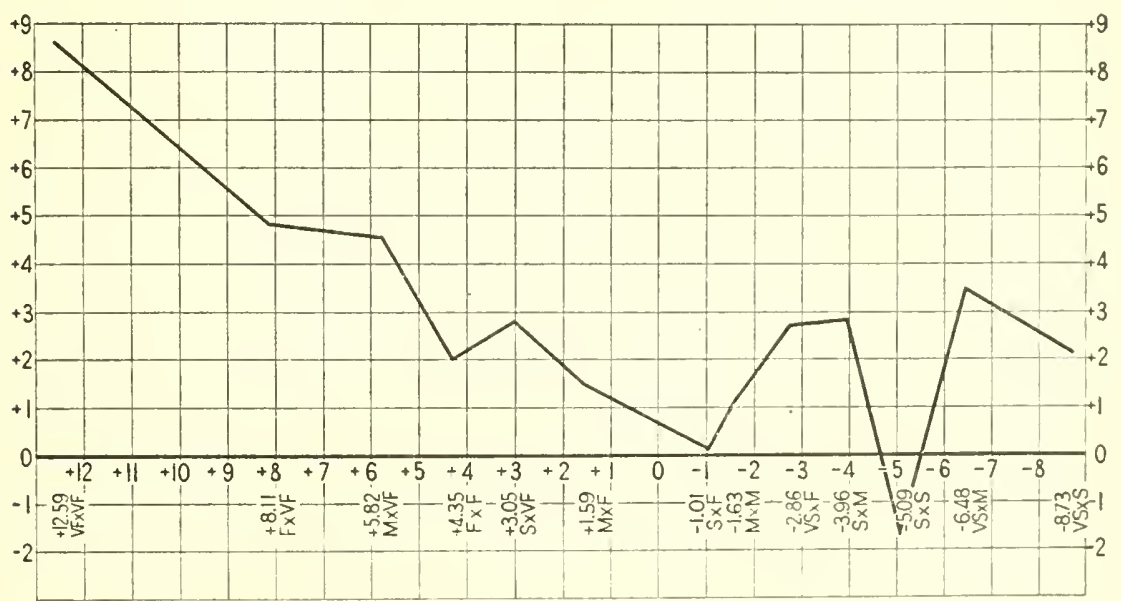

FIG. 8.- Line of regression of progeny on parents, based on the difference betweell average filial and parental departures from medioerity. The abscissæ measure the average parental departure of each class of mating. The ordinates are proportional to the filial regression.

but on account of the small number of the progeny the probable error is large, and it is possible that this difference in variability between $\mathrm{S} \times \mathrm{S}$ and VS $\times \mathrm{S}$ progeny is not a significant one. Next to the least 
variable are the offspring of the $\mathrm{M} \times \mathrm{M}$ mating, $4.06 \pm 0.11$, and this leads to the conclusion that a large proportion of the M parents are not merely heterozygous, but constitute a "pure race" of medium build. The offspring of the $\mathrm{S} \times \mathrm{F}$ mating have a fairly small variability $4.13 \pm 0.16$. as befits a first generation $\left(\mathrm{F}_{1}\right)$ hybrid. On the other extreme, we have the $\mathrm{M} \times \mathrm{VF}$ mating with a standard deviation of $9.11 \pm 0.41$. This large standard deviation is due chiefly to the inclusion of one family (Ber-A) which contains 2 progeny of builds 79 and 103, weighing $180 \mathrm{~kg}$. (400 pounds) and $215 \mathrm{~kg}$. (475 pounds) respectively. Otherwise the variability of this mating is not extreme. It is $5.25 \pm 0.24$. The next largest variability is from the $\mathrm{VF} \times \mathrm{VF}$ mating. $6.31 \pm 0.55$, a variability that is due to the absence of any important mode. The progeny of the $\mathrm{VS} \times \mathrm{F}$ mating are highly variable, $6.18 \pm 0.59$. but this standard deviation has the largest probable error of any except VS $\times$ S, so that great stress must not be laid upon its exact position. In general, the progeny of matings with 2 or $1 \mathrm{~F}$ or $\mathrm{VF}$ parents, belong to the more variable group and those with $\&$ (or VS) parents to the less variable group. The meaning of this is clear to the geneticist who has dealt with multiple factors. It indieates that some or all of the factors that make for fleshy build dominate to a greater or less degree over the factors for slenderness. The test of the regression of progeny toward mediocrity and the test of the variability of the progeny of the various matings thus lead to the same result - the factors for fleshiness are imperfectly dominant over those for slenderness, and the latter probably lack some or all of those factors that make for fleshy build.

\section{HYPOTHESIS.}

The foregoing brief studies of the progeny of classes of matings suggest the following hypothesis:

Fleshy build results from the action of several positive (dominant) factors that make for stoutness, while slenderness results from the absence of one or more of such factors, or is due to recessive factors. Fleshy parents inay, and frequently do, carry gametes which lack the "fleshy" or carry the "slender" factor, while in slender parents for the most part the gametes earry only the slender factor, hence the gametes of slender parents are more nearly homogeneous. This hypothesis may be further developed as follows:

Assuming that there are two independent factors A and B for build, then these may be found in different zygotes in the following combinations:

$\begin{array}{llll}\text { AABB } & \text { AaBB } & \text { aABB } & \text { aaBB } \\ \text { AABb } & \text { AaBb } & \text { aABb } & a a B b \\ \text { AAbB } & \text { AabB } & \text { aAbB } & \text { aabB } \\ \text { AAbb } & \text { Aabb } & \text { aAbb } & \text { aabb }\end{array}$


Or, disregarding order of the letters, and considering only the number and kind of genes in each kind of zygote, we have:

$\begin{array}{lll}A A B B & 2 A a B B & a a B B \\ 2 A A B b & 4 A a B b & 2 a a B b \\ \text { AAbb } & 2 A a b b & a a b b\end{array}$

in which the coefficients indicate the relative frequency of the different combinations.

We may assume that:

4 positive factors in a zygote correspond to a very fleshy person.

3 factors correspond to a fleshy person.

2 factors correspond to a person of medium build.

1 factor corresponds to a slender person.

0 factor corresponds to a very slender person.

Table 17 indicates the possible matings and their progeny.

TAB1E 17-Percentage distribution of the progeny of the various matings, on the ossumption that extreme fleshy build is dependent upon \& zygotic faciors in the parents.

\begin{tabular}{|c|c|c|c|c|c|c|c|c|}
\hline \multirow{2}{*}{$\begin{array}{c}\text { One } \\
\text { parent }\end{array}$} & \multirow{2}{*}{$\begin{array}{l}\text { Other } \\
\text { parent }\end{array}$} & \multirow{2}{*}{ Zygotic formulie. } & \multirow{2}{*}{$\begin{array}{l}\text { Ginmetic } \\
\text { formulie. }\end{array}$} & \multicolumn{5}{|c|}{$\begin{array}{c}\text { Perrentage of each number of } \\
\text { zyotes in progenr. }\end{array}$} \\
\hline & & & & (1) (VS & $1(S)$ & $2(\mathrm{M})$ & $: 3(F)$ & $4(V F)$ \\
\hline 4 & 4 & $A A B B \times A A B B$ & $A B \times A B$ & & & & & 100 \\
\hline 4 & 3 & $A \triangle B B \times A \triangle B W$ & $\left.\begin{array}{l}A B \times A B \\
A B \times A h\end{array}\right\}$ & . & & & 50 & 50 \\
\hline 4 & 2 & $\left\{\begin{array}{l}A \mathrm{ABB} \times \mathrm{AAb} \\
\mathrm{ABBB} \times \mathrm{AaBh}\end{array}\right.$ & $\begin{array}{l}A B \times A b \\
A B \times A B \\
A B \times A b \\
A B \times a B \\
A B \times a b\end{array}$ & & & 25 & $\begin{array}{l}10 t) \\
50\end{array}$ & 2.5 \\
\hline 4 & 1 & $A A B B \times A a b b$ & $\left.\begin{array}{l}A B \times A b \\
A B \times a b\end{array}\right\}$ & & & 50 & i1) & \\
\hline 4 & 0 & $A A B B \times a a b b$ & $A B \times a b$ & & $\ldots \ldots$ & 100 & $\cdots$ & $\ldots \ldots$ \\
\hline 3 & 3 & $A \triangle B b \times A A B b$ & $\left.\begin{array}{l}A B \times A B \\
A B \times A b \\
A b \times A B \\
A b \times A b\end{array}\right\}$ & & & 23 & 50 & 2.5 \\
\hline 3 & 2 & $\begin{array}{l}A A B b \times A A b b \\
A A B b \times A a B b\end{array}$ & $\left.\begin{array}{l}A B \times A b \\
A b \times A b \\
A B \times A B \\
A B \times A b \\
A B \times a B \\
A B \times a b \\
A b \times A B \\
A b \times A b \\
A b \times a B \\
A b \times a b\end{array}\right\}$ & & 12.5 & 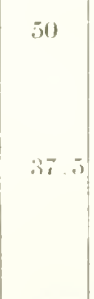 & 37.5 & 12.5 \\
\hline
\end{tabular}


TABLE 17.-Percentage distribution of the progeny of the various matings, on the assumption that extreme fleshy build is dependent upon 4 zygotic factors in the parents-Con.

\begin{tabular}{|c|c|c|c|c|c|c|c|c|}
\hline \multirow{2}{*}{$\begin{array}{c}\text { One } \\
\text { parent. }\end{array}$} & \multirow{2}{*}{$\begin{array}{l}\text { Other } \\
\text { parent. }\end{array}$} & \multirow{2}{*}{ Zygotic formulæ. } & \multirow{2}{*}{$\begin{array}{l}\text { Gametic } \\
\text { formula. }\end{array}$} & \multicolumn{5}{|c|}{$\begin{array}{l}\text { Percentage of each number of } \\
\text { zygotes in progeny. }\end{array}$} \\
\hline & & & & 0 (VS) & $1(\mathrm{~S})$ & $2(\mathrm{M})$ & $3(\mathrm{~F})$ & $4(\mathrm{VF})$ \\
\hline 3 & 1 & $A A B b \times A a b b$ & $\left.\begin{array}{l}A B \times A b \\
A B \times a b \\
A b \times A b \\
A b \times a b\end{array}\right\}$ & & 25 & 50 & 25 & \\
\hline 3 & 0 & $\mathrm{AABb} \times \mathrm{aabb}$ & $\left\{\begin{array}{l}A B \times a b \\
A b \times a b\end{array}\right\}$ & & 50 & 50 & $\ldots$ & \\
\hline 2 & 2 & $\left\{\begin{array}{l}\mathrm{AAbb} \times \mathrm{AAbb} \\
\mathrm{AAbb} \times \mathrm{AaBb} \\
\mathrm{AaBb} \times \mathrm{AAbb} \\
\mathrm{AaBb} \times \mathrm{AaBb}\end{array}\right.$ & $\begin{array}{c}A b \times A b \\
\left\{\begin{array}{c}A b \times A B \\
A b \times A b \\
A b \times a B \\
A b \times a b\end{array}\right\} \\
\left\{\begin{array}{c}A B \times A b \\
A b \times A b \\
a B \times A b \\
a b \times A b\end{array}\right\} \\
\left\{\begin{array}{c}A B \times A B \\
A B \times A b \\
A B \times a B \\
A B \times a b \\
2 A b \times A B \\
2 A b \times A b \\
2 A b \times a B \\
2 A b \times a b \\
a b \times A B \\
a b \times A b \\
a b \times a B \\
a b \times a b\end{array}\right\}\end{array}$ & 6.25 & 25 & 50 & 25 & 6.25 \\
\hline 2 & 1 & $\left\{\begin{array}{l}\mathrm{AAbb} \times \mathrm{Aabh} \\
\mathrm{AABb} \times \mathrm{Aabb}\end{array}\right.$ & $\left.\begin{array}{l}A b \times A b \\
A b \times a b \\
A B \times A b \\
A b \times A b \\
A B \times a b \\
A b \times a b \\
a B \times A b \\
a B \times a B \\
a b \times A b \\
a b \times a b\end{array}\right\}$ & 12.5 & 37.5 & 37.5 & 12.5 & \\
\hline 2 & 0 & $\begin{array}{l}\mathrm{AAbb} \times \mathrm{aabb} \\
\mathrm{AaBb} \times \mathrm{aabb}\end{array}$ & 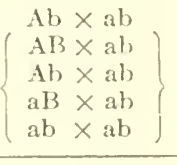 & 25 & $\begin{array}{r}100 \\
50\end{array}$ & 25 & & \\
\hline 1 & 1 & Aabb $\times$ Aabb & $\left.\begin{array}{l}A b \times A b \\
A b \times a b \\
a b \times A b \\
a b \times a b\end{array}\right\}$ & 2 & 50 & का & & \\
\hline 1 & 0 & Aabb $\times$ aabb & $\begin{array}{l}\text { Abah } \\
\text { abah }\end{array}$ & 50 & 50 & & & \\
\hline 0 & 0 & $a a b b \times a a b b$ & & 100 & & & & \\
\hline
\end{tabular}


TABLE 18.-Percentage distribution of the progeny of the varions matings on the assumption that extreme fleshy build is dependent on ti zygotic factors in the parents.

\begin{tabular}{|c|c|c|c|c|c|c|c|c|}
\hline \multicolumn{2}{|c|}{ No. of factors in } & \multicolumn{7}{|c|}{ Perentage of etach clathe of zyentie fiaclore. } \\
\hline $\begin{array}{c}\text { One } \\
\text { parent. }\end{array}$ & $\begin{array}{l}\text { Wther } \\
\text { parent. }\end{array}$ & i & $\pi$ & 4 & 3 & 2 & 1 & 1) \\
\hline 6 & i & 100 & & & & & & \\
\hline 6 & .5 & 50 & 50 & & & & & \\
\hline 6 & 4 & 25 & $\begin{array}{r}100 \\
\text { int }\end{array}$ & 25 & & & & \\
\hline 6 & 3 & 12.5 & 37.5 & 30.5 & $12 . j$ & & & \\
\hline 6 & 2 & & 25 & $\begin{array}{r}100 \\
011 \\
\end{array}$ & 25 & & & \\
\hline 6 & 1 & $x_{0}$ & & .50 & .0 & & & \\
\hline 6 & 0 & & & & 100 & & & \\
\hline 5 & 5 & 2.5 & 30 & 2.5 & & & & \\
\hline 5 & 4 & 12.5 & 37.5 & $\begin{array}{l}30 \\
37.5\end{array}$ & 12.5 & & - & \\
\hline 5 & 3 & (i. 25 & $\begin{array}{l}2.5 \\
2.5\end{array}$ & $\begin{array}{l}37.5 \\
\text { (i) }\end{array}$ & $\begin{array}{l}2.5 \\
2.5\end{array}$ & (i) $2 ;$ & & \\
\hline 5 & 2 & s. & 12.5 & $\begin{array}{l}37.5 \\
50\end{array}$ & $\begin{array}{l}37.5 \\
511 \\
\end{array}$ & 12.5 & & \\
\hline$j$ & 1 & & & 25 & .50 & 2.5 & & \\
\hline 5 & 11 & …..... & $\ldots \ldots \ldots$ & $\ldots$ & 30 & .30 & 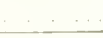 & $\ldots$ \\
\hline+ & 4 & $\begin{array}{c}425 \\
\cdots \\
\cdots\end{array}$ & $\begin{array}{l}25 \\
25 \\
2.5\end{array}$ & $\begin{array}{l}37.5 \\
51) \\
\text { in } \\
1(10) \\
\end{array}$ & $\begin{array}{l}2.5 \\
2.5 \\
2.5\end{array}$ & 1. 2.5 & $\cdots$ & \\
\hline 4 & 3 & $\begin{array}{l}3.125 \\
\ldots \\
\cdots \\
\end{array}$ & $\begin{array}{l}15.625 \\
12.5 \\
12.5 \\
\end{array}$ & $\begin{array}{l}31.25 \\
37.5 \\
37.5 \\
30\end{array}$ & $\begin{array}{l}31.25 \\
37.5 \\
37.5 \\
50\end{array}$ & $\begin{array}{l}1.5 .625 \\
12.5 \\
125 \\
\end{array}$ & 3.125 & \\
\hline 4 & 2 & $\ldots \ldots \ldots$ & i. 25 & $\begin{array}{l}2.3 \\
2.5 \\
2.5\end{array}$ & $\begin{array}{l}37.5 \\
501 \\
50 \\
100\end{array}$ & $\begin{array}{l}2.5 \\
2.5 \\
2.5\end{array}$ & b 2.5 & $\cdots$ \\
\hline 4 & 1 & $\ldots \ldots \ldots$ & $\cdots$ & 12.5 & 305 & $\begin{array}{l}50 \\
37.5\end{array}$ & 125 & \\
\hline 4 & 0 & $\ldots \ldots$ &.$\quad$. & & 2.5 & 50 & 23 & \\
\hline 3 & 3 & 1.5625 & $\begin{array}{l}9.37 .5 \\
6.25 \\
6.25\end{array}$ & $\begin{array}{l}23.4375 \\
2.5 \\
2.5 \\
2.5\end{array}$ & $\begin{array}{l}31.25 \\
37.5 \\
37.5 \\
50\end{array}$ & $\begin{array}{l}2.3 .4375 \\
2.5 \\
2.5 \\
2.5 \\
\end{array}$ & $\begin{array}{l}9.375 \\
6.25 \\
\text { ti } 2.5\end{array}$ & 1.5625 \\
\hline 3 & 2 & & 3.125 & $\begin{array}{l}16.225 \\
12.5 \\
12.5\end{array}$ & $\begin{array}{l}31.25 \\
37.5 \\
37.5 \\
50 \\
\end{array}$ & $\begin{array}{ll}31 & 25 \\
37 & 5 \\
37 & 5 \\
30\end{array}$ & $\begin{array}{l}16.625 \\
12.5 \\
12.5\end{array}$ & 3.125 \\
\hline 3 & 1 & $\ldots \ldots$ & $\ldots$ & 6.2 .5 & $\begin{array}{l}25 \\
25\end{array}$ & $\begin{array}{l}37.5 \\
.01\end{array}$ & $\begin{array}{l}25 \\
25 \\
\end{array}$ & $t i .5$ \\
\hline 3 & 0 & $\ldots \ldots$ & . & $\ldots$ & 12 i & $\begin{array}{l}37.5 \\
50\end{array}$ & $\begin{array}{l}375 \\
.0\end{array}$ & $12 . i$ \\
\hline 2 & 2 & & & 1. 25 & 25 & $\begin{array}{l}37.5 \\
50 \\
\text { J(k) } \\
\end{array}$ & $\begin{array}{l}25 \\
25\end{array}$ & ti. 2.7 \\
\hline 2 & 1 & $\ldots$ & t & . & 12.5 & 37 & $\begin{array}{l}37.5 \\
811\end{array}$ & 12.5 \\
\hline 2 & 0 & $\ldots \ldots$ & & & & 25 & iv & $2 . i$ \\
\hline 1 & 1 & $\therefore$ & $\ldots \ldots$ & $\ldots \ldots$ & & 2.5 & io) & 25 \\
\hline 1 & 0 & $\ldots$ & $\ldots \ldots$ & . & & 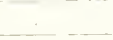 & 30 & 50 \\
\hline 0 & 0 & . & & & & & & 100 \\
\hline
\end{tabular}


On the hypothesis of 6 zygotic factors for build, the possible combinations in the progeny are much more numerous. Seven classes of zygotic combinations are possible. We recognize in our work only 5 classes of build. Accordingly, it would be necessary to redistribute our classes of build into 7 or else assume that the two lowest classes are both comprised in "very slender" and the two highest in "very fleshy." The former operation would require an amount of work hardly justified by the possible advantage; so the latter procedure was adopted as perhaps a sufficiently close approximation. The distributions are given in table 18 which is given in detail only in part.

\section{MATE SELECTION IN BUILD.}

Statistics on temperament and stature of consorts (Davenport, 1915 , p. $106 ; 1917$, p. 329 ) seem clearly to show that there is an assortative mating in respect to these traits. The question arises: Is there assortative mating in respect to build? The inquiry is rendered the more difficult, inasmuch as build changes to such an extent with age. Nevertheless, as there appears to be a considerable correlation (though not yet calculated) between build at 25 and at 50 years, it is fair to assume that some degree of the mature build is already indicated at the period just before marriage.

TABLE 19.-Percentagc distribution of parents of each sex among the various classes of build as found in 531 selected matings. Based on Appendix tables.

\begin{tabular}{|c|c|c|c|c|}
\hline \multirow{2}{*}{ Claszes. } & \multicolumn{2}{|c|}{ Males. } & \multicolumn{2}{|c|}{ Females. } \\
\hline & Frequency. & Per cent. & Frequency. & Por cent. \\
\hline VS. . & $2: 2$ & .30 & 15 & 3.39 \\
\hline & 97 & 15.27 & 127 & 23.92 \\
\hline & 230 & 43.31 & 210 & 39.55 \\
\hline & 158 & 29.75 & 120 & 22.59 \\
\hline $\mathrm{Vi}$. & 44 & ४. 29 & 56 & 10.55 \\
\hline Total. & $5: 31$ & 100 & 531 & 100 \\
\hline
\end{tabular}

If, now, there is no assortative mating in respect to build, we should find that persons of any given build, say slender, would have very slender, slender, medium, fleshy, and very fleshy consorts in the respective proportions in which such classes of build occur in the whole population of parents. A marked deviation from this expectation would indicate the falseness of this hypothesis and that there is an assortative mating in respect to build.

To test the hypothesis we can make use of 531 matings, including those which are employed in the main tables. We find the male and the female consorts in these matings to occur in the different classes in the numbers and proportions shown in table 19. 
In applying the test to the hypothesis we may assume in turn that the groom has done the selecting and that the bride has done the selecting. We then compare, in the selections made by the grooms, the expected proportion of the classes of build on the assumption of no assortative mating, with the proportions actually found in the brides. Similarly, with suitable changes for the selections made by the brides. The results are given in table 20 .

TABLE 20.-Percentage distribution of build of consorts selected by grooms and by brides belonging to each of the classes of build, and comparson with the standards of table 19.

$P$, percentages found or expected. E, percentage excess of found over expected.

Selections made by Groons.

\begin{tabular}{|c|c|c|c|c|c|c|c|c|c|c|c|}
\hline & \multicolumn{2}{|r|}{ vs } & \multicolumn{2}{|c|}{$\mathrm{S}$} & \multicolumn{2}{|c|}{$\mathrm{MI}$} & \multicolumn{2}{|c|}{$\mathrm{F}$} & \multicolumn{2}{|c|}{ VF } & \multirow{2}{*}{ Total } \\
\hline & $\mathrm{P}$ & $\mathrm{E}$ & $\mathrm{P}$ & $\mathrm{E}$ & $\mathrm{P}$ & $\mathrm{E}$ & $\mathrm{P}$ & $\mathrm{E}$ & $\mathrm{P}$ & $\mathrm{E}$ & \\
\hline 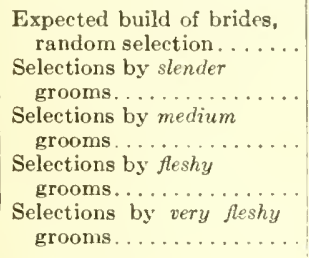 & $\begin{array}{l}3.4 \\
5.2 \\
3.5 \\
3.2 \\
0.0\end{array}$ & $\begin{array}{r}52.9 \\
+\quad 2.9 \\
-\quad 5.9 \\
-100\end{array}$ & $\begin{array}{l}23.9 \\
24.7 \\
28.3 \\
18.3 \\
15.9\end{array}$ & $\begin{array}{l}+3.3 \\
+18.4 \\
-23.4 \\
-33.5\end{array}$ & $\begin{array}{l}39.6 \\
37.1 \\
40.4 \\
40.5 \\
38.6\end{array}$ & $\begin{array}{l}+6.3 \\
+2.0 \\
+2.3 \\
-2.5\end{array}$ & $\begin{array}{l}22.6 \\
23.7 \\
22.3 \\
21.5 \\
27.3\end{array}$ & $\begin{array}{r}\ldots \ldots \\
+\quad 4.9 \\
-\quad 1.3 \\
-\quad 4.9 \\
+20.8\end{array}$ & \begin{tabular}{r|}
10.6 \\
9.3 \\
5.6 \\
16.5 \\
18.2
\end{tabular} & $\begin{array}{r}-12.3 \\
-47.2 \\
+55.7 \\
+71.7\end{array}$ & 100 \\
\hline \multicolumn{12}{|c|}{ Selections made by Brides. } \\
\hline 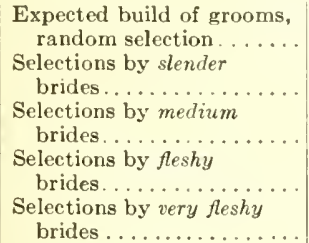 & $\begin{array}{l}0.4 \\
1.59 \\
0.0 \\
0.0 \\
0.0\end{array}$ & $\begin{array}{l}+297.5 \\
-100 \\
-100 \\
-100\end{array}$ & $\begin{array}{l}17.1 \\
19.2 \\
16.1\end{array}$ & $\begin{array}{l}\ldots \ldots \\
+\quad 3.3 \\
-\quad 6.6 \\
+\quad 4.9 \\
-12.0\end{array}$ & $\begin{array}{l}43.3 \\
51.2 \\
44.3 \\
42.5 \\
23.2\end{array}$ & $\begin{array}{l}+18.2 \\
+\quad 2.3 \\
-\quad 1.8 \\
-46.4\end{array}$ & $\begin{array}{l}30.5 \\
28.3 \\
46.4\end{array}$ & $\begin{array}{r}-23.5 \\
+\quad 2.3 \\
-\quad 5.0 \\
+55.7\end{array}$ & $\begin{array}{r}8.3 \\
5.5 \\
8.1 \\
10.0 \\
14.3\end{array}$ & $\begin{array}{l}-33.7 \\
-\quad 2.4 \\
+20.5 \\
+72.3\end{array}$ & 100 \\
\hline
\end{tabular}

An inspection of tables 19 and 20 shows that the hypothesis that wives and husbands of men of each different class of build are merely random samples of the whole population of parents is not supported by the facts. Thus on the part of both very fleshy grooms and brides over 70 per cent more consorts, who will ultimately be very fleshy are selected than are expected on the hypothesis of random sampling. Also, among fleshy fathers there is a marked excess of very fleshy wives. Slender parents have an excess of similar consorts. Medium parents have selected consorts nearly at random so far as regards build. Slender parents have selected a smaller proportion of very fleshy consorts than expectation on random choice, and very fleshy parents have selected less than the average of very slender and slender consorts. In a word, there is some degree of assortative 
mating and, incleed, a mating of similars. This result agrees with the findings in respect to stature: similars tend to mate; while in the case of temperament. dissimilars tend to marry each other.

\section{THE BASAL TABLES.}

In the Appendix are given in tabular form details concerning the different types of matings. with some information coneerning the grandparents, the sibs of parents, and the children. These are the tables that have been used for the mass study and from which table 11 was drawn up." "They will afford much of our data for the detailed Mendelian studies, and will be briefly considered in this section.

These tables are derived chiefly from the Records of Family Traits; some from special schedules and, in a few cases, from the $A$ file of the Eugenies Record Office.

Table I.-Mating of very slender, 1.50 to 1.75 metric (21 to 25 English) $X$ very slender. This rombination does not oecur in our 506 standard matings.

Table 11.-Matings of very slender X slender. 1.80 to $2.10(26$ to 30 ). There are seven matings altogether. They yielded 20 progeny: $4 \mathrm{VS}, 12 \mathrm{~S}$, $2 \mathrm{M}$, and $2 \mathrm{~F}$. Four-fifths of the progeny thus fall in the parental groups; the distribution shows little variability (fig. 9).

Table III.-Matings of very slender $\times$ medium, 2.2 to 2.6 (31 to 36$)$. 28 children derived from 8 matings have indices of build as follows: $1 \mathrm{KS}, 7 \mathrm{~s}, 1 \mathrm{~T} \mathrm{M}, 3 \mathrm{~F}$. The mode of the progeny, as compared with table 2 , has shifted to the medium grade ifig. 10 )

Table IV.-Matings of very slenter $X$ fleshy, 2.6 to 3.0 (37 to 43 ). There are 5 matings. These viekled 25 progeny: $1 \mathrm{VS}, 5 \mathrm{~s}, 10 \mathrm{M}, 7 \mathrm{~F}$, and $2 \mathrm{VF}$. The mode is at medium grade, but the whole distribution is much more rariable than in tables 2 and 3 (fig. 11).

Table I.-Matings of very slender $X$ very fleshy, 3.1 to 4.5 (44 to 64$)$. There is only 1 mating in this class, so that no table is formed. It is described in full on page 97 . It produced 7 chilelren: 3 S. 3 M, and $1 \mathrm{VF}$.

Table 1\%.-Matings of slenler $X$ slender. There are 24 matings of this type. They yielded 51 progeny: 5 VS, 35 S, $11 \mathrm{M}$. The mode is strongly in the S grade; the progeny show relatively little variability (fig. 12).

Table VII.-Mating of slenter $X$ medium parents. There are 101 matings of this type. They yielded 313 progeny: 49 今, $200 \mathrm{M}, 53 \mathrm{~F}, 11 \mathrm{VF}$. The mode is at medium; the progeny show rather low variability (fig. 13).

Table IIII.-Matings of slenter $X$ fleshy parents. There ane 52 matings of this type. They yielded 179 progeny: $5 \mathrm{VS}, 25 \mathrm{~S}, 85 \mathrm{M}, 57 \mathrm{~F}, 7 \mathrm{VF}$. The mode is at medium: the progeny slow rather low variability (fig. 14).

a The families in the tables of the Ippendix which are marked by an asterisk (*) are not included in table 11 . The reason is that they were selected fanilies, usually beeanse containing very fleshy persons. It was deened undesirable to combine these selerted families with the unarlected fanilies that make up most of table 11 ; a table which forms the hasis for figure 7 . To have included them would have distorted the form of that figure. 


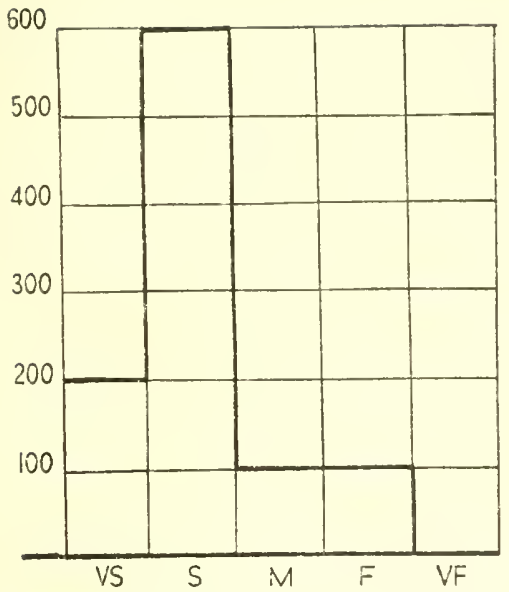

Fig. 9.-Per mille distribution of progeny of table II, IS $\times$ S matings. Number of indiriduals, 20 .

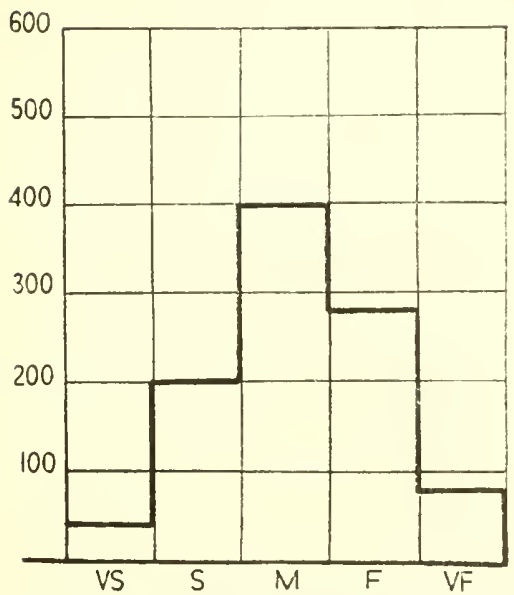

Fic. 11.-Percentage distribution of progeny of table IV, IS $\times \mathrm{F}$ matings. Number of individuals, 2.5.

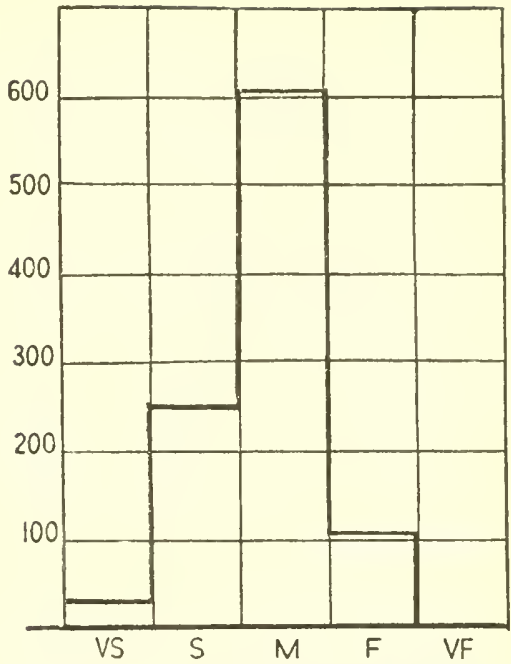

Fic. 10.-Per mille distribution of progeny of table III, Vs $\times$ M matings. Number of individuals, 28.

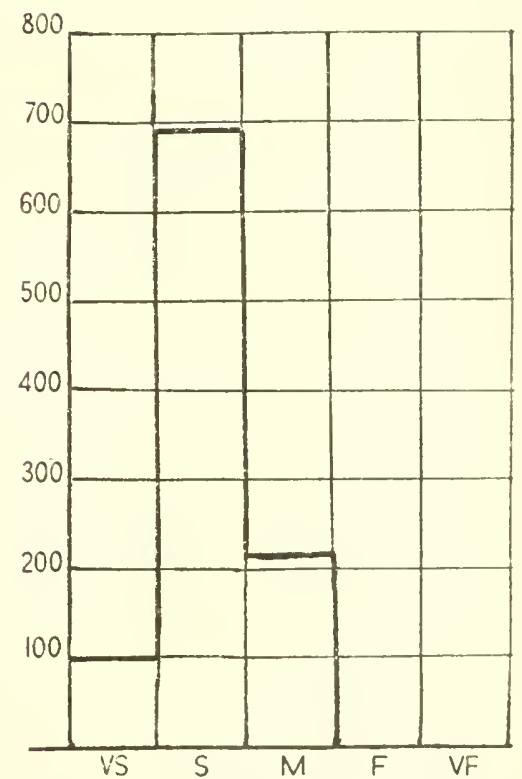

Frc. 12.-Percentage distribution of progeny of table VI, $\mathrm{S} \times \mathrm{S}$ matintr. Number of individuals, 51. 


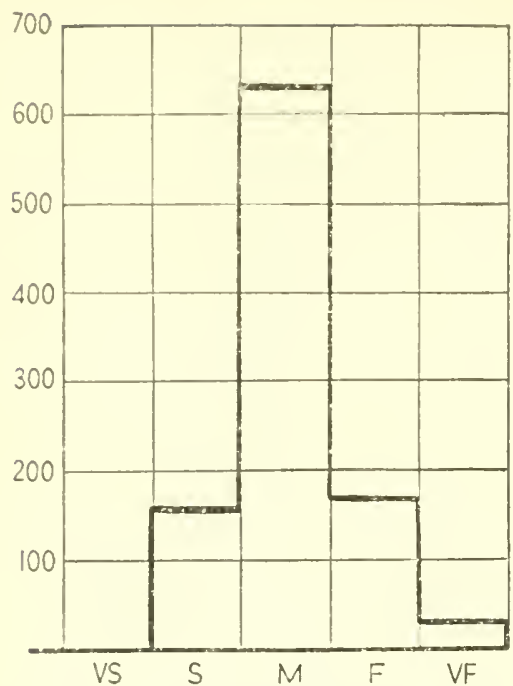

Fig. 13.-Percentage distribution of progeny of table VII, $S \times M$ matings. Number of individuals, 313.

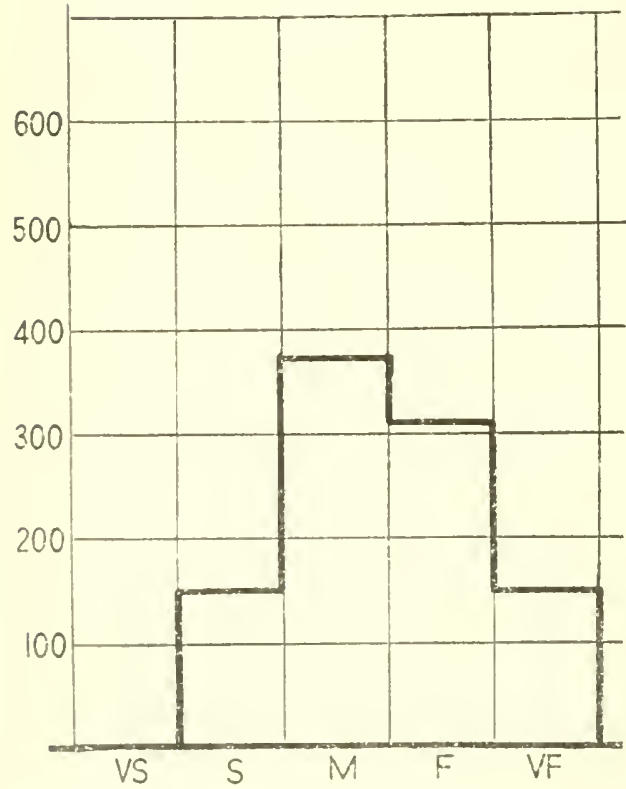

Fig. 15.-Pereentage distribution of progeny of table $\mathrm{L}, \$ \times \mathrm{VF}$ matings. Number of individuals, 50 .

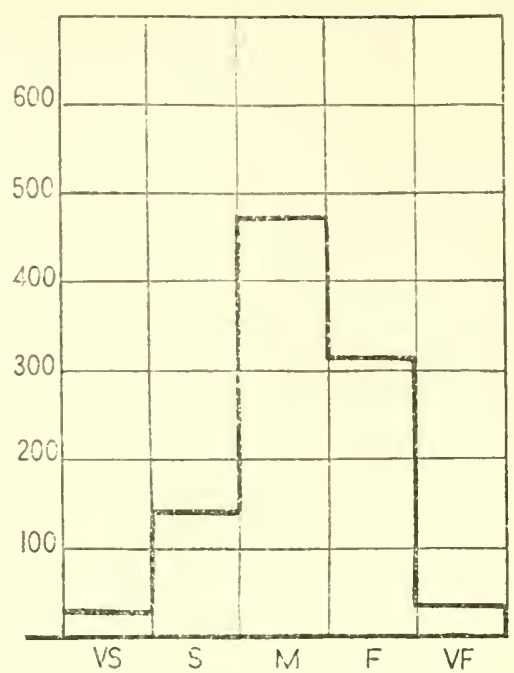

Fig. 14.-Percentage distribution of progeny of table VIII, $S \times F$ matings. Number of individuals, 179.

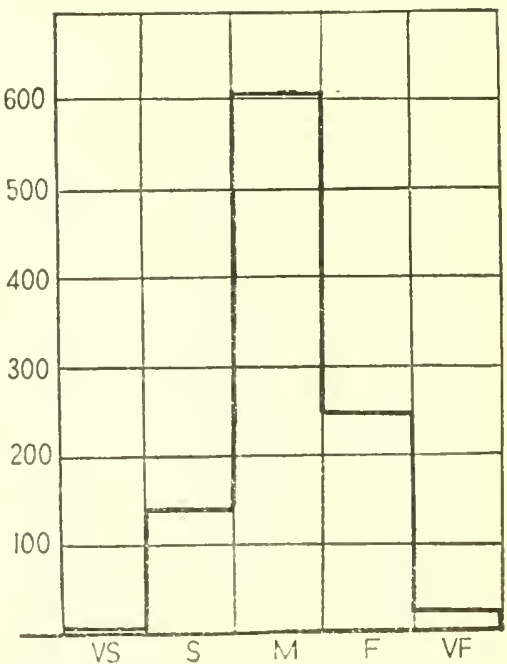

Fig. 16.-Percentage distribution of progeny of table $\mathrm{I}$, $\mathrm{M} \times \mathrm{M}$ matings. Number of individuals, 332. 
Table IX.-Matings of slender $X$ very fle hy parents. There are 16 matings of this type. They vielded 50 progeny: 7 S. $18 \mathrm{M}, 17 \mathrm{~F}, 8 \mathrm{VF}$. The progeny are very variable (fig. 15 ).

Table 1 - Matings of medium X neclium parents. There as 93 mutings of this type. They yielded 332 off-pring: $2 \mathrm{TS}, 40 \mathrm{~S}, 201 \mathrm{M}, 82 \mathrm{~F}$, 7 VF. The progeny are not very variable (fig. 16), indicating that all individuals of medium build are not "heterozgentes"; but that there is also a "medium" race.

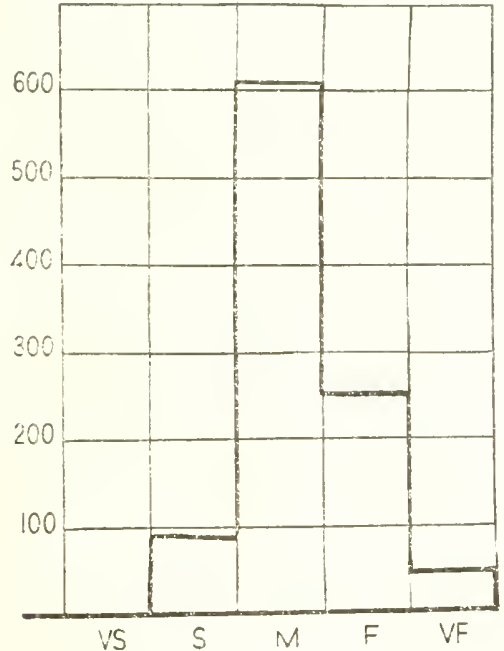

FIG. 17.-Percentage distribution of progeny of table $\mathrm{XI}, \mathrm{M} \times \mathrm{F}$ matings. Number of individuals, 1,346 .

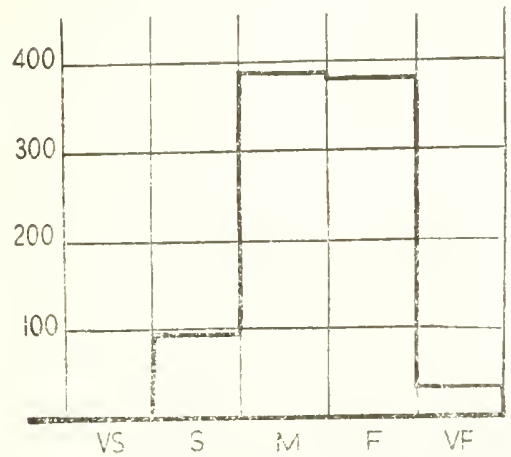

FIg. 19.- Percentage distribution of progeny of table XIII, $F \times F$ matings. Number of individuals, 159.

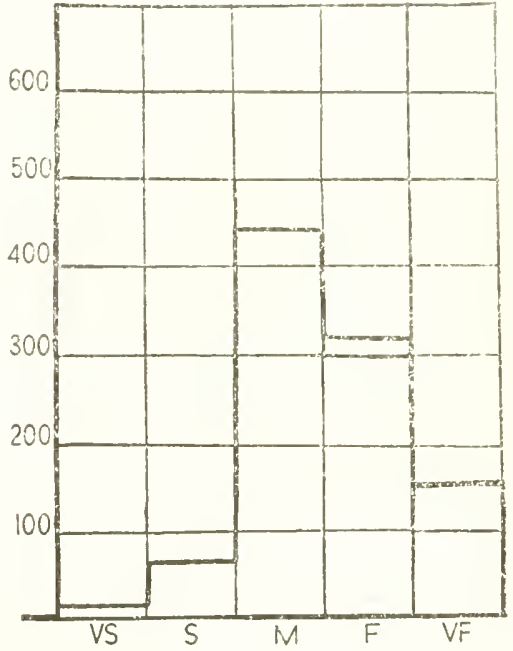

FIG. 1s.-Percentage distrilution of progeny of table XII, M $\times \mathrm{VF}$ matings. Number of individuals, 112.

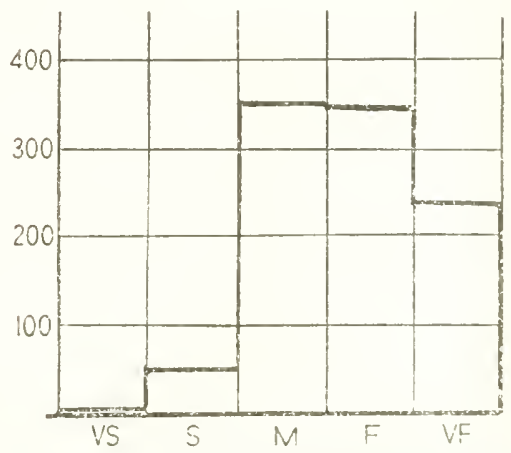

F1G. 20.-Percentage distrilution of progeny of table $\mathrm{XIV}, \mathrm{F} \times \mathrm{VF}$ matings. Number of individuals, 1.16 .

Table NI.-Miatings of medium X flesy parents. There are 115 matings of this type. They yielded 316 offspring: $31 s, 210$ M. 88 F, 17 VF. The progeny slow an intermediate degree of variability (fig. 17).

Table NII.-Miting: of medium $\times$ very fleshy parents. There are 30 matings of this type. They yielded 112 off pring: $2 \mathrm{~V}, \mathrm{~T}, 50 \mathrm{~N}, 36 \mathrm{~F}$, $17 \mathrm{VF}$. The progeny show considerable viuriability (fig. 18). 
Table 13.-Matings of fleshy $\times$ fleshy parents. There are 33 matings of this type. They yielded 159 offepring: 15 s, $62 \mathrm{M}, 61 \mathrm{~F}, 21 \mathrm{VF}$. The progeny show it rather high variability (fig. 19).

Table XIV.-Mating of fle hy $\times$ very fleshy parent - There are 30 matings of this type. They rickled 146 offepring: $1 \mathrm{VS}, 7 \mathrm{~S}, 52 \mathrm{M}, 51 \mathrm{~F}, 35$ VF. The progeny are very variable (fig. 20).

Table XV.-Mating of very fleshy $\times$ very fleshy parents. There are 7 matings of this type. They yielded 37 offipring: 1 s, $12 \mathrm{M}, 11 \mathrm{~F}$, $13 \mathrm{VF}$. The progeny are exceedingly variable (fig. 21).

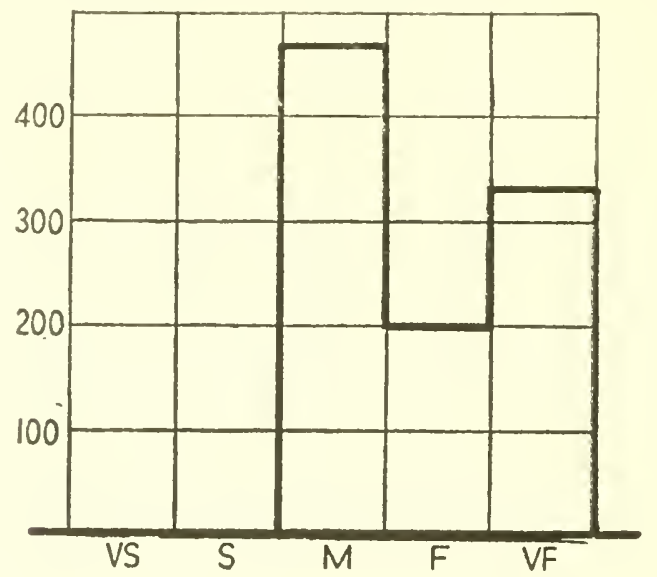

V14. 21.-Percentage distribution of progeny of table $\mathrm{NV}, \mathrm{VF} \times \mathrm{VF}$ matings. Number of individuals, 37 .

The diversity of the distributions of the progeny of the various matings and the great difference in their variabilities indicates that there is not only an inheritance of tendencies to particular types of build, but also that there is a strong evirlence of some sort of Mendelian inheritance. 


\section{PART III. FAMIIY STUDIES IN HEREDITY OI BUILD. \\ A. STATEMENT OF PROBLEM.}

Our study of the mass relation in build between parental and filial generation has followed the ordinary pre-Mendelian method of analysis of heredity, a method that has proved rather sterile for prediction of filial traits. It has, however, enabled us to formulate an hypothesis in Mendelian language. It now remains to use our data in Mendelian fashion, to seek a test of the hypothesis.

In this study we shall not use all of the families listed in the main tables of the Appendix, because some of them are for various reasons not adequate for Mendelian analysis; for example, in some cases the ancestry is insufficiently known, so that the gametic nature of the parents can not be inferred. It is considered preferable to analyze a few of the more completely known families than to rest content with the mass statistics. I shall take up in order the more significant matings.

\section{B. DISCUSSION OF SPECIAL MATINGS. \\ Class I. Both Parents Slemder.}

Mating 1. One Parent Is Very Slender, of Slender Stock, the Otiler Slendik.

We have only two fair cases falling into this category. The ${ }^{*}$ Fun family with the paternal formula $27,29,27$ and the maternal formula $32,27,25$; and the Sch-37 family with the paternal formula

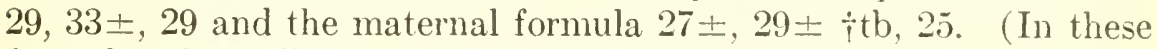
formulas the indices of father's father, father's mother, father, and similarly for the mother's side of the house are given in that order.) The full history of these cases follows:

\section{"Fun Famluy. (Fig. 22.)}

II $6, \hat{o}, 170 \mathrm{~cm}$. (67 inches) tall, and weighing $56 \mathrm{~kg}$. (123 pounds); build $1.9(27)$; slender and of exclusively slender sibship and parentage; married II 7, o, $167 \mathrm{~cm}$. (66 inches) tall and weighing $50 \mathrm{~kg}$. (110 pounds); build, 1.8 (25); very slender and of slender or medium sibship and parentage. They have 2 children: (1) o , at 27 years, $165 \mathrm{~cm}$. (65 inches) tall and weighing $54 \mathrm{~kg}$. (118 pounds) ; build 1.9 (28), slender; (2) of, at 24 years, $183 \mathrm{~cm}$. (72 inches) tall and weighing $68 \mathrm{~kg}$. (149 pounds). build 2.0 (29), slender.

Thus this mating of very slender $x$ slender parents yielded only (2) slender offspring. A slender $X$ slender mating from the same family may be added here.

\footnotetext{
* The asterisk immediately preceding the reference letters means that the family referred to is not included in the statistics of table 11 .

$\dagger t b$ or $\dagger t$, immediately following an index number in this study, signifies that the person with that index number had active tuberculosis. The $f$ indicates death by the disesse.
} 
I $1, \hat{o}, 172 \mathrm{~cm}$. (6S inches) tall and meighing $57 \mathrm{~kg}$. (125 pouncts); build 1.9 (27), slender. Married I 2, o, $157 \mathrm{~cm}$. (62 inches) tall and weighing $50 \mathrm{~kg}$. (110 pounds), build 2.0 (29), slender. They had 4 children: (1) ô, $173 \mathrm{~cm}$. (68 inches) tall, weighing $54 \mathrm{~kg}$. (120 pounds); build 1.8 (26), slender; (2) o, $173 \mathrm{~cm}$. (68 inches) tall, weighing $60.4 \mathrm{~kg}$. (133 pounds); build 2.0 (29), slender; (3) \&, $165 \mathrm{~cm}$. (65 inches) tall, weighing $52 \mathrm{~kg}$. (115 pounds); build 1.9 (27), slender; (4) ô, $170 \mathrm{~cm}$. (67 inehes) tall, weighing $56 \mathrm{~kg}$. (123 pounds); build 1.9 (2)), slender.

Two slender parents have thus only (4) slender offspring (A : 034).

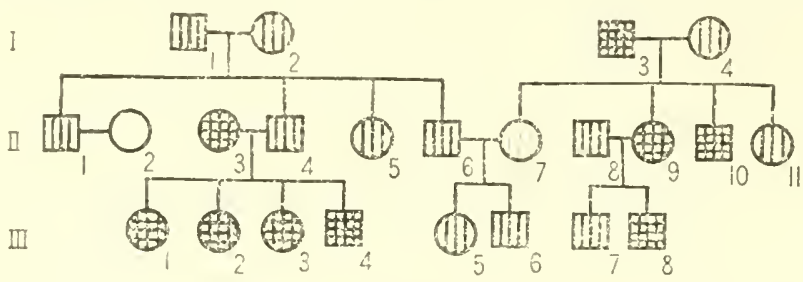

FIG. 22.- Pedigree chart showing distribution of build in Fun family.

In this and the following pedigree charts the following symbolism is adopted. The generations are marked at the left margin; members of one fraternity are suspended from one horizontal line; square, males; circles, females. The abbreviations: d. inf. (died in infancy), and d. yg. (died young) are easily interpreted.

The degree of shading indicates the degree of build according to the following scheme:

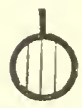

very slender

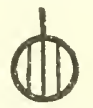

steride:

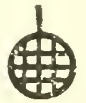

medium

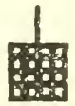

fleshy

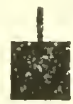

veryfleshy unknown

\section{Sch-37 FaMily.}

A family of German extraction living in Ohio. The Father, a farmer, who in youth suffered from inflammation of the bowels and in middle age from congestion of the brain, died at 69 years from tetanus and apoplexy. Formula: 150/72 inches, build 2.0 (29). His father, a farmer, died of apoplexy at 83 years. At 80 years his formula was: 150/72 inches; build 2.0 (29). His mother, who in middle age was subject to stomach trouble and "shingles," died of old age at 83 years, having at 80 years the formula $130 / \mathrm{M}$; build $2.3(33 \pm)$. Thus, this side of the house is prevailingly slender.

The Mother, who in youth was subject to hives, and in middle age to asthma and eczema, has at 73 years the formula 94/63 inches; build 1.7 (25). Her father, a farmer, who always suffered from asthma and died of it at 74 years, had at 70 years the formula $120 / \mathrm{M}$; build $1.9(27 \pm)$. Her mother, who died at 83 years of tuberculosis of intestine, had at 80 years the formula $110 / \mathrm{M}$; build $2.0(29 \pm)$. This is a decidedly slender family, more so than that of the paternal side. The five children:

1. Male, who in youth had measles, whooping-cough, hay-fever, colds, and, in middle age, asthma and liemorrhoids, has at 47 years the formula 165/72.5 inches; build 2.2 (31). 
2. Female, who in youth suffered from sore throat. colds, diphtheria, and quinsy, and in middle age from sore throat: is quick-tempererl and astigmatic. At 42 years she has the formula 140.68 inches; build 2.1 (30).

3. Female, who died at 7 yons, accident.

4. Female, who in youth was subject to lung trouble and bronchitis. weighed 160 pounds at 27 years, 7 poumls at birth. She has grurlually lost weight since 27 years, till at 37 years the has tho formula 13568 inches; build 2.1 (29).

5. Male. who in youth suffered from lung inere has a nerrons temperament, at 30 years has the formula $137.5 / 72$ inclies: Huild 1.9 (27).

Comment.-All but one of this fraternity of 4 who grew up are of sledrder build (unadjusted). The exception is a man of 47 years who is of slendermedium build ( $R$ : Seh-37).

To summarize: Of 10 progeny (who grew up) of these 3 matings all are slender except 1 who falls just over the line into medium.

Mating 2. Both Parents Are Slender, of Slexder Stock.

Table 21 gives the progeny of matings of slender stock. Of the 5 matured progeny, 4 are slender and 1 just over the line into medium. The details of the families are given below.

Table 21.-Matings of two slender parents; together with their progeny.

[From Table VI.]

\begin{tabular}{|c|c|c|c|c|c|c|c|c|c|c|c|c|c|}
\hline & \multirow{2}{*}{$\mathrm{FF}$} & \multirow{2}{*}{ FMI } & \multirow{2}{*}{$\mathrm{F}$} & \multirow{2}{*}{ F's silos } & \multirow{2}{*}{$\mathrm{MF}$} & \multirow{2}{*}{$\mathrm{MM}$} & \multirow{2}{*}{ MI } & \multirow{2}{*}{ M's sibs } & \multicolumn{5}{|c|}{ Offspring } \\
\hline & & & & & & & & & Vs & $\mathrm{S}$ & $M I$ & $\mathrm{~F}$ & VF \\
\hline Ker 5........ & $M$ & $\begin{array}{r}30 \\
5\end{array}$ & 29 & & $M$ & 27 & 29 & & 1 & & 1 & & \\
\hline Ste $9 \ldots \ldots$ & $\mathrm{MI}$ & S & 25 & & $\mathrm{~S}$ & $3 I$ & $2 S$ & & & 3 & & & \\
\hline
\end{tabular}

KER-5 FAMILY.

A family of English extraction, living mostly in western United StatesColorado, Texas, New Mexico.

The Father, who was an army officer, is a railload official who suffered in middle age from tropical fever. He has, at 51 vears, the formula 15072 inches; build 2.0 (29). His father, who was a mechanic, died at $7 \pm$ years from hardening of arteries, having had at 60 vears the formula $160 \mathrm{MI}$. His mother, who had 2 children, suffered in middle are from trphoid: she died at about 47 years from pneumonia. At 40 rears, her formula $110 / \mathrm{s}$; build probably about 2.1 (30). This side of the house is prevailingly slender.

The Mother, who has had 4 children, suffered in middle age from nemitis She is living at 49 years. Formula, $115 / 63$ inches; build 2.0 (29). Her father, who was an army officer, suffered in midlle age from heart trouble and rheumatiom. He died at 58 years from heart trouble. At 38 years his formula $160 / \mathrm{MI}$. Her mother, who had 2 dhikdren. was an invalid; she died at 36 years from consumption. Formula 100 s; say about 2.0 (27). This side of the house is prevalingly slender. Three children grew up: 
1. Male, a railroad man, who in youth suffered from throat trouble and pneumonia and who is very nervous, has at 21 years the formula $150 / 78$ inches; build 1.7 (25).

2. Male, formerly a teacher, now in the army, has at 20 years the formula $158 / 71$ inches; build 2.2 (31).

Male, is slender at 15 years.

Comment.-The somewhat slender parents have 2 slender children and a third who is in the army and has a slender-medium build (R : Fier-5).

$$
\text { STE-9 FAMILY. }
$$

A family of German extraction, paternal grandparents living first in Ciermany, later in Alabama; maternal grandparents, parents, and children living in Alabama. The Father, who is a farmer, and suffered in routh from intermittent fever and in middle age from hay ferer and gallstone or intestinal trouble, is living at 52 years. At 40 years his formula $120 / 65.5$ inches: build 1.9 128). His father, who was a farmer, suffered in middle age from intermittent fever. He died at 82 years from congestion of bowels. At 60 vears he was of medium build. His mother died at 57 years irom intermittent fever. At 55 years she was slender. This side of the house should contribute a slender to medium tendeney, unless the Father's weight is abnormally low, due to his intestinal trouble.

The Mother, who in vouth suffered from "enlarged tonsils," and in middle age from bronchitis, is living at 50 years. At 40 years her formula $115 / 64.5$ inches; build 1.9 (28). Her father, who was a blacksmith, died at 32 years from "hemorrhage of lungs." At 30 vears he was slender. Her mother, who in routh suffered from malarial fever and in middle age from tumor: died at about 64 years from "intestinal trouble-tumors (?)." At 40 years her formula $140 / 67$ inches; build 2.2 (31). The gametes from this side of the house also should tend to produce slenderness in the children. Four children grew up:

1. Male, an engineer, who in youth suffered from tonsillitis and bron(hitis, has at 27 years the formula 125/66 inclies; build 2.0 (29).

2. Male, a teacher, who in youth suffered from bronchitis, has at 24 years the formula $14 j / 70$ inches; build 2.1 (30).

3. Female, a sehool teacher, who in youth suffered from malarial fever, has at 22 years the formula $115 / 62.8$ inches; build 2.0 (29).

4. Female, under 18 years, of slender build, but about average for her age.

Comment.-All 3 grown children have a slender build at present; it is possible that build may bo increased at they grow older (R: ste-9).

Mating 3. Other Slexder $\times$ Very Slexder Matings.

There are 3 matings of this type: (1) Nob-1, (2) Cod-1, Jos-1 (table 22).

Of 7 grown and 4 inmature children derived from this mating, 5 grown children and 2 (or 3 ) adolescents are slender. In one mating (Jos-1) of ethnieally dissimilar parents (from Riga and Baden respectively), both adult children are of much heavier build than either parent, i. e., of medium to fleshy build. This might be explained as an example of the extra-vigorous growth of hybrids; but we find few other examples of this result in human hybrids. It seems more probable that both parents carry 1 or more factors for fleshiness and 
that all were combined in their eldest son, causing him to develop fleshiness further than either of his parents.

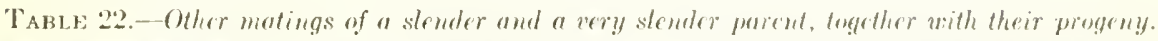

\begin{tabular}{|c|c|c|c|c|c|c|c|c|c|c|c|c|c|}
\hline \multirow{2}{*}{ Ref. } & \multirow{2}{*}{$\mathrm{FF}$} & \multirow{2}{*}{$F M$} & \multirow{2}{*}{$F$} & \multirow{2}{*}{$\begin{array}{c}\text { Father's } \\
\text { silss. }\end{array}$} & \multirow{2}{*}{$M I F$} & \multirow{2}{*}{$\$ 1.11$} & \multirow{2}{*}{$M$} & \multirow{2}{*}{$\begin{array}{l}\text { Mother's } \\
\text { sils. }\end{array}$} & \multicolumn{5}{|c|}{ Off-p ring. } \\
\hline & & & & & & & & & is & i & MI & 1 & $\mathrm{IF}$ \\
\hline Rovd 1 & 35 & 33 & 29 & & 30 & 30 & 25 & & & 2 & & & \\
\hline R Jos 1 . & & & 24 & & & & 27 & & & & 1 & 1 & \\
\hline R Nobl 1 & & & 26 & & $M$ & $M$ & 24 & Sui, Xemr & 2 & 1 & & & \\
\hline Total & & & & & & & & & 2 & 3 & 1 & 1 & \\
\hline
\end{tabular}

\section{COD-1 FAMHL:}

A family of English extraction living in Ohio. The Father, a salesman, suffered in youth from whooping-cough, measles, inflammatory rheumation; in middle age from mumps and smallpox. He is living at 45 years, having the formula $125 / 66$ inches; build 2.0 (29). His father, a farmer, died at 56 years from influenza and heart trouble. At 45 years he had the formulit $160 / 68$ inches; build 2.4 (35). His mother, who suffered from indigestion, clied at 72 years from "sclerosis of liver." At 45 years her formula was $135 / 64$ inches; build 2.3133 . Thus this side of the house is of medium to slender build.

The Mother, who in youth had mumps. measles. hives, sarlet fever. tonsillitis, and rheumation, and in middle life sick headaches, tonsillitis, and pneumonia, is living at 45 years, having the formula $95 / 62$ inches; build 1.8 (25). Her father, a farmer, who in youth suffered from malaria and indigestion and in middle age from heart trouble, gravel, and indigestion, died at 80 years from pnemmonia and heart trouble, having the formula 150/71 inches; build 2.1 (30). Her mother, who in youth had whooping-cough, mumps, erysipelas, asthma, pneumonia, and in middle age measles, asthma, neuralgia, pneumonia, and a slight attack of rheumatism, is living at 77 years. At 45 years her formula was 108/60 inches; build 2.1 (30). Thus this side of the house is sender to very slender. The 2 children are:

1. Male, a druggist, who suffered from all the children's diseases and appendicitis, pneumonia, smallpox, rheumatism, and astlma, and loses 8 to 10 pounds in winter and gains it back in summer, has at 20 years the formula 100/62 inches; build 1.8 (26).

2. Female, who in youth suffered from all the children's diseases, besides nervous nausea, pneumonia, and tonsillitis, hats at 18 years the formula $95 / 61$ inches; build $1.8(26)$.

Comment.-Thus both children are of slender build ( R: Cod-1).

$$
\text { Jos-1 FamiLr. }
$$

A family whose paternal and maternal grandparents lived in Baden and Latvia respertively; parents and children living in Pennsyania.

The Latvian Father, who in middle age suffered from a "touch" of typhoid, has at 60 years the formula $112 / 68$ inches; build 1.7 (24).

The Badenish Mother, who had three children, died at 54 years from pneumonia, having the formula $120 / 67$ inches; build 1.9 (27). 
Of the two ehildren who grew up:

1. Male, a civil engineer, has at 33 years the formula $180 / 68$ inches; build 2.7 (39); adjusted to 55 years, $189 / 68$ inches; build 2.9 (41).

2. Female, a student, has at 26 vears the formula $150 / 69$ inches; build 2.2 (32); adjusted to 55 vears, $170 / 69$ inches; build 2.5 (36).

Comment.-The children exeed in build the stouter parent; probably a result either of heterozygosis or multiple factors (R: Jos-1).

\section{NoB-1 Famil:}

A family of English extraction; paternal grandparents living in Illinois and Mimnesota, maternal grandparents living in Canada and Minnesota, parents and children living in Illinois and Minnesota. The Father, a liveryman, a very energetic. nervous man, is in middle age liable to rheumatism. He has at 47 years the formula $140 / 7+$ inches; build 1.8 (26). His father, a farmer, who in middle age suffered from asthma, colds, and heart trouble. died at 65 years from heart failure, having the formula $M / M$. His mother, who had 11 children. suffered in middle age from bronchitis. She is living at 77 years, having the formula $\mathrm{M} / \mathrm{M}$.

The Mother, who has had 7 children, has the formula 105/66 inches; build 1.7 (21). One of her brothers hung himself; one of her sisters was always "sickly" and toward the end of her life "very peculiar." Their father, a farmer, suffered in middle age from heart trouble. He died from "dropsy of heart." At 60 vears his formula was M/M. Their mother, who had 7 children, is living, now insane. At 61 years her formula was M/ M.

The 7 children are:

1. Female, a student, who in youth suffered from adenoids and tonsillitis, has at 21 years the formula $110 / 65$ inches; build 1.8 (26).

2. Female, a bookkeeper, has at 19 years the formula $100 / 66$ inches; build $1.6(23)$.

3. Nale, a student, has at 18 years the formula $112 / 67$ inches; build $1.8(25)$.

Comment.-There are four children below 18 years. Of these, No. 4, at 14 years, is 18 pounds below standard; No. 5 , at 12 years, 15 pounds below; No. 6, at 8 years, 2 pounds below; and No. 7 , at 5 years, 2 pounds above standard.

Thus the entire family, omitting the 5-year-old, is below the standard and mostly very slender or slender. In view of the fact that the parents are, at around 45 years, still slender or very slender, it is doubtful if the children's weights should be adjusted; it is probably a family characteristic not to put on weight in middle life. This family supports the view that extreme slenderness is a recessive condition, or, at least, is determined by prevailing recessive factors (R: Nob-1).

Mating 4. Other Slexder $\times$ Slexder Matixgs (included in table 23).

Since by hypothesis slender parents will rarely carry gametes with more than 1 factor for fleshiness, it becomes important to consider the remaining slender $X$ slender matings, i. e., without special regard to the grandparental conditions. A summary of the distribution of the progeny of all slender $\times$ slender matings is given in Table VI (Appendix). This shows that of 51 grown children (resulting from 24 matings), 5 are very slender, 35 slender, and 11 of medium build. 
Here is a great preponderance of very slender and slender offspring40 out of the 51, and all of the 11 of medium build are below the middle class. There clearly are factors which drive even these progeny of two slender parents in some cases to become of slightly heavier build than their parents, and this result is to be expected if fleshy build depends on several zygotic factors, and slender build lacks all these factors but two. The distribution of builds in the offspring of the selected slender (and very slender) parents is shown in table 23. The percentage distribution of the progeny is: $12 \mathrm{VS}, 73 \mathrm{~S}, 13 \mathrm{M}$, $2 \mathrm{~F}$. On any hypothesis we should expect a large proportion of slender offspring. Close conformity to any theoretical distribution is hardly to be expected in this table, owing to the variety of matings included.

TABLE 23.- Summary of selected slender $\times$ slender matings, and those of very slender parents, together with their progeny.

\begin{tabular}{|c|c|c|c|c|c|c|c|c|c|c|c|}
\hline & $\mathrm{VS}$ & $s$ & II & $\mathrm{F}$ & $\mathrm{Fi}$ & & IS & 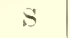 & MI & F & $\mathrm{VF}$ \\
\hline Ada $4 \ldots .$. & & 2 & & & & *Pal. & 1 & & & 1 & \\
\hline $\operatorname{Cod} 1 \ldots \ldots$ & $\cdots$ & 2 & & $\cdots$ & & $\operatorname{Ran} 4 \ldots \ldots \ldots$ & 1 & 2 & & & \\
\hline Fel ........ & $\ldots$ & 1 & $\cdots$ & $\ldots$ & & Sch $8 \ldots \ldots \ldots$ & $\ldots \ldots$ & 1 & 1 & & \\
\hline *Fun (a)..... & ... & 2 & $\cdots$ & ... & & Sch $37 \ldots \ldots \ldots$ & $\ldots \ldots$ & 3 & 1 & & \\
\hline *Fun (b)..... & $\ldots$ & 4 & . & . & & Sco $5 \ldots . . .$. & $\ldots \ldots$ & 2 & 1 & ... & \\
\hline Hay $4 \ldots . .$. & $\ldots \ldots$ & 2 & .. & .. & & Shi $5 \ldots \ldots \ldots$ & $\ldots \ldots$ & .. & 1 & ... & $\cdots$ \\
\hline Hay $12 \ldots \ldots$ & $\ldots$. & 1 & 1 & ... & & *smi........... & $\cdots \cdots$ & 2 & $\ldots$ & $\ldots$ & . \\
\hline Hen $12 \ldots$. & 1 & 2 & 1 & & & Ste $9 \ldots \ldots \ldots$ & $\ldots \ldots$ & 3 & $\ldots$. & $\ldots$ & $\cdots$ \\
\hline Jos $1 \ldots \ldots$ & $\ldots$ & . & 1 & 1 & & Wil $23 . . . \ldots \ldots$ & $\ldots \ldots$ & 4 & 1 & $\ldots$ & \\
\hline Ker $5 \ldots . .$. & 1 & . & 1 & ... & & You $9 \ldots \ldots \ldots$ & $\ldots \ldots$ & 1 & $\cdots \cdots$ & $\ldots$ & .. \\
\hline Lan $4 \ldots . .$. & 1 & 1 & $\ldots$ & $\cdots$ & & A $01: 44 \ldots \ldots$ & $\ldots \ldots$ & 1 & ... & $\ldots$ & \\
\hline Law $7 \ldots . .$. & $\cdots$ & 1 & - & . & & A $01: 19 \ldots \ldots$ & $\ldots \ldots$ & 1 & $\ldots$ & . & \\
\hline *Leo (a)... . & 1 & 4 & .. & . & & A $01: 60 \ldots \ldots$ & $\ldots$. & 1 & $\ldots$ & .. & \\
\hline *Leo (b). . & $\cdots$ & 3 & . & & & A $01: 63 \ldots$ & $\ldots \ldots$ & 1 & & .. & \\
\hline Lou $2 \ldots$ & 1 & 1 & 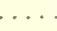 & & & & & & & & \\
\hline $\operatorname{MeA} 2 \ldots$ & $\ldots$. & 3 & & & & Total . . . . . T7 & 9 & 56 & 10 & 2 & \\
\hline $\mathrm{MicC} 11 \ldots$ & $\cdots$ & 1 & 1 & . & & Percentage 100 & 11.7 & 72.7 & 13.0 & 2.6 & \\
\hline *Mor.... & & 3 & $\cdots$ & & & & & & & & \\
\hline Nob 1. & 2 & 1 & & & & Mean, $28.50 \pm 0$ & $.24: \mathrm{S}$. & D. 3 & $.13 \pm$ & 0.17 & \\
\hline
\end{tabular}

Detailed family histories of these slender $X$ slender matings are given herewith.

\section{AdA 4 FAMILY.}

A family of old English American (Massachusetts and Ohio) stock, living in Michigan and Kansas. The Father, a merchant, who in youth suffered from brain fever, is living at 77 years, having had at 50 years the formula 150/71 inches; build 2.1 (30). His 4 sibs are all tall. His father, a farmer, died at 49 years from typhoid. At 40 years his formula 160/70 inches; build 2.3 (33). His mother, who had 6 children, and who was always well, died at 65 years from pneumonia. At 40 years her formula $130 / 69$ inches; build 1.9 (27). This side of the house is of prevailingly slender to medium build.

The mother, who has had 3 children and who suffered in middle age from rheumatism and colitis, is living at 66 years, having had at 50 years the 
formula 120, 66 inches: build 1.9 (28). Her father, a farmer, died from paresis. At 45 vears he had the formula $175 / 69$ inches; build 2.6 (37). Her mother, who in middle age suffered from diphtheria, died at 73 vears from paralysis. At 45 years her formula 130/68 inches; build 2.0 (28). This side of the house is prevailingly slender (though with 1 stout grandparent). Two grown children:

1. Male, a photographer, who in youth suffered from tetanus, has at 25 years the formula $140 / 71$ inches; build $2.0(28)$.

2. Male, a teacher, has at 22 years the formula 130/70 inches: build $1.9(27)$.

Comment.-Both slender in the madjusted build ( $\mathrm{R}:$ Ada-4).

$$
\text { FEl-1 Fanili: }
$$

A family of Scoteh and Welsh extraction. living mostly in the mid-western United states. The Father, who is a builder, and who has suffered from several attacks of inflammation of the lungs. is living at 50 years. having the formula $143 / 70.5$ inches; build 2.0 (29). His father, who was in business, suffered from lung fever and was almost helpless from rheumatism several years before he was killed in an accident. At 60 years he had the formula $140 / 71$ inches; build 2.0 (28). His father's father, a farmer, died from lung fever, became emaciated before death. At 38 years, his formula $162 / 67$ inches; build 2.5 (36). His father's mother, who had 6 children, and who was always well, died at 89 years from old age. At 30 years her formula $96 / 60$ inches; build 1.9 (27). His mother, who had 4 children, was liable to chronic neuralgia. She died at 68 from pneumonia. At 30 years her formula $125 / 64.5$ inches; build 2.1 (30). His mother's father, who died at 76 years from pneumonia, had the formula $168 / 77$ inches; build $2.0(28)$. A previalingly slender family.

The Nother, who has only 1 child, has always been well. She is living at 46 years, having the formula 110/62 inches; build 2.0 (29). Her father, who was an expert machinist, always well, died at 43 years from appendicitis. Formula, 200/69 inches; build 3.0 (42). Her mother, who had but 1 child, was always well. She is living at 62 years, having the formula $120 / 61$ inches; build 2.3 (32). A slender mother, with medium to stout parents.

The one child, a male, student, always well, has at 19 years the formula $125 / 68.5$ inches; build $1.9(27)$.

Comment.-A slender ehild (D) : Fel-1).

$$
\text { HAY-4 FAMIIY: }
$$

A family of Scotch extraction; grandparcnts living in Massachusetts, New York state, Kansas, and California. Parents living in Massachusetts, California, Kansas, and Japan. The first two children were born in Japan, but live in California, where the rest were born. The Father, who is a rancher, has at 54 years the formula $155 / 73$ inches; build 2.0 (29). His father, who was an accountant, died at 67 years from apoplexy. Their mother died from tubereulosis. Apparently a slender strain not very resistant to tuberculosis.

The Mother, who in youth suffered from lung fever, has at 45 years the formula $123 / 65.5$ inches; build 2.0 (29). Her three sibs are tall. Their father, who was a merchant, suffered in middle age from tuberculosis and died from it. At 44 years he was tall and sender. Their mother, who in middle age suffered from chronic indigestion, had at 71 years the formula 
$155 / 64$ inches; build 2.7 (38). This side of the louse is prevailingly slender, with a possible tubercular diathesis. Six rhildren:

1. Male, a forester, has at 23 years the formula $170 / 76.8$ inches; build $2.0(29)$.

2. Male, a student, at 21 years is 71.5 inches tall.

3. Female, at 18 years, his the formula $130 / 70$ inclues; build 1.9 (27). There are 3 ehildren under 18 years, 2 slender and 1 whose build is unknown.

Comment.- The children are slender, though they may develop into adults of medium build ( $\mathrm{R}$ : Hay-4).

$$
\text { HaY-12 FaMlLY. }
$$

A family of English and Scotch extraction, living in Pennsylvania, West Virginia, and Washington, D. C. The Father, who is a clerk, always well, is living at 67 years. At 65 years his formula 150/74 inches; build 1.9 (27). Of his 6 sibs, 3 are slender and 3 of medium build. Their father, who was State senator, suffered in middle age from typhoid. He died at 85 years from old age. At 75 years his formula was 135/68 inches; build 2.1 (29). Their mother, who had 8 children and was always well until at 42 years she died from dropsy, was of medium build. This side of the house carries a tendency to slenderness.

The Mother underwent an operation at 63 years for tic douloureux. She is living at 67 vears. At 65 vears her formula $108 / 64$ inches; build 1.9 (27). Of her 9 known sibs, 3 are slender and 3 fleshy. One of the corpulent brothers luas 2 children, 1 corpulent and 1 medium. Their father, who was a farmer, always well, died at 55 years from "congestion of spine, result of accident." At 50 years he was of medium build. Their mother, who had 8 children, was always well, till at 71 years she died from "adhesion of bowels-caused by rupture." Formula, 90/64 inches: build 1.5 (22). A prevailing slender family, with some tendeney to leary build. Four children:

1. Female, married, who in youth was liable to goiter, is at 38 years of medium build.

2. Female, married, always well, is at 36 years slender.

3. Male, a clerk, always well, has at 31 years the formula 150/69 inches; build 2.2 (32).

4. Male, a clerk, always well, has at 25 years the formula $135 / 71$ inches; build 1.9 (27).

Comment.-Two of the children are slender, like both parents; 2 are medium (R: Hay-12).

$$
\text { Hex-12 FAMiLY. }
$$

A family of Scotch and Irish extraction. The grandparents on both sides of the house were southerners. The family is now located in Florida, in which State 4 children were born.

The Father, interested in farming, had at 40 years the formula $140 / 70$ inches; build 2.0 (29). His father, who was killed in the Civil War, was of medium build. The father's mother died at 30 year's from child-birth; sle was also, at 25 years, of medium build.

The Mother suffered with laryngitis in middle age and died of it at 29 years. Her formula then was $112 / 63$ inches; build 1.9 (28). Her father, a physician, and later a fruit grower, died at 75 from gemeral debility. At 50 he was of medium build. Her mother died at 85 from old age, having at 50 a medium build. Four children are: 
1. Female, at 25 , has the formula $96 / 66 \pm$ inches; build 1.5 (22).

2. Male, at 26 , has the formula 146/69 inches; build 2.1 (31); adjusted to 33 years, $151 / 69$ inches; build $2.2(32)$.

3. Female, at 25 , has the formula $115 / 67 \pm$ inches; build $1.8(26 \pm)$.

4. Male, at 22 , has the formula $135 / 70 \pm$ inches; build $1.9(28 \pm)$.

Comment.-The children are all slender, except perhaps one of slendermedium build ( $R$ : Hen-12).

\section{LAW-4 FAMLY.}

A family of English extraction, living mostly in Vermont and Minnesota. The Father, who was a clerk, died at 25 years from "typhoid pneumonia," having the formula $150 / 74$ inches; build 1.9 (27). One of his brothers is tall, one very tall. Their father, a farmer, died at 74 years. At 50 years he was of medium build. Their mother, who had 5 children, suffered in middle age from asthma; grew fleshy at 50 ; died at 65 years. Thus the Father is a slender parent of medium to fleshy ancestry, who died young from lung trouble.

The Mother suffered in youth from tonsillitis, erysipelas, and diphtheria; in middle age from pneumonia and pleurisy. She is living at 45 years. At 22 years her formula 122/68 inches; build 1.8 (26). Two of her sibs were tall. Their father, a farmer, suffered in youth from fever and ague. He died at 69 years from paralysis. At 48 years his formula 165/68 inches; build 2.5 (36). Their mother, who had 5 children, suffered in middle age from neuralgia. She died at 67 years from heart disease. At 45 years her formula $120 / \mathrm{M}$; build 2.1 (30). A slender parent who has had troubles of the respiratory tract. Two grown children:

1. Male, a salesman, who in youth suffered from tonsillitis and diphtheria, has at 26 years the formula $155 / 74$ inches; build 2.0 (28).

2. Female, married, who in youth suffered from tonsillitis and diphtheria, has at 25 years the formula $110 / 67$ inches; build $1.7(25)$.

Comment.-One child is slender; the other very slender ( $R$ : Law-4).

\section{LAW-7 FAMILY.}

A family of English extraction, living in New Jersey. The Father, a clerk, and always well, has at 43 years the formula $129 / 65.5$ inches; build 2.1 (30). His father, who was a manufacturer, suffered in youth from typhoid fever, and in middle age from pneumonia. He died of the latter at 31 years; was of medium build. His mother, who had 4 children, was always well. She is living at 65 years and is of medium build. This side of the house brings in medium-slender elements.

The Mother has always been well. She is living at 42 years, having the formula 115/64 inches; build 2.0 (28). Her father, who was a grain dealer, died at 63 years from apoplexy; he was of medium build. Her mother, who had 3 children, suffered in youth from pneumonia. She is living at 68 years and is tall and slender. This side of the house is prevailingly slender. Three children:

1. Female, a teacher, always well, has at 18 years the formula $128 / 63.5$ inches; build $2.2(32)$.

2 and 3 . Two girls at 11 and 8 years who are below average build.

Comment.-The one grown child is of medium build, somewhat stouter than her Father; the other two children are rather slender for their ages ( R : Law-7). 


\section{Leo Family. (Fig. 23.)}

I 1, J. L., very slender, died of pneumonia. His wife, I 2, at 87 years is slender and measures $141 \mathrm{~cm}$. in stocking feet; she has two brothers who are slender. There are 5 children:

II 4, of, was $183 \mathrm{~cm}$. tall and very slender; he died at 63 years of catarrh of stomach.

II 5 , $\delta$, was short and slender; he died at 52 years of Bright's disease.

II $6, q$, single, is $165 \mathrm{~cm}$. tall and weighs $51.7 \mathrm{~kg}$. (65 inches and 114 pounds); index 1.9 (27), obviously slender.

II 3 , $q$, slender.

II $7, \delta$, always slender.

So far we have only slender persons to deal with. Now enters a ehange. II 3 married a fleshy man who has a fleshy sister; all 3 children are fleshy. Also II 7 married a woman whose index is $86.2 \mathrm{~kg} . / 114 \mathrm{~cm}$., or $6.6(190 / 60$ inches, or 53). She has always been fleshy (except during an attack of
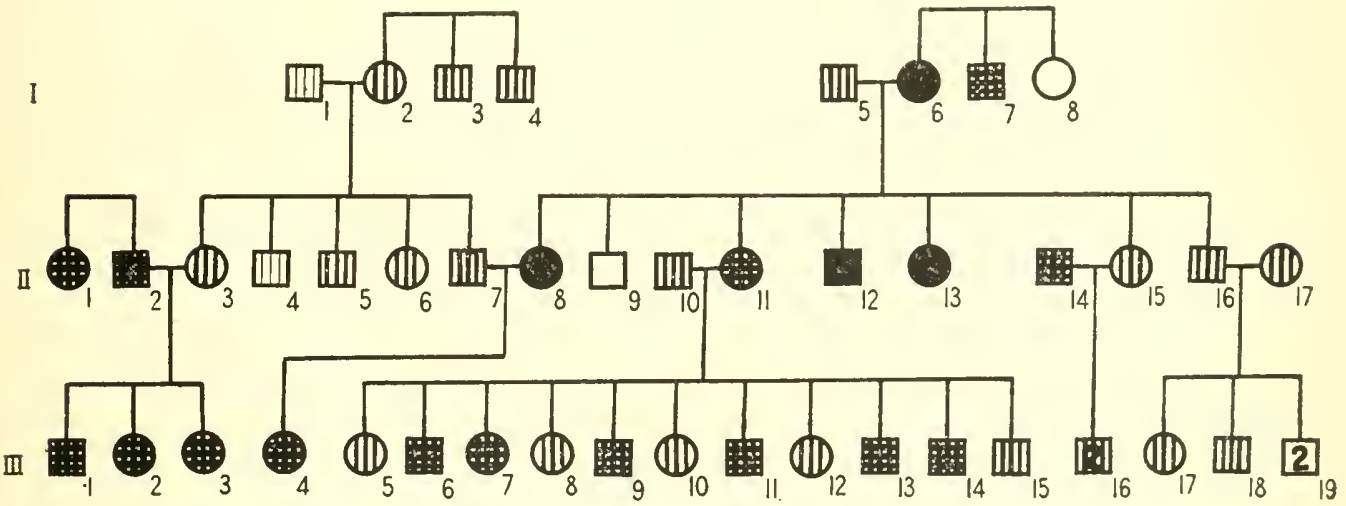

Frg. 23.-Pedigree chart showing distribution of build in the Leo family.

anemia). She had both slender and fleshy sibs. Their only child (III 4) is a girl of 9 years. Her relative chest-girth is 57 per cent instead of the 49 per cent expected at that age; that is, she is fleshy. Thus the two marriages of this slender stock into fleshy lines result altogether in 4 children, all fleshy; indicating dominance of fleshiness.

II $16, \hat{\delta}$, at 50 years is tall and slender. He has 1 slender and 4 fleshy and very fleshy sibs. His father, I 5, was slender; his mother was short and weighed $86 \mathrm{~kg}$. (190 pounds). He married II 17, a slender woman; the 2 living children are tall and slender. Thus II 16 apparently did not carry the gene for fleshiness from his mother $(73: 676)$.

\section{Lou-2 Family.}

A family of Irish and English extraction, living mostly in New York State. The Father, who is a doctor, suffered in middle age from "nervous breakdown, indigestion, and stomach trouble"; is living at 60 years, and has the formula $155 / 73$ inches; build 2.0 (29). His three brothers, who are living, are tall. Their father, who survives, is a farmer and suffered in middle age from "nervousness." Their mother died from consumption "caused from taking care of son who died from same." 
The Mother, who is living at 50 years, has the formula 115/65 inches; build 1.9 (27). Two children:

1. Female, a student (married), has at 25 years the formula $110 / 66.5$ inches; build $1.8(25)$.

2. Female, a student, has at 22 years the formula $120 / 68$ inches; build $1.8(26)$.

Comment.-Both children are now slender, but may approach a medium weight as they grow older ( $\mathrm{R}: \mathrm{Lou}-2)$.

\section{MCA-2 FAMILY.}

A Scotch-English family living chiefly in Ohio. The Father, a farmer, had an attack of diphtheria in middle life, is energetic, and, at 62 years, has the formula $135 / 70$ inches; build 1.9 (28). His sister died of tuberculosis. Their father, somewhat easy-going, was a farmer, had typhoid fever and died of cancer at 68 years. His formula, 135/72 inches; build 1.8 (26). Their mother, of mediocre activity and mentality, died at 36 years, having borne 4 ehildren. Two of her sisters died of pneunonia. She was of medium build. This side of the house tends to slenderness.

The Mother, who once had typhoid fever and is physically active, has, at 60 years, the formula 120/65 inches; build 2.0 (28). Her father, who had typhoid fever in the army and was very active, had the formula 180/74 inches; build 2.3 (33). The Mother's mother, who was also very active, was of medium build. This side of the house brings in a slender-medium tendency. Three children:

1. Female, a teacher, who has had typhoid fever and her tonsils and appendix removed, is energetic, and has a formula at 30 years of 109/64 inches; build 1.9 (27).

2. Male, a student and farmer, who has had diphtheria and typhoid fever, energetic, at 28 years has the formula 135/69 inches; build 2.0 (28).

3. Male, student and farmer, who has always been well, energetic, weighed 9 pounds at birth, formula at 23 years, $138 / 69$ inches; build 2.1 (29).

Comment.-The unadjusted build of the children averages the same as the parents and differs little from them; it is hardly probable that they will reach the adjusted weight.

\section{MCC-11 Fanily.}

A family of Scotch and English extraction, living in the Middle West and northwestern United States. The Father, who is a proot-reader, suffered in youth from fever and ague. He is living at 74 years, having at 48 years the formula $140 / 68$ inches; build 2.1 (30). His father, who was a farmer, died at 87 years from dysenterv. At 40 years, his formula $160 / \mathrm{T}$; build say 2.3 (33). Their mother, who had 4 children, died at 29 years "probably from effects of child-birth." At 26 years she was of medium build. This side of the house probably contributes a tendency to slender or slendermediun build.

The Mother suffered in youth from tonsillitis and asthma; in middle age from nervous prostration and abscess. She is living at 60 years, having had at 36 years the formula $130 / 65.5$ inches; build 2.1 (30). Her father, who was a farmer and carpenter, suffered in middle age from internal abscess and rheumatism. He died at 72 years from apoplexy. At 40 years he was of medium build. Her mother, who had 4 children, died in child-birth, at 27 years; she was of medium build. This side of the house, likewise, contributes a tendency to slender or medium build. Two ehildren: 
1. Female, a student, who in youth suffered from tonsillitis and nervousness, has at 28 years the formula $125 / 65.3$ inches; build 2.1 (30).

2. Male, a farmer, who in youth suffered from asthma, enlargement of liver, and attacks similar to epilepsy, has at 25 years the formula $180 / 74.3$ inches; build 2.3 (33).

Comment.-Both children are of mediun or slender-medium build (R: McC-11).

Mon Family. (Fig. 24.)

IV 3 , of, at 46 years is short and very slender. He married a tall. slender woman; their son, at 22 years, is tall and slender.
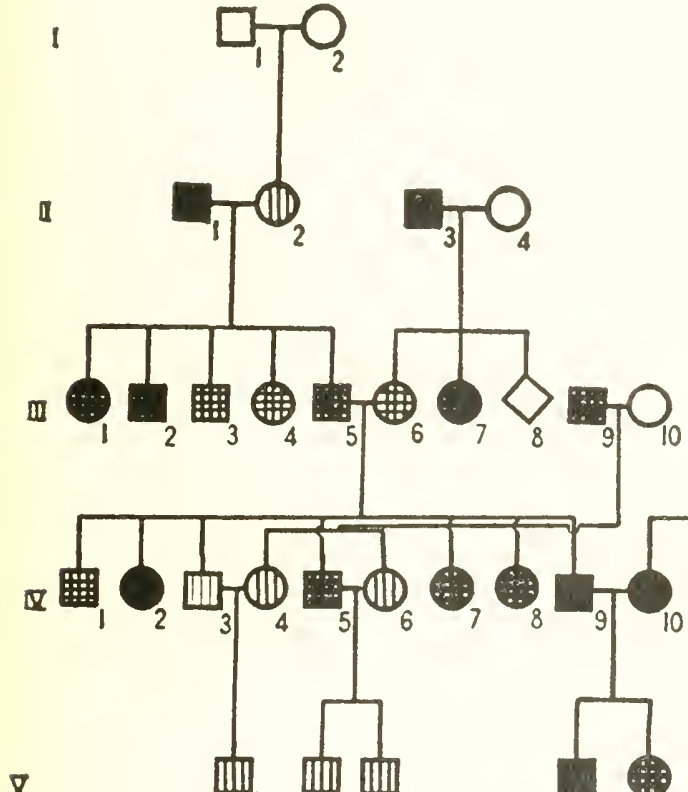

$\mathbf{Z}$

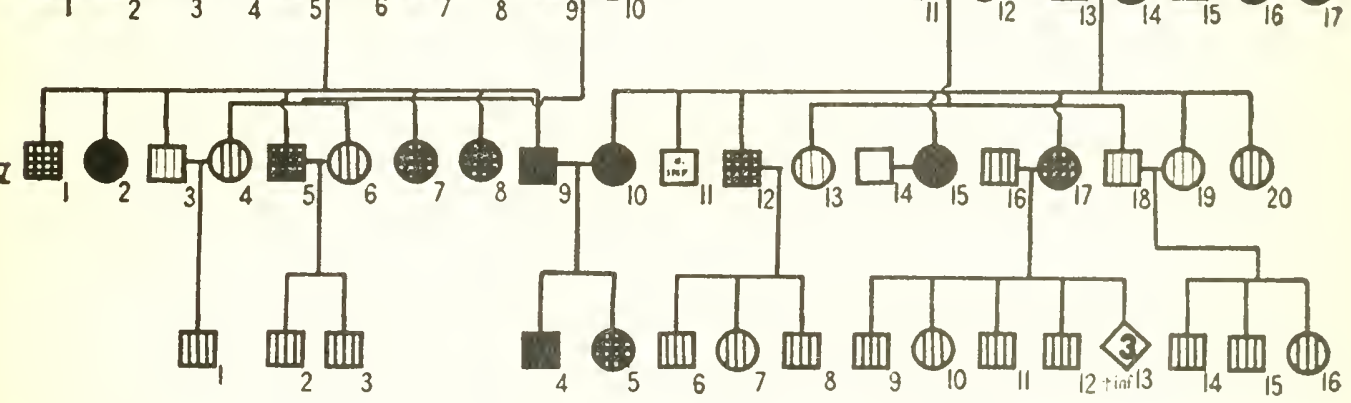

Frg. 24.-Pedigree chart showing distribution of build in Mor family

IV 19, $\&$, is tall, like her Father's father, and very slender. She has 1 etender and 3 or 4 Heshy sibs and both of her parents were fleshy. Her husband is $182 \mathrm{~cm}$. (72 in.) tall and very slender. They have 3 children, all tall and slender.

The Mother apparently carries no "fleshy" gametes (73: 690).

\section{Pal Family. (Fig. 2j.1}

III 2 , J. T. C., of , at 64 years is of medium height and slender. One of his sisters is slender and one (III 7) at 56 years is $157 \mathrm{~cm}$. tall (without shoes), weighs $74 \mathrm{~kg}$. net, and has a chest-girth of $105 \mathrm{~cm}$. net. This gives a relative chest-girth of 67 per cent. This sister is thus very fleshy. Their father (II 3) was of medium build, his wife rather fleshy. J. T. C.'s wife, III 3 , is of medium height and very slender, though her two parents were of medium build.

The two surviving children are: 
IV 1 , \&, at 43 years weighs 165 pounds and is 62 inches tall. She has thus an index of build of 3.0 (43) and is fleshy.

IV 2, 34 years old is very slender; she is, however, an invalid and bedridden. Here we have a well-authenticated record of two slender parents with a fleshy daughter; obviously both of the slender parents must have carried gametes with one or more genes for fleshiness; and a combination of such genes induced fleshy build in the child.

Comment. $-A$ rather remarkable family in that a slender $X$ very slender mating has produced a fleshy child, as well as a very slender one. But the slender Father doubtless carries 2 or possibly (and exceptionally) 3 zygotic

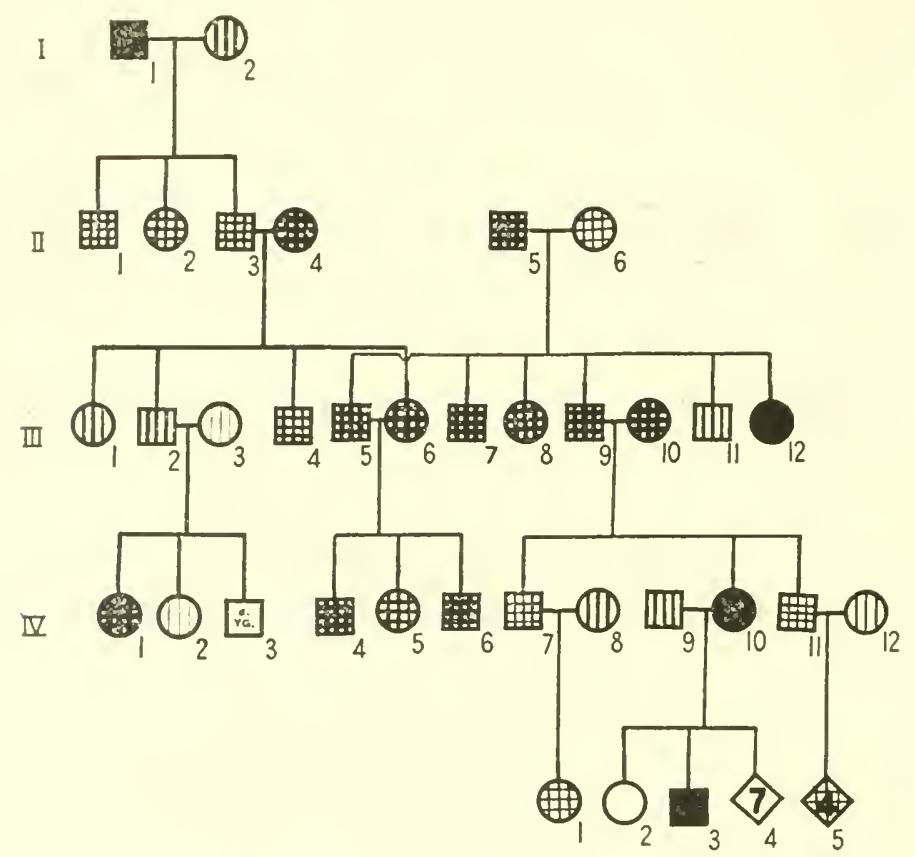

FIG. 25.-Pedigree chart showing distribution of build in PAL family.

factors for build (on the 6-zygotic factor hypothesis); for his mother was fleshy and a sister very fleshy. On this hypothesis the very slender Mother may contribute one such factor $(73: 709)$.

\section{RAN-4 FAMILY.}

A family of English extraction, living in New York State and Massachusetts. The Father, who is an editor, has at 58 years the formula $150 / 72$ inches; build 2.0 (29).

The Mother has at 56 years the formula 130/66 inches; build 2.1 (30). Her brother died at 55 years from tuberculosis; height 72 inches. Her father, a minister, suffered in middle age from bronchial consumption and died of it at 60 years. Her mother, who in youth suffered from dropsy and consumption, in middle age from rheumatism, died at 96 years from heart trouble. This side of the house is slender-medium; probably because of tuberculosis. Three children: 
1. Male, secretary of an insurance company, who in youth suffered from hay fever, catarrh, and typhoid fever, has at 30 years the formula 140/72 inches; build 1.9 (27).

2. Female, has at 25 years the formula $130 / 69$ inches; build 1.9 (27).

3. Female, a clerical worker, has at 24 years the formula 120/70 inches; build $1.7(25)$.

Comment.-All 3 children are of slender build (one very slender) in the unadjusted ratio. It seems a little doubtful whether, with the inheritance they have, they will ever reach the medium build ( $\mathrm{R}$ : Ran-4).

\section{SCH-8 FaMiLY.}

A family of mixed German and American origin, living in Connecticut. The Father, a master mechanic, always well, has at 51 years the formula $132 / 66$ inches; build 2.1 (30). His father, a farmer, always well, died at 67 years from heart failure; formula $180 / 72$ inches; build 2.4 (35). His mother, who had 3 children and who was always well, died at 67 years of heart failure. Formula, 115/63 inches; build 2.0 (29). This side of the house is slender-medium.

The Mother, who has 3 children, has at 47 years the formula 120/64 inches; build 2.1 (29). Her two sisters are tall. Her father, a foreman and always well, has at 73 years the formula 184/69 inches; build 2.7 (39). Her mother was of average stature. This side of the house might be expected to help determine slenderness in the children. Three children:

1. Male, a stenographer, well, has at 21 years the formula 130/66 inches; build 2.1 (30) (adjusted to 49 years, 144/66 inches; build 2.3 (33)) .

2. Male, a student, always well, has at 19 years the formula $138 / 66$ inches; build 2.3 (32) [adjusted to 49 years, 157/68 inches; build 2.4 (34)].

3 . Female, at 13 years, is very slender, even for her age.

Comment.-The children are slightly below (one is close to) average build (R : Sch-8).

\section{Sco-5 Family.}

A family of English extraction, living mostly in middle western United States. The Father, a broker, who in middle age suffered from cirrhosis of the liver, has, at 57 years, the formula 140/70 inches; build 2.0 (29). His father, a lumberman, died at 60 years from paralysis, having the formula $170 / 68$ inches; build 2.6 (37). His mother died at 75 years from arteriosclerosis; formula 100/64 inches; build 1.7 (24).

The Mother has at 49 years the formula 110/62 inches; build 2.0 (29). Her father, a wholesale merchant, died at 63 years from sarcoma. His formula 170/69 inches; build 2.5 (36). Her mother, who has 2 children, has at 74 years the formula $90 / 61$ inches; build 2.1 (24). Three children:

1. Male, a surveyor, has at 25 years the formula $150 / 68$ inches; build $2.3(32)$.

2. Male, a clerk, has at 23 years the formula $135 / 67$ inches; build 2.1 (30).

3. Male, a student, has at 20 years the formula $125 / 65$ inches; build $2.1(30)$.

Comment.-The unadjusted build of the children is only a point.or two greater than that of the parents $(\mathrm{R}: \mathrm{Sco-}-5)$.

$$
\text { Shi-5 Family. }
$$

A family of English and German extraction. The Father's parents were born in England. The Mother's parents were born in Germany. The 
parents and their one child were born in New York City, where the family is now settled.

The Father, inclined to indigestion in middle age, has, at 47 , the formula 143/70 inches; build 2.1 (29). His father, a dry-goods man, has bronchial trouble in middle age. At 73 his formula is $145 / 70.5$ inches; build $2.0(29)$. The Father's mother, having borne 2 sons and 4 daughters, died of kidney trouble and pneumonia at 52 years of age. Her formula, at 51, was $150 / 65$ inches; build $2.5(36)$.

The Mother, who suffered from bronchitis in youth, at 46 has the formula 120/67 inches; build 1.9 (27). Her father died around the age of 35 from wounds received in the Ciril War. He was of medium build. Her mother at 71 years of age has the formula $85 / 56$ inches; build 1.9 (27). One grown child:

1. Female, at 19 , has the formula $145 / 67$ inches; build 2.3 (32).

Comment.-The child is somewhat of heavier build than either parent and may approach the build of her Father's mother ( $R$ : Shi-5).

\section{Sum Family. (Fig. 26.)}

II 9, M. E. S., o , at 74 years is $162.5 \mathrm{~cm}$. (64 inches) tall without shoes and weighs $48 \mathrm{~kg}$. (106 pounds) net. Her index of build is 1.9 (27); she

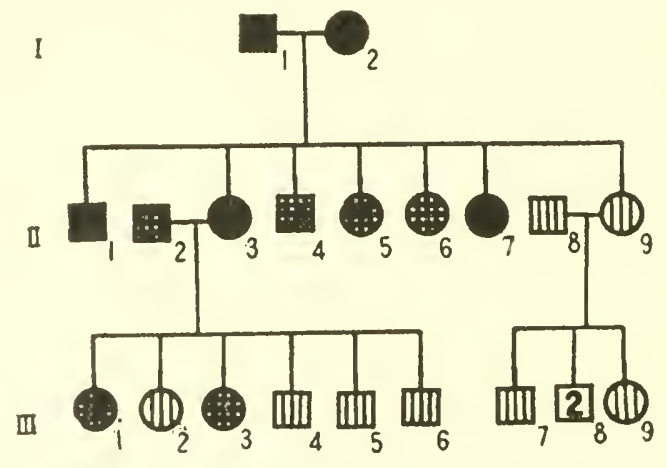

FId, 2fi.-Pedigree chart of part of SMI family.

is slender. All of her 6 sibs are fleshy or very fleshy and so are their two parents (I 1,2). Her husband was tall and slender. They had 4 children: (1) a boy, who died at 19 of "kidney trouble"; he was slender. (2) and (3) died young; (4) female, at 33 is $172 \mathrm{~cm}$. (68 inches) tall and weighs $59 \mathrm{~kg}$. (129 pounds) net; index 2.0 (28); she is slender. Thus the mating of two slender persons (one arising in the midst of fleshy stock) has resulted in 2 slender children $(73: 736)$.

Wh-23 FamiLY.

A family of English extraction, living in New York State and Connecticut. The Father, who is a teacher, is living at 61 years. At 45 years he had the formula 155/72 inches; build 2.1 (30). One of his sisters died from "quick consumption." His father, who was a farmer, always well, died at 61 years from pneumonia. At 45 years he was of medium build. His mother, who had 10 children, was always well. She is living at 81 years. At 45 years she was of medium build. This side of the house might be expected to determine medium build in children. 
The Mother suffered in youth from pneumonia, in middle age from typhoid fever and hernia. She is living at 63 years. At 45 years her formula was 125/66 inches; build 2.0 (29). Her brother died at 55 years from tuberculosis of larynx. Her father, who was a farmer, always well, died at 83 years from "cancer of the face." At 50 years he was of medium build. Her mother, who had 5 children, was always well. She died at 67 years from typhoid pneumonia; was slender. Five children:

1. Male, a buyer, always well, has at 30 years the formula 145/73 inches; build $1.9(27)$.

2. Male, an electrical engineer, who in youth suffered from typhoid fever, has at 29 years the formula $185 / 75$ inches; build 2.3 (33).

3. Male, a physician and surgeon, who in youth suffered from typhoid and in middle age from acute nephritis, has at 27 years the formula $145 / 72$ inches; build 2.0 (28).

4. Female, a teacher, always well, has at 25 years the formula $138 / 69$ inches; build 2.1 (29).

5. Male, who in youth suffered from typhoid fever, has at 22 years the formula 150/74 inches; build 1.9 (27).

Comment.-The unadjusted builds of 4 of the children is a little less than the parental builds of 30 and 29. The adjusted builds are a point or two higher. In the case of child No. 2 we have an exceptionally large index of build for this fraternity of 2.3 (33). It is possible that the tubercular tendency on both sides may have pulled down the hereditary potentiality of one or both parents ( $R$ : Wil-23).

\section{Yoc-9 Fanily.}

A family of Pennsylvania Dutch blood; all born in and about Pennsylvania. The Father, an educationalist, has had in middle age a nervous breakdown and bronchial trouble. At 44 he has the formula 118/64 inches; build 2.1 (29). His father, a miller, died of old age at 76 . At 68 he had the formula 130/60 inches; build 2.5 (36). The Father's mother having had 7 sons and 4 daughters, died of old age at 82 . When 75 she had the formula 120/59 inches; build 2.4 (34). It is possible that the bronchial trouble may have reduced the Father's build somewhat below its normal potentialities.

The Mother, inclined to nervous disorders, at 43 had the formula $98 / 59.5$; build 2.0 (28). Her father, a railroad man, had malarial fever in middle age. At 70 he has the formula 160/66 inches; build 2.6 (37). Her mother in youth had bronchial trouble and St. Vitus dance and in middle age, asthma, pneumonia, rheumatism, nervous prostration, etc. She died at 64 , from a complication of diseases. At the time of her death she had the formula $80 / 59$ inches; build $1.6(23)$. The two children are:

1. Female, has had bronchitis and encephalitis, at 19 has the formula 94/59.5 inches; build $1.9(27)$.

2. Female, at 15 years is slender for her age.

Comment.-Slender children from two slender parents ( $R$ : You-9).

$$
\text { A : 01-19 Family. }
$$

A family of probable English extraction. The Father, a lawyer, is troubled with catarrh, but otherwise his general health is pretty good. At 20 years of age he had the formula 129.5/70 inches; build 2.0 (26).

The Mother has good general health, although troubled with palpitation of the heart and headache. At 20 years she had the formula 106/61 inches; build 2.0 (29). 
The one daughter for whom data are given has had numerous children's discases. Her general health is now good. At 18 years of age she has the formula 114/64 inches; build 2.0 (28).

Comment.-Parents and child are all slender (A :011d-19).

$$
\text { A : 01-44 FAMILY. }
$$

A family of English extraction. The Father, a dentist, has good general health, but habitual constipation. At 20 vears of age he had the formula 140/68 inches; build 2.1 (30).

The Mother has oceasional headaches. At the age of 18 her formula was 104/62 inches; build 1.9 (27).

The son has general good health. but is inclined to kidney trouble, skin diseases, and headache, presumably from his eyes. At 18 he has the formula $124 / 66$; build 2.0 (29) A : 011d-19).

$$
\text { A : 01-60 FAMILY. }
$$

A family of English extraction with some Irish and Scotch blood in addition.

The Father, a minister, has had pneumonia and dyspepsia, but his general health is good. At 22 years he had the formula $132.5 / 68$ inches; build $2.0(29)$.

The Mother has had piles and slight attacks of rheumatism. Her general health is very good. At 19 years she had the formula 110/64 inches; build $1.9(27)$. The one child for whom data are available is:

1. Female, inclined to rheumatism and kidney trouble, like her Mother. She has had practically all children's diseases, and at 19 her formula is 108/65 inches; build 1.8 (26).

Comment.-Both parents and their child are slender (A : 0i1d-60).

$$
\text { A : 01-63 FAMiLY. }
$$

A family of English extraction. The Fatler, a teacher, is in good health. At 45 his formula is $134 / 69$ inches; build 2.0 (28).

The Mother's health is generally good. She is inclined to some skin trouble and is troubled with headache and habitual constipation. At 34 years she had the formula $97 / 59$ inches; build 2.0 (28).

The one child is a son in general good health, although he has rheumatism and constipation. He is also subject to frequent colds and grippe. At 19 years of age he has the formula $111 / 68$ inches; build $1.7(24)$.

Comment.-Both parents and the ehild are of slender build (A : 011d-63).

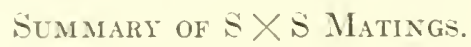

The gametic constitution of slender parents is certainly very diverse. Assuming that both slender parents produce only gametes of the type Abc, their offspring would be exclusively of the type AAbbce, which we may take as a zygotic formula for slender progeny. Assume that in another case both slender parents have the zygotic formula AaBbcc; then they would each produce gametes $\mathrm{ABc}, \mathrm{Abc}$, aBc, and abc. Uniting at random, these gametes would produce zygotes as follows:

$\begin{array}{lrrrrr}\text { Number of dominant factors... } & 4 & 3 & 2 & 1 & 0 \\ \text { Proportions............... } & 6.25 & 25 & 37.5 & 25 & 6.25\end{array}$


Thus a very variable progeny would be produced: very slender, slender, medium, and fleshy. Now it seems probable that the totals of table 23 are a combination of these two kinds of matings and another which would yield very slender, slender, and medium offspring in the proportions of 25,50 , and 25 , respectively.

Considering only the families of table 23 who have 3 or more children, we get a total distribution for these children of:

$$
\begin{array}{ccc}
\text { vs } & \text { S } & \text { M } \\
5 & 34 & 4
\end{array}
$$

If we subtract from the $\mathrm{S}$ total the 16 children who belong exclusively to slender fraternities, the children who remain have the distribution 5:18:4, which is fairly close to the $1: 2: 1$ ratio of $6.75: 13.5: 6.75$ which is to be expected from a mating of parents of the zygotic constitution AAbbce and AaBbcc respectively.

We conclude, therefore, that the $\mathrm{S} \times \mathrm{S}$ matings are gametically of two kinds, one slightly, the other more greatly variable. The distribution found is determined by a combination of these two kinds.

Also, the statistical results of the distribution of the progeny of $\mathrm{S} \times \mathrm{S}$ matings are in harmony with the hypothesis that slender parents in extreme cases carry not more than two zygotic factors for fleshy build. The slender parent is, accordingly, to be regarded as one who carries gametes with prevailingly recessive factors.

\section{Class II. Both Parents Fleshy.}

Next we turn to the matter of inheritance of fleshiness in fleshy stock. That fleshiness may be a true hereditary character is indicated by the existence of fleshy races of men. Examples are the SouthRussian Jews, especially of the female sex; and certain of the Chinese, who have strikingly short legs. The matter is discussed in more detail at page 7 . The fact that the body reacts to food and climate must not blind us to the constitutional factors that are probably present in racial obesity. At any rate, it becomes of interest to inquire as to inheritance of fleshiness in families characterized by the trait. For this purpose we shall consider various matings between more or less fleshy parents.

Mating 1. One Parext is Very Fleshy, the Other Fleshy (or Very Fleshy) of Fleshy Stock. (Table 24.)

From this mating of "pure" or nearly "pure" fleshy parents are derived (table 24) 50 offspring: $2 \mathrm{~S}, 11 \mathrm{M}, 23 \mathrm{~F}, 14 \mathrm{VF}$, or, in percentages, $4 \mathrm{~S}, 22 \mathrm{M}, 46 \mathrm{~F}, 28 \mathrm{VF}$. This distribution of the total does not agree with the 4-zygotic-factor hypothesis ( $p .41$ ), which gives a filial distribution of $50 \mathrm{~F}, 50 \mathrm{VF}$. It agrees better with the 6 -factor hypothesis (p. 43), assuming the proper dividing-line between fleshy and very fleshy to lie somerwhere in column 5, and the mating 


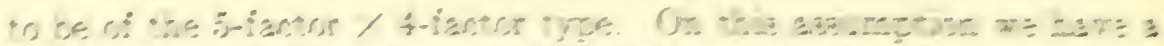

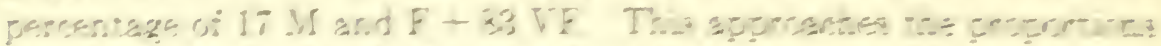

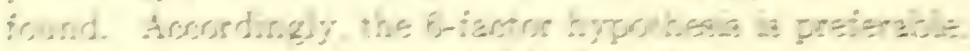

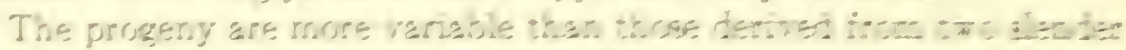
perenta $23.5 .74=0.33$ ia er, $3.13=09.1 \%$.

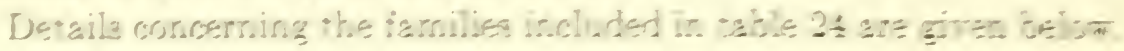

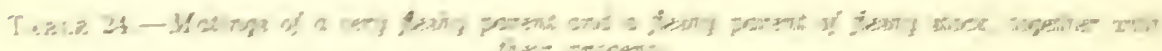
ind prisen?

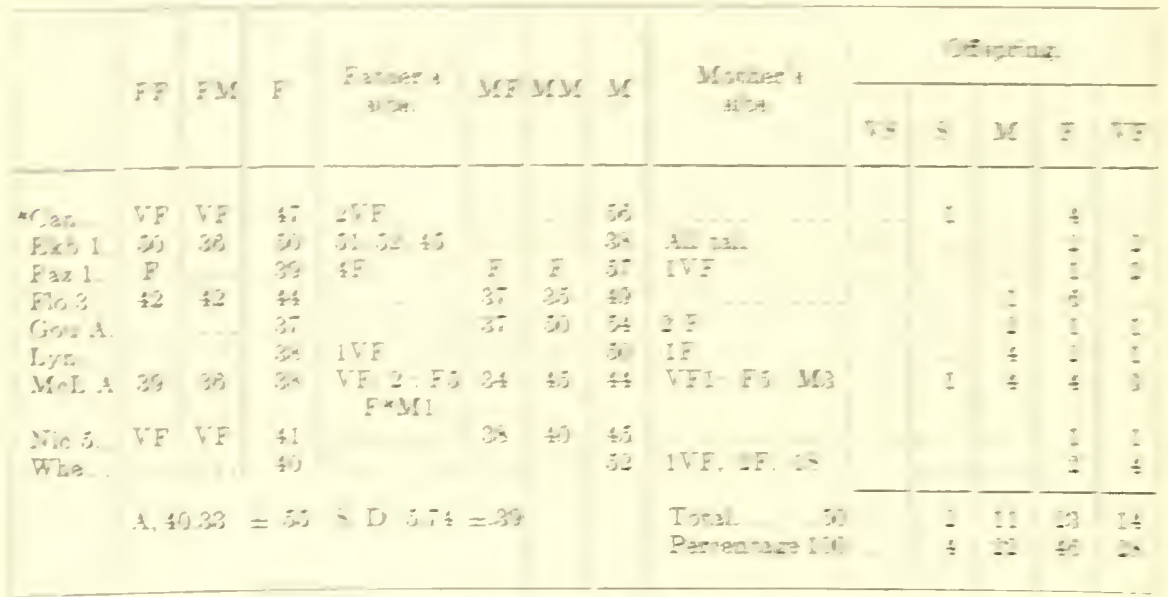

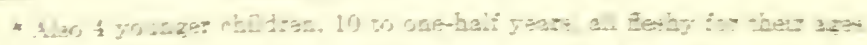

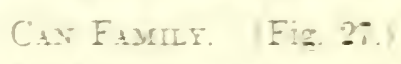

A iamily of Italian exraction. living in a pooty tumisted. ber: moth

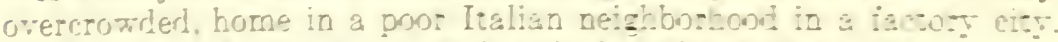

I $1, \hat{z}$, was tall and "ery fleshy: died of "heart disesse."

I 2, $z$, was tall and very flechy and had a brother o: simils built. Inis very fleshy pair had 3 rhildren, a: bollow:

II 1 and II 4 broth very Reshy. II jat 46 yesrs $171 \mathrm{~cm}$. 167 inches 23. (without shoes) and weighing $96 \mathrm{~kg}$. 212 pounds) ne:; build 3.3147 . ver: fleshy. His chest-girth. $106 \mathrm{~cm}$. net; relative chest-girh 62 per cent. The result suggests that the parents were homozygous jor feshines.

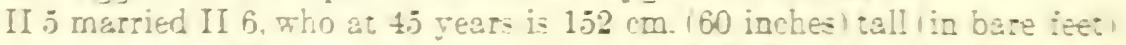
and weighs over $30 \mathrm{~kg}$. (200 pounds), build 3.9 150). Her net chest-girth is $110 \mathrm{~cm}$, relative chest-girth is 72 . This very teshy pair has 9 surtiving rhildren, as follow: the elde-t. III 3, a boy at 23 vears is said to be slender (not seen), married. without children. The second. III j. 3. 3i 22 yess is fleshy, as he has alkays been; married. without children. III $i, s, s:$ 19 years is slender but was feshy until the age oi 18 years. III s. $\mathbf{s}$. si 17 years is short and fleshy. III 9 , $\vec{z}$, at 12 years is shor and feshy. III 10. z, at 10 years is $136 \mathrm{~cm}$. (53.j inches) tall, and weighs about $4 j \mathrm{~kg} .1100$ pounds); build 2.5 ( 3.5 ). Her chest-girth is $8.5 \mathrm{~cm}$. net, relative chest-girth 63. This indicates a girl of far above average relative chest-girth, fleshy. III 12 is a girl of 9 years with a relative chest-girth of $\$ 0 \div 135$ or 59 . 
fleshy. III 13 is a boy of 5 years; his relative chest-girth is $68 \div 112$ or 61 , fleshy. III 14 is a 6 -months-old baby weighing $64 \mathrm{~kg}$. or 14.1 pounds and very chubby.

Comment.-Thus with the exception of the first fof whom no details were obtained), all of the children are. or have been, fleshy; the fraternity suggests that both parents are homozygous for fleshiness. "The meaning of the exceptional son is uncertain; various hypotheses may be entertained: illegitimary, poor health following a fleshy childhood, the possible pre:ence of a factor for slenderness in both parental ganetes (73:652).

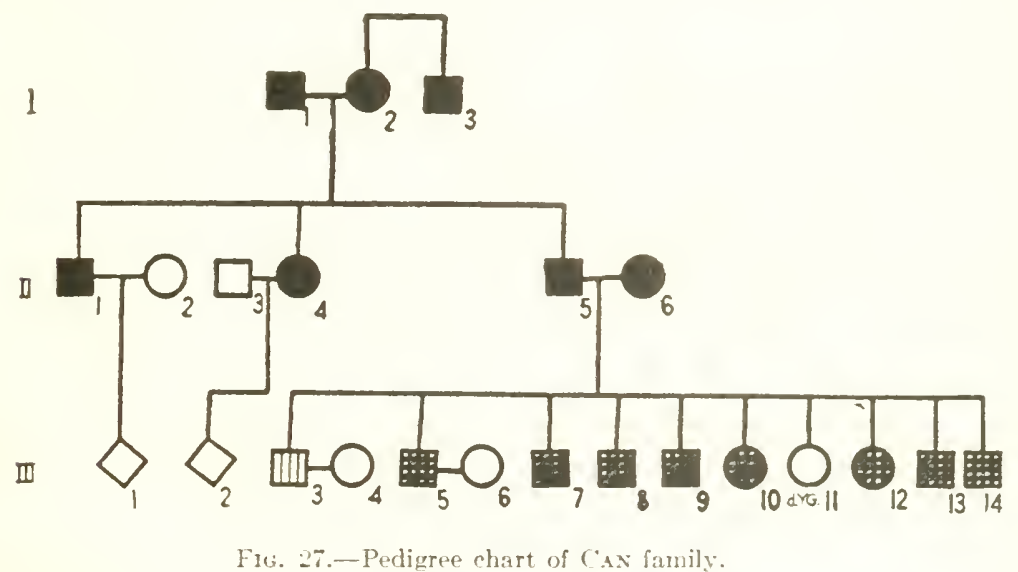

EkB-1 FAMlly.

A family of Swedish extraction; parents emigrated to Illinois, where all the children were born. The Father, a farmer, suffered in middle age from dropsy and severe headaches. He is living at 56 vears, haring the formula $225 / 67$ inches; build $3.5(501$. He has 6 sibs: 11 ) brother, dead, formula 250/70 inches; build 3.6 (51): (2) brother, 225/66 inches; build 3.6 (52); (3) sister, 180/63 inches; build 3.2 (45). Others are not described. Their father, a farmer, died at 79 rears from "gangrene subsequent to senile paralysis," having a formula 170/M inches; build, say 2.6 (36). Their mother died at 79 years from senile paralysis, haring the formula 200/ M inches; build, say $3.5(50)$.

The Mother, who in routh and middle age suffered from eczema, has at 51 rears the formula $160 / 65$ inches: build 2.7 1381. Two of her brothers and one sister are tall and nervous. Of the 6 children. 4 survive as adults:

1. Male, a university instructor, nervous, has at 30 vears the formula 190/70 inches; build 2.7 (39); adjusted to 55 years, 202/70 inches, build $2.9(41)$.

2. Male. a university instructor. who in vouth suffered from poliomyelitis, has at 28 the formula 200 , 68 inche: : build 3.01431 ; arlju-ted to 5.5 years, 212/68 inches, build $3.2(46)$.

3. Female, who suffered in vouth from headaches, has at 25 years the formula $180 / 64$ inches; build 3.1 (44); adjusted to 55 vears, 196 64 inches, build $3.3(48)$.

4. Male, a farmer, who in youth suffered from headaches, has at 22 vears the formula $180 / 68$ inches; build 2.7 (39); adjustert to 55 years, $197 / 68$ inches, build $3.0(43)$. 


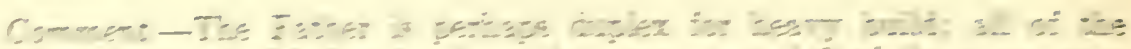

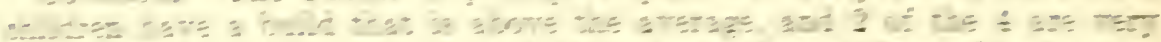

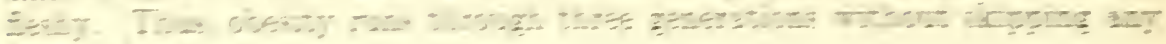
E: $=2-11$

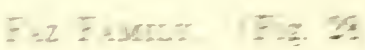

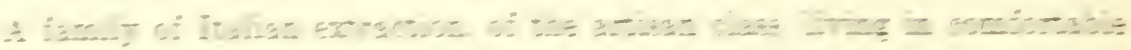
$\therefore=\frac{10}{2}$

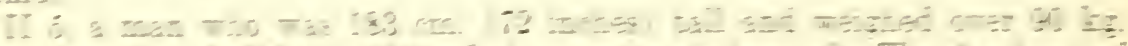

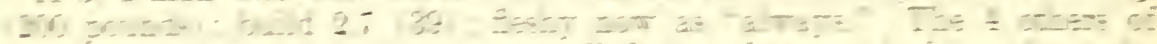
$\therefore$ 일

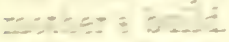

II 8 此

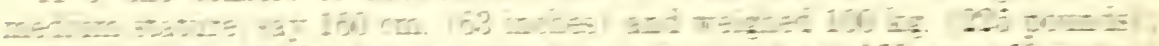

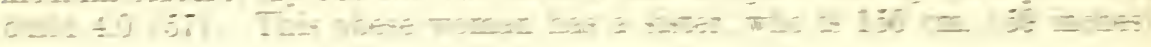

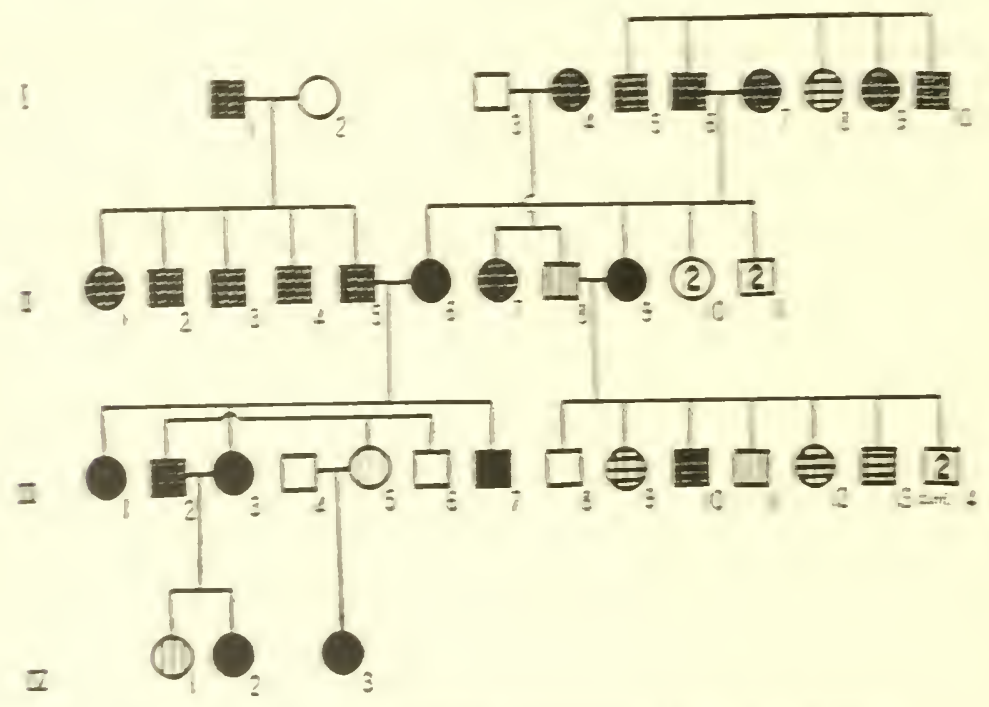

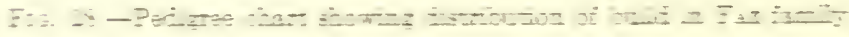

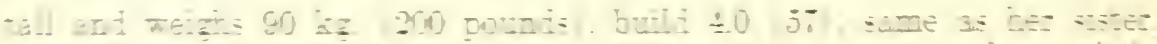

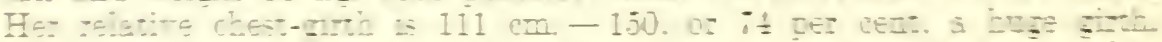

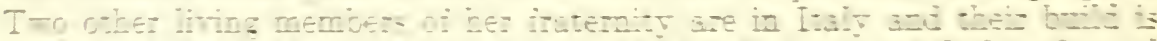

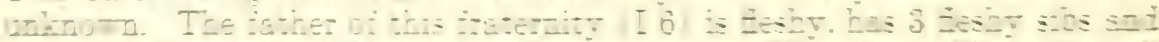

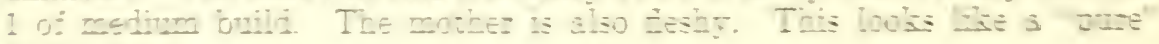
Esit Etreir.

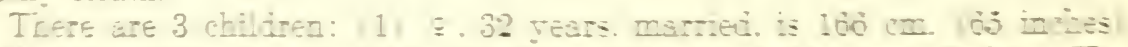

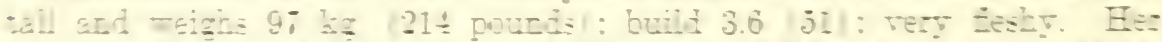

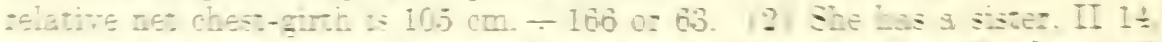

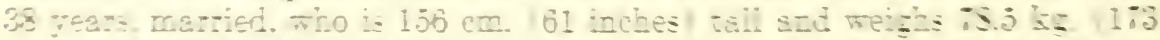

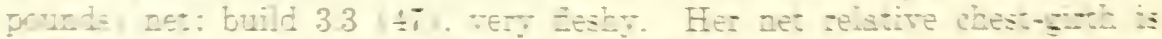

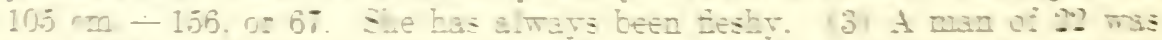

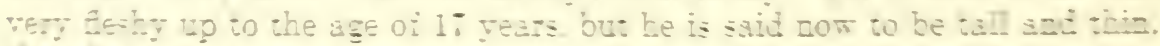
onuar nell He is no maried. 
Comment.-This result is difficult to interpret. A mating of two "pure" strains of obesity produces 3 offspring, all of whom were fleshy before adolescence and of whom 2 remain very fleshy; but 1 (at 22 years) is said to have become "thin" since the age of 17 years. It seems probable that he also should be recorded as essentially fleshy $(73: 665)$.

\section{Flo-3 Fanil.: (Fig. 29.)}

This is a family of which all grandparents and Father were born in north Ireland; the children were born and reared in Greater New York. The Father, a blacksmith and farmer, suffers from digestion troubles; at 63 his formula 185/65 inches; build 3.1 (44). His father, a blacksmith, died at 40 of acute indigestion; his formula 204/70 inches; build 2.9 (42). His mother, who died of pleurisy at 50 years, had the formula 200/69 inches; build $2.9(42)$. Thus this side of the house is of stout build.

The Mother has at 60 years the formula 200/64 inches; build 3.4 (49). She is fat, good-natured, and a poor housekeeper. Her father, who was a carpenter and killed by an accident at 47 years, had the formula $180 / 70$ inches; build 2.6 (37). Her mother, who died of old age at 75 years, had the formula 140/63 inches; build 2.5 (35). No "direct" heredity appears in the Mother's obesity. The 7 children:

1. Male, a bookkeeper, who has spinal curvature, has at 38 years the formula $140 / 60$ inches; build 2.7 (39); but this is clearly abnormally high, associated with his pathologically short stature.

2. Female, a musician, has at 36 years the formula $160 / 68$ inches; build 2.4 (35); adjusted to 50 years, $173 / 68$ inches; build 2.7 (37).

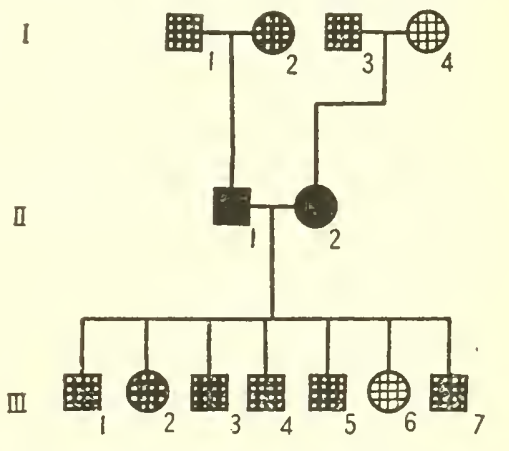

FIG. 29-Pedigree chart showing distribution of build the FLo-3 family.

3. Male, a detective, fond of outdoor life, has at 32 years the formula 190/69 inches; build 2.8 (40); adjusted to 50 years, 200/69 inches; build $3.0(42)$.

4. Male, an army officer, at 29 years $186 / 71$ inches; build 2.6 (37); adjusted to 50 years, $199 / 71$; build 2.8 (39).

5 . Male, a policeman, with a history of pneumonia, at 27 years, $200 / 72$ inches; build 2.7 (39); adjusted to 50 years, $215 / 72$ inches; build 2.9 (42).

6. Female, a teacher, subject to indigestion, at 21 years, $131 / 65$ inches; build 2.2 (31) ; adjusted to 50 years, $150 / 65$ inches; build 2.5 (36).

7. Male, in the automobile business, with a history of pneumonia, has at 20 years the formula $168 / 68$ inches; build 2.6 (36) ; adjusted to 50 years, $187 / 68$ inches; build 2.8 (40).

Comment.-The build of the children is rather uniformly between 2.5 (36) and 2.9 (42), mostly in the stout class, like the Father, but far below the obese Mother (R:Flo-3).

$$
\text { Gou-A Fanily. }
$$

A family of English extraction, living in Maine. The Father, at 36, had the formula $160 / 67$ inches; build 2.5 (37).

The Mother, at 60, had the formula $250 / 68$ inches; build 3.8 (54). Her eldest brother weighed 200 pounds at 60 years. Her youngest brother 
weighed 220 pounds at 50 years. Her father had the formula 190/72 inches; build $2.6(37)$, at 70 vears. Her mother had, at 70 years, the formula 225/66 inches; build 3.6 (50). Four grown children:

1. Female, at 48 , has the formula $210 / 66$ inches; build 3.4 (48).

2. Male, at $46,160 / 68$ inches; build 2.6 (35).

3. Male, at $44,180 / 67$ inches; build $2.8(40)$.

4. Female, at 40, 140/66 inches; build 2.3 (32).

Comment.-Obesity appears in three generations in the direct line without a break; 2 of the 4 children are of medium build, less than either parent (S: Gou-A).

\section{Lyx FaMILY. (Fig. 30.)}

I 1, $\hat{o}$, from Ireland, died at 54 of brain fever; was $173 \mathrm{~cm}$. (68 inches) tall and weighed $78 \mathrm{~kg}$. (175 pounds); build 2.7 (38); fleshy. His sister

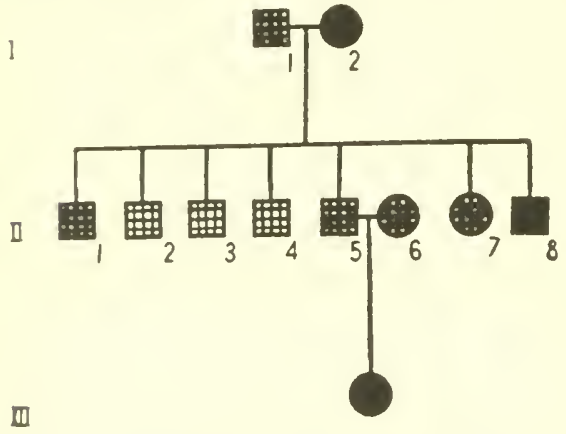

F1G. 30.- Pedigree ehart showing distribution of build in the Lry family. weighs $90 \mathrm{~kg}$. He married I 2, an Irish woman, who died at 68 years. She was $155 \mathrm{~cm}$. (61 inches) tall and weighed $84 \mathrm{~kg}$. (185 pounds); build 3.5 (50); very fleshy. She had a sister who was fleshy. The pair had 7 children who grew up:

(1) Male, fleshy; (2) ô, of medium build; 13$) \hat{\text {, }}$, died, at 50 years, of pneumonia, his stature $169 \mathrm{~cm}$. (66.5 inches); weight $63.5 \mathrm{~kg} . \quad(140$ pounds); build 2.2 (31) ; medium; (4) ô, died at 70 years, stature 173 cm. (68 inches); weight $72.5 \mathrm{~kg}$. (160 pounds); build 2.4 (35); medium. (5) $\hat{o}$, died, at 37 vears, of pneumonia; stature $173 \mathrm{~cm}$. (68 inches) ; weight $82 \mathrm{~kg}$. (180 pounds); build 2.7 (39) : fleshy. Married to a fleshy woman, he has a child who is $165 \mathrm{~cm}$. (65 inches) tall, weighs $72.5 \mathrm{~kg}$. (160 pounds); build 3.2 (46) ; very fleshy. (6) \&, at 56 years, stature $160 \mathrm{~cm}$. (63 inches), weight $63 \mathrm{~kg}$. (139 pounds); build 2.4 (34); medium. Her net relative chest-girth is $95 \div 160$, or 36 per cent. Though now of medium build (or less), she used to be very fleshy, weighing over $80 \mathrm{~kg} .1175$ pounds); build 3.1 (44). She may properly be classified as of stout build, secondarily reduced. (7) ô, aged 54 rears, is $178 \mathrm{~cm}$. (70 inches) tall; and weighs $103 \mathrm{~kg}$. (227 pounds; build 3.2 (46); very fleshy. His net relative chest-girth is $117 \mathrm{~cm} \div 178$, or 66 per rent. This man las always been fleshy; at 21 years he weighed $90 \mathrm{~kg}$. (200 pounds).

Comment.-This scems to be nearly a "pure" $\mathrm{F} \times \mathrm{F}$ mating. Of the progeny 4 are fleshy (or very fleshy) and 3 medium (73-684).

\section{MrI,-A FaMILY. (Fig. 31.)}

A family of Scotch extraction from Maine. The Father (II 9), at 77 years, had the formula $200 / 73$ inches; build 2.6 (38). Of his 8 sibs: (1) Brother, at 70 years, luad the formula $170 / 69$ inches; build 2.5 (36). (2) Brother, at 75 years, 200/74 inches; build 2.6 (37). (3) Brother, at 65 years, $210 / 73$ inches; build 2.8 (39). (4) Brother, at 78 years, 200/74 inches; build 2.6 (37). (5) Brother, at 71 years, $215 / 75$ inches; build 2.7 (38). (6) Sister, at 75 years, 170/65 inches; build 2.8 (40). (7) Sister, at 
65 years, $200 / 67$ inches; build 3.1 (45). (8) Sister, at 68 years, $190 / 66$ inches; build 3.1 (44). Their father, at 85 years, $200 / 72$ inches; build 2.7 (39). Their mother, at 80 years, 150/65 inches; build 2.5 (36).

The Mother (II 10), at 74 years, had the formula $190 / 66$ inches; build 3.1 (44). Of her 9 sibs: (1) Brother, at 80 years, $170 / 70$ inches; build 2.4 (35). (2) Brother, at 60 years, 200/77 inches; build 2.4 (34). (3) Brother, at 55 years, $180 / 72$ inches; build 2.4 (35). (4) Brother, at 70 years, $200 / 74$ inches; build 2.6 (37). (5) Brother, at 80 years, $200 / 73$ inches; build 2.6 (38). (6) Sister, at 60 years, 150/64 inches; build 2.6 (37). (7) Sister, at 65 years, $160 / 63$ inches; build 2.8 (40). (8) Sister, at 70 years, $175 / 64$ inches; build $3.0(43)$. (9) Sister, at 75 vears, $180 / 63$ inclies; build 3.2 (45). Their father, at 70 years, $175 / 72$ inches; build 2.4 (34). Their mother, at 86 years, 200/67 inches; build 3.1 (45). 12 children:

1. Female, at 47 years, has the formula 180,63 inclies; build 3.2 (45).

2. Male, at 22 years, $22 / 72$ inches; build 2.7 (39); adjusted to $55+$ years, 221/72 inches; build 3.1 (43).

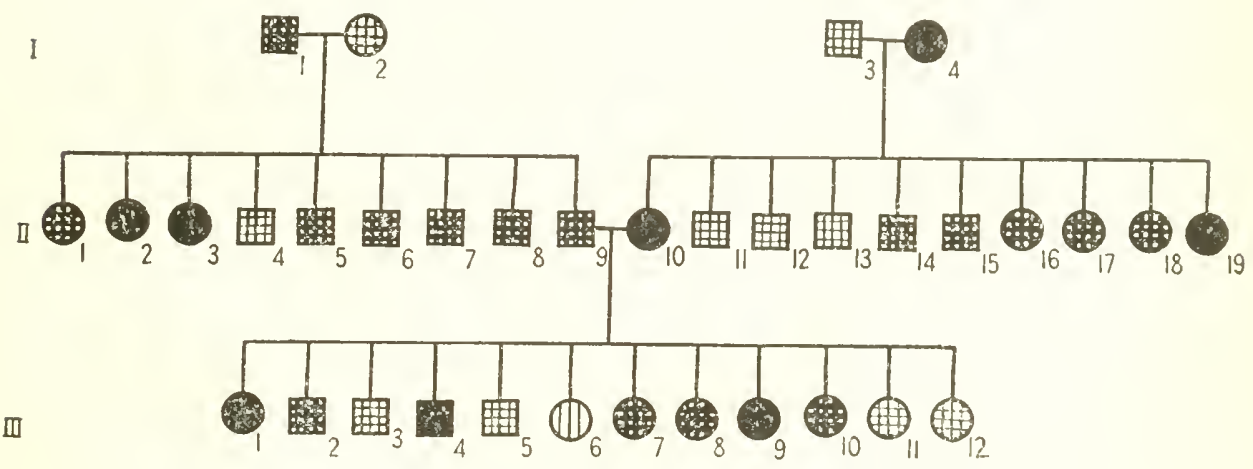

Fic. 31.--Pedigree chart showing distribution of build in the McL-A family.

3. Male, at 58 years, $180 / 72$ inches; build 2.4 (35).

4. Male, at 50 years, $230 / 71$ inches; build 3.2 (46).

5. Male, at 43 years, $160 / 72$ inches; build 2.3 (31) : adjusted to 55 years, $163 / 72$ inches; build 2.2 (32).

6. Female, at 70 years, $130 / 66$ inches; build 2.1 (30).

7. Female, at 38 years, $180 / 67$ inches; build 2.8 (40); adjusted to 55 years, $189 / 67$ inches; build 3.0 (42).

8. Female, at 65 years, $160 / 65$ inches; build 2.7 (38).

9. Fcmale, at 61 years, $180 / 63$ inches: build $3.2(45)$.

10. Female, at 54 years, $175 / 66$ inches; build 2.8 (40).

11. Female, at 52 years, $125 / 64$ inches; build 2.1 (31).

12. Female, at 50 years, $130 / 65$ inches; build 2.2 (31).

Comment.-Mother's mother, Mother, and 3 children out of 12 have a build of 3.1 to 3.2 (44 to 46 ), very fleshy; 3 children have a build of 2.1 (30 to 31 ), a lower index than any parent, uncle, aunt, or grandparent. Evidently fleshy stock may yield gametes with not more than 2 or even only 1 ganete for fleshy build. (see p. 43.) (s: McL-A.)

$$
\text { Nic-5 Family. }
$$

A family of English extraction; paternal grandparents born in Massachusetts and Kentucky; family living mostly in Ohio. The Father, a 
farmer, suffered in middle age from rheumatism and lupus. He is a distant cousin of his wife. He diect at 67 years, having at 60 years the formula $175 / 65$ inches; build 2.9 (41). His father, a farmer, died at 65 years from kidney trouble; was corpulent. His mother, who had 8 children, died at 70 years; was corpulent.

The Mother, who has 2 children, suffered in youth from pneumonia. She is living at 70 years, having the formula $165 / 60.5$ inches; build 3.2 (45). Her father, a farmer and surveyor, who died at 78 years, had a formula $175 / \mathrm{M}$, and build, say, 2.7 (38). Her mother had 7 children and died at 78 years, having the formula $160 / \mathrm{M}$; build, say, 28 (40). The 2 grown children:

1. Male, a farmer, who in youth suffered from lung fever, has at 41 years the formula $150 / 64$ inches; build 2.6 (37); adjusted to 55 years, $154 / 64$ inches; build 2.7 (38).

2. Female, married, has at 38 years the formula 190/61.3 inches; build 3.6 (51) ; adjusted to 55 years, 198/61.3 inches; build 3.7 (53).

Comment.-There are 3 generations of corpulent persons; in the last generation 1 is very Heshy and 1 fleshy (R: Nic-5).

\section{Whe Fanily. (Fig. 32.)}

I 1, o , fleshy; his wife, I 2, fleshy; 3 ehildren about whom something is known.

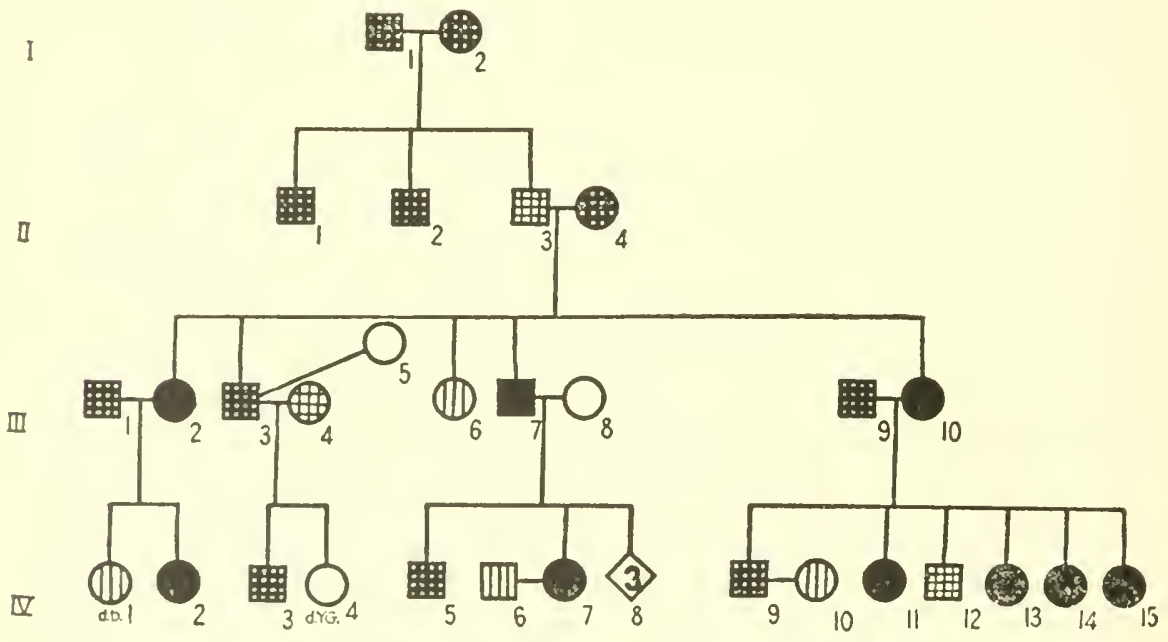

F1G. 32.-- Pedigree chart showing distribution of build in the Whe family.

II 1 , f , fleshy; married a fleshy woman and had 5 children, none of whom, it is said, are fleshy. II 2 , $\delta$, died at over 75 years; fleshy. II 3 , $\delta$, died at 80 years; was of medium weight. Thus, in this generation, 2 fleshy and 1 of medium build.

III 9 , o , at 61 years has a stature of $160 \mathrm{~cm}$. (63 inches) and weight of $73 \mathrm{~kg}$. (162 pounds); build 2.8 (40); fleshy. Nothing is known about the build of his relatives. His wife is III 10, age 64, stature $156 \mathrm{~cm}$. (61 inches); weight $88 \mathrm{~kg}$. (194 pounds); build 3.7 (52); very fleshy, relative chest-girth $112 \div 156$, or 72 per cent. When she married at 29 years she weighed 160 pounds and did not begin to grow flesty until 50 years. She 
had 4 sibs, about whose build something is known. (1) III 2 , 9 , died at 70 of uterine cancer; stature $156 \mathrm{~cm}$. (61 inches); weight over $90 \mathrm{~kg}$. (200 pounds); build over 3.8 (54) ; very fleshy. (2) III 3 , $\hat{\delta}$, dier at 73 years of "heart trouble"; stature $153 \mathrm{em}$. (64 inches) ; weight $77 \mathrm{~kg}$. (170 pounds); build 2.9 (42) ; fleshy. He married a woman of medium build and had a son who, at 45 years, has a stature of $163 \mathrm{~cm}$. (64 inches) and weight of $80 \mathrm{~kg}$. (175 pounds); build 3.0 (43) ; fleshy. (3) III 6, 오, always slender. (4) III 7 , $\hat{\delta}$, died at 60 of diabetes; he weighed over $90 \mathrm{~kg}$. (200 pounds), but became very thin of disease before his death. He had 2 fleshy children; 1 , indeed, quite obese.

The union of these two fleshy strains represented in III 9 and 10 has produced 6 children, as follows: (1) IV 9, of, died at 33, was "fleshy" and by a slender wife (whose mother was fleshy) has a fleshy little daughter." (2) IV 11, ㅇ, at 32 years, has stature $168 \mathrm{~cm}$. (66 inches) and weight $93 \mathrm{~kg}$. (206 pounds) ; build 3.3 (48) ; very fleshy. Relative chest-girth $119 \div 168$, or 73 per cent. (3) IV 12, ô, at 30 years, has stature $180 \mathrm{~cm}$. (71 inehes); weight $82 \mathrm{~kg}$. (180 pounds); build 2.5 (36); medium; fleshy and growing fleshier. (4) IV 13, o, at 28 years, stature $159 \mathrm{em}$. (62.5 inches), weight $79 \mathrm{~kg}$. (174 pounds); build 3.1 (44); very fleshy. Her relative ehest-girth $107 \div 159$ or 68 per cent. She was a slender child; at her marriage at 24 years she weighed 145 pounds and began to gain after the birth of her second child. Married to a man of build 35.4 or medium fleshy (who onee weighed 200 pounds) and with 3 stout brothers and 5 slender sisters; they have 2 children, a son of 4 years who has a relative chest-girth of 56 per cent and is of medium build, and a daughter who at 2 years has a relative chest-girth of 64 per cent, which is above the average for that age.* (5) IV 14, , at 26 years, stature $157 \mathrm{em}$. (62 inches); weight $86 \mathrm{~kg}$. (190 pounds) ; build 3.5 (49) ; very fleshy. Her relative chest-girth is $119 \div 157$, or 77 per cent. (6) IV 15, 오, at 23 years, stature $165 \mathrm{~cm}$. (65 inehes); weight $88 \mathrm{~kg}$. (194 pounds) ; build 3.2 (46) ; very fleshy.

Comment.-This union of a fleshy and a very fleshy person (the latter of a fleshy strain) produces 4 very fleshy and 2 fleshy progeny (including 1 medium near the fleshy line and growing fleshier). This approaches a "pure line" of fleshiness $(73: 754)$.

Mating 2. Вотн Parents Fleshy of Fleshy Stock. (Table 25, from Table XiII.)

From this mating, as shown in table 25, there are 15 offspring, $1 \mathrm{~S}, 5 \mathrm{M}, 8 \mathrm{~F}, 1 \mathrm{VF}$. In this case one-fifteenth of the offspring are TABLE 25.-Matings of two fleshy parents, both of fleshy stock, together with their progeny. [The indices of the build of the progeny have been adjusted.]

\begin{tabular}{|c|c|c|c|c|c|c|c|c|c|c|c|c|c|}
\hline & FF & FM & F & $\begin{array}{l}\text { Father's } \\
\text { sibs. }\end{array}$ & MF & MM & M & $\begin{array}{l}\text { Mother's } \\
\text { sibs. }\end{array}$ & Vs & $\mathrm{S}$ & M & F & VF \\
\hline Dol 3... & 36 & 38 & 40 & & 37 & 41 & 40 & & & & 5 & & \\
\hline Lan A. . & 37 & 37 & 37 & $37,36,29$ & 43 & 37 & 40 & 35 & & 1 & $\ldots$ & & 1 \\
\hline Sle $2 \ldots$ & 36 & 40 & 39 & $\ldots \ldots \ldots \ldots$ & 37 & 43 & 37 & & & $\ldots$ & $\ldots$ & 2 & $\ldots$ \\
\hline Thr $2 \ldots$ & 27 & 34 & 38 & FF3, F3, M3 & 38 & 38 & 40 & $\ldots \ldots \ldots$ & & $\ldots$ & $\ldots$ & 6 & $\ldots$ \\
\hline Total. & & & & & & & & & . & 1 & 5 & 8 & 1 \\
\hline
\end{tabular}

A, $37.57 \pm 0.82$ S. D. $4.70 \pm 0.52$.

* Not shown in figure : $: 2$. 
slender, which suggests a trihybrid ratio and that there are at least 3 pairs of factors present for fleshiness; and that, of these, 3 or 2 pairs are present in each parent (table 18). It may be that in the Dol-3, Sle-2, and Thi-2 families the parental gametes carry fewer genes for fleshiness. Details are given in the following histories.

\section{Dol-3 FamiLY.}

A family of German extraction living in Ohio. The Father, an inventor, suffered in youth from typhoid, has at 59 years the formula 180/67 inches; build 2.8 (40). His father, an inventor and machinist, died at 73 years from "old age," with the formula $165 / \mathrm{AI}$ inches; build, say, 2.5 (36). His mother, always well, died at 70 years from "general debility," with the formula 140/S inches; build, say, 2.7 (38).

The Mother, who underwent an operation for "fatty tumor," is living at 57 years, having the formula $175 / 66$ inches; build 2.8 (40). Three of her sisters died in infancy from convulsions. Her father, a bookkeeper, died at 98 years from a paralytic stroke, having the formula 160/66 inches; build 2.6 (37). Her mother's build was $180 / 66$, or 3.7 (41). The 5 children who grew up:

1. Female, who in youth suffered from diphtheria, has at 30 years the formula $118 / 64$ inches; build 2.0 (29) ; adjusted to 55 years, 131/64 inches; build $2.2(32)$.

2. Male, a machinist, who in youth suffered from diphtheria, has at 27 years the formula $160 / 73$ inches; build 2.1 (30); adjusted to 55 years, 176/73 inches; build 2.3 (33).

3. Male, a student, who in youth suffered from typhoid, has at 25 years the formula $150 / 68$ inches; build 2.2 (32) ; adjusted to 55 years, $164 / 68$ inches; build 2.5 (36).

4. Male, a man of science, always well, has at 23 years the formula $150 / 68$ inches; build 2.3 (32); adjusted to 55 years, 166/68 inches; build $2.5(36)$.

5. Female, a teacher, always well, has at 20 years the formula $120 / 64$ inches; build 2.1 (29); adjusted to 55 years, 139/64 inches; build 2.4 (34).

Comment.-Both stout parents come of stout or medium stock. Of the children, 3 are slender, 2 are medium. Adjusted, all are of medium build $(\mathrm{R}:$ Dol-3).

\section{LaN-A Fanily:}

A family from the State of Washington. The Father at 82 years had the formula 180/70 inches; build 2.6 (37). His 3 sibs are: (1) brother, at 50 years, $160 / 74$ inches; build $2.1(29) ;(2)$ brother, at 26 years, $190 / 73$ inches; build 2.5 (36); (3) sister, at 70 years, 180/70 inches; build 2.6 (37). Their father, at 90 years, had the formula $200 / 74$ inches; build 2.6 (37); their mother at 95 years, $160 / 66$ inches; build 2.6 (37).

The Mother at 52 years had the formula 170/65 inches; build 2.9 (40). Her one sister at 78 years, 145/64 inches; build 2.5 (35). Her father at 54 years, 200/68.5 inches; build 3.0 (43). Her mother at 82 years, 170/68 inches; build 2.6 (37). The two children:

1. Male, at 58 years, has the formula $240 / 68.5$ inches; build 3.6 (51).

2. Female, at 48 years, 120/64 inches; build 2.1 (29).

Comment.-Details concerning this family are lacking. From two stout parents, one of whom has a slender 2.1 (29) brother and the other a father 
of build 3.0 (43), arise two children with indices of 3.6 (51) and 2.1 (29) respectively (S : Lan-A).

$$
\text { Sle-2 Family. }
$$

A family of Irish extraction living in Michigan. The Father, a lawyer, is recorded to have suffered from no illnesses. He died at 52 years from "dipsomania," having the formula 200/72 inches; build 2.7 (39). His father, a shoemaker, is living, having partially lost his mind through excessive use of tobacco. He has at 83 years the formula 150/65 inches; build 2.5 (36). His mother died at 50 years from "cancer of the breast," having the formula $170 / 65$ inches; build 2.8 (40).

The Mother, who suffered in middle age from asthma, is living at 54 years, having the formula 170/68 inches; build 2.6 (37). Her father, a lumber dealer, suffered in middle age from typhoid fever and erysipelas, and died of old age at 84 years, having the formula 180/70 inches; build 2.6 (37). Her mother, who had "swelling and lameness of hands, due perhaps to gout," was killed at 78 years by a fall due to defective sight. Her formula was $180 / 65$ inches; build 3.0 (43). The 2 children:

1. Male, a teacher, has at 28 years the formula $175 / 71$ inches; build 2.4 (35) ; adjusted to 53 years, 189/71 inches; build 2.7 (37).

2. Female, a school teacher, who in youth suffered from diphtheria, has at 25 years the formula $160 / 65$ inches; build 2.7 (38); adjusted to 53 years, 177/65 inches; build $3.0(42)$.

Comment.-The two fleshy parents and fleshy grandparents have 2 children whose adjusted build is fleshy ( $\mathrm{R}$ : Sle-2).

\section{Thr-2 Fanily. (Fig. 33.)}

In this family the Father is the same as child No. 2 of family Thr-1 (p. 138). It lives in Iowa. The father (III 4), a physician, had at 25 years a weight of 180 pounds, height 69 inches; build 2.7 (38). At 70 years he weighs 188 pounds, height 68.7 inches; build 2.7 (39). His 5 brothers were of about medium build, "called sturdy, hearty boys"; they all became stout.

Their father, though of slender build (following lung disease) in middle life, "took on flesh" in later life; probably came to be of "fleshy" build. Their mother was of medium build.

The Mother (III 5) weighs around 170 pounds and is 65 inches tall; thus a build of 2.8 (40). Her parents (II 5-6) each had a build of 2.7 (38). The 6 children (IV 1-6) :

1. Male, weighed 10 pounds at birth; when in high school he weighed 160 pounds; at the university was a football player; at 36 he weighed 240 pounds, and at 41 he weighs about 200. His build is probably about $3.0(43)$.

2. Female, is "very large"; at 35 years she weighs about 180 pounds, stature 65.5 inches; build 3.0 (42).

3. Female, at 33 is of the same weight and stature as her sister; build $3.0(42)$.

4. Male, weighed at 23 years about 117 pounds; at 33 years up to 130 pounds; at 36 weighs about 190 pounds; stature 71 inclies; build 2.7 (38).

5. Female, at 26 has a weight of $17 j$ pounds, stature 66 inches; build $2.8(40)$.

6. Male, weighed while in the Navy at 23 years 175 pounds, stature 70 inches; build 2.5 (36); at 26 he weighs 165 pounds; build 2.7 (38). 
Comment.-In this family both parents are of fleshy build and all the children are, likewise, of fleshy build (R : Thr-2).

Mating 3. Other Very Fleshy $\times$ Very Fleshy Matiags. (Table XV.)

There are 7 instances of this type of mating. These are summarized in table $\mathrm{XV}$, Appendix. An examination of this table shows that in all families with 2 or more offspring one or more of them are obese. There is no case of slender offspring, though 12 out of 30 , or two-fifths, are of medium build and only 10, or one-third of all, are very fleshy. This indicates the presence of recessive factors in the very fleshy parents. It suggests further that there are two or more pairs of factors that must be present to produce very fleshy children. Assuming that there are two factors and that both parents are

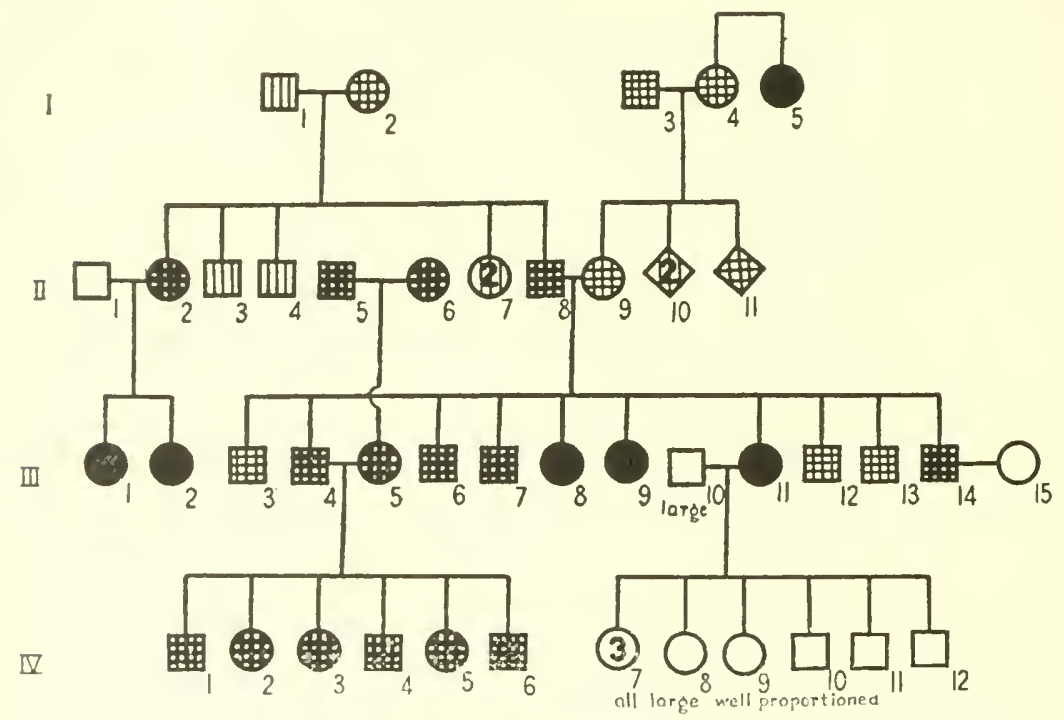

Fig. 33.-Pedigree chart showing distribution of build in the Tur-1, 2 families.

heterozygous for one of them, we should expect very fleshy, fleshy, and medium offspring in about the proportions of $25: 50: 25$, which distribution is not very close to the aetual proportions of $40: 27: 33$. On the assumption of 3 pairs of factors, we might expect $17: 32: 49$ respectively from a $4 \times 5$ factor mating. Or the $4 \times 4$ factor mating would give on one hypothesis $31(\mathrm{~S}+\mathrm{MI}): 38: 31$, which is closest of all. All of these very fleshy parents are heterozygous.

Table XV shows also that when all grandparents are known there is always one on each side who is at least of grade 36 .

The contrast between the families of table II and table XV is this: In table II, of the 20 grandparents 40 per cent are slender or very slender. In table $\mathrm{XV}$ of 20 grandparents only 30 per cent are fleshy, 
the others are of lower grades of huild. Aceordingly we are apparently justified in concluding that some of the rory fleshy parents were heterozygous in the factors for build: and, indeed, as stated, of the :30) children 12 are of medium build. Table II romtains slender strains: table XV largely heterozygous ones. The destailed history of these cases follows.

\section{Bow-B Fanily. (Fig. 34.)}

A Virginia family, probably of English stock. The Father has the formula $200 / 66.5$ inches; build 3.2 (45). His father had the formula $187 / 64.5$ inches; build 3.2 (45). His mother had the formula 165/66 inches; build 2.7 (38). Thus this side of the house has a fleshy or very fleshy build.

The Mother has the formula 220/68 inches; build 3.4 (48). Her 3 brothers, all 6 feet tall or more, each has a build of about 35. Her 2 tall sisters have builds of 38 and 50 respectively. Her father had the formula 190/73 inches; build 2.5 (36). Her mother had the formula $90 / 62$ inches; build 1.6 (23). Thus this side of the house, aside from the fleshy mother, has prevailingly medium build. The mother's mother wis even very slender. Six children:

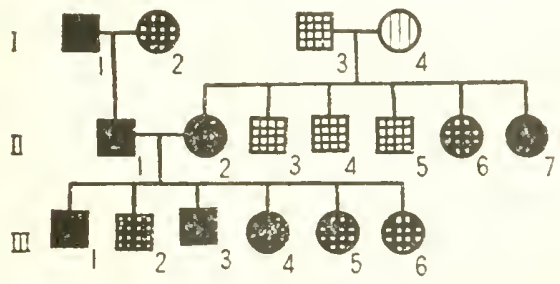

FIs. 34.- Pedigree chart showing distribution build in the Bow-B family.

1. Male, at 56 years, $222 / 66.5$ inches; build $3.5(50)$.

2. Male, $175 / 69$ inches; build $2.6(37)$.

3. Mitle, $240 / 73$ inches; build $3.2(45)$.

4. Fcmale, 200/65 inches; build 3.31471 .

5. Female, $187 / 68$ inches; build $2.8(40)$.

6. Female, $170 / 64$ inches; build $2.9(42)$.

Comment.-Thus of the children, half are fleshy and half very fleshy, and one exceeds any record of build in either side of the house. The Father acts like a homozygous dominant (S : Bow-B).

\section{Bow-2 Fanily. (Fig. 34a.)}

The grandparents and parents were born in Cornmall, England; the children, except the first, in Connecticut.

The Father, II 6, a contractor, who sufferel from hernia and flat foot. had, at 66 , the formula $200^{\prime} 67$ inches; build 3.2 (45). 'Two of his sibs died of consumption; other sibs are as follows: (1) sister, has the formula 225/66 inches; build 3.7 (52); (2) brother, has formula 22567.5 inches; build 3.4 (49); (3) brother, has formula 225/66 inches; build 3.7 (52); (4) sister, has formula $200 / 65$ inches; build $3.3(47)$ : (5) sister, has formula 190/66 inches; build 3.1 (44). Some of these suffer from varicose veins and one is bow-legged. Their father, who was a shocmaker, and asthmatic, died at 77 years of arterio-sclerotic hemorrhage of lungs. Formula 150/66 inches; build 2.4 (34). Their mother had varicose veins on the leg and died at 68 years of "stoppage of the bowels." Formula $250 / 66$ inches; build 4.0 (57). This is an extraordinary family of very fleshy people (cxcept the father's father. who had lung trouble), the obesity coming from the Timmins side, of Penryn, Cornwall. 
The Mother, II 7, who was much subject to sore throat, indigestion, and piles, died of dropsy and cancer of the liver, at 57 years. Formula 180/61.5 inches; build 3.4 (48). One of her sisters died of consumption; other sibs were as follows: (1) ot died of pneumonia; formula, 150/68 inches; build 2.3 (32); (2) ô, died at 47 years; formula, $150 / 65$ inches; build 2.5 (36); (3) 9 , has the formula $136 / 60$ inches; build 2.7 (38). The mother's father was a miner; had asthma and miner's disease, and died at 59 years of paralytic shock. Formula, 180/66 inches; build 2.9 (41). Her mother died at 69 years of pneumonia. Formula, 120/61 inches; build 2.3 (32). Except for the very fleshy-3.4 (48)-Mother, this sirle of the house is less fleshy than the other. Five grown children:

1. Male, who has had naso-pharyngeal infections, has at 43 years the formula $140 / 67.5$ inches; build 2.1 (30) ; adjusted to $55+$ years, $144 / 67.5$ inches; build 2.3 (32).

2. Female, who has suffered from naso-pharyngeal infections, diarrhea, and nervous exhaustion, has at 42 years the formula $112 / 61.5$ inches; build 2.1 (30); adjusted to $55+$ years, $117 / 61.5$ inches; build $2.2(31)$.

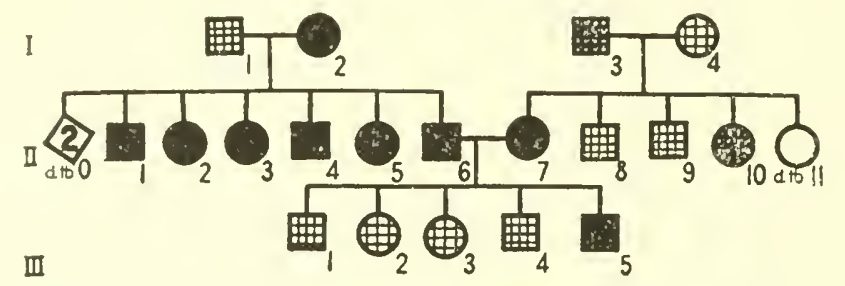

FIG. 34a.-Pedigree chart showing distribution of build in Bow-2 family.

3. Female, subject to indigestion, has at 40 years the formula $125 / 62.5$ inches; build 2.3 (32) ; adjusted to 55 years, 131/62.5 inches; build 2.4 (34).

4. Male, a bricklayer, subject to diarrhea, has at 35 years the formula $135 / 67$ inches; build 2.1 (30); adjusted to 55 years, $143 / 67$ inches; build $2.3(32)$.

5. Male, subject to biliousness and sleep-walling, has at 32 years the formula 185/66 inches; build 3.0 (43) ; adjusted to 55 years, 193/66 inches; build 3.1 (44).

Comment.-Thus 4 of the 5 children have a medium build; only 1 is very fleshy (S : Bow-2).

\section{BYR-A FAMILY.}

A family from South Carolina. The Father, at 60 years, had the formula 235 /72 inches; build 3.2 (45). Of his 3 sibs, (1) brother, 200/66 inches; build 3.2 (46); (2) brother, weighed 150 pounds; (3) sister, 165/66 inches; build 2.7 (38). Their father, at 73 years, had the formula $200 / 64$ inches; build 3.4 (49). Their mother, at 73 years, 175/64 inches; build 3.0 (43). All but one of the Father's brothers are very fleshy.

The Mother, at 73 years, had the formula 165/60 inches; build 3.2 (46). Her 6 sibs weighed from 130 to 165 pounds. Her father, at 84 years, had the formula 160/72 inches; build 2.2 (31). Except for the Mother, this side of the house is apparently of only medium build. Four children:

1. Male, at 54 years, has the formula $235 / 71$ inches; build 3.3 (47).

2. Male, at 50 years, $160 / 71$ inches; build 2.2 (32). 
3. Male, at 64 years, $165 / 71$ inches; build 2.3 (33).

4. Female, $150 / 62$ inches; build 2.7 (39).

Comment.-Thus 1 in 4 is very fleshy, 1 is fleshy, and 2 are medium (S: Byr-A).

\section{CAT -3 FAMILY}

A family of Italian origin; grandparents and parents all born in sieily. moved to Cleveland, Ohio, where the children were all born. The Father, a sailor till 24 years, then "in business," suffered in youth (16 years) from malaria, and at 20 years and again at 40 years from bronchitis; he is living at 63 years; formula $180 / 64$ inches; build 3.1 (44). His father, a sailor till 30 years, then a fish dealer, suffered in youth from colds and in middle age from bronchitis. He died, at 85 years, from stomach trouble. Formula. 180/68 inches; build 2.7 (39). His mother, who was "short and slim," died at child-birth at 23 years, having the formula $130 / 61$ inches; build 2.5 (35).

The Mother suffered in middle age from appendicitis and influenza. She is living at 56 years, having the formula 195/62 inches; build 3.6 (51). Her father, who operated an oil mill, was short and "stocky" and had high blood-pressure. He died, at 77 years, from "sudden shoek, caused by ehill," having the formula $160 / 62$ inches; build 3.0 (42). Her mother, who had 11 children, was a quick-tempered, heavy-set, broad-shouldered woman. She died at 77 years of pneumonia, having the formula 200/64 inches; build 3.4 (49). Six grown ehildren:

1. Male, a pharmacist, who in youth suffered from diphtheria, has, at 27 years, the formula $145 / 66$ inches; build 2.3 (33); adjusted to 55 - years, 156/66 inches; build 2.5 (36).

2. Female, who in youth suffered from diphtheria, has, at 26 years, the formula $150 / 66$ inches; build 2.4 (34) ; adjusted to 55 years, 168/66 inches; build 2.2 (39).

3. Male, a student, who in youth suffered from measles, chicken-pox, and colds, is fond of athleties and out-of-door life. At birth he weighed 10 pounds; at 14 years, 140 pounds. Began athletics and at 17 years reighed 180 pounds. At 23 years has the formula 190/67 inches; build 3.0 (42); adjusted to $55+$ years, $209 / 67$ inches; build 3.3 (47).

4. Female, a student, who at 22 years has the formula $120 / 62$ inches; build 2.2 (31); adjusted to 55 + years, $138 / 62$ inches; build 2.5 (36).

5. Male, a student, who in youth suffered from measles, diphtheria, and pneumonia. Died at 18 years in military service. from pneumonia. Formula. $140 / 67$ inches; build 2.2 (31); adjusted to 55 years, $165 / 70$ inches; build $2.4(34)$.

6. Male, a student, who in youth suffered from searlet fever, has at 18 years the formula $147 / 66$ inches; build 2.4 (34); adjusted to $55+$ years, $172 / 70$ inches; build 2.5 (35).

Comment.-The Mother's side of the house is decidedly the heavier. One son approached the maternal build; the other children are fir below either parent in build, even with the adjustment (which is probubly inalequate) $(\mathrm{R}: \mathrm{Car}-3)$.

$$
\text { DiI-A FAxhis. }
$$

A family from North Carolina. The Father, at 69 years, hat the formula 225/68 inches; build 3.4 (49). Of his 7 sibs. (1) brother, at 64 years, has the formula $160 / 69$ inches; build $2.4(34)$; (2) brother, at 35 years, $150 / 70$ 
inches; build 2.2 (31) ; 13 ) brother, at 45 years, $140 / 67.5$ inches; build 2.1 (30); (4) brother, at 40 years, $230 / 70$ inches; build $3.3(47)$; (5) brother, $180 / 72$ inches; build $2.4(35)$; $(6)$ sister, at 60 years, $166 / 66$ inches; build 2.7 (38); (7) sister, at 70 years, $140 / 70$ inches; build 2.0 (29). Their father, at 75 years, $220 / 68$ inches; build 3.3 (48). A rery fleshy Father of whose 7 sibs 1 is very fleshy, 1 fleshy, 4 medium, and 1 slender. The gametic constitution is apparently mixed.

The Mother, at 36 years, has the formula $225 / 65$ inches; build 3.7 (53). Her father, at 80 years, 330/72 inches; build 4.6 (64). Apparently this side of the house is exceptionally fleshy. Six children:

1. Male, at 64 years, $212 / 69$ inches; build 3.1 (45).

2. Male, at 66 years, $185 / 68$ inches; build 2.8 (40).

3. Male, at 59 years, $240 / 69$ inches; build 3.5 (50).

4. Male, at 54 years, $240 / 72$ inches; build 3.3 (46).

5. Female, at 61 years, $140 / 64$ inches; build 2.4 (34).

6. Female, at 54 years, $130 / 64$ inches; build 2.2 (32).

Comment.-Thus 3 out of 6 children are very fleshy, 1 is fleshy and the

2 daughters are medium (s: : Dal-A).

\section{Ded-A Family.}

A family of Irish extraction from North Carolina.

The Father, at 75 years, had the formula 200/64 inches; build 3.4 (49). His brother, at 70 years, $160 / 70$ inches; build 2.3 (33).

The Mother, at 86 years, had the formula $220 / 66$ inches; build 3.6 (51). Two grown children:

1. Male, at 60 years, $251 / 70$ inches; build 3.6 (51).

2. Male, at 70 years, $150 / 70$ inches; build 2.2 (31).

Comment.-The children of these parents, the family of one of whom at least is of mixed build, were one very fleshy and one medium (s : Dud-A).

\section{SMI-36 FAMILY.}

A family of English extraction. The grandparents, parents, and one child are all New Englanders.

The Father, a physician, in excellent health, has at 53 the formula $208 / 67.5$ inches; build 3.2 (46). His father, a physician also, died, at 82 years, from angina pectoris. He had pulmonary tuberculosis in youth. At 65 his formula was $160 / 67$ inches; build 2.5 (36). The father's mother had three sons and two daughters. She died of tuberculosis, at 35 years of age. Her formula at 30 was $140 / 64$ inches; build 2.4 (34). This side of the house shows heavy build of mixed origin.

The Mother in middle age had cerebral embolus. At 51 her formula is 176/63.5 inches; build 3.1 (44). Her father, a farmer, had erysipelas in middle age. He died, at 64 , from typhoid fever. At 60 he had the formula $225 / 70$ inches; build 3.2 (46). Her mother, having had 3 sons and 4 daughters, died at 78 from dysentery. At 65 her formula was 160/63 inches; build 2.8 (40). This side of the bouse is very fleshy to fleshy. One child:

1. Male, a medical student. He has, at 22 , the formula $165 / 74$ inches; build 2.1 (30); adjusted to 52 years, 190/74 inches, build 2.5 (34).

Comment.-Thus the child is slenderer than either parent and like his tubercular father's mother ( $\mathrm{R}: \mathrm{Smi}-36)$. 


\section{SUMMARY.}

The progeny of the three matings may now be compared (table 26). While even very fleshy parents are sometimes heterozygous (perhaps carrying 5 or rarely even 4 zygotic factors for build), yet they do not produce any slender children. The merely "fleshy" parents, on the other hand, produce about 7 per cent slender. None would be expected on the 4-zygotic-factor hypothesis, but about 6 per cent would be on the 6 -factor hypothesis.

TABLE 26.- Summary of selected fleshy matings, together with their progeny.

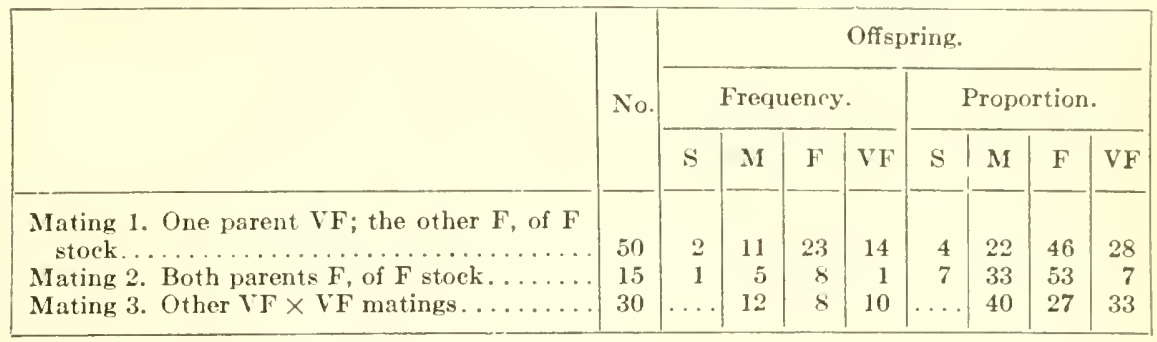

A comparison of tables 23 and 26 shows a profound difference in the distribution of build in the two sets of progenies. From the matings of slender parents come predominantly ( 84 per cent) slender and very slender offspring; from the mating of two fleshy or very fleshy parents come predominantly (67 per cent) fleshy and very fleshy offspring. The ranges of the offspring classes overlap somewhat, for the slender matings produce 16 per cent progeny who are above slender build; and the fleshy matings produce 32 per cent of progeny who are below fleshy build. The progeny of the slender matings are much less variable than those of fleshy matings. Thus, the standard deviation of the offspring in table 23 is only $3.13 \pm 0.17$; while the standard deviation of the offspring of the fleshy parents listed in table 24 is $5.74 \pm 0.39$ and in table $254.70 \pm 0.52$. From the standpoint of genetics this indicates the presence of more genetical factors in the fleshy parents than in the slender.

However, there is one consideration that must not be overlooked. This is that the mean index of build of the slender offspring is lower than that of the fleshy ones. If we place the average index of the very slender and slender groups at 26 , and of the pure fleshy at 40 , then the coefficient of variability of the slender and very slender is $3.13 \div 26$, or 12 per cent, and that of the fleshy of table 24 is $4.70 \div$ 40 , or 14 per cent. Thus the fleshy offspring are not only absolutely but also relatively more variable than the slender offspring.

Perhaps a fairer comparison is obtained from the data of table 12. The standard deviation of the progeny of the $\mathrm{S} \times \mathrm{S}$ matings is 241 ; of the $\mathrm{F} \times \mathrm{F}$ matings is 5.37. The corresponding coefficients of 
variability are $2.41 \div 28.47$ and $5.35 \div 37.56$, or 8.46 per cent and 14.25 per cent respectively. That is, the coefficient of variability of build of the offspring of the $\mathrm{F} \times \mathrm{F}$ mating is 68 per eent greater than that of the $\mathrm{S} \times \mathrm{S}$ mating. The ranges of the logarithms of the indices of the $\mathrm{S}$ and the $\mathrm{F}$ groups is as near as possible the same, and the arithmetic range of the $\mathrm{F}$ is only 40 per cent greater than of the $\mathrm{S}$ group. Hence the greater variability of the offspring of the $\mathrm{F} \times \mathrm{F}$ as compared with the $S \times S$ matings ean not be accounted for on a difference in the range of index values of the $S$ and $F$ classes. The most reasonable conclusion seems to be that the gametes of the fleshy parents are somewhat more variable than the gametes of the slender and the very slender parents.

Class III. Matixg of Slender with Fleshy Stock-The $F_{1}$ Generation.

After having considered the inheritance of build in the progeny of slender and of fleshy stoek respectively, we have next to consider the distribution of build in hybrids between such stocks. This class of matings produces the familiar $\mathrm{F}_{1}$ generation. Incidentally it may be pointed out that where multiple factors are concerned the $F_{1}$ generation has not that uniformity that it has when only one factor is concerned. This is partly because there are several kinds of $F_{1}$ offspring. For example, the progeny of very fleshy $x$ slender, fleshy $\times$ very slender, fleshy $X$ slender, and even subdivisions of some of these categories. If we analyze the progeny of all these matings together, a considerable range of variation in the $F_{1}$ generation is to be expected. If we deal with each type of mating separately, the numbers are insufficient to be significant. Compromises of various sorts will be necessary between too small numbers of offspring, on the one hand, and too heterogeneous parents on the other. Further complications arise from the fact that on the hypothesis that fleshy persons carry factors that dominate over slender, it is to be expected that the children shall be, on the average, of above medium build; and, again, from the fact that the children are younger than the parents and, for the most part, do not as yet show their full adult build. This is a matter of especial importance in this mating, since heterozygous individuals are slow in developing their potential build. Three kinds of matings will be considered.

Mating 1. One Parext Stexder, of Slender Stock, and the Other Fleshy, of Fleshy Srock. (Table VIII in Part.)

If mainly those fleshy parents are selected whose parents and sibs (so far as known) are fleshy, then the progeny will correspond as nearly as possible to a Mendelian $\mathrm{F}_{1}$ generation, and should be charactcrized by relatively low variability. Such selected matings are given in table 27, extracted from table VIII, Appendix. 
TABLE 27.- Matings of a slender parent of slender stock and a feshy parent of fleshy stock, together with their progeny.

\begin{tabular}{|c|c|c|c|c|c|c|c|c|c|c|c|c|}
\hline & \multirow{2}{*}{$\mathrm{FF}^{\mathrm{F}}$} & \multirow{2}{*}{ FM } & \multirow{2}{*}{$\mathrm{F}$} & \multirow{2}{*}{$\begin{array}{l}\text { Father's } \\
\text { siles. }\end{array}$} & \multirow{2}{*}{$M \mathrm{~F}$} & \multirow{2}{*}{$M M$} & \multirow{2}{*}{$M$} & \multirow{2}{*}{$\begin{array}{l}\text { Mother's } \\
\text { sibs. }\end{array}$} & \multicolumn{4}{|c|}{ Offspring. } \\
\hline & & & & & & & & & S & 11 & $\mathrm{~F}$ & $\mathrm{VF}$ \\
\hline Ale 2... & 33 & 28 & 27 & 3 tall ........ & 36 & 42 & 34 & $\ddot{t} \mathbf{t} \ldots \ldots$ & - & 2 & 1 & \\
\hline Coo $6 \ldots$ & $3 s$ & 38 & 39 & $\ldots \ldots \ldots \ldots$ & 33 & 29 & 28 & Short... & & 1 & 2 & \\
\hline Cla 32. & 29 & 29 & 29 & & 31 & 42 & 38 & $\ldots \ldots \ldots$ & $\ldots$ & 1 & 1 & \\
\hline Dol 2. & 30 & S & 26 & $\ldots \ldots \ldots \ldots$ & $\mathrm{F}$ & $F$ & 42 & & & 4 & 1 & \\
\hline Dud $1 .$. & 48 & 61 & 43 & $\begin{array}{l}10 \mathrm{~F} \text { and } \mathrm{VF} \text {; } \\
\mathrm{l}(\mathrm{t}(\mathrm{t}) \text {. }\end{array}$ & 31 & 28 & 28 & $\begin{array}{l}3 \text { of } 12, \mathrm{~F} \text { or } \\
\mathrm{VF} .\end{array}$ & 2 & $\ldots$ & . & $\cdots$ \\
\hline Elk $1 \ldots$ & 36 & 44 & 41 & $\ldots \ldots \ldots \ldots$ & 30 & 32 & 27 & & 1 & 3 & . & \\
\hline Faz.... & $\ldots$ & $\mathrm{F}$ & s & $1 \mathrm{~F} \ldots \ldots$ & $\mathrm{F}$ & F & 57 & $1 \mathrm{Vl} \ldots \ldots$ & $\ldots$ & 1 & 1 & \\
\hline Leo..... & $\cdots$ & & F & $1 \mathrm{~F} \ldots \ldots$ & s & $s$ & $S$ & $4 s \ldots \ldots$ & $\ldots$ & $\ldots$ & 3 & \\
\hline Lyn . . . & $\ldots$ & $F$ & F & $2 \mathrm{~F} \ldots \ldots \ldots$ & $\ldots$ & $\ldots$ & s' & $\ldots \ldots \ldots \ldots$ & $\ldots$ & $\ldots$ & 6 & $\cdots$ \\
\hline Ofi a... & & $\ldots$ & S & & . & $\ldots$ & $\mathrm{VF}$ & & $\ldots$ & 1 & 6 & 1 \\
\hline Ofi b... & $\ldots$ & $\ldots$ & S & $1 \mathrm{M} 3 \mathrm{~F} \ldots$ & . & $\ldots$ & $F$ & $7 \mathrm{~F} \ldots \ldots$ & $\ldots$ & 2 & 4 & 2 \\
\hline Ofi $c . .$. & $\ldots$ & $\ldots$ & $S$ & $\ldots \ldots \ldots \ldots \ldots$ & $\ldots$ & $\ldots$ & $\mathrm{VF}$ & $\ldots \ldots \ldots$ & $\ldots$ & 1 & 6 & 1 \\
\hline Smi ... & & $\ldots$. & 45 & & $\ldots$ & $\ldots$ & 30 & $\ldots \ldots \ldots$ & 1 & 1 & 3 & 3 \\
\hline $\mathrm{Wal}+\ldots$ & 38 & 34 & 41 & & 31 & 24 & 27 & $\ldots \ldots \ldots$ & $\ldots$ & 1 & 1 & $\cdots$ \\
\hline Total... & & & . & & $\cdots$ & $\cdots$ & 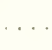 & 6.1 & $\begin{array}{l}4 \\
0\end{array}$ & Is & 35 & 7 \\
\hline Percent & & & . & & . & $\cdots$ & & 100 & 6.2 & $2 x .1$ & 54,6 & 11.1 \\
\hline
\end{tabular}
A, $38.24 \pm 0.43$.
S. D., $5.02 \pm 0.30$.

In table 27, of 64 offspring the proportions are $6,5,28 \mathrm{MI}, 5.5 \mathrm{~F}$, $11 \mathrm{VF}$. On the assumption of 6 zygotic factors, and that the matings are of 5 -factor and 2 -factor parents, and that they were equally of the two types of matings of this class, then we should expect the following proportions; $S \mathrm{~S}, 42 \mathrm{M}, 42 \mathrm{~F}, 8 \mathrm{VF}$. That this does not more closely approximate the observed proportions is probably due to the partial dominance of $\mathrm{F}$ over $\mathrm{S}$. At any rate, it is a closer fit than would be given on the 4-factor hypothesis. The details of each family included in this mating are given below.

\section{Ale-2 Family.}

A family of English extraction; grandparents and parents living mostly in Pennsylvania, Ohio, and West Virginia. Two of the ehildren were born in West Virginia, the other two in Ohio. The Father. a minister, has at 55 years the formula $135 / 70.8$ inches; build $1.9(27)$. His 3 brothers are tall. Their father, who was a minister, always well, died at 81 years from "diseases incident to old age," at 70 years having the formula M VT: "build, say, 2.3 (33). Their mother, who had 6 children, in youth was "delicate." She died at 85 years from old age, having the formula S/T; build, say, 2.0 (28). Thus this side of the house is prevailingly of slender build.

The Mother, who had 4 children, suffered in middle age from erysipelas and gallstones. She is living at 54 years, having at 50 years the formula $145 / 62$ inches; build $2.7(38)$. One of her brothers died at 18 years from tuberculosis, height 70 inches; another brother became feeble-minded after an attack of spinal meningitis, height 62.5 inches; one sister also died from

* M, medium weight; VT, very tall. 
tuberculosis at 48 years. Their father, who was a miller, suffered in youth from typhoid fever and in middle age from neuralgia and acute indigestion, and was killed in an accident at 77 years. At 60 years his formula was $165 / \mathrm{M}$; build, say, 2.5 (36). Their mother, who had 9 children, was alwavs well. She died at 78 years from angina pectoris. At 50 years her formula was $165 / \mathrm{MI}$; build, say, 3.0 (42). Thus this side of the house is prevailingly of fleshy build, despite some tuberculosis. The 3 grown children:

1. Male, a minister, always well, has at 30 years the formula $165 / 67$ inches; build 2.6 (37) ; adjusted to 52 years, $174 / 67$ inches; build $2.7(39)$.

2. Female, a school teacher, always well, has at 28 years the formula $108 / 62.5$ inches; build 2.0 (28); adjusted to 52 years, $123 / 62.5$ inches; build $2.2(31)$.

3. Male, a student, always well, has at 23 years the formula $140 / 66.5$ inches; build 2.3 ( 32 ) ; adjusted to 52 years, $154 / 67$ inches; build 2.4 (34).

Comment.-The build of the children ranges from 2.0 or 2.2 (28 or 31 ) to 2.6 or 2.7 (37 or 39 ), almost exactly the difference between the parents. but the build is slightly higher on the average than theirs. One should probably be classified as slender, one as medium, and one as fleshy. There is a slight evidence of dominance of fleshiness ( $R$ : Ale-2).

Coo-6 Family.

A family of mixed Nordic stock, chiefly English, living in the Central States. The Father, a farmer, who has always been well, is a man of great bodily energy and calm temperament. Formula at 40 years 180/68 inches; build 2.7 (39). His father, a farmer, who was killed in the Civil War, had at 40 years the formula $180 / 69$ inches; build 2.7 (38). His mother, who was always well and energetic, had at 40 years the formula $160 / 65$ inches: build 2.7 (38). Thus this side of the house is uniformly fleshy.

The Mother, who had a throat infection, had the formula $110 / 63$ inches; build 1.9 (28). Her sibs were mostly short and two of them suffered from asthma. Their father, a farmer. who had a throat infection and died at $\mathbf{5 5}$ of smallpox, had the formula $150 / 67.5$ inehes; build 2.3 (33). Their mother, who also died at 55 of smallpox, had the formula $125 / 66$ inches; build 2.0 (29). Thus the maternal side of the house has a distinctly slenderer build than the paternal. The 3 children:

1. Male, who died in early infancy of brain fever.

2. Male, 30 years old, a traveling salesman and soldier, with a eatarrhal nasal infection, had the formula at 20 years $160 / 67.5$ inches; build 2.5 (35) ; adjusted to 50 years, $178 / 69.4$ inches; build 2.7 (37).

3. Female, 25 years old, a music teacher, with a catarrhal nasal infection, has at 20 years the formula $120 / 62$ inches; build 2.2 (31) ; adjusted to 50 years, 139/62 inches; build 2.6 (36).

4. Male, 21 years old, a farmer, from whom a skin tumor and tonsils have been removed, has at 20 years the formula $150 / 65.5$ inches; build 2.4 (35) ; adjusted to 50 years, 166/67 inches; build 2.6 (37).

Comment.-A mating of fleshy with slender build has produced only medium-fleshy offspring ( $\mathrm{R}: \mathrm{Coo}-6)$.

\section{Cla-32 Family.}

A family of English extraction living in Vermont. The Father, who is a farmer, suffered in youth from catarrh and influenza. He is living at $\mathbf{5 7}$ years, having the formula $150 / 72$ inches; build 2.0 (29). His father, who is a farmer, always well, has at 84 years the formula $150 / 72$ inches; build 29 . 
His mother, who had 2 ehildren, always well, has at 80 years the formula 120/64 inches; build 2.1 (29). This family is prevailingly slender.

The Mother, who has 2 children, always well, has at 52 years the formula $157 / 64$ inches; build 2.7 (38). Her father, who was a farmer, suffered in middle age from weak heart, sciatica, and rheumatism. He died, at 67 years, from "blood-clot on brain," having the formula 160/72 inches; build 2.2 (31). Her mother, who had 1 child, was always well till, at 68 years. she died of eancer of liver; formula 160/62 inches; build 2.9 (42). Of the 2 ehildren:

1. Female, married, always well, has at 30 years the formula $145 / 66$ inches; build 2.3 (33) ; adjusted to 55 years, $160 / 66$ inches; build 2.6 (37).

2. Male, a farmer, always well, has, at 24 years, the formula $150 / 72$ inches; build 2.0 (29); adjusted to 55 years, 169/72 inches; build 2.3 (33).

Comment.-The daughter will probably become fleshy like her Mother; the son will probably remain slender like his Father (R: Cla-32).

\section{Dob-2 Family.}

A family of Seoteh-Irish and German extraction, living in the middle western States. The Father, a real-estate agent, who in youth suffered from diphtheria, has at 65 years the formula $120 / 67.5$ inehes; build 1.9 (26). His father, a farmer, always well, dicd at 89 vears of old age, with the formula 145/70 inches; build 2.1 (30). His mother died at 29 years of tubereulosis; she was slender.

The Mother, who in youth suffered from whooping-cough and scarlet fever, has at 65 years the formula 170/64 inches; build 2.9 (42)-fleshy. Her father, a German farmer, died of old age at 81 years; he was corpulent. Her mother died at 81 years of "heart leakage"; she was corpulent. The 5 children:

1. Male, a school teacher, always well, has at 34 years the formula $130 / 66.5$ inches; build 2.1 (29) ; adjusted to 55 years, $138 / 66.5$ inches; build $2.3(31)$.

2. Female, a music and art teacher, who in youth suffered from catarrial fever, has at 32 years the formula 135/61 inches; build 2.6 (36) ; adjusted to 55 years, $147 / 61$ inches; build 2.7 (39).

3. Male, electrical engineer, always well, has at 29 years the formula $140 /$ 67 inches; build $2.2(31)$; adjusted to 55 years, $150 / 67$ inches; build $2.3(33)$.

4. Male, student, had pneumonia, has at 26 years the formula $150 / 67$ inches; build 2.3 (33); adjusted to 55 years, $162 / 67$ inches; build 2.5 (36).

5. Male, a student, who has had malaria, has at 24 years the formula $130 / 67$ inches; build 2.0 (29) ; adjusted to 55 years, $144 / 67$ inches; build $2.3(32)$.

Comment.-A man of a family of a prevailing slender build, whose mother died of tuberculosis, married a fleshy woman of two fleshy parents. Of the 5 children, 1 and perhaps 2 will become fleshy; 1 is of medium build, and 2 will probably remain slender like the Father. Since all children are fleshier than the slender Father, and since members of the family tend to grow fleshy as they grow older, it seems probable (barring disease) that child No. 2 will gain the build of her stout Mother and that the others will become of at least medium build ( $\mathrm{R}$ : Dob-2).

$$
\text { Ded-1 Family. }
$$

A family of Scotch stock residing principally in Ohio and Iowa. The Father, a farmer until his retirement at 50 years, who died at 56 of diabetes, had at 40 years the formula $215 / 71$ inches; build 3.0 (43). Of his 6 sisters, 4 were stout to very stout and 1 was slender and died of tuberculosis. Of 
his 2 brothers, one was 72 inches tall and died of kirlncy trouble; the other was 67 inches tall. The Father's father, also a farmer all his life and very strong, died at 60 years of apoplexy, having the formula $250 / 64$ inehes; build 4.3 (61). This side of the house brings into the combination a tendency to extreme fleshiness.

The Mother, who was operated on for eancer, at 40 years had the formula $115 / 64$ inches; build 2.0 (28). She had 12 sibs, of whom 3 were fleshy or very fleshy. Her father, a carpenter, who died of Briglit's disease at 70, had the formula $160 / 72$ inches; build 2.2 (31). Her mother, who died at 50 years of tuberculosis, had at 40 years of age the formula $120 / 65$ inches; build $2.0(28)$. This side of the house is prevailingly slender. The 2 elildren:

1. Male, a college student and subject to migraine, has at 25 years the formula 158/70 inches; build 2.3 (32) ; adjusted to 40 years, 169/70 inches; build $2.4(35)$.

2. Female, a school girl, operated on at 16 for appendicitis, has at 25 years the formula 120/64 inches; build 2.1 (29); adjusted to 40 years, $135 / 64$ inches; build 2.3 (33).

Comment.-This mating of parents of stout and of slender stock results in children who are still young and of only medium to slender build. It is to be expected that the young man, at least, will become stout, approaching his father's build ( $\mathrm{R}$ : Dud-1).

\section{ELK-1 Fanily.}

A family of English extraction living in Massachusetts and New Hampshire. The Father, a "superintendent," suffered in youth from pneumonia. He is living at 47 years, having the formula 200/70 inches; build 2.9 (41). One of his brothers died, at 43 years, from consumption of the stomach "due to accident"; his formula, 175/70 inches; build 2.5 (36). Their mother is living at 73 years, having the formula 160/60 inches; build 3.1 (44). This side of the house is prevailingly fleshy.

The Mother, who suffered in middle age from bronchial trouble, has at 49 years the formula 98/60.3 inches; build 2.0 (27). Her father, a farmer, is living at 76 years with the formula $135 / 67.3$ inches; build 2.1 (30). Her mother, who suffered in middle age from bronchitis, pneumonia, and heart trouble, is living at 68 years with the formula 124/62 inches; build 32 . This is a prevailingly slender family. The 4 children:

1. Female, a student, has at 23 years the formula $120 / 64.5$ inches; build 2.0 (29) ; adjusted to 48 years, $137 / 64.5$ inches; build 2.2 (33) .

2. Female, a student, has at 21 years the formula 108/64.5 inches; build 1.8 (26) ; adjusted to 48 years, $126 / 64.5$ inches; build 2.1 (30) .

3. Female, a student, has at 18 years the formula $107 / 61$ inches; build 2.0 (29) ; adjusted to 48 years, $125 / 61$ inches; build 2.4 (34).

4. Female, a student, twin to No. 3 , has at 18 years the formula $107 / 61.6$ inches; build 1.9 (28) ; adjusted to 48 years, 127/61.6 inches; build 2.3 (33).

Comment.-The ehildren are all fairly young and have the youthful slender and medium build. Even on adjustment they do not rise above the medium class. Unfortunately, we do not know how this family derelops its index of build ( $\mathrm{R}: \mathrm{Elk}-1)$.

\section{FAZ FaMilu. (Fig. 28.)}

II 8 , $\hat{o}$, is slender; he has a fleshy sister and their mother is fleshy.

His wife is II 9, who, at 46 years, has stature $151 \mathrm{~cm}$. (59 inches) and weight $90 \mathrm{~kg}$. (200 pounds); build 4.0 (57); very fleshy. Her relative chest-girth, is $111 \div 151$, or 74 per cent. Her sister, II 6 , who died at 66 
of cerebral hemorrhage, had the formula $225 / 63$ inches; build 4.0 (57); very fleshy. Both of their parents were fleshy.

The children of II 8, 9 who grew up are: (1) III 9, $\%$, at 19 of medium weight. (2) III 10, of, at 18 years fleshy. Two others are too young to include in the statisties.

Comment.-Medium and fleshy progeny recur, suggesting that the fleshy parent is not entirely homozygous $(73: 665)$.

\section{Leo Family. (Fig. 23.)}

II 2 o, 72 inches tall and fleshy, has a tall and fleshy sister. His wife, II $3, \&$, is of medium stature and slender. She has 4 sibs, all slender; their parents also slender. Three children, all fleshy.

Again, II 7, the slender brother of II 3, married an obese woman, and has 1 child who, at 9 years, is 20 per cent over weight. ciee also page 61 ( $\mathrm{S} \times \mathrm{S}$ mating). $(73: 676$.

\section{LyN FaniLY.}

D. O., of, weighs over $90 \mathrm{~kg}$. (200 pounds), fleshy, has 2 fleshy sibs and fleshy mother. He married a slender woman, who grew fleshier in middle life. They had 6 children, all fleshy. D. O. is a second cousin of figure 30 , II 1 (p. 74). The fleshy parent was apparently a homozygous dominant (73:684).

\section{Ofi Family, A. (Fig. 35.)}

I 1 o was tall and slender. His wife I 2 was tall and very fleshy. There were 8 children, about whose build something is known.

II 1 fleshy. II 3 o at 40 years is fleshy, married to a slender man, has slender and fleshy children. II 4 $\hat{o}$ at 30 years is fleshy. II $7 \hat{\delta}$ is tall and fleshy. II 10 o is inclined to be fleshy. II 12 o at 42 years is fleshy, and has children of both types. II 14 of at 45 years, stature 165 cm. (65 inches) ; weight 62.5 (138 pounds); build 2.3 (33) ; medium. II $13 \hat{o}$ died at 35 years; very fleshy. Thus 1 is rery fleshy, 6 are fleshy, and 1 is of medium build $(73: 697)$.

\section{Ofi Fanily, B. (Fig. 35.)}

I 7 o , slender, has 3 fleshy sibs and 1 of medium weight. His wife, I 8 o, died at 68 , fleshy, had 7 sibs, all fleshy. There were 8 children: II 15 q at 38 years, stature $153 \mathrm{~cm}$. (60 inches); weight $69 \mathrm{~kg}$. (151

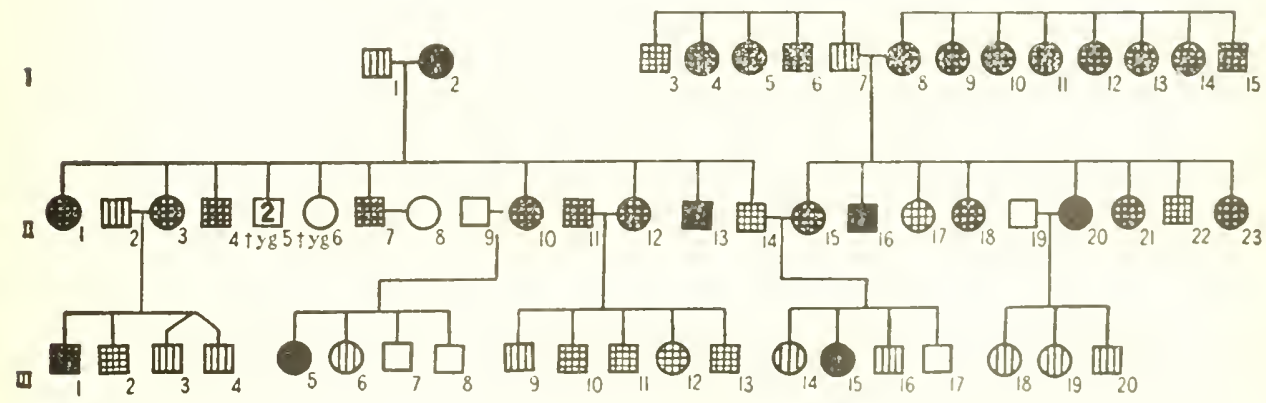

FIG. 35.-Pedigree chart showing distribution of build in OFI family. 
pounds); build 2.9 (42), fleshy; relative ehest-girth $92 \div 153$, or 61 per cent. She has always been fleshy, was formerly more so than now. Narried to a man of medium build. there were 4 children, 2 -lenter, and 1 fleshy* and 1 very fleshy. II 16 o died at 48 of "heart disease," very fleshy. II 17 \%, stature $151 \mathrm{~cm}$. (59 inches); weight $56 \mathrm{~kg}$. (124 pounds); build 2.5 (36), fleshy-medium; relative chest-girth $95 \div 151$, or 63 per cent. II 18 ㅇ fleshy. II 20 o, very fleshy, has 3 slender children. II 21 ㅇ fleshy. II 22 of of medium build. II 23 q, at 31 years, stature $150 \mathrm{~cm}$. (59 inches); weight $69 \mathrm{~kg}$. (151 pounds); build 3.0 (43 per cent), fleshy. Relative chest-girth $100 \div 150$, or 67 per eent. Thus, of the 8 children 2 are of medium build, 4 fleshy, and 2 very fleshy.

\section{Ori Fandur, C. (Fig. 35.)}

II $2 \hat{o}$. slender, married II 3 , at 40 years fleshy and heterozygous, and had 4 children. III 1 of fleshy; III 2 of of medium build, and III 3 s, 4 o twins, slender. 'Thus 1 fleshy, 1 medium, and 2 slender.

Comment.-Mating B is apparently that of a nearly homozygous dominant fleshy mated to a slender, and producing fleshy and rery fleshy offspring and 2 who are just below fleshy build $(73: 697)$.

\section{Sin Fanily:}

II 1 d (fig. 26), at 50 , stature $173 \mathrm{~cm}$. (68 inches); and weight 90 to $100 \mathrm{~kg}$. (200 to 215 pounds); build 3.2 (45), very fleshy. As a lad he was very slender, but at 28 years began to grow fleshy.

Marricd a woman who, at 68 years, has a stature of $150 \mathrm{~cm}$. (59 inches), weight $45 \mathrm{~kg}$. (100 pounds); build 2.0 (30). slender. They had 8 ehildren:

(1) Male, at 50 years, stature $165 \mathrm{~cm}$. (65 inches); weight $80 \mathrm{~kg}$. (175 pounds); build 2.9 (41), fleshy; slender as a child. (2) o , at 48 years, stature $155 \mathrm{~cm}$. (61 inches); weight $79 \mathrm{~kg}$. (174 pounds); build 3.3 (47), very fleshy; was slender until about 16 years of age. (3) $q$, at 46 years, stature $155 \mathrm{~cm}$. (61 inches); weight $86 \mathrm{~kg}$. (190 pounds); build 3.6 (51), very fleshy; was slender until 20 years old. By a slender husband she has 3 children, 13 to 5 years of age, all slender, but the eldest boy growing fleshicr. (4) $q$ died at 28 years of kidney trouble, agoravated by childbirth; at that time she was slender. (5) $q$. at 34 years, stature $155 \mathrm{~cm}$. (61 inches) ; weight $82 \mathrm{~kg}$. (180 pounds); build 3.4 (48), very fleshy, rather uniformly over the body. She was fleshy as a child; then became slender and remained so up to the age of 16 or 18 years. By a slender man she has 3 children, all young and slender. (6) ô, at 31 years of medium build with a tendency to grow fleshier, by a slender wife has a slender child. (7) o, at 29 vears, stature $157 \mathrm{~cm}$. (62 inches); weight now about $62 \mathrm{~kg}$. (135 pounds); build 2.5 (35), fleshy-medium, and varying inversely with his activity. (8) ô, at 24 years, stature $168 \mathrm{~cm}$. (66 inches); weight $59 \mathrm{~kg}$. (130 pounds); build 2.1 (30), medium-slender, but this is the age when in this family they first begin to put on flesh.

Comment.-This is an excecdingly instructire family; first, because they are all slender until 20 to 25 and then begin to grow fleshier. The heterozygous condition of fleshiness retards the full development of the trait, as so often scen in genetics. It is probable that III 1 is nearly homozygous for fleshiness $(73: 736)$.

* III 7 , shading omitted, by error, on chart. 


\section{WAL-1 FAMILY.}

A New York State family of English and sotch ancestry.

The Father, a business man, with riabetic tendencies, has at 60 years the formula $180 / 66$ inches; build 2.9 (41). His sibs are all tall or very tall. His father, a Scotch farmer, who had "kidney trouble," which, aggravated by influenza, caused his death at 86 years, hat the formula 175/68 inches; build 2.7 (38). His mother, who suffered from neuralgia and died of blood-poisoning at 64 years, had the formula $150 / 66$ inches; build 2.4 (34). This side of the house is thus of medium to fleshy build.

The Mother is subject to nervous prostration and intestinal indigestion and has been operated on for uterine lacerations. At 52 she has the formula $125 / 67.5$ inches; build 1.9 (27). Her father, who kept a country store and died at 83 years of heart failure, had the formula $156 / 71$ inches; build 2.2 (31). The Mother's mother, who died at 75 years of cancer of the stomach, was hunch-backed from an aceident when 3 rears old; had long arms and would probably have been tall. At 60 she had the formula $100 / 60$ inches; build $2.0(28)$. This side of the house is prevailingly slender. Two children are:

1. Male, a social worker, has at 30 years the formula $200 / 74$ inches; build 2.6 (37) ; adjusted to 55 years, 214/74 inches; build 2.8 (39).

2. Male, a business man, has at 24 years the formula $160 / 71$ inches; build 2.2 (32); adjusted to 55 years, 178/71 inches; build 2.5 (35).

Comment.-One child is fleshy like the Father, the other is of intermediate build ( $\mathrm{R}$ : Wal-4).

\section{Mating 2. Other Slendek $\times$ Fleshy Matings.}

In addition to the selected cases of table $2 \bar{\gamma}$, reference may be made to other families of table VIII of which details are published herewith; and which reveal special matters of interest. They are not included in mating 1 , because there is always at least one mediumgrade parent of the fleshy side of the house. The families are listed in table 28, summarized here and described in extenso further on.

TABLE 28.-Matings of a slender parent of slender stock and a fleshy parent of mixed stock; together with their progeny.

\begin{tabular}{|c|c|c|c|c|c|c|c|c|c|c|c|c|c|}
\hline & \multirow{2}{*}{ FF } & \multirow{2}{*}{ FMI } & \multirow{2}{*}{$F$} & \multirow{2}{*}{$\begin{array}{l}\text { Father's } \\
\text { sibs. }\end{array}$} & \multirow{2}{*}{ MF } & \multirow{2}{*}{ MM } & \multirow{2}{*}{ MI } & \multirow{2}{*}{$\begin{array}{l}\text { Mother's } \\
\text { sibs. }\end{array}$} & \multicolumn{5}{|c|}{ Offspring. } \\
\hline & & & & & & & & & is & s & M & $\mathrm{F}$ & $\mathrm{VF}$ \\
\hline Bro 30 . & 31 & 27 & 30 & & 35 & 40 & 37 & & & & 1 & 1 & 1 \\
\hline Fin $1 \ldots$ & 34 & 31 & 30 & & $3 s$ & 33 & 37 & & & & 1 & 2 & \\
\hline Met A. & M & M & 39 & $3 \mathrm{MI}, 1 \mathrm{~F}, 1 \mathrm{VF}$ & $33 \pm$ & $20 \pm$ & 30 & $2 S, 3 M$. & & & 1 & 4 & \\
\hline Olm A. & 34 & $\ldots$ & $3 s$ & IF $\ldots \ldots$ & 34 & 28 & 24 & $1 \mathrm{MI}, 1 \mathrm{~F}$. & & & 1 & 4 & 1 \\
\hline She 12 . & 34 & 46 & $3 s$ & $\ldots$ & 34 & $2 \mathrm{~S}$ & $2 S$ & & & & 3 & 4 & \\
\hline Van 3. & 29 & 29 & 29 & & 33 & 39 & 37 & & & 2 & . & 1 & \\
\hline Total... & & $\ldots$ & & & & & & & & 2 & 7 & 16 & 2 \\
\hline
\end{tabular}

Off spring: $\mathrm{A}, 38.01 \pm 0.55$ s. D., $4.74 \pm 0.39$.

Bro-30.-One child out of 3 is very fleshy, of a grade that in our experience never occurs when both parents are slender. 
Fin-1.-In this family all 3 children have already a build nearly equal to that of the fleshier parent. Assuming that they increase in weight in the same degree as the average person, they may be expected to be eonsiderably fleshier than the fleshy parent.

Met-A.-Of the 5 ehildren, 3 already exceed in build the fleshy parent.

Olm-A.-Of 6 children, all but 1 are fleshier than the fleshy parent.

She-12.-Of 7 children, 4 are fleshy like the Father, the others are slender to medium.

Van-3.-One out of 3 is fleshy.

The distribution of indices of build in the offspring is summarized in table 28. This distribution of offspring is characterized by about the same means as in mating 1 , and by about the same variability. It seems probable, consequently, that the fleshy parents were nearly homozygous for this trait.

\section{Bro-30 FaMily.}

A family of prevailingly English stock. The members of this family, including the grandparents, parents, and 3 children, were born and have lived in Connecticut. The Father in youth had typhoid fever, in middle age neuritis. Now, at 72, his formula is 140/68 inches; build 2.1 (30). His father, a school-teacher and farmer, died at 65 from old age, premature because of his strenuous life. His formula was 150/70 inches; build 2.0 (31). The Father's mother had sick headaches and inflammatory rheumatism in middle age. She died at 82 from old age, having then the formula 115/65 inches; build 1.9 (27).

The Mother, who had inflammatory rheumatism in youth and malaria in middle age, has now, at 63, the formula 150/64 inches; build 2.6 (37). Her father, a farmer and politician, suffered from Bright's disease in middle age, and dicd at 54 from an abscess of the liver as the immediate cause. His formula 175/71 inches; build 2.4 (35). Her mother, having enjoyed good health all her life, died at 87 from old age. Her formula was 175/66 inches; build $2.8(40)$. The 3 children are:

1. Male, at $42,145 / 67$ inches; build 2.3 (32) ; adjusted to 55 years, $149 / 67$ inches; build 2.3 (33).

2. Male, at $40,165 / 68$ inches; build 2.5 (36) ; adjusted to 55 years, $170 / 68$ inches; build 2.6 (37).

3. Male, at $39,200 / 68$ inches; build 3.0 (43); adjusted to 55 years, 206/68 inches; build 3.1 (45).

Comment.-The children's range of build exceeds that of the parents; the youngest is indeed very fleshy. Probably there is an obese tendency which comes down through the line of the Mother and Mother's mother (R : Bro-30).

\section{F1N-1 Family.}

A family of Russian Jewish stock. The grandparents and parents were natives of Russia; the family emigrated to America and settled in Pennsylvania, where the 3 children were born. The Father, a manufacturer, is living at 47 years, having the formula 140/68 inches; build 2.1 (30). His father, a merchant, is living at 69 years, having the formula 150/66 inches; build 2.4 (34). His mother, who had 12 children, died at 55 years from cancer, having the formula 145/68 inches; build 2.2 (31). 
The Mother has at 43 years the formula 165/67 inches; build 2.6 (37). Her sibs are mostly of heavy build. Her father, a merchant, has at 68 years the formula $180 / 69$ inches; build 2.7 (38). Her mother, who had 5 children, died at 53 years, having the formula 135/64 inches; build 2.3 (33). The 3 children:

1. Male, a salesman, had at 23 years the formula $195 / 70$ inches; build 2.8 (40); adjusted to 45 years, $210 / 70$ inches; build $3.0(43)$.

2. Male, a law student, has at 23 years the formula $175 / 70$ inches; build 2.5 (36); adjusted to 45 years, 190/70 inches; build 2.7 (39).

3. Male, a college student, has at 21 years the formula $169 / 70$ inches; build 2.4 (35); adjusted to 45 years, 186/70 inches; build 2.7 (38).

Comment.-All 3 ehildren have a fleshy build and may be expeeted to become fleshier than the Mother $(R:$ Fin-1).

\section{MeT-A FAMILY.}

A family of English extraction, living in Illinois. The Father, at 50 years, had the formula $200 / 72$ inches; build 2.7 (39). Of his 5 sibs: (1) Brother, at 50 years. $170 / 68$ inches; build 2.6 (37). (2) Brother, at 50 years, $160 / 68$ inches; build 2.4 (35). (3) Brother, at 50 years, $160 / 68$ inches; build 2.4 (35). (4) Sister, at 50 years, hart the formula $200 / \mathrm{T}$; build, say, 3.2 (46士). (5) Sister, at 50 years, had formula $140 / \mathrm{M}$; build, say, 2.5 (35). Both their father and mother are said to have been of medium build.

The Mother, at 50 years, had the formula 120/63 inches; build 2.1 (30). Of her 5 sibs who reached maturity: (1) Brother, at 50 years, had the formula 160/68 inches; build 2.4 (35). (2) Sister, 130/64 inches: build 2.2 (32). (3) Sister, 110/60 inches; build 2.1 (31). (4) Sister, 120/63 inches; build 2.1 (30). (5) Sister, 110/63 inches; build 1.9 (28.) Their

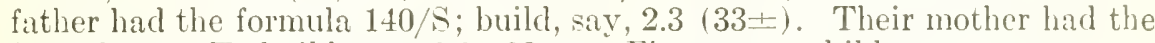
formula $120 / \mathrm{T}$; build, say, 2.0 (28土). Five grown children:

1. Female, at 35 ycars, has the formula $165 / 65$ inches; build 2.7 (39); adjusted to 50 years, $175 / 65$ inches; build 2.9 (41).

2. Male, at 40 years, $180 / 68$ inches; build 2.7 (39) ; arljustect to 50 years, $183 / 68$ inches; build $2.8(40)$.

3. Male, at 40 years, $185 / 68$ inches; build 2.8 ( 40$)$; adjusted to 50 years. 188/68 inches; build 2.9 (41).

4. Male, at 20 years, $160 / 68$ inches; build 2.4 (35); adjusted to 50 years, 178/69 inches; build 2.7 (37).

5. Female, at 35 years, $150 / 68$ inches; build 2.3 (32); adjusted to 50 years, 161/68 inches; build 2.4 (35).

Comment.-On the adjusted build, all children are abore the mid-parent and 3 of the 5 exceed the stouter parent ( $\mathrm{S}:$ Met-A).

$$
\text { OLM-A Fanily. (Fig: 36.) }
$$

A family of old American stock living in New York state. The Father has the formula $170 / 67$ inches; build 2.7 (38). He has a fleshy brother. His father had the formula $150 / 66$ inches; build 2.4 (34).

The Mother has the formula 100/64.5 inches; build 1.7 (24). She has 1 medium brother and a fleshy sister. Her father had the iormula 150, 66.5 inches; build 2.4 (34). Her mother had the formula 125, 60.5 inches; build $2.0(28)$. The 6 children:

1. Male, at 60 years, has the formula $192 / 61$ inches; build 3.6 (43).

2. Male, $250 / 67$ inches; build 3.6 (51). 
3. Male, $180 / 66.5$ inches; build 2.9 (41).

4. Male, $150 / 68$ inches; build $2.3(32)$.

5. Male, $155 / 65$ inches; build 2.6 (37).

6. Female, 175/66 inches; build 2.8 (40).

Comment.-A fleshy man, whose known family is fleshy or medium, has by a very slender woman whose family shows a variety of builds, 6 children: 1 medium, 4 fleshy, and 1 very fleshy. This suggests that the Father is nearly homozygous for the factors of build (S : Olm-A).

\section{SHE-12 FAMILY.}

This family, whose grandparents came from Pennsylvania and New Jersey, is ehiefly of English and German stock. The 10 children were born in Iowa and Nebraska.

The Father, soldier and editor, is in good health at 76 years, except for "rheumatism"; formula, 180/69 inches; build 2.7 (38). His father, a blacksmith, who was killed by the kick of a horse, had the formula 160/69 inches; build 2.4 (34). The Father's mother, who had a large family and died of dropsy, at 74 years had the formula 200/66 inches; build 3.2 (46). Thus this side

1

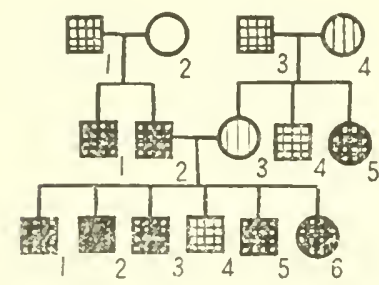

Fic. 36.-Pedigree chart showing distribution of build in OLM-A family. of the house is prevailingly of fleshy build.

The Mother, with 10 children, had an attack of pneumonia and died at 56 of throat and bronchial trouble and had the formula $120 / 65$ inches; build 2.0 (28). The Mother's father, a merchant, who died of a fever, had the formula $175 / 72$ inches; build 2.4 (34). The Mother's mother, who was inclined to bronchial and lung diseases, had the formula $120 / 65$ inches; build 2.0 (28). She died of "old age" at 82 years. This side of the house is medium to slender. The 7 grown children are:

1. Female, married, has suffered from intestinal indigestion and "some rheumatism." At 48 her formula is 170/64 inches; build 2.9 (42).

2. Male, a journalist, who was weak after an attack of scarlet fever, but developed into a robust man, has at 46 the formula 180/69 inches; build 2.7 (38).

3. Female, now 40 years old, married and with a family, has the formula $155 / 66$ inches; build 2.5 (36) ; adjusted to 55 years, 162/66 inches; build $2.6(37)$.

4. Male, a linotype operator, subject to throat and stomach trouble, has the formula $170 / 72$ inches, build 2.3 (33), at the age of 37 years; adjusted to 55 years, $176 / 72$ inches; build 2.4 (34).

5. Male, a promoter, in fine health, has at 34 the formula $160 / 72$ inehes; build 2.2 (31); adjusted to 55 years, 168/72 inches; build $2.3(32)$.

6. Male, a journalist, who has had ear and throat trouble following scarlet fever, has, at 32, the formula 170/69 inches; build 2.5 (36) ; adjusted to 55 years, $180 / 69$ inches; build 2.7 (38).

7. Female, delicate and inclined to rheumatism, at 29 years has the formula $120 / 65$ inches; build 2.0 (28); adjusted to 55 years, $135 / 65$ inches; build 2.2 (32).

Comment.-Four of the children are stout like the Father; the others are intermediate to slender ( $\mathrm{R}$ : She-12). 


\section{VAN-3 FaMiLY.}

Grandparents from Pennsylvania and New York; children born in Pennsylvania and Michigan; chiefly of English origin. Father, iron-worker, subject to bronchial and catarrhal troubles; formula, at 60 years, 135/68 inches; build 2.1 (29). Father's father, a minister, subject to catarrhal and bronchial troubles, died at 92 years of pneumonia; formula 130/67 inches; build 2.0 (29). Father's mother died of pneumonia at 84 years; formula 122/65 inches; build 2.0 (29). This side of the house is slender.

The Mother, who has some catarrhal and bronchial trouble, has the formula 150/64 inches; build 2.6 (36.6). Her father, who died at 72 years of kidney trouble and constipation, had the formula $150 / 67$ inches; build 2.3 (33). Her mother had the formula $160 / 64$ inches; build 2.7 (39). This side of the house is of or above the average build. There are 3 chilktren:

1. Female, a teacher, has at 27 years old the formula $110 / 65$ inches; build $1.8(26)$.

2. Female, who had an attack of typhoid fever, had the formula $150 / 64$ inches; build 2.6 (36.6) ("physically and mentally like mother").

3. Male, at 18 years, has the formula $125 / 68.5$ inches; build 1.8 (27); adjusted to 50 years, $135 / 69$ inches; build 2.0 (28). Thus 2 of the children resemble the (slender) paternal side and 1 the maternal ( $R$ : Van-3).

\section{Mating 3. Very Slender $\times$ Very Fleshy.}

Mention may be made of one example of this extreme mating, namely, of a very fleshy man with a very slender woman, whose slenderness may be due to the fact that she had formerly suffered an acute attack of tuberculosis. The two children are still young (19 and 21 years), but are already 3 and 5 points respectively above average build (English system), suggesting dominance of fleshiness. The detailed history of this mating follows.

\section{Goo-8 Fanily.}

A family of English extraction living in Massachusetts. The Father, a shoe manufaeturer, is living at 47 years, having the formula $210 / 66$ inches; build 3.4 (48). His father, a farmer, who died at 63 years from Bright's disease, was of medium build. His mother, who harl only 1 child, suffered in youth from tonsillitis. She is living at 75 years and is of medium build. The very stout Father is probably heterozygous in build.

The Mother, who has 2 children, suffered in youth from tonsillitis and scarlet fever; in middle age from tubercular trouble ("cured"). She is living at 46 years, having the formula 100/66 inches; build 1.6 (23). Her 2 brothers were tall. Her father, a farmer, well except for headaches, was a distant cousin to his wife. He is living at 72 years, having the formula 150/66 inches; build 2.4 (34). Her mother, who had 3 children, died from cancer at 58 years, having the formuła $130 / 63$ inches; build 2.3 (33). Thus the mother comes of medium (heterozygous?) stock; her extreme slenderness is associated with a tendency to active tuberculosis. The 2 children:

1. Male, a student, who in youth suffered from tonsillitis, has at 21 years the formula $153 / 69$ inches; build 2.3 (32); adjusted to 47 years, $170 / 69$ inches; build 2.5 (36).

2. Male, a student, who in youth suffered from diphtheria, has at 19 years the formula $160 / 67$ inches; build 2.5 (36); adjusted to 47 years, 180/69 inches; build 2.7 (38).

Comment.-The children are medium to fleshy; they are still young (R: Goo-8). 
Mating 4. Slexder $\times$ Very Fleshy Mativgs (Table IX).

Another test of dominance of the fleshy factors is afforded by table IX. The details will be found in the following pages. The distribution of the progeny is indieated in table 29. The sums of table 29, reduced to percentages, are: $12.5 \mathrm{~S}, 42.5 \mathrm{M}, 35 \mathrm{~F}, 10 \mathrm{VF}$. On the 4-zygotic-factor hypothesis of build, an equality of medium and fleshy progeny is expeeted. On the 6 -factor hypothesis, a $5 \times 2$ mating would produce two types of families. Averaging these two types, the expected proportions are $9 \mathrm{~S}, 41 \mathrm{M}, 41 \mathrm{~F}, 9 \mathrm{VF}$, which is fairly close to the proportions actually found. It will be observed that fleshy progeny are not far less frequent than those of medium build.

TABLE 29.-Matings of a slender parent and a very fleshy one, together with their progeny.

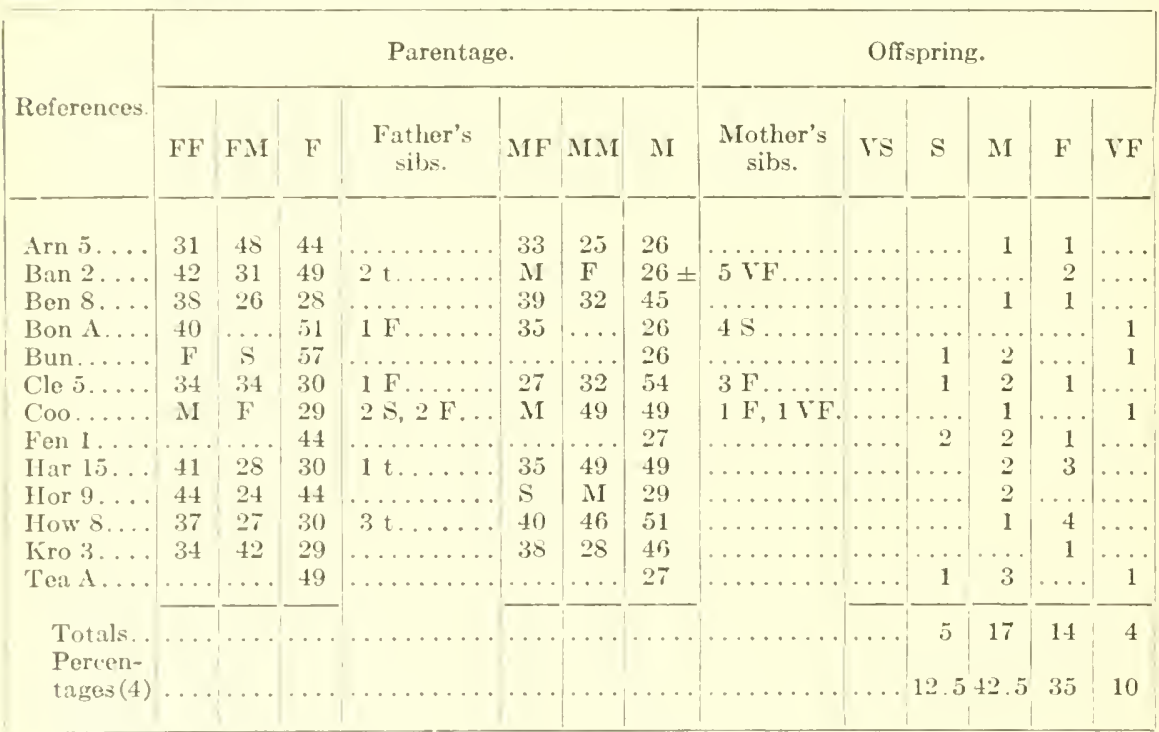

Off spring: A, $36.54 \pm 0.59$

S. D., $5.51 \pm 0.42$.

Before passing to the deseription of the 13 families based on Eugenies Reeord Office data, reference may be made to a case described by Rose (1907). A slender man (II 1) of slender parents married a woman who weighed 200 pounds ("livres") and over. Her father weighed 270 pounds and her mother, while not obese, has a goiter. From the primary slender $X$ very fleshy mating were derived 4 children (fig. 37, III 1 to 5). The first is fleshy; the third slender. The second, a girl, at 16 weighed 150 pounds, but after chlorosis became slenderer. This girl married a man apparently of medium build, and they had 4 children, of whom 3 died of meningitis and the other is an obese infant, weighing 36 pounds at 15 months. The fourth and last of the main fraternity is a girl who, at 15 years, is $145 \mathrm{~cm}$. tall and weighs $75 \mathrm{~kg}$. This gives her an index of build of $3.6(51)$, very 
fleshy. She was very fleshy at 4 years, and has a big appetite. The fat is accumulated on abdomen, breasts, and appendages, except hands and feet. The extreme obesity came on at puberty and menstruation has never been regular. Epiphyses of radius and metacarpals of fingers are fused to their diaphyses. These facts indicate an obesity of both the dystrophic adiposo-genitalis type and the hypothyroid type. The progeny are thus $1 \mathrm{~S}, 1 \mathrm{M}, 1 \mathrm{~F}$, and $1 \mathrm{VF}$.

ARN-5 Fanilly.

This is a family of the north central States, of English stock. The Father, an engineer, had pneumonia in youth and an attack of gravel at 45 ; his

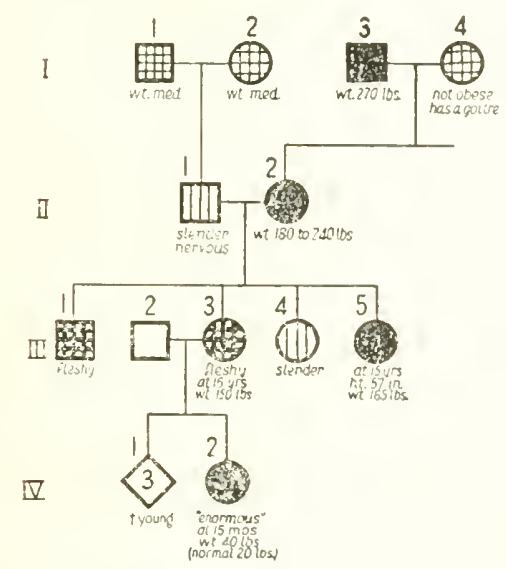

F1G. 37.-Pedigree chart of Rose's case. formula at 60 years is $193 / 66$ inches: build 3.1 (44). His 9 brothers are all one-eighth to 3 inches below average stature. His father, who suffered five attacks of inflammatory rheumatism, died at 59 years of enlargement of the heart; formula, $135 / 65.5$ inches; build 2.2 (31). His mother, who had typhoid at 25 years and catarrh of stomach at 55. has fat 70 years the formula 186/62.4 inches; build 3.3 (48). Thus the Father, like his mother, is very fleshy; but there is a slender strain in the family.

The Mother, who died of tuberculosis of the lungs at 46 years a fter having had 5 children, had the formula $95 / 61$ inches; build 1.8 (25.5). One of her 4 sibs died of "hardening of lungs." Her father, who after attacks of pneumonia died at 67 of tuberculosis, had the formula $140 / 65$ inches; build 2.3 (33). Her mother, who had artive tubereulosis at 43 years, with recovery, has at 73 years the formula 10565 inches; build 1.7 (25). Thus Mother and Mother"s mother are very slender (associated with tuberculosis); and there is no fleshiness in the record. There are 2 grown children:

1. Female, who has always been well, has at 24 years the formula 124.61 inches; build 2.4 (33); adjusted to 55 years, 14061 inches: build 2.6 (38).

2. Male, who has always been well, has at 22 years the formula 13367.5 inches; build 2.1 (29); adjusted to 55 years, 149/68 inches; build 2.3 (32.3)

Comment.-Thus the progeny of these parents of opposite build are intermediate; in the adjusted build inclining toward fleshines: (R:Arn-5).

\section{BAN-2 FAMILY.}

A family of Dutch extraction living in northern New York. The Father, a farmer, suffered in youth from typhoid fever; in middle age from tic douloureux. He died at 54 years from heart faiture. "blood became thin and watery"; formula, 225/68 inches; build 3.4 (49). One of his sisters died at 40 years from tuberculosis of lungs. One of his brothers diect at 29 years from "consumption of bowels." His father, a farmer, suffered in middle age from inflammatory rheumatism, and died at $7 t$ years irom apoplexy. At 60 years his formula was $210 / 71$ inches; build 2.9 (42). His mother died at 68 years from heart failure, having at 60 years the formula 
140/67 inches; build 2.2 (31). Thus we have a very fleshy parent with tuberculous sibs and a fleshy father.

The Mother, who in middle age suffered from dyspepsia, "after menopause very gradually lost her mind, becoming imbecile and helpless till death, at 66 vears." liaving the formula $96 / \mathrm{s}$ inches; build $26 \pm$. Five of her sibs were corpulent. One brother, "small and light framed," died at 27 years from tuberculosis. Their father was of medium build. 'Their mother, who in middle age suffered from paralysis, died at 73 years from eancer of breast; at 60 years was corpulent. The slender mother is from fleshy stock. The 2 children:

1. Male, head of a factory, has at 50 years the formula $180 / 68$ inches; build $2.7(39)$.

2. Male, a teacher, has at 45 years the formula $185 / 69$ inches; build $2.7(39)$.

Comment.-Both offspring at middle age are intermediate in build between the two parents, but somewhat closer to the very fleshy one ( $\mathrm{R}$ : Ban-2).

\section{BEN-8 FAMILY.}

A northern family, of which the 4 children were born in Michigan, of mixed English, Seoteh, and other stock.

The Father, a farmer, who enjors good health, has at 40 years the formula $135 / 69$ inches; build 2.0 (28). Both his sibs are above the average in stature. His father, a farmer, who died from over-exertion in the sun at 48 years, had the formula $190 / 71$ inches; build 2.7 (38). His mother died of "heart trouble" at 71 years; formula 100/62 inches; build 1.8 (26). Thus, the slender parent has one fleshy parent in turn.

The Mother, who has "leart trouble," has at 40 years the formula 195/66 inches; build 3.1 (45). Her 3 sibs are all tall. The Mother's father, a millman, died at 61 years of Bright's disease, having the formula 205/73 inches; build 2.7 (39). 'The Mother's mother, who is well, had at 56 years the formula $150 / 67$ inches; build 2.3 (32). This side of the house is prevailingly fleshy. The 2 grown children are:

1. Male, has, at 21 years, the formula $185 / 71$ inches; build 2.6 (36); adjusted to 40 years, $202 / 71$ inches; build 2.8 (40).

2. Female, at 19 years, has the formula $130 / 67$ inches; build 2.9 (29); adjusted to 40 years, $145 / 67$ inches; build 2.3 (32).

Comment.-One child is fleshy like the Mother (adjusted build); the other is of medium build; both are between the parental extremes.

\section{BOx-A FAMILY.}

A family from New Hampshire. 'The Father, at 55 years, had the formula $250 / 70$ inches; build 3.6 (51). His brother, at 55 years, had the formula 160/63 inches; build 2.8 (40). Their father, at 61 years, had the formula $200 / 71$ inches; build 2.8 (40).

The Mother, at 55 years, had the formula $120 / 68$ inches; build 1.8 (26). Of her 4 sibs: (1) Brother, at 50 years, 150/72 inches; build 2.0 (29). (2) Sister, at 55 years, $115 / 65$ inches; build 1.9 (27). (3) sister, at 58 years, $119 / 65$ inches; build 2.0 (28). (4) Sister, at 60 years, $130 / 68$ inches; build 2.0 (28). Their father, at 85 years, $180 / 71.5$ inches; build 2.5 (35).

The one child, male, at 40 years, $220 / 71$ inches; build 3.1 (44).

Comment.-The progeny of these two parents, one of prevailingly fleshy stock, the other of slender stock, is a very fleshy child, but less extreme than his parent, who is 15 years older (s : Bon-A). 
Bun FaMlLY. (Fig. 38.)

A Long Island family of English stock. The Father, at maturity, had the formula $280 / 70$ inches; build 4.0 (57); very fleshy. His father was fleshy; his mother slender. The Mother, at maturity, had the formula 125/69 inches; build 1.8 (26); slender. She belongs to a slender family.

The four offspring are all mature, 40 to 50 years: (1) female, 110/65.5 inches; build 1.8 (25.5); very slender; (2) female, 140/66 inches; build 2.3 (32) ; medium; (3) male, 160/70 inches; build 2.3 (33) ; medium; (4) male, 198/67 inches; build, at 45 years, 3.1 (44); very fleshy (at 30 years his

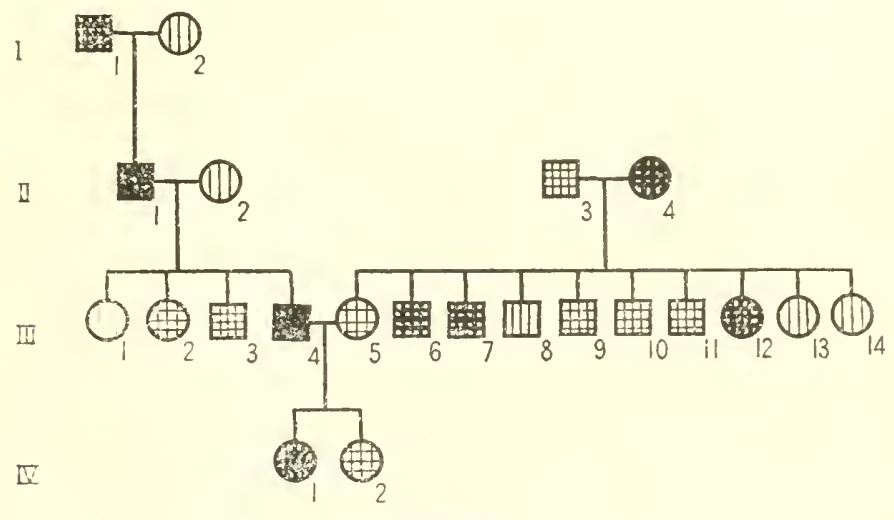

FIG. 3s.-Pedigree chart showing distribution of build in Br.s family.

build was 2.3 (33) or medium). This very fieshy man has by a wife of medium build (but 3 of whose 9 sibs are fleshy) 2 daughters; one, at 18 years, is 121/62.5 inches; build 2.1 (31); medium; the other at 12 years, is 145/62 inches; build 2.7 (38) ; fleshy; far above normal build for her age.

Comment.-The principal mating has produced a variable progeny, but the tendency to obesity is traceable through three generations.

Cle-5 Familx.

A family of English extraction living in Ohio. The Father, a farmer, who has for years been subject to stomach trouble, has at 62 years the formula 140/68 inches; build 2.1 (30). He has a fleshy brother. His father, a farmer, died at 86 years from "probable cancer of ear," having the formula $140 / 64$ inches; build 2.4 (34). His mother died at 80 years of indigestion; formula, 150/66 inches; build 2.4 (34). This is a family of slender to medium build.

The Mother, who in youth was liable to asthma and throat trouble and in middle age to rheumatism, underwent an operation at 48 years for cancer of breast. At 25 or 30 years she began to grow fleshy; at 56 years she has the formula $200 / 61$ inches; build 3.8 (54). She has 3 fleshy sibs. Her father, a farmer, died at 69 years of "enlargement (probably cancer) of liver"; formula, 130/69 inches; build 1.9 (27). Her mother, who had 12 children, and who underwent two operations for cancer on nose, died at 83 years of indigestion; formula, 130/64 inches; build 2.2 (32). The very fleshy Mother's fraternity is apparently derived from slender-medium parents. But one of these had probably lost weight before her death at 83 years. The 4 grown children: 
1. Female, who has suffered from asthma, stomach trouble, gallstones, diphtheria, and appendicitis, has at 36 years the formula $120 / 63$ inches; build 2.1 (30) ; adjusted to 55 years, 130/63 inches; build 2.3 (33).

2. Male, a farmer, has at 35 years the formula $140 / 70$ inches; build 2.0 (29) ; adjusted to 55 years, 148/70 inches; build 2.1 (30).

3. Nale, a farmer, subject in youth to indigestion and catarrh of throat and nose. At 25 years he lias the formula 165/68 inches; build 2.5 (36); adjusted to 55 years, $179 / 68$ inches; build 2.7 (39).

4. Male, a teacher, who has suffered from diphtheria and colds, has at 23 years the formula $125 / 63$ inches; build 2.2 (32) ; adjusted to 55 years, $139 / 63$ inches; build 2.5 (35).

Comment.-The offspring are still young, and we do not know just how they will develop. One is fleshy (but far less so than his Mother); 2 are intermediate, and 1 , at 35 years, is even slender ( $\mathrm{R}: \mathrm{Cle}-5)$.

\section{Coo Family. (Fig. 39.)}

This is a New York State family upon which I personally made obserrations. A slender-medium man (II $5)$; build about 2.0 (29), who has 2 fleshy and 2 slender sibs, married a very fleshy woman, build 3.4 (49), whose 2 sibs are also fleshy, 3.4 (48) and 2.8 (40) respectively. Her mother was also about 3.4 (49). There were two daughters. One has now at 42 years a build of 3.4 (48); her sister a build of 2.4 (34) with a tendeney to increase. The fleshy sister married a man of slender build, wiose 3 sibs are of slender to medium build. There are 5 children, all under 16 except one boy who, at 20 years, has a build of 2.3 (32). He is 73 inches $(183 \mathrm{~cm}$.$) tall. All of the$ other children are of about medium build.

Comment.-The very fleshy (but

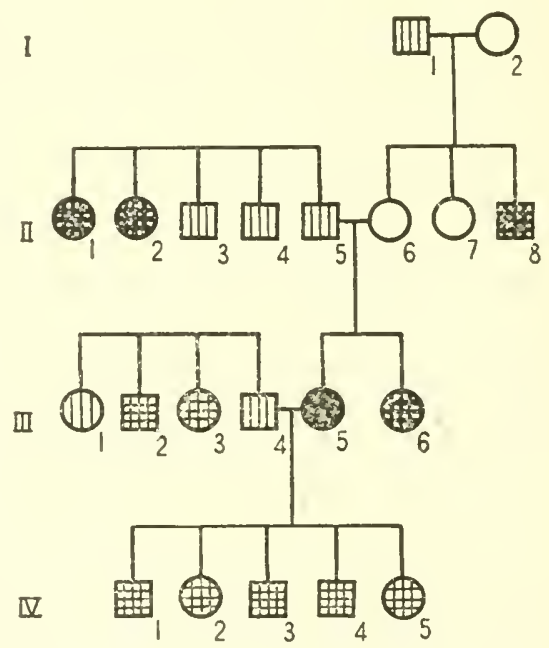

FIG. 39.-Pedigree chart showing distribution of build in the Coo family. heterozygous) Mother mated with a slender man has children, all of whom are apparently of medium build $(73: 656)$.

\section{FEN-1 FAMILY.}

A family of English, Austrian, and Swiss extraction, grandparents and children living in New York State and California. The Father, a merchant, died at 81 years from ulcer of the stomach. At 50 years he had the formula $210 / 69.5$ inches; build 3.1 (44).

The Mother, who has 5 children, has always been well. She is living at 77 years, having at 50 years the formula $102 / 61.5$ inches; build 1.8 (27). One of her sisters died at 79 years from "rheumatism of heart." The 5 children are:

1. Male, a manufacturer, who suffered in youth from typhoid ferer. He has at 50 years the formula $180 / 68.5$ inches; build 2.7 (38). 
2. Male, a merchant, has at 40 years the formula $140 / 66$ inches; build 2.3 (32) ; adjusted to 50 years, 143/66 inches; build 2.3 (33).

3. Female, always well, married, has at 40 years the formula $120 / 66.5$ inches; build 1.9 (27) ; adjusted to 50 years, 126/66.5 inches; build 2.0 (29).

4. Male, a broker, who in youth suffered from typhoid fever, at 47 years, $147 / 69.5$ inches; build 2.1 (30) .

5. Male, who suffered from hemorrhage of lungs while at college, caused by "excessive running," died at 31 years from tuberculosis, at 28 years having the formula 158/74 inches; build 2.1 (29); adjusted to 50 years, $173 / 74$ inches; build $2.2(32)$.

Comment.-The children are intermediate in build between the parents. Only 1 out of 5 is even fleshy.

\section{HaR-15 FAMIIY.}

A family of English (and Welsh) extraction; grandparents living in the northern United States.

The Father, a twin, who was in the Civil War and has since suffered from a tendency toward tuberculosis but was living at 71 years, has the formula 150/70.5 inches; build 2.1 (30). One of his sisters died of tuberculosis at 30 years, and one of pneumonia at 77 years. His father, who was a farmer and "never sick," died of pneumonia at 47 years, and had the approximate formula 180/66.5 inches; build 2.9 (41). His mother, who died at 48 years of "abscess on the back" after years of ailing, was of slender build, say, 2.0 (28). Thus, probably on account of the tubercular tendency, the Father's build is slender like his mother.

The Mother, who had 11 children, had a tendency toward tuberculosis in youth, but in middle life suffered from "obesity, rheumatism, and varicose veins," was genial and a ready and humorous talker; at 61 years her formula 200/64 inches; build 3.4 (49). Her father, who was a traveling salesman and seldom ill except for "tobaceo heart," died of paralysis at 77 years; his formula, 170/70 inches; build 2.4 (35). Her mother, who had pneumonia in middle life and suffered much from "delicate lungs." died of a pulmonary abseess at 37 years; her formula, 194/63 inches; build 3.5 (49). Thus the Mother's build is just like her mother's. Of the 5 children who grew up:

1. Female, a teacher, who has suffered from bronchitis, tuberculosis, and rheumatism, at 34 years has the formula $162 / 66$ inches; build 2.6 (37); adjusted to 50 years, 173/66 inches; build 2.8 (40).

2. Male, a mechanical engineer, always well, at 30 years has the formula $170 / 68.5$ inches; build 2.5 (36); adjusted to 50 years, 181/68.5 inches; build $2.7(39)$.

3. Female, married and always well, at 26 years has the formula 135/64 inches; build 2.3 (33); adjusted to 50 years, 151/64 inches; build $2.6(36.9)$.

4. Male, a millwright, who suffers from valvular heart trouble, at 26 years has the formula $140 / 67$ inches; build 2.2 (31) ; adjusted to 50 years, 150/67 inches; build 33.

5. Male, an optometrist, always well, has at 23 years the formula $150 / 69.8$ inches; build 2.2 (30.6); adjusted to 50 years, 169/70 inches; build 2.1 (34).

Comment. - Thus 3 of the children are intermediate in build between the parents and 2 are fleshy. The build of the children inclines slightly toward the fleshier side of the house; but variability between indices 40 and 33 is marked (R : Har-15). 


\section{HOR-9 FAMILY.}

A family of Dutch and Fnglish extraction, living in Pennsylvania and New York State. The Father, who is a manufacturer, always well, has at 53 years the formula $218 / 70.5$ inches; build 3.1 (44). His father, who is a manufacturer, and suffered in middle age from malaria and measles, is living, at 75 years having the formula $215 / 70$ inches; build 3.1 (44). His mother, who has 5 children, always well, has at 70 years the formula $83 / \mathrm{S}$; build, say, 1.7 (24).

The Mother, who has 2 children and who in middle age suffered from pneumonia, has at 52 years the formula 124/66 inches; build 2.0 (29). Her father, who was a cabinet-maker, always well, till at 41 years he died from chronic diarrhea, was a slender man. Her mother, who had 5 children, was always well; she dierl, at 24 years, of child-birth; she was of medium build. Two grown children:

1. Female, who in youth suffered from measles (4 times), diphtheria, and pneumonia, and has undergone operations for hernia, tubercular glands, and appendicitis, has at 23 years the formula $116 / 66.5$ inches; build 1.9 (26) ; adjusted to 53 years, $135 / 66.5$ inches; build 2.1 (31).

2. Female, who in youth suffered from typhoid fever and influenza, has at 20 years the formula $119 / 62$ inches; build 2.2 (31); adjusted to 53 years, $138 / 62$ inches; build 2.5 (36).

Comment.-The children, who are quite young, are of a build intermediate between (or less than) that of parents, though a tendency to obesity is found in Father and grandfather (R : Hor-9).

$$
\text { How-8 Faxily. }
$$

A Vermont family of English origin. The Father, an author, was supposed to have had active tuberculosis in youth. He is living, at 83 years, with the formula $135 / 67$ inches; build 2.1 (30). All 3 of his sibs died of pulmonary tuberculosis. His father, a farmer, died at 79 years, having the formula $180 / 70$ inches; build 2.6 (37). His mother died at 81 years, formula, 100/61 inches; build 1.9 (27). This is a prevailingly slender family with tubereular tendency.

The Mother, who has suffered from enlarged tonsils and inflammatory rheumatism, has, at 70 years, the formula $220 / 66$ inches; build 3.6 (51). One of her brothers has a powerful physique. The Mother's father, a legislator, died at 75 years; formula, 200/71 inches; build 2.8 (40). The Nother's mother, who died at 70 years of Bright's disease, had the formula $200 / 66$ inches; build 3.2 (46). This family is characterized by fleshiness. The 5 children are all sons:

1. A writer, at 48 , has the formula $150 / 65.5$ inches; build 2.4 (35).

2. A farmer, with an organic defect of the heart, has, at 47 , the formula $170 / 67$ inches; build 2.7 (38) .

3. A farmer, with chronic Bright's disease, has the formula 180/70 inches; build 2.6 (37), at the age of 44 .

4. A teacher, troubled with rheumatism, has, at 41 years, the formula $185 / 68$ inches; build $2.8(40)$; adjusted to 55 years, $190 / 68$ inches; build $2.9(41)$.

5. Twin to (4), a forester, has, at 41 years, the formula $180 / 68.5$ inches; build 2.7 (38) ; adjusted to 55 years, 185/68.5 inches; build 2.8 (39).

Comment.-Thus the children are intermediate in build between parents. Tuberculosis is absent. Conditions that induced fleshiness on the mother's side are reduced in the offspring of the slender and fleshy mating (R : How-8). 
KRo-3 FasILY:

A family of Russian and Austrian extration, living in New York City. The Father. who is a tailor, nervous, has, at 45 yoars, the formula 12.5/66 inches: build 2.0 (29). His father, who was a tailor, always well, died at 85 years from pneumonia. Formula, $150 / 66$ inches; build 2.4 (34). His mother, who had 5 children, always well, died at 56 years from preumonia. Formulat $140 / 58$; build 2.9 (42).

The Mother, who has 3 children, has at 44 roars the formula $172 / 61$ inches: huild 3.2 (46). Her father, who wats a tailor, is living at 81 rours. Formula. 175/68 inches; build 2.7 (38). Her mother, who had 6 children, died at 58 vears from pneumonia. Formula, 101/60 inclues; build 2.0 (28).

The only grown child, a male, who in youth suffered from cliphtheria, scarlet ferer, and pneumonia. has at 19 years the formula 20)3/72 inches; build 2.7 (39); adjusted to 45 years, 228/74 inches; build 2.8 (42).

Comment.-The child is young and the possibilitios of luuild in his case can not he foreseen, but he is already stout and may be expecterl to approach his fleshy Nother in build ( $R$ : Kro-3).

\section{TEA-A FAMILY:}

A family from New York State. The Father, at 70 years, hat the formula $225 / 68$ inches; build 3.4 (49).

The Mother, at 50 years, hard the formula $115 / 65$ inches; build 1.9 (27). The 5 children are:

1. Nale, at 58 rears, has the formula 22570 inches: build 3.21461.

2. Male, at 40 years. $140 / 69$ inches; build 2.1 (29); adjusted to 5.5 years, $145 / 69$ inches; build $2.1(31)$

3. Nale, at 68 years, $130 / 68$ inches: build $2.0(28)$.

4. Female, at 60 years, $125 / 64$ inches: build 2.21311 .

5. Female, at 62 years, $140 / 66$ inches; build 2.3 (32).

Commont.-There are 2 slender children, 2 medium, and 1 rery fleshy, suggesting a sire who is heterozygous for build (s : Tea-A).

\section{STMMARY.}

Combining the progeny of the 4 matings of the $F$, generation, we get the results shown in table 30 . The mean of this series is $37.82 \pm 0.31$; the standard deviation is $5.07 \pm 0.22$. It will be observerl that the proportions of the totals agree closely with those of mating 1 and give a somewhat closer agreement, with the expectation of $8: 42: 42: 8$, than mating 1 does.

The standard deviation of $5.07 \pm 0.22$ is greater than that of the progeny of slender $\times$ slender parents $(3.17 \pm 0.17)$, but not so sreat as that of very fleshy $\times$ fleshy parents of fleshy stock (table 24) which is $5.74 \pm 0.39$. It is much less than the standard deviation of the $F_{2}$ progeny (table 31 ), which is $6.78 \pm 0.26$. This is in accordance with the usual genetical finding, that the $\mathrm{F}_{1}$ generation is less rariable than the $\mathrm{F}_{2}$ generation. In this respect, as in so many others, the distribution of progeny is exactly that found in experimentally determined multiple-factor characters. The heredity of build follows closely the Mendelian formulæ. 
It is noteworthy that the $F_{1}$ generation has an average build that is above the mean of the population; the progeny of $\mathrm{F} \times \mathrm{S}$ matings are not strictly intermediate, but incline toward fleshiness. This indicates again the presence of dominant fleshy factors.

TABLE 30.-Matings of a slender parent and one of fleshy stock, together with their progeny.

\begin{tabular}{|c|c|c|c|c|c|c|}
\hline \multirow[b]{2}{*}{ No. } & \multirow{2}{*}{ Nature of mating. } & \multicolumn{5}{|c|}{ Grades of offspring. } \\
\hline & & VS & $S$ & $\mathbf{M}$ & $\mathrm{F}$ & VF \\
\hline $\begin{array}{l}1 \\
2 \\
3 \\
4\end{array}$ & 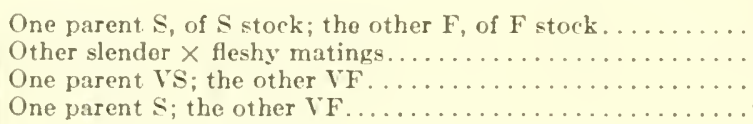 & \begin{tabular}{l|}
$\cdots$ \\
$\cdots$ \\
$\cdots$ \\
$\cdots$
\end{tabular} & $\begin{array}{r}4 \\
2 \\
\cdots \\
5\end{array}$ & $\begin{array}{r}18 \\
7 \\
1 \\
17\end{array}$ & $\begin{array}{r}35 \\
15 \\
1 \\
14\end{array}$ & $\begin{array}{r}7 \\
2 \\
\cdots \\
4\end{array}$ \\
\hline & $\begin{array}{l}\text { Total } \ldots \ldots \ldots \ldots \ldots \ldots \ldots \ldots \ldots \ldots \ldots \ldots \ldots \ldots \ldots \\
\text { Proportion } \ldots \ldots \ldots \ldots \ldots \ldots \ldots \ldots \ldots \ldots \ldots \ldots \ldots\end{array}$ & $\ldots$ & 9 & $\begin{array}{l}43 \\
33\end{array}$ & $\begin{array}{l}65 \\
50\end{array}$ & $\begin{array}{l}13 \\
10\end{array}$ \\
\hline
\end{tabular}

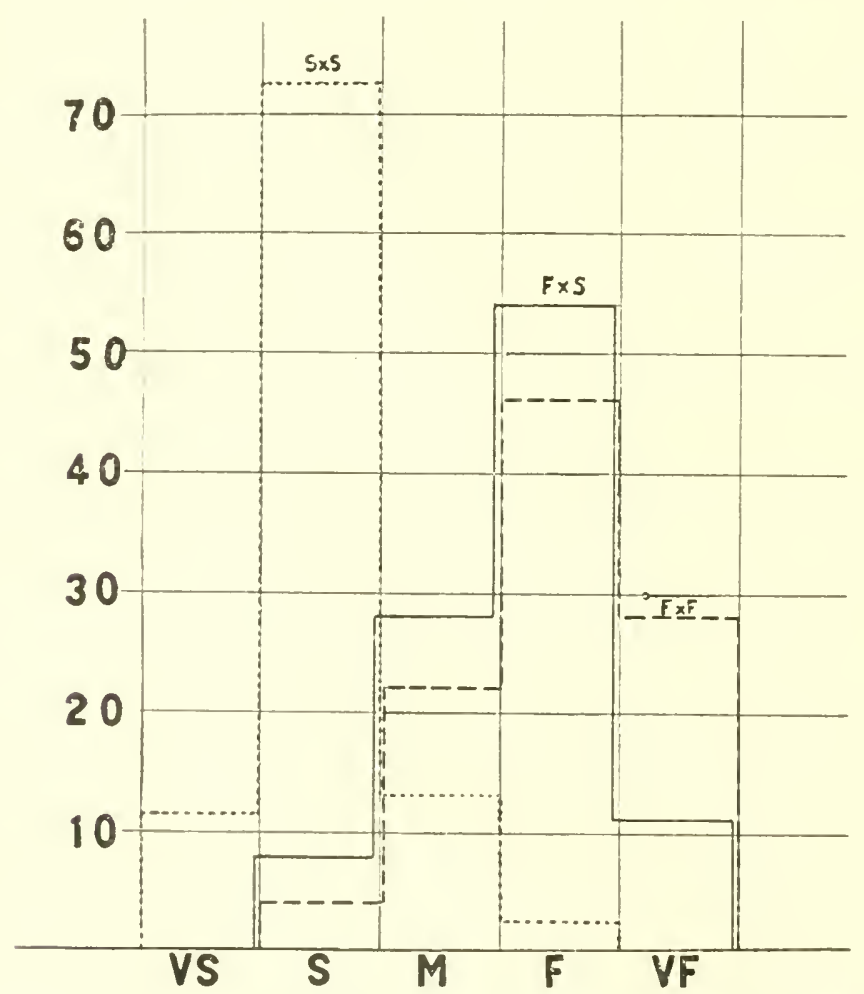

11. 40.-Three superimposed polygons showing distribution, in the various classes of build, of the progeny of the following matings:

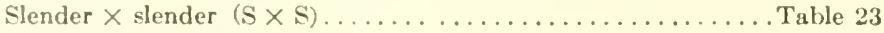

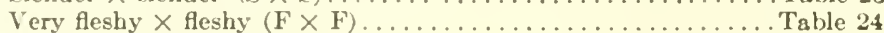

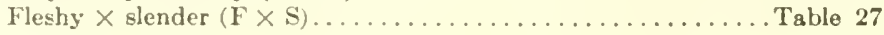


If one superimposes in the same drawing the distribution polyons of the parental and $F_{1}$ generations tables 23, 24, 25) and 30 (fig. 40), the modes of the fleshy parents and the $\mathrm{F}_{1}$ gencration stand at fleshy, though the mean of the $F_{1}$ generation is intermediate between the means of the parental stocks.

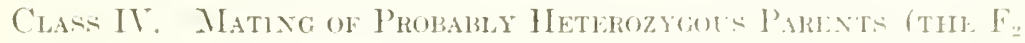
GexkRationi.

We have next to consider the distribution of build in the progeny of parents both of whom are certainly or probably heterozygous and. as such, probably carry gametes for slenderness, as woll as fleshiness. This is the mating in which the geneticist finds evidence for segregation, in that the parental types reappear nearly or quite as they went into the combination. At any rate, this generation is characterized by a greater variability than the $\mathrm{F}_{1}$ generation. However, this greater variability is the less marker the greater the munber of factors involved in the prevailing dominant trait-in this case fleshiness.

Two classes of matings will be considered-that of parents, whether medium or fleshy, who probably carry gametes for slenderness, and that of other parents who are both of medium build.

Mating 1. Both Parests Either Mediem on Fleshy axd Probaim. Cirmying Gametes

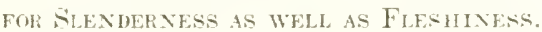

This mating includes certain parents selected, usually on the ground of dissimilar grandparents on each side. as those which are probably of the $F_{1}$ generation. The families used are summarized in table 31. which is made up of the appropriate families taken from tables X. XI, and XIII.

The range of variation of the $F$. generation includes both the slender and the fleshy types which are found in the grandparents. The distribution of the progeny is more in accord with the hypothesis of the 6-zygotic factors than that of 4-zygotic factors.

The mean variability as measured by the standard deviation is $6.78 \pm 0.26$, as contrasted with that of $5.02 \pm 0.30$ of table 27 (the $F_{1}$ generation). The difference is 1.76 , which is more than four times the probable difference between the means. Thus, the variability of the $F_{2}$ generation is nearly a third greater than of the $F_{1}$ generation. That the difference is not greater is, of course, due in large part to the presence of multiple factors.

The family histories upon which table 31 depends are given below.

$$
\text { BEA-17 FAMILY. (Fig. 41.) }
$$

A family reared in the Contral states. Father (II 5) a contractor and farmer, who died of pneumonia at 70 years, had the formula $170 / 71$; build 2.4 (34); medium. Three brother' who were killed in the Civil War at 17 . 19 , and 21 years respectively had the formular 183, 72. build 2.5 (35); 
$169 / 69$, build $2.5(36) ; 174 / 69$, build $2.6(37)$; all about medium. A sister, who died at 68 years, was $138 / 65$; build $2.3(33)$; medium. The Father's father was a preacher; died at 79 years, had build $185 / 68 ; 2.8$ (40) ; fleshy. His wife, who died at 81 years, had build $145 / 62 ; 2.7$ (38) ; fleshy. This side of the house comprises medium-build children of fleshy parents.

The Mother (II 6). of quiet disposition, at 60 years has the build $145 / 66$; 2.3 (33) ; medium. A brother, who is a machinist, at 33 has the formula $154 / 69$; build 2.3 (33). Another brother, carpenter, at 30 years, has the formula $145 / 70$; build 2.1 (30); medium. A sister has the formula 136/65; build $2.2(32)$; medium. The eldest brother, a farmer, at 55 years has the formula $160 / 70$; build 2.3 (33) ; medium. The Mother's father, a farmer, died of cerebral hemorrhage at 81 vears; $170 / 72$; build 2.3 (33) ; medium. He had a brother, still living at 80 years, with a build $185 / 71$; build 2.6 (37); fleshy. The Mother's mother, living at 81 years, has the formula $140 / 64$; build 2.4 (34) ; medium. Thus this side of the house is prevailingly of medium build. There are 4 children:

TABLE 31.-Matings of two heterozygous parents of either medium or fleshy build, together with the progeny, the $\mathrm{F}_{2}$ generation.

\begin{tabular}{|c|c|c|c|c|c|c|c|c|c|c|c|c|c|}
\hline & \multirow{2}{*}{ FF } & \multirow{2}{*}{ FM } & \multirow{2}{*}{$F$} & \multirow{2}{*}{$\begin{array}{l}\text { Father's } \\
\text { sibs. }\end{array}$} & \multirow{2}{*}{$\mathrm{MF}$} & \multirow{2}{*}{ MM } & \multirow{2}{*}{ M } & \multirow{2}{*}{$\begin{array}{l}\text { Mother's } \\
\text { sibs. }\end{array}$} & \multicolumn{5}{|c|}{ Offspring. } \\
\hline & & & & & & & & & VS & $S$ & M & $\mathrm{F}$ & VF \\
\hline $\begin{array}{l}\text { Group } \mathbf{X} \\
\mathbf{M} \times \mathbf{M}\end{array}$ & & & & & & & & & & & & & \\
\hline Bea 17... & 40 & 37 & 31 & $\begin{array}{l}4 \text { range betw. } \\
33 \text { and } 37 \text {. }\end{array}$ & $32 *$ & 34 & 33 & $\begin{array}{l}4 \text { range } 30 \text { to } \\
33 .\end{array}$ & & 1 & & $3 \dagger$ & \\
\hline Cas $4 \ldots$ & 39 & 29 & 34 & $\ldots \ldots \ldots \ldots \ldots$ & 43 & 27 & 34 & $\ldots \ldots \ldots \ldots$ & $\ldots$ & $\ldots$ & 3 & 3 & $\ldots$ \\
\hline Smi.... & $\mathrm{S}$ & $\mathrm{F}$ & 35 & $7 \mathrm{M}, 1 \mathrm{~F} \ldots \ldots$ & M & $\mathrm{M} \ddagger$ & 33 & $1 S, 1 M \ldots \ldots$ & $\ldots$ & $\ldots$ & $\ldots$ & 1 & $\ldots$ \\
\hline War $3 \ldots$ & 33 & $\mathrm{~S}$ & 33 & $\ldots \ldots \ldots \ldots \ldots$ & 41 & 26 & 31 & $\ldots \ldots \ldots \ldots \ldots$ & $\ldots$ & 3 & 7 & $\ldots$ & ... \\
\hline Whi $22 \ldots$ & 41 & 27 & 32 & $\ldots \ldots \ldots \ldots$ & 31 & 44 & 36 & $\ldots \ldots \ldots \ldots$ & $\cdots$ & $\cdots$ & 2 & $\cdots$ & $\cdots$ \\
\hline Total. & & & & $\ldots$ & $\ldots$ & $\ldots$ & . & $\ldots \ldots$ & $\ldots$ & 4 & 12 & 7 & .. \\
\hline $\begin{array}{r}\text { Group XI, } \\
\mathrm{F} \times \mathbf{M}:\end{array}$ & & & & & & & & & & & & & $=$ \\
\hline Cri $1 \ldots$ & 37 & 26 & 34 & $\ldots \ldots$ & 45 & 34 & 39 & & & $\ldots \ldots$ & 2 & $\ldots$ & $\ldots$ \\
\hline Hor $5 \ldots$ & M & F & 31 & $\ldots \ldots$ & M & $\mathrm{F}$ & 42 & $\ldots \ldots \ldots \ldots$ & $\ldots$ & $\ldots$ & 6 & 2 & $\ldots$ \\
\hline $\mathrm{McF} 2 \ldots$ & 28 & $\ldots$ & 39 & $\ldots \ldots \ldots \ldots \ldots$ & 35 & 27 & 32 & $\ldots \ldots \ldots \ldots \ldots$ & $\ldots$ & 1 & 2 & 1 & .. \\
\hline Mil 23... & 30 & 37 & 38 & & 40 & 26 & 33 & $\ldots \ldots \ldots \ldots$ & $\ldots$ & $\ldots$ & 1 & 1 & \\
\hline Ofi $1 \ldots$ & S & VF & 33 & $6 \mathrm{~F}, 1 \mathrm{VF} \ldots \ldots$ & $\ldots$ & $\ldots$ & 42 & $2 \mathrm{M}, 3 \mathrm{~F}, 2 \mathrm{VF}$ & $\ldots$ & 2 & & ... & 1 \\
\hline Pot $4 \ldots$ & 35 & 28 & 33 & $\ldots \ldots \ldots \ldots$ & 29 & 43 & 39 & $\ldots \ldots \ldots \ldots \ldots$ & $\ldots$ & $\ldots$ & 1 & 2 & $\ldots$ \\
\hline Sta $7 \ldots$ & 35 & 29 & 34 & $\ldots \ldots \ldots \ldots \ldots$ & 37 & 44 & 43 & $\ldots \ldots \ldots \ldots$ & $\ldots$ & 1 & 2 & 3 & $\ldots$ \\
\hline $\operatorname{Tra} 4 \ldots$ & 39 & 23 & 39 & $\ldots \ldots \ldots \ldots \ldots$ & 37 & 30 & 32 & $\ldots \ldots \ldots \ldots \ldots$ & $\ldots$ & $\ldots$ & 2 & 3 & $\cdots$ \\
\hline Total. & $\cdots$ & & & & $\cdots$ & $\ldots$ & $\cdots$ & $\ldots \ldots \ldots$ & $\ldots$ & 4 & 16 & 12 & 1 \\
\hline $\begin{array}{l}\text { Group } \\
\text { XIII, } \mathrm{F} \times \mathrm{F} \text { : }\end{array}$ & & & & & & & & & & & & & \\
\hline Ber.... & $\ldots$ & $\ldots$ & 50 & $2 S \ldots \ldots \ldots$ & & $\ldots$ & 39 & $1 \mathrm{~S}, 1 \mathrm{VF} \ldots$ & & & 2 & 2 & 3 \\
\hline Hod A... & $\cdots$ & $\because$ & 43 & $1 \mathrm{M}, 2 \mathrm{~F}, 1 \mathrm{VF}$. & & 37 & 38 & $\ldots \ldots \ldots \ldots \ldots$ & $\cdots$ & 2 & 1 & 3 & 4 \\
\hline Mor..... & S & $\mathbf{F}$ & $V F$ & $\ldots \ldots \ldots \ldots \ldots$ & $F$ & $\mathrm{~F}$ & 39 & All F1....... & 1 & 1 & & 2 & 2 \\
\hline Total. . & $\cdots$ & & & (5. & & & $\cdots$ & $\ldots \ldots \ldots \ldots$ & 1 & 3 & 3 & 7 & 9 \\
\hline $\begin{array}{l}\text { Grand } \\
\text { total.. }\end{array}$ & & & & & & & & & 1 & 11 & 31 & 26 & 10 \\
\hline
\end{tabular}
$A, 36.58 \pm 0.51$
S. D., $6.78 \pm 0.26$. 
III 1 of, a farmer, at 35 years, has the formula $140 / 69$; build 2.1 (29); slender; adjusted to 50 years, 2.14 (30). III 2 o, a teacher, at 30 years, $180 / 69$; build 2.7 (38); fleshy; adjusted to 50 years, 2.8 (40). III 3 o a farmer, at 31 years, $175 / 68$; build 2.7 (38) ; fleshy; adjusted to 50 years, 2.8 (40). III 4 \% , married, at 27 years, $150 / 63$; build 2.7 (38); fleshy; adjusted to 50 years, 2.9 (42).

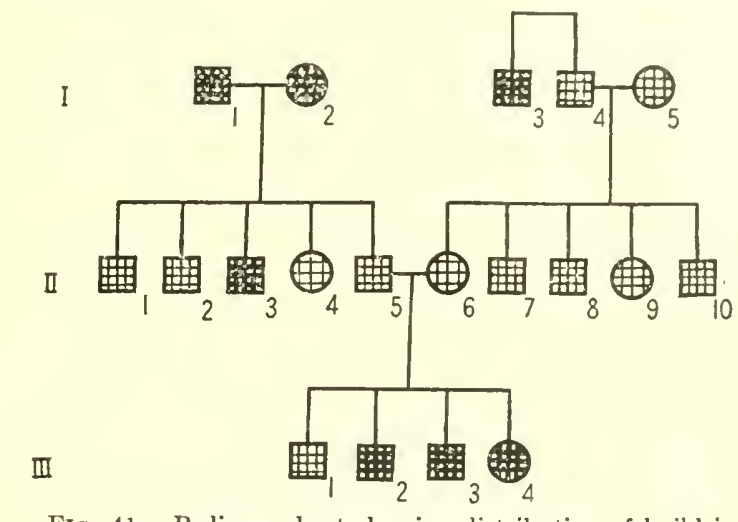

FIG. 41.-Pedigree chart showing distribution of build in BEA-17 family.

Comment.-A mating of prevailingly medium stock with a medium parent from fleshy ancestors yields one slender and 3 fleshy children (R: Bea-17).

\section{CAS-4 FaMiLY.}

A family of English stock, living in New York State. The Father, a farmer and lumberman, had at 60 years the formula 160/69 inches; build 2.4 (34). His father, also a farmer and lumberman, who died of old age at 71 years, had at 38 years the formula 200/72 inches; build 2.7 (39). His mother, who suffered in middle age from consumption, died at 34 years with the formula $110 / 62$ inches; build 2.0 (29).

The Mother, who died at 57 years from catarrh of the stomach, had at 40 years the formula 130/62 inches; build 2.4 (34). Her father, an iron worker, who died at 75 years from fatty degeneration of heart, had the formula 180/65 inches; build 3.0 (43). Her mother, who died at 77 years, had the formula 100/61 inches; build 1.9 (27). The children:

1. Female, who suffered in middle life from rheumatism, had at 40 years the formula 140/63 inches; build 2.5 (35) ; adjusted to 50 years, 146/63 inches; build 2.6 (37).

2. Female, had at 38 years the formula $120 / 63$ inches; build 2.1 (30); adjusted to 50 years $128 / 63$ inches; build 2.3 (32).

3. Male, had at 35 years the formula $180 / 65.5$ inches; build 3.0 (42); adjusted to 50 years, $186 / 65.5$ inches; build 3.0 (43).

4. Female, who suffered in youth from stomach trouble, had at 32 years the formula $135 / 66$ inches; build 2.2 (31); adjusted to 50 years; $147 / 66$ inches; build 2.4 (34).

5. Male, who suffered in youth from stomach and bladder trouble, had at 29 years the formula 190/70.5 inches; build 2.7 (39); adjusted to 50 years, 202/70.5 inches; build 2.9 (41).

6. Male, had at 27 years the formula $155 / 70.5$ inches; build 2.2 (31); adjusted to 50 years, $169 / 70.5$ inches; build 2.4 (34).

Comment.-The 6 children vary greatly in index of build. The index varies from 30 to 42 , despite the similar build of the parents. But the 
grandparents vary from 27 to 43 . This ease suggests the uniformity of $\mathrm{F}_{1}$ and variability of $\mathrm{F}_{2}(\mathrm{R}: \mathrm{Cas}-4)$.

\section{SaII Family.}

The Father, of Scandinarian name and living in New York City, at 50 vears has a stature of $171 \mathrm{~cm}$. $(67$ inches); weight $70 \mathrm{~kg} .(154$ pounds): build $2.4(34.5)$; medium. His father is said to have been slender, his mother fleshy; his sibs intermediate: one fleshy after 48 years. The Mother, at 41 years, has a stature $162 \mathrm{~cm}$. (64 inches); weiglit $61 \mathrm{~kg}$. (136 pounds); build 2.3 (33) ; medium; relative chest-girth $76 \div 162$, or 47 per cent. She has a slender brother and one who is of more medium build. Their parents were of medium build; their mother's father was fleshy (build 2.7 or 39); their mother's mother was "slender."

There is only one child of above mating. She was a full-term baby, who meighed $3.8 \mathrm{~kg}$. ( 8.5 pounds), somewhat above the average. She was always plump as a child and, until 11 years of age, always well. Then she had "discase of the tonsils" and of the kidneys (infection), wrew thin (weighing only $40 \mathrm{~kg}$. [90 pounds]), and developed a chorea. After a year she recovered and began to gatin steadily in weight, and now at the age of 13.7 years she is $170 \mathrm{~cm}$. $(67$ inches) tall, weighs $79 \mathrm{~kg}$. (174 pounds) and has a build of 2.7 (39) ; is fleshy. Relative chest-girth $102 \div 170$, or 60 per cent. Her arms and calves are relatively slender, as they have recently been engaged in linear growth. She has monthy headaches. (Plate 9, fig. 5.)

Comment.-It seems probable that this girl has received factors for fleshiness from each medium parent, which have combined to give her a full set of fleshy factors $(73: 736)$.

\section{IVAR-3 FAMILY.}

A family descended from English and German stock, living in Pennsylvania principally.

The Father, a nurseryman, had malarial fever at 40 . He is now living at 67 years, with a formula $135 / 64$ inches; build 2.3 (33). His father, a nurseryman and horticulturist, died at 89 from a fall. His formula was 140/S; build, say, 2.3 (33). His mother, luving had 5 sons, died at 42 from consumption; she was slender.

The Mother died, at 40 , of child-birth. Her formula was $122 / 62$ inches; build 2.2 (31). Her father, a miller, had a temporary attack of melancholia in middle age. He died at 75 from natural infirmities. His formula was 200/70 inches; build 2.9 (41). Her mother, having had 5 sons and 8 daughters, died of paralysis at 74 . Her formula was 100/62 inches; build 1.8 (26). Ten children are:

1. Male, at 43 , has the formula $125 / 65.5$ inches; build 2.0 (29) ; adjusted to 55 years, $128 / 65.5$ inches; build 2.1 (30).

2. Male, at 41, has the formula 138/68 inches; build 2.1 (30); adjusted to 55 years, $143 / 68$ inches; build 2.2 (31).

3. Female, at 39 , has the formula $120 / 63.5$ inches; build 2.1 (30); adjusted to 55 years, $126.5 / 63.5$ inches; build $2.2(31)$.

4. Male, at 36 , has the formula $158 / 72$ inches; build 2.1 (30) ; adjusted to 55 years, $165 / 72$ inches; build $2.3(32)$.

5. Male, at 53 , has the formula $127 / 67$ inehes; build 2.0 (28); adjusted to 55 years, $136 / 67$ inches; build 2.1 (30).

6. Female, at 31 , has the formula $110 / 64.5$ inches; build 1.8 (26); adjusted to 55 years, $122.5 / 64.5$ inches; build 2.1 (30). 
7. Male, at 29 , has the formula $125 / 6.4$ inches; buile 2.2 131): ardjusted to 55 years, $134 / 64$ inches; build $2.3+(33)$.

8. Female, at 27, has the formula $110 / 62.5$ inches; build 2.0 (28); adjusted to 55 years, $126 / 62.5$ inches; build $2.3(32)$.

9. Male, at 25 years, has the formula 138/68.5 inclues; build 2.0 (29); adjusted to 55 years, $152.5 / 68.5$ incles; build 2.3 (3.3).

10. Female, at 23 years, has the formula $132 / 65$ inches; build 2.2 (31); adjusted to 55 years, $150 / 6.5$ inches; build $2.5(36)$.

Comment.- Tnarljusterl. the indices range from 26 to 31 ; anliusterl. from 30 to 36 . Using adjusted indices, 4 of the children are slenderer than either parent; the parents are doubtles: heterozygums in -tature (R: War-31.

\section{WHI-22 FanILY:}

A family of Fnglish and German extraction, living partly in New York, but mostly in Wisconsin and Minnesota.

The Father, who is a ronstructor, is living at 56 years, having the formula 150/68 inches; build 2.3 (32). His father, who was a farmer and laborer. suffered in middle age from partial paralysis, liad one hand amputated at 48 vears, one foot at 72 rears. He died at 79 vears from "stricture of the bladder," having the formula 200/70 inches; build 2.9 (41). His mother, who is recorded to have suffered from no illness till at 79 years the died from "progressve paralysis," had the formula 110 , 64 inches; build 1.9 (27).

The Mother, who is recorted as always well, has at 54 years the formula 150/65 inches; build 2.5 (36). Her father, who was a farmer, is recorded as always well, died at 55 years from paralysis, laving the formula $150 / 70$ inches; build 2.2 (31). Her mother, who was always well, died at 78 years from old age, having the formula $180 / 64$ inches; build 3.1 (44). Two grown children:

1. Male, who in youth suffered from adenoids, at 25 years has the formula $145 / 68$ inches; build 2.2 (31); adjusted to 55 years, $159 / 68$ inches; build $2.4(34)$.

2. Female, a college student, has at 21 vears the formula $110 / 65$ inches; build 1.8 (26); adjusted to 55 years, 129/65 inches; build 2.2 (31).

Comment.-One of the children has a slighter build than the parents, but may grow heavier (R: Whi-22).

\section{('RI Famll. (Table AI.)}

A family of English extraction; earlier generations in Pennsylrania, the last generation in Kansas. The Father, a lawyer, living at 48 years, suffered in youth from pnemonia, in mildle age from rheumatism, has the formula 165/70 inches; build 2.4 (34). His father, a farmer, suffered in middle age from rheumatism; at 75 years had one leg amputated below the knee; died from "arterio-selerosis ending in gangrene." lraving the formula at 74 years, $180 / 70$ inches; build 2.6 (37). His mother, who suffered from no illnesses, is living at 76 years, having the formula $110 / 65$ inches; build $1.8(26)$.

The Mother, who is subject to heart trouble and small goiter, is living at 43 years, having the formula $145 / 61$ inches; build 2.7 (39). Her 4 brothers are of medium height. Her father, a farmer and public official, died from paraiysis at 57 years, his formula being 190/65 inches; build 3.2 (45). Her mother, who in middle age suffered from heart trouble and goiter, died at 65 years from heart failure, having the formula 150/66 inches; build $2.4(34)$. The 2 grown children: 
2. Female, at 21 years has the formula $125 / 64$ inches; build 2.2 (31); adjusted to 45 years, $140 / 64$ inches; build 2.4 (34).

1. Female, died at 18 years from typhoid fever, having the formula 120/63 inches; build 2.1 (30); adjusted to 45 years, 139/65 inches; build $2.3(33)$.

Comment.-Both the children have the build of the slighter parent (R: Cri-1).

\section{Hor-5 FaMily.}

A family of English extraction, living in the Middle States. The Father, who is "superintendent of bridges and buildings on a railroad," suffered in youth from bilious fever. He has, at 70 years, the formula $140 / 67.5$ inches; build 2.2 (31). One of his brothers died from "tuberculosis of liver." His father, who was a lumberman, died at 77 years from "consumption of the bowels"; was of medium build. His mother died, at 78 years, from Bright's disease; she was corpulent.

The Mother suffered in youth from bilious fever and pleurisy; is living, at 58 years. Formula, 165/63 inches; build 2.9 (42). Her father, who was a millwright, suffered in middle age from bilious fever and morphine poisoning; left eye removed; died at 75 years from "pneumonia (tubercular tendency)"; was of medium build. Her mother, who suffered in youth from typhoid fever, in middle age from paralysis, died at 68 years from paralysis; of fleshy build. Eight grown children:

1. Male, an electrical engineer, has, at 33 years, the formula $155 / 67$ inches; build 2.4 (35) ; adjusted to 55 ycars, 164/67 inches; build 2.6 (37).

2. Female, who in youth suffered from "spinal and nerve trouble," has at 30 years the formula $115 / 63.8$ inches; build 2.0 (28); adjusted to 55 years, 128/63.8 inches; build 2.2 (31).

3. Male, a civil engineer, suffered in youth from typho-malaria. Has at 27 years the formula $157 / 64$ inches; build 2.7 (38) ; adjusted to $55+$ years, $168 / 64$ inches; build 2.9 (41).

4. Female, who has at 25 years the formula $117 / 63$ inches; build 2.1 (30); adjusted to $55+$ years, $134 / 63$ inches; build 2.4 (34).

5. Male, an accountant, who in youth suffered from a "nervous collapse due to a severe electrical shock," has at 23 years the formula $145 / 69$ inches; build 2.1 (30) ; adjusted to $55+$ years, $162 / 69$ inches; build 2.4 (34).

6. Female, who in youth suffered from blood-poisoning, erysipelas, and anemia, has at 21 years the formula $115 / 64$ inches; build 2.0 (28) ; adjusted to 55 + years, $133 / 64$ inches; build 2.3 (33).

7. Male, a pattern-maker, who in youth suffered from hemorrhages, has at 20 years the formula $130 / 67$ inches; build 2.0 (29); adjusted to $55+$ years, $150 / 69$ inches; build 2.2 (32).

8. Male, at 18 years has the formula $135 / 67$ inches; build 2.1 (30); adjusted to $55+$ years, $160 / 70$ inches; build 2.3 (33).

Comment.-The children's indices range between the two parental indices (R: Hor-5).

\section{McF-2 FaMily.}

A family of Irish extraction living in Maine. The Father, who was a shipwright, died at 40 years as a result of an injury received in battle. At 39 years he had the formula 180/68 inches; build 2.7 (39). His father died at 82 years from a "general breakdown," having the formula $145 / 72$ inches; build 2.0 (28).

The Mother, who had 5 children, died at 74 years from apoplexy, having 
the formula at 50 years, 130/64 inches; build 2.2 (32). Her father, who was a farmer, died at 64 years from "fever," having the formula $160 / 68$ inches; build 2.4 (35). Her mother, who in middle age was "struck by lightning," died at 86 years from a "general breakrlown." having the formula 115/65 inches; build $1.9(27)$. The 4 children who grew up:

1. Male, a farmer, who had right arm and three fingers of left hand amputated as result of a wound received in war, is living at 69 years, having at 50 years the formula $140 / 66$ inches; build 2.3 (32).

2. Female, who in middle age underwent an operation for gallstones, has at 40 years the formula $110 / 63$ inches; build $1.9(28)$.

3. Male, a "master mariner," has at 50 years the formula 170/66 inches; build 2.7 (39).

4. Male, an attorney, has at 40 years the formula $160 / 67$ inches; build $2.5(36)$.

Comment.-Three of the children have indices like that of the medium parent; the other is somewhat fleshier ( $\mathrm{R}: \mathrm{McF}-2)$.

$$
\text { MiL-23 Family. }
$$

A family of English extraction, living in New England and Ohio.

The Father, who is a clergyman, and who suffered in middle age from la grippe, is living at 58 years. At 50 years he had the formula $180 / 68.5$ inches; build 2.7 (38). His father, who was a preacher, died at 72 years. At 50 years, formula 130/66 inches; build 2.1 (30). His mother, who had 4 children at 30 years, suffered from typhoid fever. At 50 years, her formula $165 / 66.5$ inches; build 2.6 (37).

The Mother, who has 2 children, suffered in middle age from pleurisy, capillary bronchitis, and nervous prostration. At 50 years her formula, 122/60.5 inches; build 2.3 (33). Her father, who was a bank president, suffered in youth from yellow fever (in West Indies), and in middle age from rheumatism and Bright's disease. At 50 years, his formula 180/67.5 inches; build 2.7 (40). Her mother, who in youth suffered from "lung fever," and in middle age from curvature of the spine and pleurisy, died at 50 years from "anemic condition with tuberculosis, induced by deformity." At 40 years her formula $95 / 60$ inches; build 1.9 (26). 'Two children:

1. Female, a student, who in youth suffered from nervous troubles and diphtheria, has at 33 years the formula $115 / 60.5$ inches; build 2.2 (31); adjusted to 50 years, $125 / 60.5$ inches; build 2.4 (34) .

2. Male, who in youth suffered from throat troubles, diphtheria, scarlet fever, tonsillitis, during war had influenza, slightly gassed. He has at 27 years the formula $180 / 72.5$ inches; build 2.4 (34); adjusted to 50 years, 195/72.5 inches; build 2.6 (37).

Comment.-Each child resembles a different parent ( $\mathrm{R}$ : Mil-23).

$$
\text { Off Family, D. (Fig. 35.) }
$$

II $14 \hat{o}$, a Syrian, at 45 years, stature $165 \mathrm{~cm}$. (65 inches), weight $63 \mathrm{~kg}$. (139 pounds), build 2.3 (33), medium. He had 7 grown sibs, as follows: II 1 \&, short and fleshy; II 3 \%, fleshy but probably heterozygous; married to a slender man she has both fleshy and slender children; II $4 \hat{o}$, fleshy. II 7 o, fleshy. II 10 $\%$, inclined to be fleshy but probably heterozygous, since she had both fleshy and slender children. II 12 \%, fleshy, but has some slender as well as medium children. II 13 ô, very fleshy. Of the foregoing fraternity the father was slender and the mother very fleshy. From the builds of his parents and the issue of his sibs we may conclude that II 14 carries factors for slenderness. 
II 15 q, the wife of II 14 , at 38 years lias a stature of $153 \mathrm{~cm}$. (60 inches); weight $69 \mathrm{~kg}$. (151 pounds); build 2.9 (42); fleshy (and has been fleshier); her relative chest-girth is 61 per cent. She has had 7 sibs, as follows: II 16 o , very fleshy; II 17 o , at 50 years, stature $151 \mathrm{~cm}$. (59 inches); weighs $56 \mathrm{~kg}$. (124 pounds); build 2.5 (36); medium; relative chest-girth 63 per cent; II 18 o, "plump." II 20 q, very fleshy and has 3 slender children; II 21 \&, "plump." II 22 ô, of medium build. II 23 \&. at 31 rears, stature $150 \mathrm{~cm}$. (59 inches); weight $69 \mathrm{~kg}$. (151 pounds); build 3.0 (43) ; fleshy; relative ehest-girth 67 per cent.

The father of the foregoing fraternity was slender and the mother fleshy. Henee it seems probable that some or all of the mother's fraternity carry a gene for slenderness.

The children of II 14 and 15 are 4 in number. III 14 의, at 16 years has stature of $157 \mathrm{~cm}$. (62 inches) ; weight $44 \mathrm{~kg}$. (97 pounds); build 1.9 (27); slender; III 15 q. 15 years, stature $145 \mathrm{em}$. (57 inches); weight $85 \mathrm{~kg}$. (187 pounds); build 4.0 (57) ; very fleshy; relative chest-girth, 78 per cent; she began to grow fleshy at 5 years; is a very heary eater; III 16 o , 9 years, is slender, and III 17 was at 4 years a very fat baby, but is now a slender ebild.

Comment.-Slenderness and fleshiness oeeur in the same fraternity; the eventual proportions ean not yet be stated, since two of the children are very young $(73: 697)$.

$$
\text { Pot-4 FaMily. }
$$

A family of British extraction; living chiefly in Illinois.

The Father, who is a farmer, suffered in youth from typhoid fever; is living at 52 years, having the formula $150 / 67$ inches; build 2.3 (33). His father, who was a farmer and in middle age subject to heart trouble, died at 57 years from lieart failure. His formula 170/70 inches; build 2.4 (35). His mother, who has always been well, is living at 77 years, having at 74 vears the formula $105 / 61$ inches; build $2.0(28)$.

The Mother, who has 5 children, has always been well. She is living at 48 years, having the formula $165 / 65$ inches; build 2.7 (39). Her father, who was a farmer, in middle age suffered from a nervous breakdown; he died at 71 years of apoplexy, having the formula $150 / 72$ inches; build 2.0 (29). Her mother, who died at 67 years from erysipelas, had the formula 200/68 inches; build 3.0 (43). Three grown children:

1. Nale, a chemist, always well, has at 24 years the formula $160 / 71$ inches; build 2.2 (32) ; adjusted to 50 years, 177/71 inches; build 2.5 (35).

2. Male, farmer, always well, has at 22 years the formula $155 / 66.5$ inches; build 2.5 (35); adjusted to 50 years, 168/66.5 inches; build 2.7 (38).

3. Female, a student at college, always well, has at 18 years the formula $135 / 64$ inches; build 2.3 (33); adjusted to 50 years, $156 / 64$ inches; build $2.7(38)$.

Comment.-The children's builds lie between those of the parents (R: Pot-4).

$$
\text { S'TA-7 FAMILY. }
$$

A family of German extraction, living in the Central States.

The Father, who is a farmer, suffered in middle age from sciatic rheumatism; he is living at 69 years, liaving the formula $165 / 70$ inches; build 2.4 (34). His father, who was a farmer, was always well; he died from apoplexy at 87 years, having the formula $155 / 67$ inches; build 2.4 (35). His mother died from heart trouble at 69 years, having the formula $130 / 67$ inches; build 2.0 (29). 
The Mother has alway's been well; she is living, at 59 years, having the formula $165 / 62$ inches; build 3.0 (43). Her father, who was a carpenter and farmer, was always well; he died from "olıl age, hard work, and exposure" at 73 years, having the formula 170/68 inches; build 2.6 (37). Her mother, who was always well, died from apoplexy at 72 years, having the formula $170 / 62$ inches; build 3.1 (44). Six children:

1. Male, who is a real-estate agent, always well, has at 34 years the formula $166 / 70$ inches; build 2.4 (34); adjusted to 65 years, $174 / 70$ inches; build $2.5(36)$.

2. Female, married, has always been well, has at 32 years the formula $118 / \mathrm{M}$; build, say, 2.1 (30).

3. Female, a school teacher, suffered in youth from appendieitis, has at 29 years the formula $124 / \mathrm{S}$; build, say, $2.3(33)$.

4. Male, a teacher, in youth suffered from typhoid fever; has at 28 years the formula $162 / 69$ inches; build 2.4 (34); adjusted to 65 years, $175 / 69$ inches; build 2.6 (37).

5. Male (twin of No. 4), a salesman, has at 28 vears the formula $160 / 68$ inches: build 2.4 (35) ; adjusted to 65 years, $172 / 68$ inches; build 2.6 (37).

6. Male, a teacher, always well; at 24 year's has the formula $162 / 69$ inches; build 2.4 (34); adjusted to 65 years, $178 / 69$ inches; build 2.6 (37).

Comment.-The children are fairly uniform in build, mostly falling in the mediun elass ( $\mathrm{R}:$ Sta-7).

\section{TRA-4 FAMILY.}

A family of English extraetion, living in Canada and the eastern United States.

The Father, who was a station-master, died at 86 years from diabetes, having the formula $200 / 72$ inches; build 2.7 (39). He was a first cousin to his wife. His father, who was a "eustoms-house officer," died at 72 years from "typhoid pneumonia," having the formula 200/72 inches; build 2.7 (39). His mother, who had 1 child, was always well, died at 91 years from "old age." Formula, 90/63 inches; build 1.6 (23).

The Mother, who had 6 children, was "never very strong-nervous," suffered in middle age from acromegalia and diabetes mellitus, iritis, and cataract. She died at 65 years from acromegalia, having the formula $140 / 66$ inches; build 2.3 (32). One of her sisters died at 26 years from epilepsy; one brother died from apoplexy, "very tall and stout." Her father, who was a "elerk in a freight office," died at 76 years from pneumonia, having the formula $190 / 72$ inches; build $2.6(3 \bar{i})$. Her mother, who had a weak heart, died at 89 years from old age and apoplectic strokes; formula, 120/M; build, say, 2.1 (30). Five grown ehildren:

1. Female. has at 47 years the formula $140 / 66$ inches; build 2.2 (32); adjusted to 55 years, $142 / 66$ inches; build 2.3 (33).

2. Male, who is a telegraph operator, suffered in youth from dyspepsia, has at 45 years the formula $190 / 71$ inches; build 2.7 (38) ; adjusted to 55 years, 192/71 inches; build 2.7 (38).

3. Male, a telegraph operator, who in youth suffered from rheumatic fever, has at 44 years the formula $210 / 71$ inches; build 3.0 (42).

4. Female, a physician, has at 42 years the formula $135 / 68$ inches; build 29 ; adjusted to 55 years, $143 / 68$ inches; build 2.3 (32).

5. Male, a draughtsman, always well, has at 39 years the formula $210 / 73$ inches; build 2.7 (39) ; adjusted to 55 years, formula 216/73 inches; build 2.9 (41).

Comment.-The children are variable (like the grandparents), ranging from medium to fleshy ( $\mathrm{R}:$ Tra -4$)$. 


\section{Ber FaMily. (Fig. 42.)}

I 5, J. B., male, born in Germany, was $175 \mathrm{~cm}$. tall (68.9 inches) and weighed $108.8 \mathrm{~kg}$. (240 pounds); build $3.5(50)$. He died at 79 years of Bright's disease. He had 2 sisters who were slender. His wife was $152 \mathrm{~cm}$. (59.8 inches) tall and weighed $63.5 \mathrm{~kg}$. (140 pounds), build 2.7 (39). One of her brothers was $183 \mathrm{~cm}$. (72 inches) tall and weighed $113 \mathrm{~kg}$. (250 pounds); build 3.4 (48); but another brother was slender, about 2.1 (30). This mating may or may not be of heterozygous parents.

There were 7 children who grew up. II 4 , male, $176 \mathrm{~cm}$ (69 inches) tall and weighing at the time of his death (at 50 years from "heart disease") about $215 \mathrm{~kg}$. ( 475 pounds); build 7.0 (100), an extraordinarily obese man. This man was fleshy as a child. The next brother (II 6) remained single, dying at 45 years. His stature $170 \mathrm{~cm}$. (67 inches) and weight $77 \mathrm{~kg}$. (170 pounds) ; build 2.7 (38). The next brother, II 7 , died at 54, single. $\mathrm{He}$ was $183 \mathrm{~cm}$. (72 inches) tall and weighed $118 \mathrm{~kg}$. (260 pounds); build 3.5

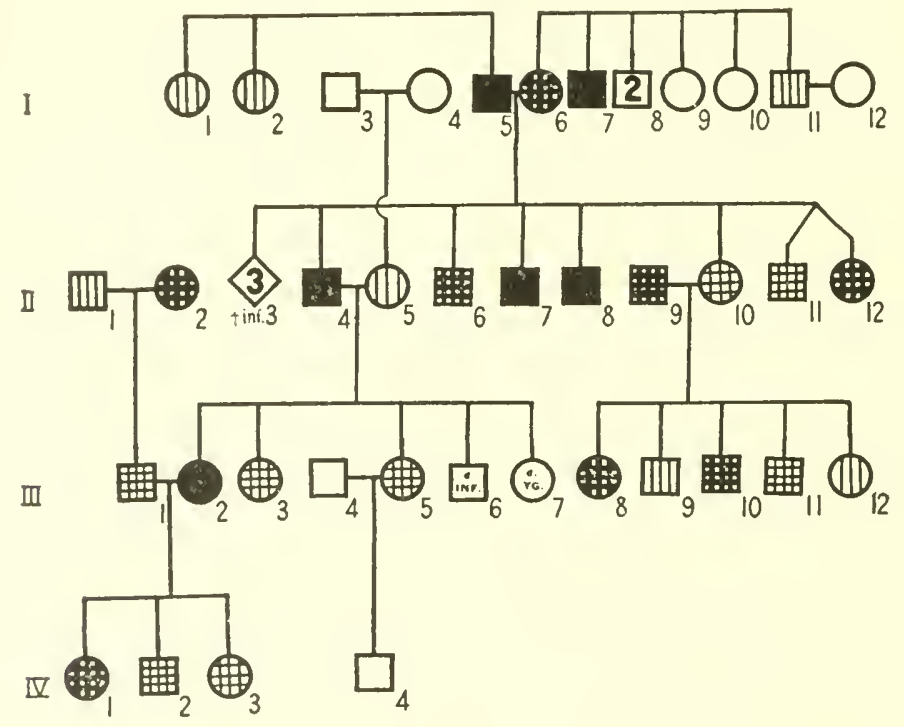

FIG. 42.-Pedigree chart showing distribution of build in BEr family.

(50); thus very fleshy. The next brother (II 8) was slender as a child and began to put on flesh at 19 years. His stature is $175 \mathrm{~cm}$. (69 inches). At 25 he weighed $93 \mathrm{~kg}$. (205 pounds); at 33 years, $115 \mathrm{~kg}$; ; at 35 years, $136 \mathrm{~kg}$; at 41 years, $163 \mathrm{~kg}$; at $52,172 \mathrm{~kg}$. and now at 57 years over 180 kg. or 400 pounds. This increase of weight occurred despite dieting and reducing cxercises. He is a very hearty eater. He is fat all over the body, especially hips, abdomen, and shoulders. He has remained single.

Next in order is II 10, who died at 46 years of rheumatism of the heart. She was $175 \mathrm{~cm}$. (69 inches) tall and weighed $73 \mathrm{~kg}$. (160 pounds); build 2.4 (34) or medium. Last was a pair of twins. II 11 , male, $182 \mathrm{~cm}$. (72 inches) tall and weighs $79 \mathrm{~kg}$. (176 pounds); build 2.4 (34); thus medium. The other twin, II 12, is a woman, who at 38 is $165 \mathrm{~cm}$. (65 inches) tall and weighs about $82 \mathrm{~kg}$. (180 pounds) ; build 3.0 (43). She is thus fleshy.

Comment.-Thus 5 of the fraternity are fleshy (2 enormously obese) and 2 are of medium build. Thus we have a proportion of 2 medium to 5 very 
fleshy, approaching a $1: 3$ ratio; or a ratio may be recognized of 2 medium, 3 fleshy to very fleshy, and 2 obese; approximately a $1: 2: 1$ ratio $(73: 646)$.

\section{HOD-A FAMILY.}

A family of English extraction from Illinois. The Father, at 84 years, had the formula $230 / 69$ inches: build 3.4 (48). Of his 4 sibs: (1) brother, at 60 years had the formula $200 / 70$ inches; build 2.9 (41); (2) sister, at 65 years, 200/64 inches; build 3.4 (49); (3) sister, at 68 years, 180/66 inches; build 2.9 (41) ; (4) sister, at 60 years, 130/60 inches; build 2.5 (36).

The Mother, at 50 years, 150/63 inches; build 2.7 (38). Her mother, at 86 , had the formula $150 / 64$ inches; build 2.6 (37). The 10 children are:

1. Male, at 55 years har the formula $242 / 69$ inches; build 3.6 (5) 1 .

2. Male, at 60 years, $125 / 66$ inches; build 2.0 (28).

3. Male, at 21 years, $180 / 69$ inches; build 2.7 (38) ; adjusted to 55 years, 199/69 inches; build 3.0 (42)

4. Male, at 49 years, $210 / 67$ inches; build 3.3 (47).

5. Male, at 45 years, $190 / 67$ inches; build 3.0 (42).

6. Male, at 47 years, $225 / 69$ inches; build 3.3 (47).

7. Male, at 37 years, $180 / 66$ inches; build 2.9 (41); arljusted to 55 years, 185/66 inches; build 3.0 (43)

8. Female, at 57 years, $125 / 64$ inches; build $2.2(31)$.

9. Female, at 53 years, $115 / 64$ inches; build 2.0 (28).

10. Female, at 39 years, had the formula $200 / 65$ inches; build 3.3 (47); adjusted to 55 years, $206 / 65$ inches; build 3.4 (49).

Comment.-This pedigree has a special interest because the original data gave the Father's build as 26 and the Mother's as 28. This led to correspondence which yielded the revised results according to which this fraternity is the progeny of parents who grew fleshy in their later years, stout instead of slender parents. Of the 10 children, 2 are slender, 1 medium, 3 stout, and 4 very stout (S:Hod-A).

\section{Mor Fanilly. (Fig. 24.)}

III 13 ô, short, in middle life weighed $90 \mathrm{~kg}$. (200 pounds); very fleshy. In later life he has grown slenderer. His mother was fleshy, like himself, but his father was slender; consequently he is heterozygous.

III 14 q, wife of above, is less than $153 \mathrm{~cm}$. (60 inches) tall and weighs about $63 \mathrm{~kg}$. (140 pounds); build 2.7 (39); fleshy. At the time of her marriage she weighed $43 \mathrm{~kg}$. (96 pounds); build 1.9 (27); slender. Her fraternity of 7 , of whom 5 are fleshy, 1 medium, and 1 slender. Their 2 Nevertheless, III 14 apparently contains some non-fleshy genes, as indicated by her 6 children:

(1) IV 10 \%, was stout as a child; when married at 24 years she weighed $75 \mathrm{~kg}$. (164 pounds); build 2.7 (39); fleshy. Now, at 41 years, she is 161 cm. (63.5 inches) tall, and weighs, net, $93 \mathrm{~kg}$. (206 pounds); build 3.6 (52); very fleshy. For the past 7 years her weight has been invariable. Her net relative chest-girth is $108 \div 161=68$ per cent. She married a man of build 3.7 (53), very fleshy, of relative chest-girth of 69 per cent. He is one of a fraternity of $\overline{7}$, of whom 5 are fleshy, 1 medium, and 1 slender. 'Their 2 children are (a) $\hat{\delta}$, who weighed $7.5 \mathrm{~kg}$. (16.5 pounds) at birth, instead of the average of about $3 \mathrm{~kg}$, and died at the age of 2 days, requiring a casket large enough for a year-old child; (b) , at 13 years is $152 \mathrm{~cm}$. (60 inches) tall, and weighis $63 \mathrm{~kg}$. (139 pounds); build 2.7 (39); fleshy; relative chest-girth $97 \div 152$, or 64 per cent. She weighed $5.6 \mathrm{~kg}$. at birth, 
grew slenderer to 5 ycars, and since then stouter. This seems like a pure line for fleshiness.

(2) IV 12 of, is of about the build 2.6 (37) or slightly fleshy.

(3) IV 15 올 at 47 years is $153 \mathrm{~cm}$. (60 inches) tall, and weighs $75 \mathrm{~kg}$. (165 pounds) ; build 3.2 (46) ; very fleshy. Like her mother, she was slender until 39 years of age.

(4) IV 17 \% at 44 years is slightly fleshy.

(5) IV 19 o , is tall and "very slender"; by a very slender husband she has 3 children, all slender.

(6) IV 20 오, at 38 years is slender.

Comment.-Thus, of the 6 ehildren, 1 is very slender, 1 is slender, 2 fleshy, and 2 very fleshy-an exceedingly variable progeny. Evidently some of the gametes from both parents are responsible for the result $(73: 690)$.

\section{REMARKS.}

The mating of two heterozygous parents produces, in general, an exceptionally variable progeny. This is one of the strongest evidences of the presence of genetical factors in build. The result can not, so far as I can see, be adequately explained on any other than the genetical basis. As an illustration of such variability in full sibs, plate 9 , figure 4, is striking. Such differences are frequently found in the offspring of heterozygous parents.

Mating 2. Other Medium $\times$ Medium Matixgs (Table $\mathrm{X}$ ).

This mating is important for deciding between the hypotheses $(a)$ that medium build is the heterozygous condition between slender and fleshy; (b) that "medium" represents an hereditary type (biotype) as truly as slender does; $(c)$ that the "medium" group is a combination of cases of the heterozygous condition and a distinct biotype.

First, it appears that the mating is the commonest one in our records, except medium $\times$ fleshy. But this is to be expected, inasmuch as the medium grade of build is the commonest grade.

Second, the variability of the progeny is small, $4.05 \pm 0.11$. The only mating that has a less variable progeny is $\mathrm{S} \times \mathrm{S}, 2.41 \pm 0.17$. This result, shown in table 12 , indicates that the persons of medium build are, for the most part, not heterozygous, but belong to a distinct biotype. On the other hand, $\mathrm{M} \times \mathrm{M}$ matings from table $\mathrm{X}$, selected mostly on account of dissimilar build of parents, give progeny distributed nearly in a $1: 2: 1$ ratio, such as is got in the second generation of a mono-hybrid. It seems probable, accordingly, that hypothesis $(c)$ is correct, but that the cases of medium that belong to a distinct biotype are much more numerous than the cases of medium parents who are heterozygous. 


\section{SUMMARY AND DISCUSSION.}

The matings selected because most obviously adapted to give an $\mathrm{F}_{2}$ progeny produced an offspring about one-third more variable than the $F_{1}$ progeny. The wide range of variability of the $F_{2}$ progeny is more in aceordance with the hypothesis of 6 zygotie factors for build than that of 4 zygotic factors.

The mating of two "medium-build" parents gives a progeny that is not very variable in build; not more variable than the progeny of the $\mathrm{S} \times \mathrm{F}$ mating. The result is like that obtained in studies in heredity of stature, where the progeny of the $\mathrm{M} \times \mathrm{M}$ was not extremely variable. This result, in the case of build, that the medium build is relatively invariable, suggests that some persons of medium build really belong to a biotype in which fleshy build is due to 4-zygotic factors, and that such parents are zygotically of the AAbb type, and produce offspring of whom 100 per cent are again of that type. Examples would seem to be found in the following families with 4 or more children: Bat-2, Bea-7, Kel-4a, Old-2, Rig-1, War-3! There is, of course, genetical justification for the assumption that the same character may in certain strains be due to 3 gametic factors, in others to only 2. This is especially well shown in susceptibility to tumorgrowth of mice.

\section{Class V. The "Back-Cross."}

The mating of heterozygous individuals with the "pure" recessives of the parental stock, as well as with "pure" dominants, is an important procedure in genetics, in order to determine the number of factors involved in the trait. This mating is of especial importance in detecting "erossing over," but our data are insufficient to permit use for this purpose. Though the total of our data is considerable, yet the nature of traits due to multiple factors is such that the table has to be broken up into a large number of small ones, of which the "constants" are subject to large probable errors. It seems best to distinguish two kinds of matings: (1) heterozygous medium or fleshy $\times$ slender, and (2) heterozygous fleshy $X$ fleshy (or very fleshy) of fleshy stock.

Mating 1. Heterozygots Medum or Fleshy $\times$ Slender.

The data for this analysis are in table 32 , which contains the apparently most significant matings from Appendix tables III, IV, and VIII.

The totals of table $32, b+c$, give the following proportions: $3 \mathrm{VS}$, $26 \mathrm{~S}, 36 \mathrm{M}, 20 \mathrm{~F}, 4 \mathrm{VF}$.

The matings of 4-factor and 2-factor parents respectively give a distribution of two types. Uniting these (on the assumption that they are equally numerous), we get proportions as follows: $3 \mathrm{VS}$. $25 \mathrm{~S}, 44 \mathrm{M}, 25 \mathrm{~F}, 3 \mathrm{VF}$.

This theoretical series is of the same general type as that given by the data, and the agreement (considering all of the unknown factors) 
is fairly close. The details of the family histories included in table 32 are given below.

\section{ACh-2 Family.}

A family of English and probable Scotch stock. The family residence is now located in Oregon, in which State the 3 children of the third generation were born. The Father, a mechanic, inclined to rheumatism and nervousness, has at 50 years the formula 150/69 inches; build 2.3 (32). His sibs

TABLE 32.-Matings of a heterozygous parent, of either medium or fleshy build, and a slender parent, together with the progeny of this back-cross.

(a) From Table III, VS $\times$ M (S).

\begin{tabular}{|c|c|c|c|c|c|c|c|c|c|c|c|c|c|}
\hline \multirow{2}{*}{ Ref. } & \multicolumn{7}{|c|}{ Parentage. } & \multicolumn{6}{|c|}{ Offspring. } \\
\hline & FF & FM & $\mathrm{F}$ & $\begin{array}{l}\text { Father's } \\
\text { sibs. }\end{array}$ & MF & $\mathbf{M M}$ & $M$ & $\begin{array}{l}\text { Mother's } \\
\text { sibs. }\end{array}$ & Vs & $\mathbf{S}$ & $M$ & $F$ & VF \\
\hline Ach $2 \ldots$ & 32 & 33 & 32 & $\ldots \ldots \ldots \ldots$ & 32 & 27 & 25 & & & 1 & 2 & $\ldots$ & \\
\hline Bic 1.. & 29 & 35 & 34 & & $M$ & $\mathrm{~S}$ & 25 & 4 t. . . & & 1 & 2 & $\ldots$ & . \\
\hline Gru 1. & $M$ & $M$ & 31 & $1 t \ldots \ldots \ldots$ & M & S & 24 & $\ldots \ldots$ & $\ldots$. & 1 & 1 & ... & $\ldots$ \\
\hline Ise 2. & 26 & 31 & 31 & $\ldots \ldots \ldots \ldots$ & 31 & 27 & 23 & & & 2 & 5 & .... & $\ldots$ \\
\hline Mil A. & 39 & $2 S$ & 36 & $1 \mathrm{~S}, 1 \mathrm{M}, 3 \mathrm{~F} \ldots$ & 35 & 30 & 22 & & 1 & $\ldots$ & 3 & 3 & $\ldots$ \\
\hline Wit $2 \ldots$ & 26 & M & 33 & $\ldots \ldots \ldots \ldots \ldots$ & M & $\mathrm{t}$ & 22 & $2 t \ldots \ldots \ldots$ & $\cdots$ & 2 & 1 & $\ldots$ & $\cdots$ \\
\hline Total. . & $\cdots$ & $\cdots$ & $\cdots$ & $\ldots \ldots$ & $\cdots$ & $\cdots$ & $\ldots$ & $\ldots \ldots$ & 1 & 7 & 14 & 3 & $\ldots$ \\
\hline
\end{tabular}

A, $32.34 \pm 0.59$; S. D., $4.38 \pm 0.42$.

(b) From Table IV, VS $\times$ F $(\mathrm{S})$.

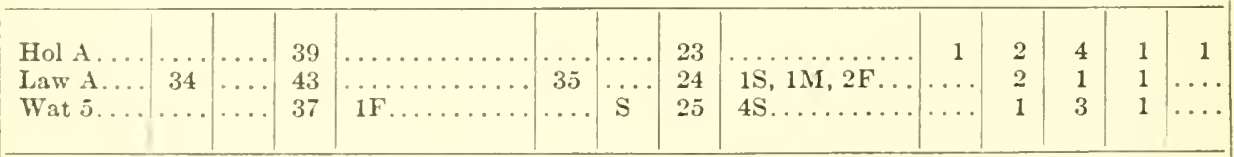

(c) IN PART FRom Table VIII, $\mathrm{S} \times \mathrm{F}(\mathrm{S})$.

\begin{tabular}{|c|c|c|c|c|c|c|c|c|c|c|c|c|c|}
\hline Gui $3 . .$. & & & 27 & & 34 & 30 & 39 & & & 1 & 3 & 3 & \\
\hline Hok 1 .... & 36 & $\mathrm{~S}$ & 37 & $\begin{array}{l}\cdots \\
\ldots \ldots \ldots \ldots\end{array}$ & 31 & 35 & 27 & $\ldots \ldots \ldots \ldots$ & & $\ldots$. & 2 & $\ldots$ & $\cdots$ \\
\hline Hot $1 \ldots$. & M & $\mathrm{S}$ & 30 & & $\mathrm{~S}$ & S & 40 & $\ldots \ldots \ldots \ldots$ & $\ldots$ & . & 1 & .... & $\ldots$ \\
\hline Hul 2... & 34 & 25 & 30 & $\ldots \ldots \ldots \ldots$ & 35 & 27 & 37 & $\ldots \ldots \ldots \ldots \ldots$ & 2 & 4 & 1 & $\ldots$ & .. \\
\hline Kie...... & & $\ldots$ & S & $\ldots \ldots \ldots \ldots \ldots$ & $\cdots$ & $\cdots$ & $F$ & $\ldots \ldots \ldots \ldots \ldots$ & ... & 2 & $\ldots$ & 2 & $\ldots$ \\
\hline Leo (a)... & $\mathrm{S}$ & $\mathrm{S}$ & S & $4 \mathrm{~S} \ldots \ldots \ldots$ & $\mathrm{F}$ & $\mathrm{S}$ & 51 & $3 \mathrm{~S}, 3 \mathrm{~F} \ldots \ldots$ & $\cdots$ & $\cdots$ & $\cdots$ & 1 & $\cdots$ \\
\hline Leo (b)... & & $\ldots$ & S & $\ldots \ldots \ldots \ldots$ & $\cdots$ & & 51 & $\ldots \ldots \ldots \ldots$ & $\ldots$ & 2 & $\cdots$ & 1 & 3 \\
\hline Lyn $2 \ldots$ & S & $F$ & 37 & $\ldots \ldots \ldots \ldots \ldots$ & S & $M$ & 29 & $\ldots \ldots \ldots \ldots$ & ... & $\cdots$ & 1 & $\cdots$ & $\cdots$ \\
\hline Mer B.... & 47 & 27 & 40 & $\ldots \ldots \ldots \ldots$ & 37 & 36 & 25 & & $\cdots$ & 1 & 3 & 1 & $\cdots$ \\
\hline Mor (a)... & $\cdots$ & $\ldots$ & 50 & . & & & S & & ... & & 10 & 3 & $\cdots$ \\
\hline Mor (b)... & & & $S$ & & $\mathrm{~F}$ & $\mathbf{F}$ & $\mathbf{F}$ & $2 \mathrm{~S}, 2 \mathrm{~F} \ldots \ldots$ & $\cdots$ & 4 & $\cdots$ & $\cdots$ & $\cdots$ \\
\hline Mor (c)... & F & M & $\mathrm{F}$ & $1 \mathrm{~S}, 1 \mathrm{MI}, 4 \mathrm{~F} \ldots$ & $\cdots$ & $\cdots$ & S & $1 S \ldots \ldots \ldots$ & $\ldots$ & 2 & $\ldots$ & $\cdots$ & $\cdots$ \\
\hline Pad 1. & 31 & 35 & 28 & $\ldots \ldots \ldots \ldots \ldots$ & 33 & 23 & 37 & & $\cdots$ & $\cdots$ & $\cdots$ & 1 & $\cdots$ \\
\hline Rid $1 \ldots$ & $F(?)$ & $\mathbf{M}(?)$ & 42 & $3 \mathrm{~F}$. & s & S & S & . & $\ldots$ & 2 & $\cdots$ & $\cdots$ & $\cdots$ \\
\hline Rom 1... & $\mathrm{S}$ & F & 38 & $3 t \ldots \ldots \ldots$ & $\mathrm{F}$ & M & 28 & & $\ldots$ & $\cdots$ & 6 & 1 & $\cdots$ \\
\hline Van & $\cdots$ & $\ldots$ & 42 & $1 S, 1 F \ldots \ldots$ & $\cdots$ & $\ldots$ & S & $1 \mathrm{MI} \ldots \ldots \ldots$ & $\ldots$ & 2 & $\cdots$ & 3 & $\cdots$ \\
\hline Wat..... & $\mathrm{S}$ & $\mathrm{F}$ & 27 & $\ldots \ldots \ldots \ldots$ & 26 & 45 & 40 & $\ldots \ldots \ldots \ldots$ & $\cdots$ & 1 & 1 & 1 & $\cdots$ \\
\hline Total. . & & & & & & & & $\ldots$ & 3 & 26 & 36 & 20 & 4 \\
\hline
\end{tabular}
A, $33.67 \pm 0.40$.
S. D., $5.58 \pm 0.28$. 
are all tall (and presumably slenter). His father, a farmer, died when 78 years old, having at 40 years the formula $150 / 69$ inches; build 2.2 (32). His mother, after having borne 6 sons and 5 daughters, died of cancer at 70 years. At that time she had the formula $125 / 62$ inches; build 2.3 (33). Thus, the Father's fraternity, though their parents were of medium build, apparently carries a slender tendency.

The Mother suffers from "rheumatism"; she is "always busy" and is living at 51 years, with the formula $93 / 61$ inches; build 1.8 (25). Her father, a farmer, died at 82 with the formula $150 / 69$ inches; build 2.2 (32). Her mother, having had 5 sons and 4 daughters, died of "heart trouble" at 42 years. She had the formula $100 / 61$ inches; build $1.9(27)$. Thus this side of the house inclines toward slenderness. The 3 children are:

1. Female, a bookkeeper and "nervous," at 26 has the formula $95 / 65$ inches; build 1.6 (23) ; adjusted to 50 years, 112/65 inches; build 1.8 (27).

2. Female, a bookkeeper, and "energetic" and "nervous," at 22 has the formula $120 / 67$ inches; build 1.9 (27); adjusted to 50 years, $139 / 67$ inches; build $2.2(31)$.

3. Female, a bookkeeper and "energetic, impulsive, and agile," has at 23 the formula $112 / 63$ inches; build 1.9 (28); adjusted to 50 years, $129 / 63$ inches; build 2.3 (33).

Comment.-A medium Father of medium and slender stock marries a slender, nervous woman who has a slender mother. One of the children is exceptionally slender and two are slender according to the unadjusted index. It is very doubtful if the most slender child would ever acquire the adjusted index of 27, though children Nos. 2 and 3, energetic and agile at 23 and 22 years respectively, with builds $1.9(28)$ and $2.0(27)$, may well acquire a medium build by maturity if they become less active ( $\mathrm{R}: \mathrm{Ach}-2)$.

\section{BiC-1 FaMily.}

A family of English and French extraction living mostly in Kentucky and Indiana. The Father, a newspaper publisher, suffered in youth from typhoid fever. He is living at 52 years, having at 45 years the formula $175 / 72$ inches; build 2.4 (34). His father, a justice of the peace, died at 39 years from pulmonary tuberculosis contracted during the Civil War. At 26 years he had the formula $140 / 70$ inches; build 20 (29). His mother, who had 4 children, suffered in middle age from eancer. She is living at 76 years. At 40 years her formula was $160 / 68$ inches; build 2.4 (35). Thus the father is of mixed ancestry; he is probably heterozygous in respect to build.

The Mother has been subject to tuberculosis of throat and lungs. She is living at 51 years, having at 45 years the formula 102/64 inches; build 1.7 (24). Four of her sibs died from tuberculosis of throat and lungs. Her father, a revenue collector, suffered in youth from rheumatism and in middle age from "very bad throat trouble." He died at 85 years from old age. At 45 years he was of medium build. Her mother, who had 9 children, always well, died at 85 years from malignant tumor. At 45 years she was slender. This side of the house is very slender, largely on account of tuberculosis. The grandfather is of medium build; the grandmother was nervously active and slender. The 3 children:

1. Female, a social worker, who in youth suffered from diphtheria, tonsillitis, and adenoids, has at 23 years the formula 105/64 inches; build 1.8 (26); adjusted to 45 years, 2.1 (29). (R : Bic-1.)

2. Female, a college graduate, who in youth suffered from tonsillitis, scarlet fever, and appendicitis and had a tendency to consumption, has at 
22 years the formula $126 / 66$ inches; build 2.0 (29); adjusted to 45 rears, $142 / 66$ inches; build 2.3 (33).

3. Female, a student. who has a "nervous temperament," has at 18 vears the formula $124 / 67$ inclies: build 2.0 (28); adjusted to 45 vears, $143 / 67$ inches; build $2.3(32)$.

Comment.-The tuberculous tendeney of the Mother's fraternity and of the Father's father reappears in at least one of the children. None is as slender as the Mother, and all approach the medium grade ( $\mathrm{R}$ : Bic-1).

$$
\text { GRT-1 FAMILY. }
$$

A family of English and German extraction living mostly in Penncylrania and New Jersey. The Father, a school-teacher and principal, is living at 52 years, having had at 45 vears the formula $134 / 66$ inches; build 2.2 (31). One of his brothers died of "consumption" and was apparently slender. His father, a farmer, often mentally depressed, is living at 75 vears, and has a "medium" build. His mother, who had 10 ehildren, and who suffered in middle age from rheumatism, is living at 73 vears, and is of "medium" build. Thus the paternal inheritance is toward medium build; the father possibly heterozygous.

The Mother suffered in middle age from inflammatory rheumatism; she has at 40 years the formula $106 / 66$ inches; build $1.7^{\prime}(24)$. Her father, a farmer, of medium build, died at 77 years from pneumonia. Her mother, who had 6 children, died at 77 years from arterio-sclerosis; she was slender. Thus the maternal build is prevailingly slender, though the grandfather is of medium build. The 3 children:

1. Female, a teacher, who in youth suffered from diphtheria, has at 20 years the formula $110 / 65$ inches; build 1.8 (26); adjusted to 42 years, $125 / 65$ inches; build 2.1 (30).

2. Female, a student, who in vouth suffered from infantile paralysis, has at 18 years the formula $120 / 64$ inches; build 2.1 (29); adjusted to 42 years, $136 / 64$ inches; build 2.3 (33).

3. Female, at 13 years, has already the build of her next older sister.

Comment.-All the children have a heavier build than the slenderer parent and approach a medium build ( $R$ : Gru-1).

$$
\text { IsE-2 FAMILY. }
$$

A family of Swiss and French origin living in Kansas. The Father, who is of Swiss parentage, a farmer, is living at 86 years, having the formula $150 / 68$ inches; build 2.3 (32). His father, a farmer, died of consumption, having the formula $120 / 68$ inches; build 1.8 (26). His mother, who had 8 children, died at 82 years from pneumonia, having the formula $130 / 65$ inches; build 2.2 (31). This side of the house is of mixed slender-medium build.

The Mother, who has had 11 children, is of French-Swiss stock and has been a farmer's wife in Kansas. She has been operated upon for glaucoma, is living at 72 years, and has the formula 88/62 inches; build 1.6 (23). Her father, a farmer, died from neuralgia of heart, having the formula 130/65 inches; build 2.2 (31). Her mother, who had 3 children, died at 46 years, suddenly, perhaps from appendicitis, having the formula $115 / 65$ inches; build 1.9 (27). The maternal side of the house has thus a build ranging from very slender to slender-medium. The 8 ehildren about whom information is given are: 
1. Male, a college professor, died at 42 years after an operation for appendieitis, having the formula 125/68 inches; build 1.9 (27); adjusted to 55 - years, $129 / 68$ inches; build 2.0 (28).

2. Female, a librarian, who in youth suffered from pneumonia, in middle age from a nervous breakdown, has at 47 years the formula 112/60 inches; build $2.2(31)$.

3. Female, a stenographer, who in middle age suffered from fever (in Afriea), has at 45 years the formula $117 / 63$ inches; build 2.1 (30).

4. Male, a college professor, always well, has at 41 years the formula $170 / 70$ inches; build 2.4 (35) ; adjusted to 55 - years, $175 / 70$ inches; build $2.5(36)$.

5. Male, a merehant, has at 39 years the formula $160 / 70$ inches; build 2.3 (33) ; adjusted to $55+$ years, 166/70 inches; build 2.4 (34).

6. Male, a merchant, who in youth suffered from acute rheumatism and leakage of heart, has at 36 years the formula $165 / 72$ inches; build 2.2 (32); adjusted to $55+$ years, $172 / 72$ inches; build 2.3 (33).

7. Male, an editor, who in middle age has suffered from pleurisy and pneumonia, has at 33 years the formula $150 / 71$ inches; build 2.1 (30); adjusted to 55 - years, $159 / 71$ inches; build 2.2 (32).

8. Male, a newspaper reporter, of unknown build.

Comment.-All children, except the first, who was of a nervous, active type and died prematurely, are of medium build, mostly slightly fleshier than the stockier parent ( $\mathrm{R}: \mathrm{Ise}-2)$.

\section{MiL-A FaMiLY.}

A family probably of old American (English) stock, living in Los Angeles, California. The Father, at 70 years, had the formula $170 / 68.5$ inches; build 2.5 (36). Of his sibs, 1 is slender, 1 medium, and 4 are fleshy. His father, at 70 years, had the formula $180 / 68$ inches; build 2.7 (39). His mother, at 70 years, had the formula 120/66 inches; build 1.9 (28). Thus the Father is of mixed fleshy and slender origin.

The Mother, at 85 years, had the formula $100 / 67$ inches; build 1.6 (22). Her father, at 70 years, 175/70 inches; build 2.5 (35). Her mother, at 70 years, $135 / 67$ inches; build 2.1 (30). Thus, the maternal parent is very slender with slender to medium grandparents. The 6 children are:

1. Male, at 56 years, has the formula $224 / 72$ inches; build 3.1 (43).

2. Male, at 53 years, $190 / 72$ inches; build 2.6 (37).

3. Female, at 27 years, $130 / 67$ inches; build $2.0(29)$; adjusted to 55 years, $148 / 67$ inches; build 2.3 (33).

4. Female, at 64 years, $100 / 68$ inches; build 1.5 (22).

5. Female, at 50 years, $140 / 67$ inches; build 2.2 (31).

6. Female, at 59 years, $190 / 67$ inches; build 3.0 (42)

Comment.-The children vary from slender to fleshy; thus two have a heavier build than any ancestor deseribed (S : Mil-A).

$$
\text { Wit-2 Fanilly. }
$$

A family of English and Irish extraction; paternal grandparents living in the Middle States and California. The Father, a merchant, suffered in middle age from pneumonia. He is living at 75 years. At 70 years his formula was $155 / 69$ inches; build 2.3 (33). His father, a farmer, died at 86 years from dropsy. At 70 years his formula was $140 / 73$ inches; build 1.8 (26). His mother, who had 8 children, died from consumption. At 50 ycars she was of medium build. 'Thus this side of the house is prevailingly 
of medium build, but the Father's father was slender, consequently the Father is probably heterozygous for build.

The Mother suffered in middle age from insanity and consumption, having the formula 100/68 inches; build 1.5 (22). Two of her 4 sibs who reached maturity died from consumption. Their father, a farmer, died at 74 years from bladder trouble. At 50 years he was of medium build. Their mother, who had 4 children, died from consumption. In this family the very slender stature is probably controlled by lung tubereulosis. The 3 children are:

1. Male, a machinist, who was accidentally killed at 19 years, $145 / 69$ inches; build 2.1 (30); adjusted to 55 years, 168/71 inches; build 2.4 (34).

2. Male, retired, who in youth suffered from dysentery and pneumonia; in middle age from indigestion, internal catarrh, tuberculosis, appendicitis, and malaria, has at 44 years the formula 140/69.5 inches; build 2.0 (29).

3. Female, who was "very healthy" in youth, but in middle age had mental "Dervous troubles," has at 40 years the formula 100/64 inches; build 1.7 (24); adjusted to 55 years, 106/64 inches; build 1.8 (26).

Comment.-The children of this mating are mixed slender to medium; one of the children is feeble-minded and is very slender; one who is slender has had active tubereulosis and much other illness; the third, who died at 19, had an average build. The record is complieated by disease ( $\mathrm{R}$ : Wit-2).

\section{HoL-A Fanily:}

A family from Illinois. The Father at 55 years has the formula: 180/68 inches; build 2.7 (39).

The Mother, at 50 years, las the formula: 100/66 inches; build 1.6 (23). The 9 ehildren are:

(1) Female, at 30 years, has the formula 180/65 inches; build 3.0 (43); adjusted to 55 years, 194/65 inches; build 3.2 (46).

(2) Male, at 30 years, 130/66 inches; build 2.1 (30); adjusted to 55 years, 139/66 inches; build 2.3 (32).

(3) Male, at 27 years, $170 / 68$ inches; build 2.6 (37) ; adjusted to 55 years, $183 / 68$ inches; build $2.8(40)$.

(4) Male, at 25 years, $165 / 74$ inches; build 2.1 (30); adjusted to 55 years, 184/74 inches; build 2.4 (34).

(5) Male, at 29 years, $140 / 68$ inches; build 2.1 (30); adjusted to 55 years, 151/68 inches; build 2.3 (33).

(6) Male, at 26 years, 125/72 inches; build 1.7 (24).

(7) Female, at 24 years, 140/69 inches; build 2.1 (29); adjusted to 55 years, 161/69 inches; build 2.4 (34).

(8) Female, at 22 years, $110 / 72$ inches; build 1.5 (21); adjusted to 55 years, 130/72 inches; build $1.8(25)$.

(9) Female, at 20 years, has the formula 100/64 inches; build 1.7 (24); adjusted to 55 years, 119/64 inches; build 2.0 (29).

Comment.-'The children vary greatly from very slender to stout or even, adjusted, to very stout. One of them is mueh stouter than either parent. Probably the Father is heterozygous (S: Hol-A).

$$
\text { LAW-A FaMily. }
$$

A family from Georgia. The Father, at 30 years, had the formula 200/68 inches; build 3.0 (43). His brothers were "all stout." His father, at 30 years, had the formula 160/69 inches; build 2.4 (34). The fleshy father carries factors for at least medium build. 
The Mother, at 30 years, had the formula $100 / 65$ inches; build 1.7 (24). Her brothers were all of "medium" build. Her sister's are: 1 slenter, 1 medium, and 2 fleshy. Their father, at 30 years, had the formulat 170/70 inches; build $2.4(35)$. The 4 children:

1. Male, at 30 years, had the formula 190/68 inches; build 2.9 (41).

2. Female, at 30 years, $110 / 61$ inches; build 2.1 (30).

3. Female, at 30 years, $100 / 60$ inches; build 2.0 (28).

4. Female, at 30 years, $130 / 61$ inches; build 2.5 (35).

Comment.-A fleshy man of medium stock has hy a very slender woman of mixed stock in respect to build, 4 children-2 slender, 1 medium, and 1 fleshy (S : Law-A).

\section{WAT-5 FanILY.}

A family of English extraction; grandparents living in Massachusetts, Michigan, England, Utah, and Montana; parents and children living in Utah and Montana. The Father, a miner, suffered in middle age from pneumonia and died at 64 years from chronic bronchitis. At 60 years his formula was 190/72 inches; build 2.6 (37). His father, a farmer, died at 37 years. The Father had a fleshy sister, at least 3 of whose children were fleshy. His mother died at 38 years. Apparently, a fleshy strain on the Father's father's side; Father's mother's side unknown.

The Mother, who had 7 chilklren, suffered in youth from searlet fever and lung fever, is living at 60 years, having the formula $107 / 65.5$ inches; build $1.8(25)$. Her 4 sibs are "thin." Their father, a lawyer, suffered at 23 years from scarlet fever, died from an aceident at 42 . Two of his sibs wore "very large" and tall. Her mother, who had 9 children, died at 76 years from pneumonia; she was slender and so was her sister. Thus the slender Mother has both slender and fleshy close relations. The 5 children who grew up are:

1. Female, married, who in youth suffered from scarlet fever, has at 37 years the formula $109 / 67$ inches; build 1.7 (2t); adjusted to 55 years, 119/67 inches; build 1.9 (27)

2. Male, a miner, who in youth suffered from scarlet fever, tonsillitis, and throat trouble, has at 34 years the formula $185 / 71$ inches; build 2.6 (37); adjusted to 55 years, $193 / 71$ inches; build 2.7 (38).

3. Female, married, who in youth suffered from searlet fever, has, at 31 years, the formula $128 / 66$ inches; build 2.0 (29); adjusted to 55 years, 143/66 inches; build 2.3 (33).

4. Female, married, who in youth suffered from throat trouble, underwent a tonsillectomy anci appendectomy, has at 25 years the formula $120 / 65.5$ inches; build 2.0 (28) ; adjusted to 55 years, $138 / 65.5$ inches; build 2.3 (32).

5. Female, married, has at 21 years. the formula $120 / 65.5$ inches; build 2.0 (28); adjusted to 55 years, $140 / 65.5$ inches; build 2.3 (33).

Comment.-The adjusted build of the children show 1 slencler (unadjusted, rery slender), 3 medium, and 1 fleshy, suggesting a heterozygous parentage. This family has been placed in this eategory, despite absence of information about the Father's parents, becalse of the great variability of the children ( $\mathrm{R}$ : Wat-5).

\section{Gei-3 Fanily.}

A family of Scandinavian extraction, living mostly in Kansas. The Father, a farmer, who suffered in middle age from asthma, has at 74 years the formula $125 / 68$ inches; build 1.9 (27). 
The Mother has at 60 years the formula $150 / 62$ inches; build 2.7 (39). Her father, a farmer, died at 83 vears from senile dementia. At 75 years his formula was 150 /S inches; build, say, 2.4 (34). Her mother, who had 6 children, died at 84 years, "probably senility." At 75 years her formula was $120 / \mathrm{M}$ inches; build, say, 2.1 (30). The 8 children:

1. Female, married, suffered in youth and middle age from heart trouble, following rheumatism. At 40 years she has the formula 110/62 inches; build 2.0 (29); adjusted to 55 years, 116/62 inches; build 2.1 (30).

2. Male, a farmer, who in youth suffered from rheumatism, has at 33 years the formula $135 / 67$ inches; build 2.1 (30); adjusted to 55 years, $144 / 67$ inches; build $2.3(33)$.

3. Male, who died at 16 years from operation for rectal tumor.

4. Male, a real-estate dealer, who in youth suffered from asthma, has at 33 years the formula $135 / 67$ inches; build 2.1 (30); adjusted to $55+$ years, $144 / 67$ inches; build 2.3 (33).

5. Female, a nure, who in youth suffered from anterior poliomyelitis (complete recovery), has at 31 years the formula $150 / 64$ inches; build 2.6 (37); adjusted to 55 years, $162 / 64$ inches; build 2.7 (39).

6. Male, a farmer, has at 29 years the formula $153 / 70$ inches; build 2.2 (31) ; adjusted to 55 years, $166 / 70$ inches; build 2.4 (34).

7. Female, has at 27 years the formula $150 / 65$ inches; build 2.5 (36); adjusted to 55 years, $166 / 65$ inches; build 2.7 (39).

8. Male, a farmer, has at 24 years the formula $150 / 67$ inches; build 2.3 (33); adjusted to $55+$ years, $164 / 67$ inches; build 2.6 (37).

Comment.-One-half of the children may be expected to exceed the mean build of the parents, and 2 to equal or exceed the fleshy build of the Mother (R : Gui-3).

\section{HoK-1 FAMILY.}

A family of German and English extraction, living in Illinois, Colorado, and Iowa. The Father, who is a carpenter, always mell, is living at 63 years, having the formula $180 / 70$ inches; build 2.6 (37). His father, who was a manufacturer, always well, died at 72 years from a fistula. At 72 years his formula $175 / 70$ inches; build 2.5 (36). The father's mother died at about 48 years; was of slender build.

The Mother, always well, has at 62 years the formula 105/62 inches: build 1.9 (27). Her father, who was a coal-mine owner, died at 46 years from exposure during Civil War. At 45 years his formula 140/67 inches; build 2.2 (31). Her mother, always well, died at 87 years from old age. Formula, 145/64 inches; build 2.5 (35). Two grown children:

1. Male, a surveyor, who in youth suffered from typhoid, has at 34 years the formula $160 / 70$ inches; build 2.3 (33); adjusted to $55+$ years, $168 / 70$ inches; build 2.4 (34).

2. Male, always well, has at 26 years the formula $165 / 72$ inches; build 2.2 (32) ; adjusted to 55 years, $181 / 72$ inches; build 2.5 (35).

Comment.-Both children are of medium build, fairly close to that of the fleshier parent ( $\mathrm{R}:$ Hok-1).

\section{Hot-1 Family.}

A family of English extraction, living mostly in New York State. The Father, who is a carpenter, suffered in middle age from pneumonia. He is living at 51 years, having the formula $150 / 71$ inches; build 2.1 (30). His 
father, who was a farmer, died at 69 years from apoplexy; was of medium build. His mother, who had 6 children, at 50 years was slender.

The Mother is living at 50 years, having the formula $150 /(\mathrm{i} 1 \mathrm{inclhes}$; build 2.8 (40). Her father, who was a grocer, suffered in youth from rheumatiom; in middle age from typhoid fever. He died at 61 years from Briglit's disease. At 61 years he was slender. Her mother, who har 3 children, was always well. She died at 79 years from cerebral hemorrhage; she was said to be slender.

One son, a teacher, always well, has at 25 years the formula $140 / 67$ inches; build 2.2 (31); adjusted to 50 years, $151 / 67$ inches; build 2.3 (33).

Comment.-The son is intermediate in build between the parents ( R : Hot-1).

\section{Hul-2 Family.}

A rural New York family of prevailingly English origin. The Father, a business man, always well, had, at 50 years, the formula 140/68 inches; build 2.1 (30). His father, who died of "rheumatism of the stomach" at 80 years, had the formula $160 / 69$ inches; build 2.4 (34). His mother, who died at 82 years of old age, with dropsical tendeneies, had the formula $95 / 62$ inches; build 1.7 (25). This family las a build at or below the average.

The Mother, who suffered much from sick headache and "rheumatism." and in later years from diabetes mellitus, had, at 50 years, the formula 150/64 inches; build 2.6 (37). Her father, who suffered from migraine, had the formula $155 / 67$ inches; buitd 2.4 (35). Her mother, always well, died at 78 years of gradual decay; her formula, at 50 years, $115 / 65$ inches; build 1.9 (27). The Mother is doubtless heterozygous. There are 7 children:

1. Female, who has had pneumonia and suffers from migraine, has, at 38 , the formula $100 / 62.5$ inclies; build 1.8 (26).

2. Female, a teacher, married, at 37 years, $115 / 65$ inches; build 1.9 (27).

3. Female, married, and died at 35 years of Addison's divease, 10j, 65 inches; build 1.8 (25).

4. Female, who has been operated on for tubercular neck glands, at 34 years, 115/62 inches; build 2.1 (30).

5. Female, who suffered in youth from tachycardia, at 28 years, $100 / 65.5$ inches; build 1.6 (23).

6. Female, who has suffered from migraine and rheumatism and hat an attack of pneumonia, at 27 years, 115/64 inches; build 2.0 (28); adjusted to 50 years, $119 / 64$ inches; build 2.0 (29).

7. Male, well, at 20 years, $140 / 67$ inches; build 2.2 (31); adjusted to 50 years, $158 / 68$ inches; build $2.4(34)$.

Comment.-On the whole the children are bolow the average build, like the slender parent ( $\mathrm{R}$ : Hul-2).

\section{Kie Family. (Fig. 43.)}

II $1 \hat{o}$, a slender German. His wife, II 2 o, fleshy. Their 4 children of whose build something is known: III $1 \hat{\delta}$, fleshy; III $2 \hat{\delta}$, slender, over 6 feet tall, married to a fleshy woman, has 6 tall, slender daughters. III 4 웅 died of "heart diccase"; slender. III 7 s. died at 56 of cancer of the lungs, weight in health $82 \mathrm{~kg}$. (180 pounds); stature $178 \mathrm{~cm}$. 170 inches); build 2.6 (37), fleshy. Thus 2 are fleshy and 2 slender.

Comment.-From the variability of the offspring we infer that the fleshy Mother was heterozygous in build $(73-670)$. 


\section{Leo Family, A. (Fig. 23.)}

II 7 is, slender with 4 slender sibs. Their parents both slender. His wife, II 8 o, at 36 years, has a stature of $152 \mathrm{~cm}$. (60 inches); weight $84 \mathrm{~kg}$. (184 pounds); build 3.6 (51); very fleshy; relative chest-girth $112 \div 152$, or 74 per cent. She has 3 fleshy and 2 slender sibs. Of their parents one was fleshy and one slender. Thus II 8 is heterozygous.

III 4 , the only child, at 9 years, has a relative chest-girth of 57 per cent; fleshy.

\section{Leo Family, B.}

I 5 s , slender, and I 6 \&, whose build is about 3.6 (51), or very fleshy, have 6 children of whom something is known, as follows: II 8 q , build 3.6 (51), very fleshy; II 11 \&, fleshy; II 15 \&, slender; II 16 \&, slender, married to a slender man and has 3 slender children; II 12 of, of medium stature and $95 \mathrm{~kg}$. (210 pounds) weight; build, say, 3.2 (45); very fleshy;

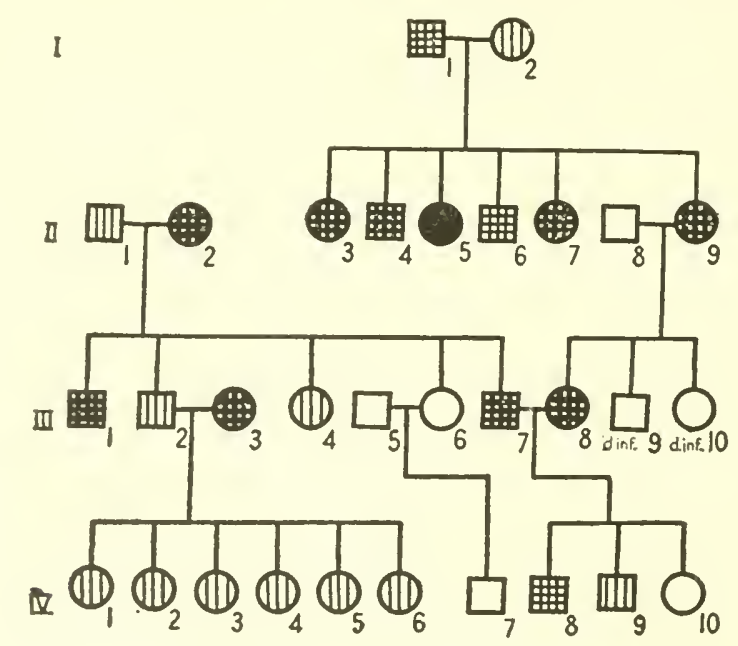

FIg. 43.-Pedigree ehart showing distribution of build in the KIE family.

II 13 ㅇ, of tall stature and $91 \mathrm{~kg}$. (200 pounds) weight; build, say, 3.2 (46); very fleshy. Thus there are 3 very fleshy, 1 fleshy, and 2 slender children. The Mother's heterozygosity is inferred from the variability of the progeny in build.

II 14 ô, fleshy, and II $15 \%$, slender, have 2 sons, both slender $(73: 676)$.

\section{LYN-2 FAMILY.}

A family of prevailingly English stock, living in Illinois and Nebraska. The Father, who was a farmer and school-teacher, died at 65 years from cancer of stomach. Formula, 150/64 inches; build 2.6 (37). His father, who was a farmer, died at 76 years from pneumonia; he was slender. His mother, who had 10 children, is living and is corpulent. Thus the Father is heterozygous.

The Mother, who has 1 child, has at 49 years the formula 120/64 inches; build 2.1 (29). Her father, who is a carpenter, always well, is at 70 years 
slender. Her mother, who had 4 ehililren, diesl at 36 years from pneumonia; she was of medium build. One child, female, a kindergarten teacher, has at 19 years the formula $110 / 63$ inches; build 2.0 (28); adjusted to $55+$ years, $130 / 63$ inches; build 2.3 (33).

Comment.-The child is now like the slender parent and will probably increase somewhat in build ( $R:$ Lyn-2).

\section{Mer-B FAMILY.}

A family of English extraction from Rochester, New York. 'The Father, at 21 years, had the formula $200 / 71$ inches; build 2.8 (40). His firther hard the formula $250 / 73$ inches; build 3.3 (47). His mother had the formula 130/70 inches; build $1.9(27)$.

The Mother, at 21 years, had the formula $96 / 61$ incles; build 1.8 (25). Her father had the formula $170 / 68$ inches; build 2.6 (37). Her mother had the formula $150 / 65$ inches; build 2.5 (36). Five children:

1. Male, at 21 years, had the formula $175 / 68$ inches; build 2.7 (38).

2. Male, at 21 years, $170 / 72$ inches; build 2.3 (33).

3. Female, $140 / 64$ inches; build 2.4 (34).

4. Female, 130/65 inches; build 2.2 (31).

5. Female, 130/67 inches; build 2.0 (29).

Comment.-All 5 children are intermediate between the parents; 1 is fleshy, 1 slender (S: Mer-B).

\section{Mor Fanily. (Fig. 24.)}

(a) II $1 \hat{o}$, stature $181 \mathrm{~cm}$. (71 inches); weight $13 \mathrm{~kg}$. (200 pounds); build 3.5 (50); very fleshy. Married II 2, a slender woman. They had 7 sons, 2 fleshy, 5 medium, and 6 daughters, 1 fleshy and 5 medium. Thus 3 fleshy and 10 of medium build. To save space only 5 are represented in figure 24.

(b) IV 16 s, slender, married IV 17 o, fleshy, who has 2 fleshy and 2 slender sibs; and both parents fleshy. They have 4 living children, all slender.

(c) IV 5 of, fleshy with 4 fleshy, 1 medium, and 1 slender sibs and a fleshy and medium parent; married IV 6 , slender, with a slender sister. They had 2 sons, both slender $(73: 690)$.

\section{PAD-1 FAnily.}

A family of English extraction, living in the middle West. The Father, a horticulturist, subject in middle life to catarrh, is living at 55 years, having had at 50 years the formula $145 / 72$ inches; build 2.0 (28). His father, a farmer, who in youth suffered from measles and bronchitis, and in middle age from liver trouble, died at 59 years from complication of stomach and liver diseases. At 55 years his formula 145/68 inches; build 2.2 (31). His mother is living at 80 years, having the formula $160 / 68$ inches; build 2.4 (35).

The Mother, at 49 years, had the formula $145 / 63$ inches; build 2.6 (37). Her father, a merchant and farmer, suffered in youth from typhoid fever and congestion of the brain. He died at 86 years from old age, having had at 70 years the formula $170 / 72$ inches; build 2.3 (33). Her mother died at 83 years of old age, having the formula 95/61 inches; build 1.6 (23). The only grown child is a male, a student, who in youth suffered from measles and catarrh, has at 21 years the formula $155 / 67$ inches; build 2.4 (35); adjusted to 50 years, 171/67.5 inches; build 2.6 (37). 
Comment.-The only grown child is like his stouter parent in build (R : Pad-1).

\section{Ron-1 Fanily.}

A family of prevailing English stock, living in Ohio, Indiana, Illinois, and Kansas. The Father, who is a lawyer, has at 72 years the formula $170 / 67$ inches; build 2.7 (38). Three of his brothers died at 26 years, 41 years, and 22 years respectively, from tuberculosis; all were of medium height. Their father, who was a "farmer and blacksmith," died at 76 years from Bright's disease; was slender. Their mother, who had 5 ehildren, died at 55 years from "tuberculosis of the liver"; was corpulent. The Father is doubtless heterozygous in build.

The Mother has at 67 years the formula 119/65 inches; build 2.0 (28). One of her sisters, who was tall, died from "quick consumption"; another from diabetes; another from dropsy. Two of her brothers, tall, died from hardening of the arteries, another from "leakage of the heart," and another from dropsy. Their father, who was a miller, died at 76 years-"a complication of diseases (asthma)." He was corpulent. Their mother, who had 10 children, died at 72 years from pneumonia; was of medium build. The 7 children are:

1. Female, married, who in middle age suffered from rheumatism, has at 44 years the formula $155 / 64$ inches; build 2.7 (38) ; adjusted to 55 years, 158/64 inches; build 2.7 (39).

2. Male, a farmer, who in youth suffered from malarial fever, has at 41 years the formula 150/68 inches; build 2.3 (32) ; adjusted to 55 years, 155/68 inches; build 2.4 (34).

3. Male, a farmer, has at 38 years the formula $155 / 68$ inches; build 2.4 (34) ; adjusted to 55 years, $161 / 68$ inches; build 2.5 (35).

4. Male, who died at 18 years from diphtheria, having the formula $145 / 72$ inches; build 2.0 (28) ; adjusted to 55 years, $171 / 72$ inehes; build $2.3(33)$.

5. Female, married, has at 31 years the formula $115 / 65$ inches; build 1.9 (27) ; adjusted to 55 years, $132 / 65$ inches; build 2.2 (31).

6. Male, a farmer, has at 28 years the formula $160 / 71$ inches; build 2.2 (32) ; adjusted to 55 years, $174 / 71$ inches; build 2.4 (35).

7. Female, a student, who in youth suffered from tonsillitis, scarlet fever, and other "children's" diseases, has at 22 years the formula 118/64 inehes; build 2.0 (29); adjusted to 55 years, 136/64 inches; build 2.3 (33).

Comment.-All except one on the adjusted weights equal or exceed the mid-parent index. One of the 7 children is as fleshy as the fleshier parent (R : Rom-1).

\section{Rid Fanily. (Fig. 48.)}

III 9 子, at 59 years, stature $157 \mathrm{~cm}$. (62 inches); weight $73 \mathrm{~kg}$. (160 pounds); build 2.9 (42); fleshy; "as fat as butter when a child." He has 3 fleshy sibs and lis parents are dissimilar in build; hence he is heterozygous; married to III 10 o, slender, of two slender parents.

Of their 2 children, IV 3 of at 30 years is slender; IV 4 s, at 16 years, slender $(73: 727)$.

\section{Vax Family. (Fig. 44.)}

I 3 o , died at 51 years of heart disease, stature $170 \mathrm{~cm}$. (67 inches); weight sti kg. (190 pounds); build 3.0 (42); Heshy. He was one of a 
fraternity of 8 of whom something is known of the following: I 1 , slender; I 2 ô, stature 183 (72 inehes); weight $90 \mathrm{~kg} .(200$ pounds); build 2.7 (38.5); fleshy; slender as a child. I 3, married I 4, who died at 32 , was tall, slender, angular. A brother is of inedium build.

They have 5 children: II 1 of, died at 53 years of indigestion; stature $189 \mathrm{~cm}$. (74 inches); weight $90 \mathrm{~kg}$. (200 pounds); build 2.6 (37); fleshy. II 2 o, always slender. II 3 o , slender. II 4 os, at 54 , stature $175 \mathrm{~cm}$. (69 inches); weight $88 \mathrm{~kg}$. (194 pounds); build 2.9 (41); fleshy. Relative chest-girth $108 \div 175$, or 62 per cent. He first began to inerease in build at 22 years and at 30 years had his present build; loses weight after vigorous exercise. He married a woman (II 5) who, like himself, was slender in youth, but began to grow fleshy at 39 , and now has a build of 2.9 (41). She has 2 slender, 2 fleshy, and 2 very fleshy sibs, and her parents were both very fleshy. The foregoing couple (II 4,5) have 2 children who grew

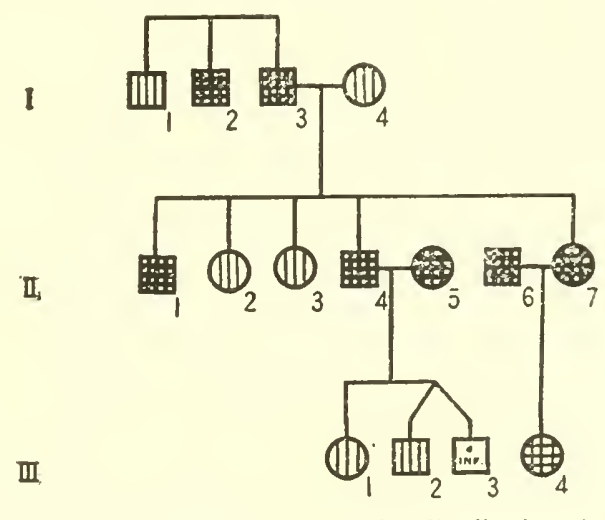

FIG. 44.--Pedigree chart showing distribution of build in VAN family.

up. III 1 \& at 28 years, keeps slender by constant dieting. III 2 f lone of twins) at 25 years, very slender, nervous, and irritable. The children have not yet reached the age when their mother became fleshy.

Finally, II $7 \%$, at 50 years, is $170 \mathrm{~cm}$. (67 inches) tall and weighs s8 kg. (195 pounds); build 3.1 (43); fleshy. She was slender up to 27 years of age. She is married to a somewhat fleshy man and their daughter at 27 is of medium build, but beginning to grow fleshy.

Comment.-The mating of a man of build 3.0, of a fraternity that is variable in build, and a woman of slender build yields grown children with following builds: 2.6, "slender," "slender," 2.9 (slender in youth), and 3.1 (slender in youth). Three of the five become fleshy, but probably only late in life-the heterozygous reaction $(73: 745)$.

\section{WaT FaMiLY.}

A family of English extraction living in Wyoming. The Father, who has tubereulosis, has the formula $125 / 68$ inches; build $1.9(2 \vec{\jmath})$. His father was slender and of arerage height. His mother was fleshy and of average height.

The Mother had at 50 the formula 165/64 inehes; build 2.8 (40), but averaged usually from 120 to 128 pounds. She had stomach trouble. Her father, an invalid and sufferer from tuberculosis, rheumatism, neuralgia, 
heart trouble, and dropsy, had the formula $120 / 68$ inches; build 1.8 (26). His weight varied from 102 to 120 pounds; very slender. Her mother, who had a goiter of which she was cured, and quinsy, had the formula $140 / 56$ inches; build 3.1 (45). The mother's father's father had the formula $180 / 73.5$ inches; build 2.3 (33). His weight raried from 180 to 200 pounds. He was muscular, not fat. The Mother's father's mother was always thin and had the formula $115 / 65$ inches; build $1.9(27)$. She had liver trouble and cancer of the face. The Mother's mother's father had eancer of the face and underwent an operation for it. His formula was 125/65 inches; build 2.1 (30). The Mother's mother's mother had at 70 years the formula 160/67 inches; build 2.5 (36). She grew heavier in middle age. The children are:

1. Male, liable to tuberculosis, has at 24 years the formula $134 / 67.5$ inches; build 2.1 (30).

2. Male, has weak lungs; has at 22 years the formula $170 / 67.5$ inches; build $2.6(37)$.

3. Male, has at 18 years the formula $126 / 68$ inches; build 1.9 (27).

Comment.-The children show the usual variability that arises from this type of mating (D : Wat.).

\section{Mating 2. Fleshy $\times$ Heterozygous Fleshy Parents.}

This includes matings between a heterozygous parent of fleshy build and a very fleshy (or fleshy) parent of fleshy stock; a back-cross to the more nearly dominant type.

The matings of this type are as shown in table 33.

TABLE 33.-Matings between a probably homozygous fleshy and a heterozygous fleshy parent, together with the progeny of this back-cross.

\begin{tabular}{|c|c|c|c|c|c|c|c|c|c|c|c|c|c|}
\hline \multirow{2}{*}{ Ref. } & \multicolumn{7}{|c|}{ Parentage. } & \multicolumn{6}{|c|}{ Offspring. } \\
\hline & FF & FM & $\mathrm{F}$ & $\begin{array}{l}\text { Father's } \\
\text { sibs. }\end{array}$ & $\mathrm{MF}$ & MM & $M$ & $\begin{array}{l}\text { Mother's } \\
\text { sibs. }\end{array}$ & VS & $\mathrm{S}$ & M & $\mathrm{F}$ & VF \\
\hline Hud..... & 28 & 46 & 45 & $\ldots \ldots \ldots \ldots$ & 38 & 35 & 40 & & $\ldots$ & $\ldots$ & 1 & 1 & 2 \\
\hline Jon $11 \mathrm{c} \ldots$ & 29 & 49 & 39 & $1 \mathrm{VF}, 3 \mathrm{~F}, 5 \mathrm{M}$. & 37 & 42 & 39 & $2 \mathrm{~F}, 4 \mathrm{M} \ldots \ldots$ & $\ldots$ & $\ldots$ & 1 & 8 & 1 \\
\hline Pal....... & $\mathrm{F}$ & M & 43 & $1 \mathrm{~S}, 3 \mathrm{~F}, 1 \mathrm{VF} \ldots$ & $\ldots$ & $\ldots$ & 40 & & $\ldots$ & $\ldots$ & 2 & $\ldots$ & 1 \\
\hline $\operatorname{Rec}(a) \ldots$ & $\mathrm{S}$ & $\ldots$ & 40 & $2 F^{2} \ldots \ldots \ldots$ & $\ldots$ & & 100 & $2 \mathrm{~F}, 1 \mathrm{~S} \ldots \ldots$ & $\ldots$ & $\ldots$ & 1 & 2 & 3 \\
\hline $\operatorname{Rec}(\mathrm{b}) \ldots$ & $\mathrm{F}$ & $\mathrm{S}$ & $40 \mathrm{~F}$ & $\ldots \ldots \ldots \ldots$ & $\mathrm{F}$ & VF & 57 & $2 \mathrm{VF}, 2 \mathrm{~F}, 1 \mathrm{M}$ & $\ldots$ & $\ldots$ & $\ldots$ & $\ldots$ & 1 \\
\hline Rid...... & $\ldots$ & $\mathrm{F}$ & 56 & & 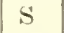 & $\ldots$ & $49 \pm$ & $4 \mathrm{~F}, 2 \mathrm{M} \ldots \ldots$ & $\ldots$ & 1 & $\ldots$ & 3 & 3 \\
\hline Smi...... & VF & $\ldots$ & VF & & M & $\ldots$ & 48 & $1 F \ldots \ldots \ldots$ & $\ldots$ & 1 & $\ldots$ & 3 & 3 \\
\hline The $1 \ldots$ & 30 & 31 & $F$ & $1 F, 4 S \ldots \ldots$ & 33 & 33 & 34 & $2 \mathrm{~S}, 1 \mathrm{M} \ldots \ldots$ & $\ldots$ & $\ldots$ & 3 & 4 & 3 \\
\hline Wen.... & 46 & M & 46 & $\ldots \ldots \ldots \ldots$ & M & M & 37 & $2 \mathrm{~F} \ldots \ldots \ldots$ & $\ldots$ & $\ldots$. & 6 & $\ldots$ & 2 \\
\hline $\begin{array}{l}\text { Total. } \\
\text { Propor- } \\
\text { tions... }\end{array}$ & .. & $\cdots$ & & $\ldots \ldots$ & $\cdots$ & $\cdots$ & $\ldots$ & $\ldots \ldots \ldots \ldots$ & $\cdots$ & $\begin{array}{c}2 \\
3.6\end{array}$ & $\begin{array}{c}14 \\
25.0\end{array}$ & $\begin{array}{c}21 \\
37.5\end{array}$ & $\begin{array}{c}19 \\
33.9\end{array}$ \\
\hline
\end{tabular}
$A=40.48 \pm 0.57$
S. D. $6.36 \pm 0.41$.

These 9 matings yielded 56 children, with the following percentage distribution: $4 \mathrm{~S}, 25 \mathrm{M}, 37 \mathrm{~F}, 34 \mathrm{VF}$. The 6-zygotic-factor mating $5 \times 3$ (both possibilities) gives a percentage distribution of $3 \mathrm{~S}, 25 \mathrm{M}, 43 \mathrm{~F}, 28 \mathrm{VF}$, which approximates that found. 
Attention is called to the distribution of offspring in the Pal, Rid, Smi, and Wen families. In these families the children are of two extreme types; intermediates are absent. The result may be due merely to small numbers, but it suggests the presence of two sorts of gametes in the heterozygous parent and hence a tendency to segregation in the offspring.

\section{Hud Family. (Fig. 45.)}

The Father's (II 7) build is 3.2 (45) ; very fleshy; his father's (I 1) was 2.0 (28) and his mother's 3.2 (46). Thus the Father is heterozygous. The Mother's (II 8) build is 2.8 (40). Her father's build was 2.7 (38), fleshy; and her mother's 2.5 (35); medium fleshy. The Mother's 7 sibs have builds ranging between 2.5 (35) and 3.2 (46); principally flcshy to very fleshy. So this may be regarded as a back-cross of a heterozygous parent with a fleshy one of fleshy stock. Of the 4 children, 1 is medium-fleshy (III 11) with a build of 2.5 (36), 1 is fleshy (III 10) 2.7 (38), and two very fleshy; build 3.2 (45); thus the build of the offspring is varied, but prevailing very fleshy.

\section{JoN-11C Fanily. (Fig. 46.)}

A family of Welsh extraction living chiefly in New York State and Ohio. The Father (II 10), a farmer, suffered in middle age from "rupture," and died at 88 years from "old age," having the formula $150 / 62$ inches; build 2.7 (39). Of his 9 sibs:

1. Brother, died at 70 years from "dissipation," having the formula $175 / 68.5$ inches; build 2.6 (36).

2 . Brother, who died at 53 years from "inflammation of kidneys and dyspepsia," had the formula $125 / 63$ inches; build $2.2(31)$.

3. Sister, who died at 68 years from Bright's disease, 140/57 inches; build 3.0 (43).

4. Sister, who died at 74 years from "flux," $150 / 58$ inches; build 3.1 (44).

5. Sister, who died at 75 years from Bright's disease, 120/59 inches; build 2.4 (34).

6 . Sister, who died at 60 years from Bright's disease, $118 / 59.5$ inches; build 2.3 (33).

7. Sister, who died at 73 years, 135/64 inches; build 2.3 (33).

8. Brother, who died from typhoid fever at 44 years, 175/68 inches; build 2.7 (38) .

9. Brother, 150/62 inches; build 2.7 (39).

Their father, a farmer, suffered in middle age from "hernia"; died of heart trouble at 65 years, having the formula 120/64.5 inches; build 2.0 (29). Their

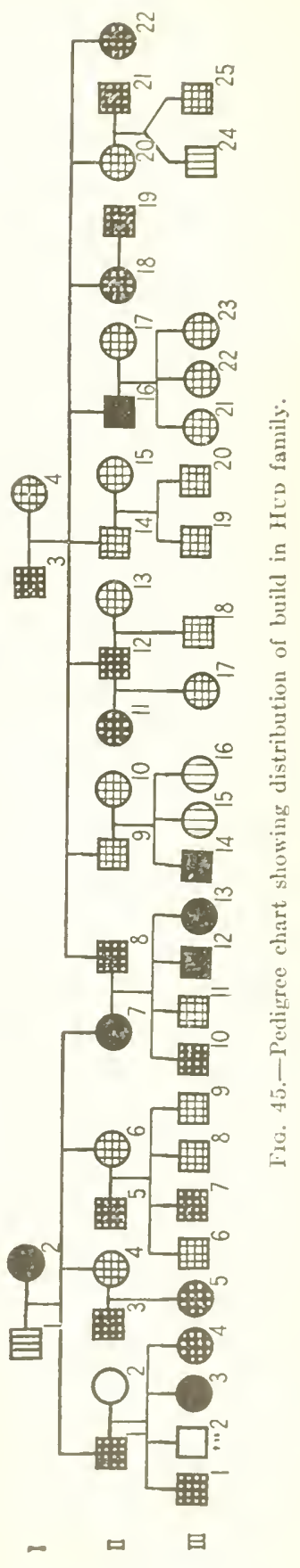


mother died at 77 years from pneumonia, having the formula $160 / 57$ inches; build 3.5 (49).

The Mother suffered from "nervousness" before marriage, then not troubled with it again till menopause. She died of "heart trouble, dropsy, paralysis, and nervousness" at 80 years, having the formula $150 / 62$ inches; build 2.7 (39). Of her 8 sibs:

1. Brother, who died from "congestive chill," was 67 inches in height.

2. Brother, who died at 56 years from "old age," $180 / 71$ inches; build $2.5(36)$.

3. Brother, who died at 81 years from "poor eireulation" and stomach trouble, had the formula $170 / 71$ inches; build 2.4 (34).

4. Brother, who died from pneumonia at 45 years, $180 / 70$ inches; build $2.6(37)$.

5. Brother, who died from "kidney trouble" at 40 years, 170/70 inehes; build $2.4(35)$.

6. Brother, who died at 57 years from "abseess on liver," $160_{i}^{\prime} 69$ inches; build $2.4(34)$.

7. Sister, who died at 25 years from "child-birth."

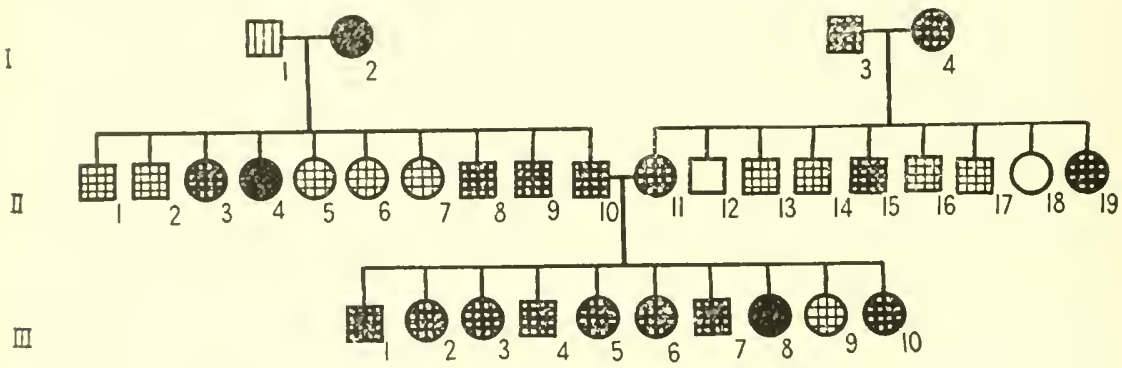

FIG. 46.-Pedigree chart showing distribution of build in the Jos-1le family.

8. Sister, who died at 72 years from "overdose of medicine," 165/67 inches; build 2.6 (37).

Their father, a farmer and eabinet-maker all his life, died at 83 years from paralysis, haring the formula 200/74 ineles; build 2.6 (37). Their mother, who in middle age suffered from dropsy and palsy, died at 83 years from "old age." Her formula was 160/62 inches; build 2.9 (42).

The 10 children:

1. Male, a farmer, reeorded as always well, has at 66 years the formula 16.5/67 inches; build 2.6 (37).

2. Female, who in youth suffered from "ague, flux, erysipelas, choler: morbus," has at 65 years the formula 130/59 inches; build 2.6 (37).

3. Female, who in youth suffered from asthma, has at 63 years the formula $150 / 61$ inches; build 2.8 (40).

4. Male, a lawyer, who in youth suffered from searlet fever, and middle age from "acquired neurasthenia," has at 59 years the formula $190 / 70$ inches; build 2.7 (39).

5. Female, a school-teacher, who died at 20 years from typhoid fever, had the formula $120 / 61$ inches; build 2.3 (32) ; adjusted to 55 years, 139/61 inches; build 2.6 (37).

6. Female, who suffered in youth from searlet fever and in middle age from typhoid and kidney trouble, has always been "nervous," has at 55 years the formula $150 / 61$ inches; build $2.8(40)$. 
7. Male, a farmer and "shopman," who in youth suffered from Bright's disease, has at 53 years the formula $170 / 67.5$ inches; build 2.6 (37).

8. Female, who at 17 years had fever, lost her mind, has not been well since-"gradual mental deterioration." At 51 years she has the formula 170/62 inches; build 3.1 (44).

9. Female, who in youth suffered from "thrush," and in middle life from malarial fever and gradual mental deterioration, has at 51 years the formula $116 / 57.5$ inches; build 2.4 (35).

10. Female, who at 48 years has the formula $165 / 63$ inches; build $2.9(42)$.

Comment.-This is an extraordinarily valuable pedigree furnished by a member of the family who has taken great pains with the record. Both parents are of middle-fleshy build (39). The Fatler's fraternity shows sibs: 5 medium, 4 fleshy, and 1 very fleshy. This is associated with semidwarfishness, one of the sisters being only 57 inches in stature and one of the brothers only 63 inches. One of their parents is slender; one obese. The Mother's fraternity comprises 4 persons of medium build and 3 stout. Their parents are both fleshy. The "children" are remarkably uniform. since they all, except one, reached the parental age, no "adjustment" is necessary; they can be compared directly. One is of medium build, 8 are stout like their parents (including the adjusted age of the girl who died at 20), and 1 is just over the line of being very stout (44), like her paternal aunt and a little less than her Father's mother. Here the obesity has skipped a generation in the direct line, possibly because the Father was phenotypically reduced in build, perhaps because of his advanced age (88). This circumstance offers, however, no theoretical difficulty. The uniformity of the progeny favors the hypothesis that in this family there are only two independent factors for fleshy build (R: Jon-11c).

\section{PaL Fanily. (Fig. 25.)}

A family living in a small town in good circumstances. III $9 \hat{o}$, a farmer, who at 67 years is $173 \mathrm{~cm}$. (68 inches) tall, weighs around $90 \mathrm{~kg}$. or 200 pounds; build 3.0 (43) ; fleshy; net relative chest-girth $120 \div 173$, or 71 per cent. This near-obese man was slender as a boy and began to grow fleshy at 30 years of age. There are 5 others in his fraternity: (1) III 7 of, a physician, at 71 years is $178 \mathrm{~cm}$. (70 inches) tall, weighs over $90 \mathrm{~kg}$. (200 pounds) ; build 2.9 (41) ; fleshy; relative chest-girth $119 \div 178$, or 67 per cent. He is doubtless heterozygous for build, since, by a slender wife, he has 2 fleshy and 2 slender children. (2) III 8 o married, at 69 years has stature $157 \mathrm{~cm}$. (62 pounds); weight $75 \mathrm{~kg}$. (155 pounds); build 2.8 (40) ; fleshy; relative chest-girth $107 \div 157$, or 68 per cent. By a man of medium build she has 1 flesliy, 1 medium, and 3 slender children. * (3) III 11 of, at 65 years has a stature of $175 \mathrm{~cm}$. (69 inches); weight $61 \mathrm{~kg}$. (135 pounds) ; build 2.0 (28) ; slender. (4) III 5 os, at 62 years, stature $178 \mathrm{~cm}$. (70 inches); weight $95 \mathrm{~kg}$. (210 pounds); build 3.0 (43); fleshy. His relative chest-girth $117 \div 178$, or 66 per cent. As a boy he was of medium build; at about 30 years, like III 7 , he began to grow fleshy, and is now dieting for diabetes (?). By a fleshy wife, whose sibs vary in build, he has 2 fleshy children and 1 of medium build. (5) III 12, at 59 years has a stature of $168 \mathrm{~cm}$. (66 inches) and weight of $102 \mathrm{~kg}$. (224 pounds); build 3.6 (52) ; very fleshy. By a husband of medium build she has 1 slender and 1 medium child.*

* Not shown in figure 25 . 
The father (II 5) of this fraternity, who died at 87 years of cancer of the face, was fleshy. He had 5 brothers, all of whom lived to be over 80 years of age and who all, save 1, weighed over $90 \mathrm{~kg}$. (200 pounds). The mother (II 6) of the man's fraternity died at 64 of pneumonia; she was of medium build, and her 4 sibs were of medium build. Thus all her children were probably somewhat heterozygous, including III 9 , the father of 3 .

III 10, the wife of III 9 , is $178 \mathrm{~cm}$. tall and weighs over $90 \mathrm{~kg}$; ; build 2.8 $(40+)$; fleshy.

Of the 3 children: (1) IV 7 o at 44 is of medium build. By a slender wife he had a daughter who at 22 years has a build 2.4 (34); medium build. (2) IV 10 q at 42 years, has a stature of $163 \mathrm{~cm}$. (64 inches) and weight of over $115 \mathrm{~kg}$. $(250+$ pounds) ; build $4.3(61+)$; obese. She married a slender man, and 1 of their 9 children, at 19 years, weighs orer $90 \mathrm{~kg}$. (200 pounds). (3) IV 11 ô is a medium weight; he married a slender woman and has 4 children who are of medium build.

Comment.-A fleshy Father, who is heterozygous for build, and his fleshy wife (of unknown gametic composition) have 1 obese child and 2 children of medium build (73: 704).

\section{Rec Family, A. (Fig. 47.)}

II 5 \& died at 84 years of "heart disease." His stature was $188 \mathrm{~cm}$. (74 inches) and weight $100 \mathrm{~kg}$. (220 pounds); build 2.8 (40); fleshy. $\mathrm{He}$ had a fleshy brother and sister. Their father was a slender man, but nothing is known about their mother. II 5 married II 6 , who died at 58 years of bronchial pneumonia. Her formula, 360/60 inches; build of 7.0 (100) ; very obese. She has 1 very fleshy and 1 fleshy sister and a slender brother.

This fleshy pair had 6 offspring, as follows: (1) III 2 ㅇ (plate 9 , fig. 2 ), build 4.0 (57), relative chest-girth, 90 per cent. She is the obese mother (by a fleshy, 2.8 (40), consort) of a slightly less

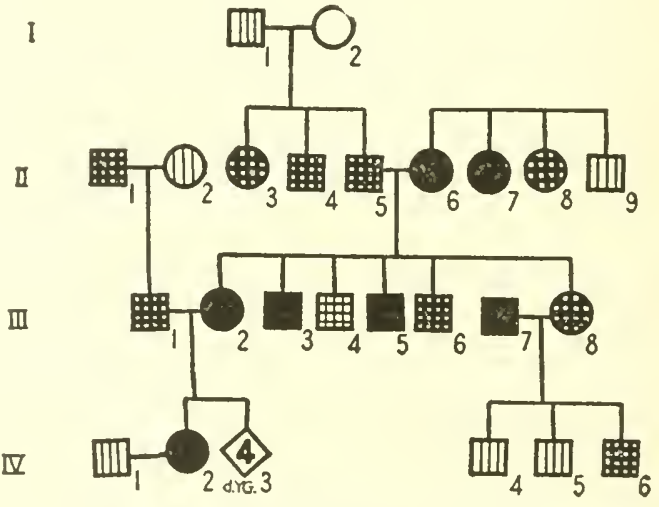

FIg 47.-Pedigree chart showing distribution of build in REC family.

obese daughter, of build 3.7 (53) (plate 9, fig. 3). (2) III 3 ô, $170 \mathrm{~cm}$. (67 inches) tall, and weighing $91 \mathrm{~kg}$. (200 pounds); build 3.1 (45); very fleshy. He is now at a State institution and weighs some 20 or 30 pounds less. (3) III 4 so, build about 2.4 (34); medium. (4) III 5 ô, very fleshy. (5) III 6 ô, about $183 \mathrm{~cm}$. (72 inches) tall, weighs over $90 \mathrm{~kg}$. (200 pounds); has very large shoulders and abdomen; build, say, 2.8 (40). (6) III 8 q, at 36 years has a stature of $168 \mathrm{~cm}$. (66 inches) and weight of $71 \mathrm{~kg}$. (157 pounds); build 2.7 (38); fleshy. Her relative ehest-girth is 52 per cent. She married a man of build 3.4 (48) and has 3 sons-2 slender and 1 fleshy.

Comment.-The parents II 5 and II 6 were probably heterozygous, so that they produced 1 in 6 of medium build. Also, their children are mostly heterozygous. Of 8 grandehildren, 2 are slender, 2 are stout $(73: 714)$. 
Rec Family, B. (Fig. 47.)

III 1 o , fleshy, with a fleshy father and slender mother, married to III 2 \% (plate 9, fig. 2), who at 53 years has a stature of $150 \mathrm{~cm}$. (59 inches) and weight of much over $90 \mathrm{~kg}$. (200 pounds); build 4.0 (57); obese. Her relative chest-girth is $135 \div 150$, or 90 per cent; extraordinarily obese. At 16, when married, she weighed 110 pounds; build 2.2 (32); medium. 4 of her 4 sibs and both parents are exceedingly obese (her mother weighs $163 \mathrm{~kg}$. [360 pounds] and has a build of $7.0[100]$ ).

The foregoing pair had 5 children, 4 of whom died young. The other, IV 2 \%, at 36 years has a stature of $168 \mathrm{~cm}$. (66 inches) and weight of $104 \mathrm{~kg}$. (229 pounds) ; build 3.7 (53); very fleshy. Her relative chest-girth is $130 \div 168$, or 77 per cent. She had at her marriage, when 23 years old (to a slender man), a build of 2.3 (33), medium grade. After marriage she increased rapidly in weight, menstruation became seant, she lost the sexinstinct, and is barren (plate 7, fig. 3).

Comment.-A tendency to extreme obesity runs in four generations. This is apparently of the adiposo-genitalis type, with sterility in the latest generation. Obvious dominant factors are at work here $(73: 714)$.

\section{Rid Family. (Fig. 48.)}

II 2 o died at 54 years; short and weighed $110 \mathrm{~kg}$. (240 pounds); build, say, 3.9 (56) ; very fleshy. A brother who died at 52 of apoplexy was fleshy, married a fleshy woman, and had a fleshy son. The mother of this fraternity was fleshy; about her consort's build nothing is known, but he had a fleshy sister (I 1).

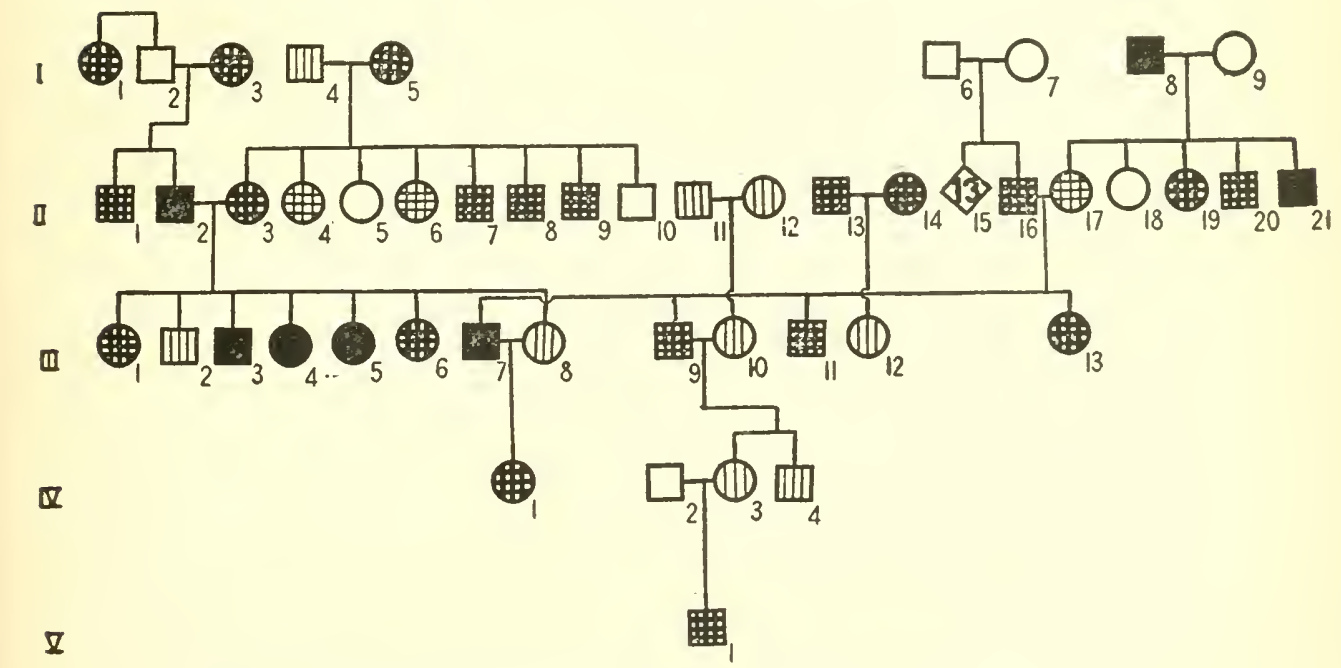

FIG. 48.-Pedigree chart showing distribution of build in the Rro family.

II 3 q, wife of II 2 , died of senility at 89 ; she weighed over $90 \mathrm{~kg}$. $(200$ pounds). She had 7 sibs: (1) II 4 q died of epilepsy, was of medium weight, married, and had 5 children, 4 of medium weight and 1 fleshy. (2) II $5 \%$ of unknown build. II $6 \%$ of medium weight, her children slender. II 7 of weighed over $90 \mathrm{~kg}$. (200 pounds); build, say, 2.9 (41), or fleshy. II 8 o weighed over $90 \mathrm{~kg}$.; fleshy. II 9 o also fleshy, like his two brothers. II 10 unknown. Thus of this fraternity of 6 known persons, 
4 are fleshy, 2 medium. Their father was slender; their mother "short and plump."

There are 7 offspring from this mating between II 2 and 3: (1) III 1 q, at 66 years, is bedridden from a broken hip; tall, weight $77 \mathrm{~kg}$. (170 pounds); ehest-girth $108 \mathrm{~cm}$. (42 inches); build, say, 2.8 (40); fleshy; she was fleshy as a child of 10 vears. (2) III 2 ô, died at 60 of paralysis, was always slender. (3) III 3 o at 62 years, is tall (say, 71 inches) and weighs $97.5 \mathrm{~kg}$. (235 pounds) ; build 3.3 (47); very fleshy. (4) III 4 o , at 56 years has the formula $91 \mathrm{~kg}$. (200 pounds); $161 \mathrm{~cm}$. (63.5 inches); build 3.4 (49) ; very fleshy; relative chest-girth 74 per cent. She was fleshy from the age of 16 years. (5) III 5 o, at 51 years, is very fleshy; was a slender child. (6) III 6 o is fleshy. (7) III 8 o , at 35 years weighed $86 \mathrm{~kg}$. (190 pounds), but now at 50 she is a helpless invalid and has grown slender; she was somewhat slender as a girl. Thus the offspring are 3 very fleshy, 2 fleshy, 1 always slender, and 1 formerly fleshy but reduced by illness $(73: 727)$.

\section{SMI FAMILY. (Fig. 26.)}

I 1 o died at 72 vears of acute indigestion; said to have been very fleshy, like his father. His wife, I 2 \%, dicd at 68 rears of paralysis. She was less than $155 \mathrm{~cm}$. (61 inches) tall and weighed $82 \mathrm{~kg}$. (180 pounds); build 3.4 (48); very fleshy. She had 3 sibs, of whom it is known that 1 was fleshy; the other 2 unknown. Her father was of medium build and had 3 ehildren by an earlier marriage, and of these 2 were slender and 1 fleshy. There were 7 children from I 1 and 2. (1) II 1, a man who died at 69 of pneumonia and diabetes and whose stature is $173 \mathrm{~cm}$. (68 inches) and weight about $95 \mathrm{~kg}$. (210 pounds); build 3.2 (45). (2) II 3 \% at 75 years is 155 $\mathrm{cm}$. (61 inches) tall and weighs $82 \mathrm{~kg}$. (180 pounds); build 3.4 (48). By a stout consort she has 2 stout and 4 slender children. (3) II 9 q, married, at 74 years is $163 \mathrm{em}$. (64 inches) tall and weighs $49 \mathrm{~kg}$. (107 pounds); build 1.8 (26) ; slender. By a slender husband she had one slender daughter, build 1.9 (27), a slender son, and 2 other ehildren who died young. (4) II 5 오, fleshy. (5) II 6 우, fleshy. (6) II 7 ㅇ said to be $157 \mathrm{~cm}$. (62 inches) tall and to weigh $82 \mathrm{~kg}$. (180 pounds); build 3.3 (47); very fleshy. (7) II 4 s, at 55 years, fleshy. By a medium wife he had a son who at 26 years weighs $77 \mathrm{~kg}$. (170 pounds) and was flesliy as a growing boy. Of the 7 children, 1 is slender, 3 are fleshy, and 3 very fleshy $(73: 736)$.

\section{Thr-1 Fanily. (Fig. 33.)}

A family of English and French stock living in the middle western States. The Father (H 8), whose oceupation has been very shifting, who suffered from "weak lungs" at 35 years, and who died at 81 years, had in middle life the formula $140 / 72$ inches; build 1.9 (27). But in answer to special inquiry it appears that he "took on flesh" in later years. He has to be recorded as fleshy. Of his 3 sisters, two are slender (both with eardiae hypertrophy), and 1 is of fleshy build. The fat sister had 2 daughters who weighed over 225 pounds each. His 2 brothers are slender. His father (I 1), a blacksmith, died at 90 years, having the formula $150 / 71$ inches; build 2.1 (30). His mother, always well, died at 68 years, having the formula 130/65 inches; build 2.2 (31); medium. This side of the house carries both fleshy and slender strains, some of the slender individuals being so, probably, through disease. Apparently the Father is heterozygous for fleshiness, perhaps one reason why he became fleshy late in life.

The Mother (II 9) suffered from arthritis deformans and died at 79 years. 
Her formula was 135/63 inches; build 2.4 (34). Two of her sibs are slender and one of medium build. Her father (I 3 ), who suffered from artlıritis deformans, was confined to his chair from rheumatism the last 15 years, and died at 72 years, having the formula $160 / 70$ inches, build 2.3 (33). Her mother, who died at 50 years, had the formula 140/65 inches; build 2.3 (33). She had a sister (I 5) who weighed about 250 pounds, "an enormous woman." This side of the house is of prevailingly medium build but with a tendency to obesity in one line. The children are 10 in number:

1. Male (III 3), a clerk, has at 66 years the formula 150/69 inches; build $2.2(32)$.

2. Male (III 4), a physician, who has always had a rheumatic tendency and is liable to sciatic neuritis, at 25 years had the formula $180 / 68.75$ inches; build 2.7 (38). He is the Father of Thr-2 family, page 79 .

3. Male (III 6), a preacher, has at 69 years the formula $170 / 68$ inches; build 2.6 (37). He has a daughter with a build of about $3.2(45)$.

4. Male (III 7), a physician, who in middle life suffered from inflammatory rheumatism, has at 59 years the formula $170 / 68$ inches; build 2.6 (37).

5. Female (III 8), who died at 34 years from appendicitis, has the formula $225 / 67$ inches; build $3.5(50)$. She was "a big overgrown woman in her teens."

6. Female (III 9), married, who has a rheumatic tendency, has at 55 years the formula 190/64 inches; build 3.3 (46).

7. Female (III 11), married, who has 9 children, suffered in middle age from rheumatism. At 53 years her formula was $225 / 67$ inches; build 3.3 (46).

8. Male, a merchant, well, has at 51 years the formula $155 / 67$ inches; build $2.4(35)$.

9. Male, a merchant, well, has at 49 years the formula $165 / 68.5$ inches; build $2.5(35)$.

10. Male (III 14), a doctor and dentist, has at 47 years formula $180 / 68$ inches; build 2.7 (39). One of his daughters has a build of about 3.2 (45).

Cliild No. 2, a physician, writes: "Many of my relatives, both on Father's and Mother's side, were afflicted with so-called muscular rheumatism (cousins, uncles, and aunts), pains in the limbs and muscles (not in the joints) ; especially those of robust and fleshy build, who possessed extraordinary good appetites and digestion, who liked good things to eat and much of it; the women being good cooks and the men generally marrying good cooks, they always had plenty to eat (rich food) and to spare. None of them are users of alcohol, simply being extra-hearty eaters" (R : Thr-1).

\section{WeN Family. (Fig. 49.)}

IV 10 is the Father; his formula is 260/74 inches; build 3.2 (46); very fleshy. His father (III 10) had the formula $245 / 73$ inches; build 3.2 (46); very fleshy. This father had a brother of just his build (who eventually died of tuberculosis) and a brother of formula 250/74, build 3.0 (43); fleshy. The Father's father's father (II 5) had the formula $200 / 70$, build 2.9 (41) ; fleshy; one of his brothers was fleshy (38), and one very fleshy, build 3.2 (45). The latter had a very fleshy son. The Father's father's father's father had a build of 2.9 (41) and a brother of the same build. These brothers of Gen. I were products of a first-cousin marriage. The Father's father's mother was a woman whose formula was 200/68.5 inches; build 3.0 (43) ; fleshy. Hence the Father's father and his brother, both of build 3.2 (46), got the fleshy tendency from both sides of the house. The Father's mother was a second cousin of the Father's father and her line also contained many fleshy representatives, but she herself was of 
medium build. Thus the Father belonge to a flesly strain, but he probably earries some non-fleshy gametes.

IV 11 is the Mother; her formula is 160/65.5 inches; build 2.6 (37); fleshy; she has 2 sibs, both fleshy; her parents are of medium build; they lave some slender grimdehildren.

There are 8 children, I 3 to 12 , whose sex and indices of build are ats

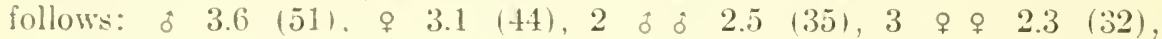
f 2.2 (31). Thus 2 are very flesly and 6 are of medium build. The

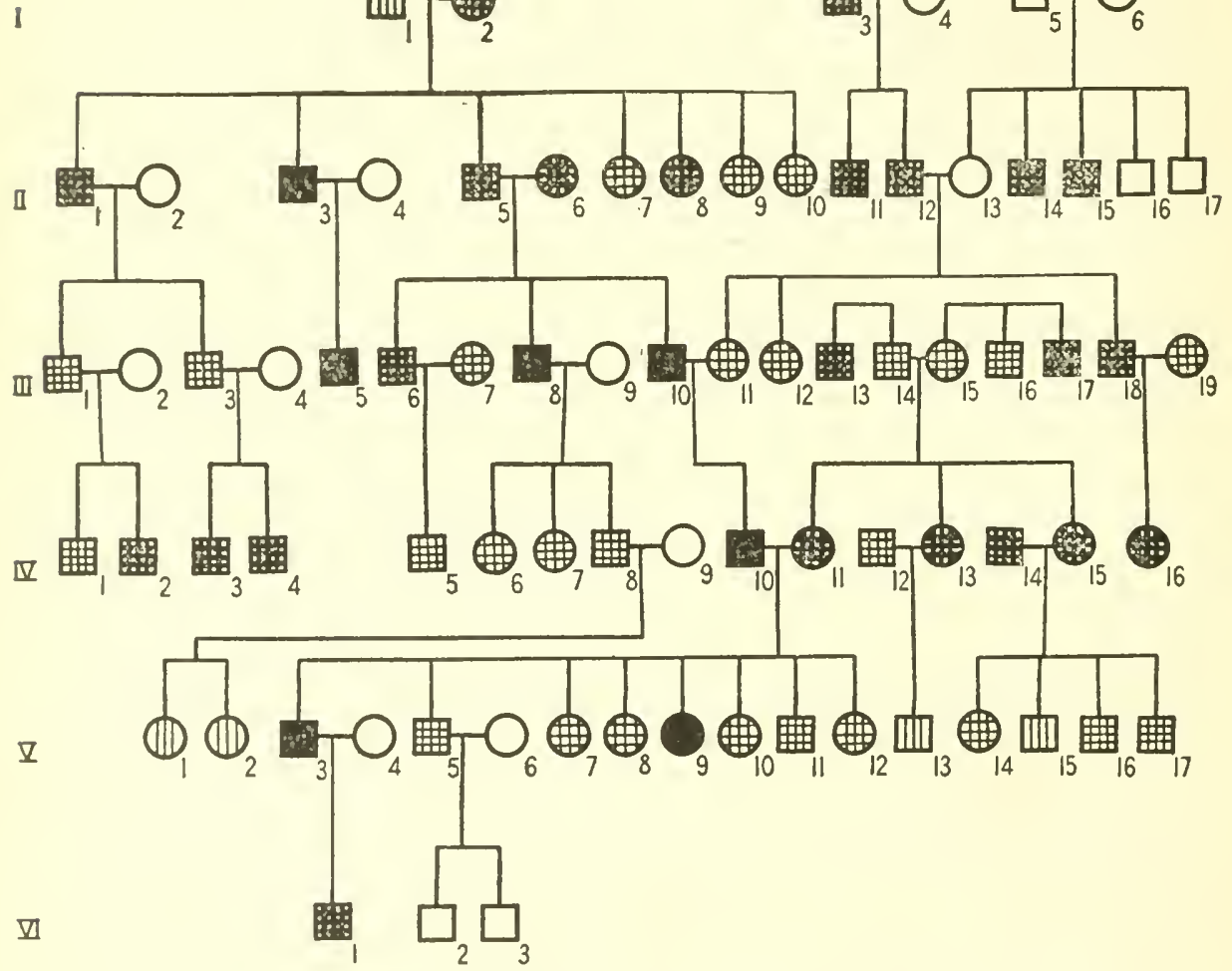

Fic. 19.- Pedifree chart showing distribution oi build in the Wes family. (Gen I 1 should be s. fure rulel, indicating fleshiness).

interval between the two groups is a wide one, indicating a elear genetic difference between them. The very fleshy brother, who weighs 265 pounds, was able to reduce about 60 pounds to be acepted for army service, but since being discharged from the army he has rebounded to his former weight. (A : $032-25$.

\section{SLMMARY ANI DISCUSSION.}

In a simple monohybrid with complete dominance the back-cross upon the recessive gives 50 per cent of the heterozygous dominant and 50 per cent of the recessive allelomorph. In a monohybrid with imperfect dominanee the back-eross upon the recessive gives 50 per 
cent of the intermerliate and 50 por cont of the recessive. Where 2 or 3 multiple factors are present and the hetcrozygote is nearly intermediate but shows a slight tendeney toward imperfect dominance, we may expect an approximation to a symmetrical ristribution of grades about the intermediate condition, with a skewess toward the recessive condition. That is what is got in both parts of table 32. This result supports the conchusion that there is segregation in the gametes of the heterozygous parent, so that the progeny tend prevailingly to fall again into the slenter and medium-fleshy grandparentai types. The results of table 33 similarly support the conclusion of segregation in the gametes of the heterozygous fleshy parent.

\section{GENERIL DISCUSSION.}

\section{Heredty ANd ENvironumet in B(ILI)}

That a tendency to slenderness or fleshiness of build "runs in families" and characterizes different races is a matter of common observation. But this fact is far from satisfying the clinician that heredity plays any part in this result. Thus, von Yoorden, who occupies a leading position among Teutonic investigators of metabolism in general and obesity in particular, denies the importance of an hereditary anomaly of metabolism in different families and races. Rejecting "anomaly of metabolism" or "peculiarity of protoplasmic metabolism," he stresses "inheritance" of habits of life that favor obesity, the quantity and quality of food, and the ideals of bodily activity. For example, the Eskimo are fat beause they eat blubber and huddle in narrow spaces, undergoing little movement throughout the long, lark winters. It is true that von Noorden speaks somewhat guardedly; he recognizes exceptions; suggests a possible hereditary hypofunction of the thyroid. But clearly constitutional peculiarities are, for him, exceptional as causes of orerweight, and here is where he fails to recognize sufficiently the fact that usually only particular individuals of a fraternity are fleshy; the others may be slender.

But besides anomalies of protoplasm and family traditions of feeding, there are obviously other possibilities. It is well known that different varieties of cattle differ greatly in their capacity for fattening. Armsby and Fries (1911) have inquired into the influence of type upon the fattening of cattle. They used a pure-bred AberdeenAngus steer and a "scrub," part Jersey, steer for comparison. As is well known, the former belongs to the easily fattening beef type; the Jersey to the difficultly fattening milk type. During over 21,2 years, beginning at under 1 year of age, these steers were under nearly continuous observations. They were fed on ordinary growing rations, 
the same for each steer. The digestibility of the total ration was determined at intervals; four tests were made of each animal in the respiration calorimeter to determine the percentage availability of the energy of the feeds consumed by each. The results were as follows: Analysis of feces and urine failed to show any difference in percentage digestibility of the food by the two animals, and calorimeter tests failed to show any difference in the proportion of the foodenergy which was being metabolized. But the two animals did not metabolize in the same way. Thus, in the serub, a larger proportion of the gain made was of protein than in the ease of the beef steer; and, conversely, the gain of the beef steer was more largely fat than in the case of the serub. Reduced to common weight, the energy requirement for maintenance of the serub steer was nearly 19 per cent greater than for the beef steer. Since the beef steer would eat more than the serub and tended to store fat rather than protein, the greater tendency of the beef steer to fatten received a biochemical explanation. The results seem to show a difference between the two varieties in the working over of the assimilated materials.

Indeed, it is easily appreciated that steers of the beef and dairy types of cattle should metabolize differently when we consider the marked difference in the milk production of the eows of these two types. The cow of the highest dairy type is capable of manufacturing 20 kilograms of milk containing 1.2 kilograms of butter fat in one day, or 6 per cent (Bailey, Enel. Am. Agric., III, 365). The cow of the meat type, of larger size, produces up to 30 kilograms of milk, and this contains, perhaps, 1.3 kilograms of butter fat per day, or only 4.3 per cent (Sinelair, 1904, p. 740-42). There is here, obviously, a difference in the metabolic processes in the cows and this is reflected in the steers also.* There is an internal biochemical difference as well as a difference in the feeding instinet. The latter is not merely a matter of family tradition, of the family economies or mores; it is a physiological phenomenon as much as internal metabolism.

Indeed, even von Noorden (1907, III, p. 700) seems to be forced to this conclusion by eases of failure to reduce weight at a diet far below that which appears to be essential to maintenance. Thus a man of 39 years, who exereised freely in the open air, had a weight of $102 \mathrm{~kg}$. For 3 months his diet never exceeded 1,720 ealories (estimated at 1,000 calories short of normal requirements) and at the end of this period he weighed $101 \mathrm{~kg}$.

That a relation between ingested food and activity is not the entire explanation of obesity is recognized by medieal men of experience. Heckel (1920, p. 371), referring to recurrent obesity, remarks on its frequeney and says: To constitute an obesity there must be

\footnotetext{
- I am indebted to Mrs. C. D. Walcott for calling my attention to this point.
} 
organic and hereditary tendencies: "Ne devient pas obèse qui veut." "Aussi la guérison accidentelle ou thérapeutique d'une obésité n'indique-t-elle pas la disparition définitive des tendances personelles ou congénitale."

Gulick (1922) has lately undertaken experiments to throw light on the question why some persons fatten easily and some with difficulty. He had noted that he himself belongs to a non-fattening strain and that his inclination toward a very copious diet of predominantly starchy nature did not lead him to put on weight, even though his round of activity was moderate. So he undertook biochemical, nutritional studies on himself. His observation covered nearly 21 months. During part of this time his caloric intake was low, 1,875 to 2,780 ; during another part high, 3,400 to 4,100. He found that he fattened somewhat during the period of heaviest feeding. There was, however, always an excess of intake over predictable need, and this excess increased absolutely and probably even relatively as the intake increased. The fecal nitrogen was $21 \%$ to $31 / 2$ times greater during over-feeding than under-feeding. The basal metabolism during maximum feeding was normal. Gulick concludes that a person belonging to the dificultly fattening type shows a wasteful rate of oxidation, whether under or over fed, but especially at the latter time. "It seems clear," concludes Gulick, "that throughout the entire experimental series there was some factor at work which caused fuel food to be burned more freely than in the average individual. This factor was not an over-active thyroid, as attested by the entirely normal basal metabolism." Gulick concludes that it was "some factor in the chemistry of nutrition" which caused extravagance. This he thinks may very possibly be comparable to the "secondary effect" of protein enrichment, which, according to Rubner, can raise the specific dynamic action of the food without raising the basal rate. It is also possible, he says, that the spare type may be accounted for by any factor that produces a high "cost of digestion," just as the obese may be supposed to suffer from an abnormally low "cost of digestion" (von Noorden).

Whatever the fundamental cause may be, the fact remains that in certain families there is a widespread inclination to the production of slender individuals, while in other fraternities certain proportions (though usually not all) of any fraternity are fleshy or even obese. Perhaps, as in the case of the Jersey as contrasted with the beef steer, the two kinds of individuals do not metabolize their food in the same way; some are spare and muscular, others lay on fat. In any case we can not disregard the constitutional factors in build.

Looking at the matter broadly, we can see that no other theory than that constitutional differences as well as nutritional differences 
determine build is sufficient to meet all the facts. In other species of animals we have precisely the same kind of differences between hereditary strains of slender and stout build that we have among humans. Thus, among dogs, the slender greyhound or Dachshund and the robust "Chow"; among horses the Thoroughbred and the stocky Percheron; among swine the "razor-back" and the Berkshire; among poultry the slender Leghom and the stocky Cochin. Slender and stocky as racial traits appear quite as white and black do and they doubtless have similarly a genetic basis.

A careful study of the families described in this paper must convince anyone, it seems to me, of the importance of the genetic factors. The Fun. family is of a wholly different type from the Thr-1 family. Even if the latter eat more, it is because of a constitutional urge like the constitutional urge that leads the Aberdeen-Angus steer to eat more than the Jersey steer. Very probably the Fun. family metabolizes in a different way from the Thr-1 family, building more protein and less fat.

In other cases it is not the whole fraternity that is fleshy or slender. This is well illustrated by the Wen. family, where 2 of 8 of the main fraternity are very fleshy and all the others of medium build. We have here to do not merely with a family habit of eating, but a differential constitution that provides one-quarter of the children with a large appetite that leads them to eat heavily and manufacture fat and provides three-quarters of them with a small appetite that leads them to eat lightly and to manufacture protein instead of fat. Constitutional differenees in the appetite and method of metabolism are the essential factors; and these are the things that are inherited. Only on such an hypothesis can we account for the clear evidence presented of constitutional factors in build-not always one only, but sometimes three or more acting together to produce the end result of obesity.

A scientific man, interested in nutrition, who has a build of 3.6 (51) himself and one of whose sisters has a build of 3.1 (44), whereas his 4 other sibs have builds of 2.5 to 2.1 (35 to 30 ), writes that his brother (of medium build, but about 75 inches tall) consumes daily about 2.700 calories; he himself and his fleshy sister about 2,500, and the others of his fraternity, who are of medium build, 2,000 to 1,800. He is a professional man, who does a good deal of office or laboratory work. He drinks about 3 to 4 quarts of water per day. His son, who is nearly 11 years of age, weighs just over 120 pounds, is 63 inches tall, and fairly fleshy. Though he is active, "never still a minute," yet he has to be urged to eat, willingly misses a meal, and uniformly declines a second helping; "he eats much less than his 6 -year-old cousins, who are actually under size for their age; he has never been a heary eater from the time he was weaned." This boy, the son of a very fleshy man, seems to afford an example of the easily fattening type in whom the slight excess of calories produces a striking result in build. 
Endocrine Glands as Links bletween Chromozomes and Somatic Qualities.

When it is concluded that there are constitutional, genetic factors for build, the validity of this conclusion is not weakened by the known rôle of endocrine glands on metabolism and build. 'Thus the experiments of recent years have emphasized the importance of the rolle that the thyroid gland plays in growth and development. As Lhlenhuth (1922, p. 182) says: "The ontogenetic development of the individual is controlied by the thyroid hormone." Since in cretins the thyroid functions imperfectly or not at all, the differences between the development of a normal child and that of a cretin are supposed to indicate the scope of the control by the thyroid hormone. In the cretin, growth is slowed up almost to cessation. In the long bones the centers of ossification develop slowly. "The epiphyses may be absent many years after they are due to appear and their union with the shafts of the long bones indefinitely delayed. Periosteal as well as endochondral bone formation may be greatly reduced and delayed. The cranial bones are thin, poorly ossified, and osteoporotic: mottling is sometimes evident ontogenologically." . . . Incomplete closure of the fontanelles is very common (Janney, 1922. pp. 391, 392). The genito-urinary system is undeveloped; the external genitalia remain infantile. The brain shows defective convolutions and all parts of the central nervous system show deficient derelopment. Owing to the fact that the long bones of the leg develop imperfectly, while the chest may continue to enlarge, the build of the cretin is usually large for his age. Thus, in general, the specific metabolic changes are retarded. When the thyreid functions imperfectly after maturity the victim puts on fat. The fat is usually distributed nearly uniformly under all parts of the skin. One of Janney's cases weighed 212 pounds at 12 years. Some degree of hypothyroidism is doubtless responsible for many of the "very fileshy" persons referred to in the preceding pages. The frequent recurrence of obesity in a family is in accordance with the tendency for hypothyroidism to recur in different members of a family; a tendency shown remarkably in Barrett's (1919) family.

The hypophysis, especially its anterior lobe, is believed to exercise an important control over differential metabolism and the resulting form. The results of hyperfunctioning of the gland are very different from those of hyperfunctioning of the thyroid. An extraordinary enlargement of certain parts of the skeleton, especially of the base of the skull, the hands, the feet, and the ribs, occurs. There is, indeed, in growing persons a tendency to the production of giants. In the underfunctioning of the hypophysis before puberty an extraordinary obesity is apt to appear, known as dystrophic adiposo-genitalis; because, the more the fat increases in amount the more the external 
genitalia appear under-developed-infantile. The obesity frequently affects the region of the pelvis only or chiefly, though the thighs also may be involved. Disfunctioning of the pituitary in later years is believed, likewise, to induce obesity. Of this disfunctioning there are, doubtless, all degrees corresponding to the variety of grades of obesity. Thus a second factor of obesity must be recognized; and this also "runs in families"-is hereditary.

The other endocrine factors in obesity are less precisely known. It is believed that the interstitial cells of the gonads secrete hormones that regulate, especially inhibit, the production of fat. This is inferred by the frequent tendency of women after the menopause to grow fat and of eunuchs (of one type, at any rate) to become fleshy. Also, the secretions of the islands of Langerhans of the pancreas are known to influence carbohydrate metabolism, so that when they do not function properly sugar is eliminated unchanged in the urine, and "diabetes," usually accompanied by fleshiness in its early stages, ensues. Of course, it can not be stated that pancreatic insufficiency is responsible for the prediabetic obesity; but the relation of the two phenomena is undeniably close.

Thus there come clearly to view two links in the chain of causes connecting chromosomal factors (such as are present in "Mendelian" heredity), on the one hand, and build, on the other. First, two or more of the endocrine glands play a great rôle in metabolism and when disturbed usually result in an abnormal build; and, secondly, just the condition of endocrine disfunctioning is an hereditary one and seems to depend on the condition of the enzymes or catalyzers that must be in the chromosomes.

That other constitutional conditions than those of the larger endocrine glands may play an important rôle in metabolism can not be denied; probably the quality of the protoplasm of every active cell influences the bodily metabolism; but the endocrine glands proper seem, as it were, to be told off for this specific purpose, and thus peculiarities in their functioning lead to striking results.

Evidence of Segregation in tile Heredity of Build.

The best single criterion of Mendelism in any hereditary distribution is segregation. If there is sufficient evidence of segregation in our study of build, then we are justified in concluding that build is inherited in "Mendelian fashion." There have been several occasions to refer to evidence of segregation in this work; some of this evidence may be brought together here and other added.

1. The difference in variability of the progeny of different matings. The offspring of slender parents are least variable, of fleshy parents most. This is evidence that the fleshy parents carry gametes for 
slenderness and thus that condition reappears in the offspring; but slender parents rarely carry gametes for fleshiness (p. 56).

2. As a corollary of the above, regression takes place in the progeny of fleshy parents to a markedly greater degree than in the progeny of slender parents (p. 39).

3 . The progeny of heterozygous parents are significantly more variable than the progeny of parents belonging respectively to slender and to fleshy stock. This is evidence that the heterozygous parents carry a greater variety of gametes than those of "purer stock."

4. In different matings of the same type the variability of the progeny differs; apparently, because some parents belong to a special biotype and others simulate the biotype merely through heterozygosity. Thus, if the $\mathrm{M} \times \mathrm{M}$ mating be considered (table $\mathrm{X}$ ), one finds some families characterized by slight variability of the offspring. The indices of build (English) in such families are given in table 34.

TABLE 34.-Indices of build of the progeny of $M \times M$ matings, in which the parents belong to the II biotype.

\begin{tabular}{|c|c|c|c|}
\hline Reference. & Indices of build of ehildren. & Mid range. & Total range. \\
\hline Bat $2 \ldots$. & $32,33,33,35 \ldots \ldots \ldots \ldots \ldots \ldots \ldots \ldots \ldots \ldots$ & 33.5 & 3 \\
\hline Bea $7 \ldots .$. & $31,32,32,34 \ldots \ldots \ldots \ldots \ldots \ldots \ldots \ldots \ldots \ldots$ & 32.5 & 3 \\
\hline Dic $4 \ldots$ & $29,31,32,33 \ldots \ldots \ldots \ldots \ldots \ldots \ldots \ldots \ldots \ldots$ & 32 & 4 \\
\hline Kel 4a. & $31,32, \mathrm{M}, \mathrm{M}, \mathrm{M}, 34 \ldots \ldots \ldots \ldots \ldots \ldots \ldots$ & 32.5 & 3 \\
\hline Old $2 \ldots$ & $33,33,33,35 \ldots \ldots \ldots \ldots \ldots \ldots \ldots \ldots \ldots$ & 34 & 2 \\
\hline $\operatorname{Rig} 1 \ldots .$. & $30,32,32,34 \ldots \ldots \ldots \ldots \ldots \ldots \ldots \ldots \ldots \ldots \ldots \ldots \ldots \ldots \ldots \ldots \ldots \ldots$ & 32 & 4 \\
\hline War $3 \ldots$. & $30,30,30,31,32,32,32,33,33,36 \ldots \ldots \ldots \ldots \ldots$ & 33 & 6 \\
\hline
\end{tabular}

The slight fluctuation in build of progeny of table 34 is obvious. The modal index of the progeny is close to 33 . On the other hand, there are matings of this type which show a much greater variability. These are listed in table 35.

TABLE 35.-Indices of build of the progeny of $H \times M$ matings in which the parents are probably heterozygous.

\begin{tabular}{|c|c|c|c|}
\hline Reference. & Indices of build of children. & Mid range. & Total range. \\
\hline $\mathrm{Cas} 4 \ldots$. & $32,34,34,37,41,43 \ldots \ldots \ldots \ldots \ldots \ldots \ldots \ldots$ & 37.5 & 11 \\
\hline Coo $5 \ldots .$. & $31,33,35,36,36,36,37,37,38,35,41 \ldots \ldots \ldots$ & 36 & 10 \\
\hline Eat A..... & $33,34,35,36,36,38,38,42 \ldots \ldots \ldots \ldots \ldots \ldots$ & 37.5 & 9 \\
\hline Fis $2 \ldots \ldots$. & $33,35,37,37,37,39,40 \ldots \ldots \ldots \ldots \ldots \ldots \ldots$ & 36.5 & 7 \\
\hline Ill $1 \ldots \ldots$ & $33,34,35,35,37,37,38,39 \ldots \ldots \ldots \ldots \ldots \ldots$ & 36 & 6 \\
\hline Mar $22 \ldots$. & $31,32,33,36,36,40 \ldots \ldots \ldots \ldots \ldots \ldots \ldots$ & $3 \tilde{j} . \tilde{3}$ & 9 \\
\hline Mer $8 \ldots . .$. & $33,36,37,40,41 \ldots \ldots \ldots \ldots \ldots \ldots \ldots \ldots$ & 37 & 8 \\
\hline Nes $1 \ldots .$. & $32,33,33,37,41,51 \ldots \ldots \ldots \ldots \ldots \ldots \ldots$ & 41.5 & 19 \\
\hline Tot A..... & $30,30,36,41,43,49,49 \ldots \ldots \ldots \ldots \ldots \ldots \ldots$ & 39.5 & 19 \\
\hline Rup $1 \ldots . .$. & $30,30,31,31,33,36,38,40 \ldots \ldots \ldots \ldots \ldots \ldots \ldots$ & 35 & 10 \\
\hline Smi $33 \ldots$. & $31,31,32,36,36,36,36,37 \ldots \ldots \ldots \ldots \ldots \ldots$ & 34 & $\underline{6}$ \\
\hline Sto $13 \ldots .$. & $33,34,36,38,38,38 \ldots \ldots \ldots \ldots \ldots \ldots \ldots \ldots \ldots$ & 35.5 & $\begin{array}{r}5 \\
10\end{array}$ \\
\hline A $01: 29 \ldots$ & $29,39,41, \ldots \ldots \ldots \ldots \ldots \ldots \ldots \ldots \ldots \ldots \ldots \ldots$ & 35 & 12 \\
\hline
\end{tabular}


These series of progeny fluctuate in build around 36. It seems probable that the variable progeny are the offspring of heterozygous parents, but this can rarely be proved. since the build of the grandparents is not of ten available in the present series.

That there are really at least two kinds of matings of the $\mathrm{M} \times \mathrm{MI}$ type is shown more conelusively by figure 50. in which two modes, at 33 and 36, respectively, are elearly seen. The conclusion seems to be justified that the mode at 33 is that of progeny derived from the M biotype and the mode at 36 is that of the progeny of heterozygous $M$ parents. The existence of these two modes in figure 50 is thus evidence of segregation.

Additional evidence is found in other matings, likewise. Thus the M $\times \mathrm{F}$ mating shows two modes, at 33 and at 36 (fig. 51). There is also one other, possibly significant, mode, namely, at 38 , in the fleshy group. Since $\mathrm{F}$ parents are sometimes homozygous, mating with $\mathrm{M}$ would tend to produce medium-fleshy progeny (i. e., 36). The F parents are, however, frequently heterozygous, containing both slender, medium, fleshy, and even very fleshy gametes; and, accordingly, we should expect somatic segregations at about the points $30,33,36$, and 38 as centers, just where we find them.

Again, the $\mathrm{S} \times \mathrm{M}$ mating yiclds (fig. 52) modes at 32 and 35 respectively, a shade lower than those of the $\mathrm{M} \times \mathrm{M}$ or $\mathrm{M} \times \mathrm{F}$ matings; but the male offspring (taken alone) gives modes at 33 and

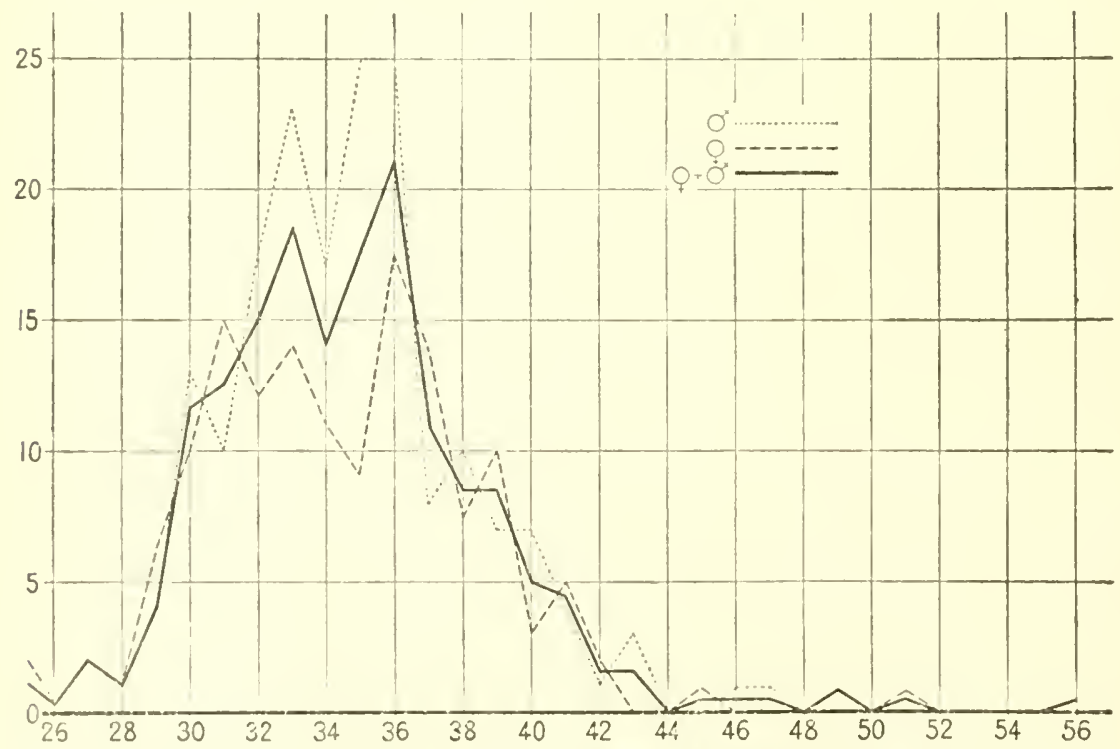

Frc. 50.-Polygon of distribution of offspring of $\mathrm{M} \times \mathrm{M}$ matings (from Appendix table $\mathrm{X}$ ) for males, females, and sexes combined. Abscissa: index of build, English system. Ordinates: absolute frequencies for males and females and their half sum for the sexes combined. 
35. Where the mode is at 33 it is probable that an S and an M gamete have met; and this condition is relatively common just because M gametes are common. The mode at 3i) may arise from an $\mathrm{F}$ gamete carried in a heterozymous M uniting with an S' ganete. The Sigmete carried in heterozygous $\mathrm{I}$ may be responsible for a probalole mode which is hidden in the form of a hump at 28 in figure 52 .

Attention is called to the probable influence of these morles on the two modes shown in figure 7 , at 33 and 35 respectively. These two modes are strong evidence for a segregation in the factors for build. Thus the very irregularity of the polygon of figure 7 is evidence of the presence of segregating factors for build. Horeover, these two modes appear at every age from birth to maturity, as is clearly shown in figure 53. This bimodality is easily accounted for on genetical grounds, but is inexplicable upon the bare nutritional hypothesis of build.

On the Number of Factors Involved in Fieshy Billd.

It is by no means an easy matter to determine the number of independent factors which are active in the case of a trait that is due to multiple factors. This matter is still less easy if there is only very imperfect dominance approaching intermediacy of the trait in the progeny of the $F_{1}$ mating. Yet that is the situation that has to be met in the study of heredity of build.

An attempt has been made in this paper to test the relative probability that there are only two, on the one hand, or three or more

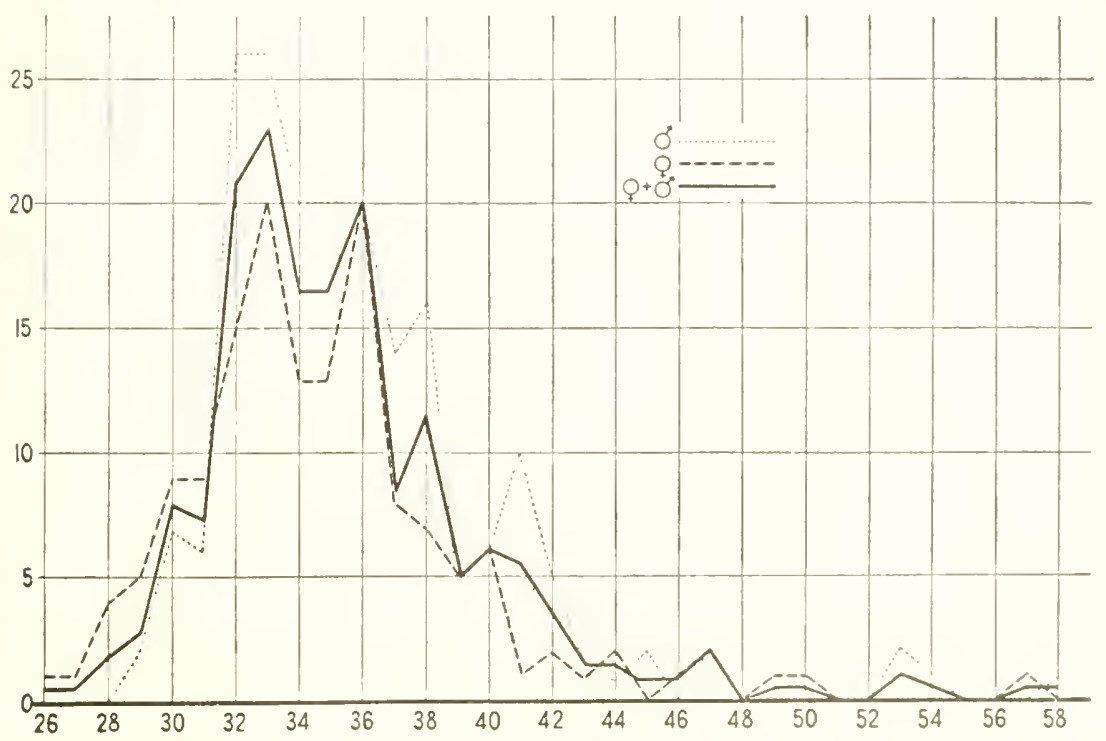

FIG. 51.-Polygon of distribution of offspring of $\mathrm{M} \times \mathrm{F}$ matings (from Appendix table $\mathrm{XI}$ ), sexes separate and combined. See also legend of fig. 50. 
independent factors, on the other, involved. We have seen, in each of the various matings, that the result is, on the whole, more closely in accord with the 3-factor hypothesis than that of 2 factors. But this is not to insist that never more than 3 independent factors are involved in build, or never less than 3 .

An attempt was made to apply Dr. Sewall Wright's formula (Castle, 1922, p. 22). Using the data of tables 12, 27, and 31, the value for $n$ (the number of factors) was calculated by the formula

$$
N=\frac{D^{2}}{8\left(\sigma_{2}{ }^{2}-\sigma_{1}{ }^{2}\right)}
$$

where $D$ is the difference between the means of parental pure races, $\sigma_{1}$ is the standard deviation of $\mathrm{F}_{1}$, and $\sigma_{2}$ is standard deviation of $\mathrm{F}_{2}$.

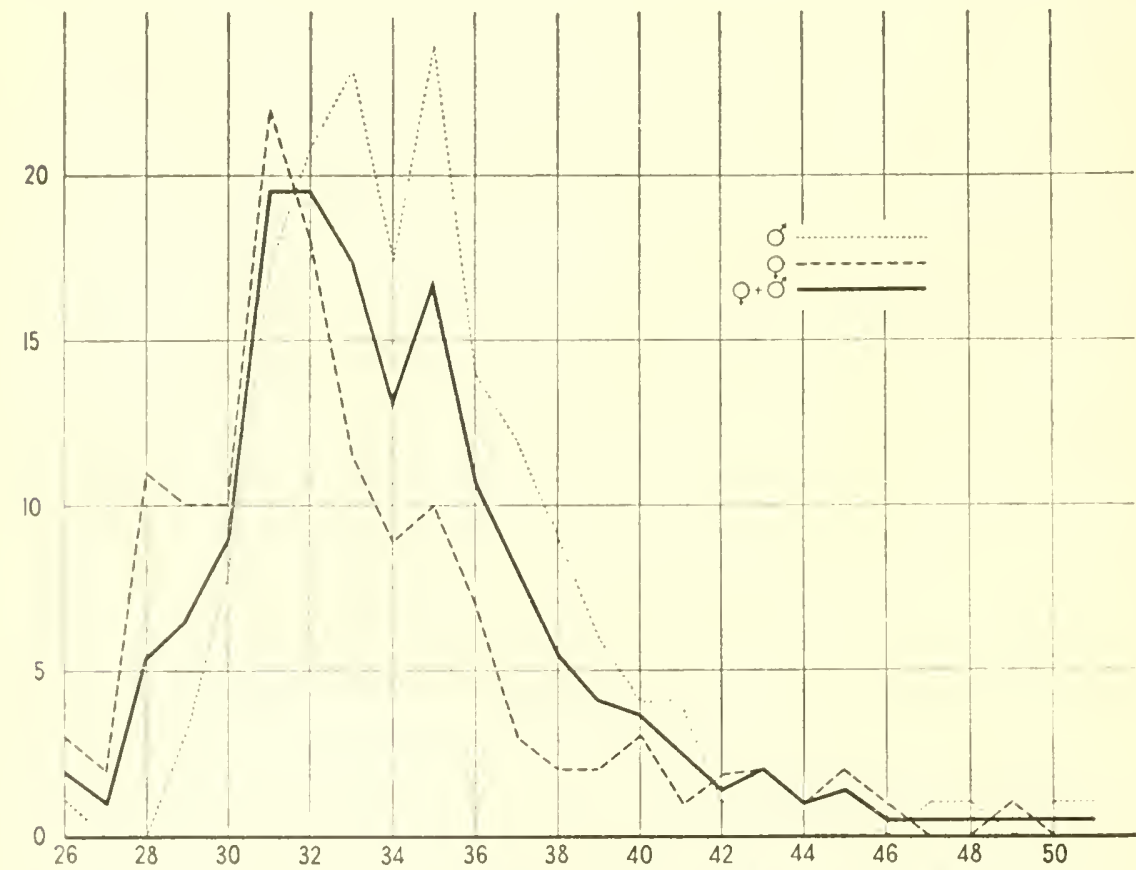

FIG. 52.- Polygon of distribution of frequencies of build of offspring of $\mathbf{S} \times \mathbf{M}$ matings (from Appendix table VI1), sexes separate and combined. See also legend to fig. 50 .

Substitution for the letters of their values given $n=(39.20-28.50)^{2}$ $\div 8\left[(6.78)^{2}-(5.02)^{2}\right]=0.69$. We can only conclude that, owing to small numbers, this formula is not applicable here.

Returning, then, to our conclusion that the assumption of at least 3 gametic factors for some, probably most, cases of build accords best with the results of the various matings, we may inquire what is the nature of these factors. It seems probable that two of them may correspond to dystrophies of the pituitary and thyroid glands respec- 
tively and the other or others to other regulatory mechanisms of metabolism in the organism. It may well be that one of our factors is the same as that which causes hypothyroidism; another as that which causes hypopituitarism, and the third that which inhibits the normal development of the genitalia, such as we see functioning in dystrophia adiposo-genitalis. This is, indeed, speculation. However, the speculation is an attempt to give a concrete form to the ideas of multiple factors in build.

If we assume three independent factors for build, it does not follow that these are present in all families. Just as it has been demonstrated that in different strains of mice there are in some eases 3 , in

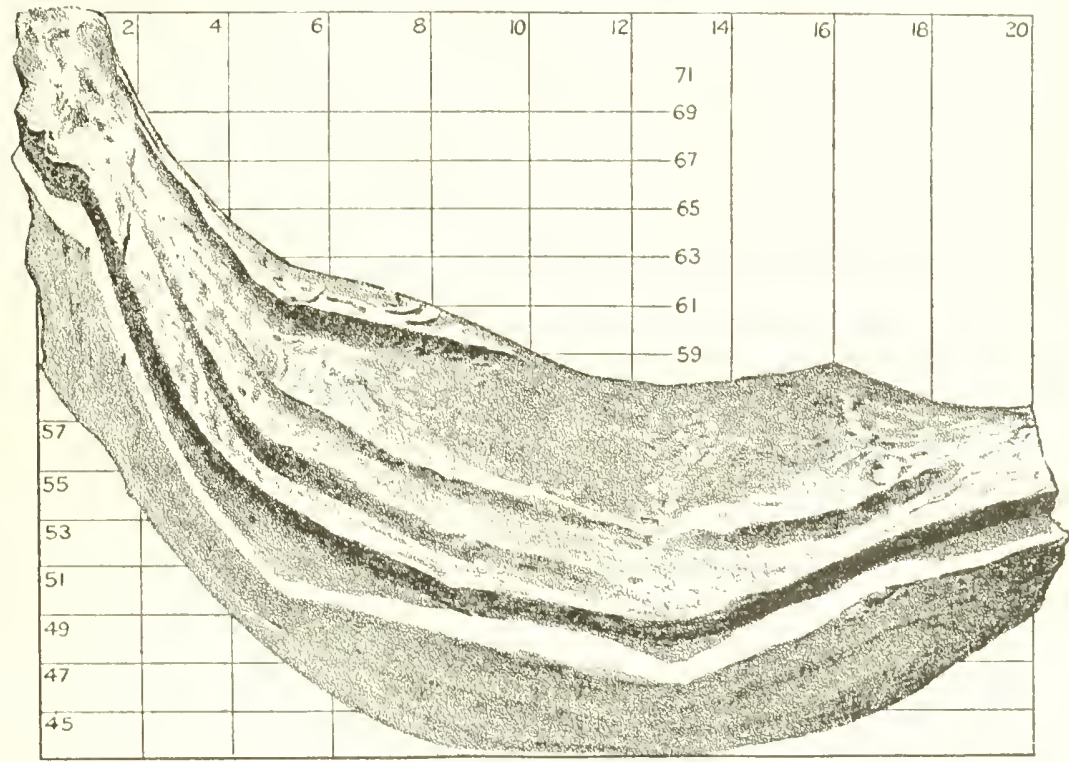

Fac, 53,-Solicl figure (model) giving distribution of relative chest-girth for rinrious ages from birth to 20 years, reading from left to right. The mean index of build at each age is centered on the curve of development of relative chest-rirth. 'llhe relative chest-girth is indicated in pererentages passing from the bottom to the top of the tigure. The solid figure is illuminated from the upper part of the page.

others only 2 factors for susceptibility to cancer. so, apparently, it is with build. In certain families the distribution of build in the progeny is best accounted for on the hypothesis that, in such families, there are only two gametic factors for build. In other families there appears to be only one gametic factor for build.

It has been repeatedly pointed out that in many cases where multiple factors are invoked to explain the genetical results, the results can be equally well explained on the theory of blended inheritance. The advantage of the factorial theory is that it brings under one type of heredity even these most difficult cases of apparently blending 
inheritance. More than that, howerer, the theory of multiple factors explains a number of phenomena that the theory of blending inheritance does not, such a the greater variability of the $F_{2}$ as contrasted with the $F_{1}$ generation, and the skemess in distribution of progeny. in the back-cross. Thus an F S mating should produce a "medium" progeny with symmetrical distribution of deviating types on the theory of blenting inheritance: actually it produces not only mediums, but an excess of fleshy orer slender, which is readily accounted for on the hypothesis that fleshiness is partially dominant over slenderness. In this ant other ways especially in focussing attention on cametes. the doetrine of multiple factors is essential to an adequate interpretation of the results of mating between persons of dissimilar build.

\section{SI MIMARI OF CONCLISIONS.}

1. Two types of variation in build are to be distinguished: (1) the change in average build that accompanies ontogeny and (2) variations in alult build.

2. The popular idea of build is best expressed as the ratio of transverse chest diameter to stature, or (since the chest diameter is rarely. known) chest-girth to stature. When only weight and stature are known, the closest approximation to the chest - -stature ratio is given by the weight $\div$ (stature) $)^{2}$ ratio, and this is taken as the standard index of build.

3. The correlation between the standard index of build and the relative chest-girth is. for males, about 0.45 .

4. The index of build of adult males is slightly greater than of females, because of the relatively greater chest-girth of males. The average index of build for males is 2.52 (35.S) and for females $2 .+3(3+. j)$

5. There are marked racial differences in build; but they are not so great as the differences in ontogenetic stages.

6. There are geographical differences in build: the heavy build of northern people- may be lue to a phrsiological reaction or. in part. to a selective survival of the fleshier indiviluals or strains.

7. The ontogenetic curve of build. expressed by relative chest-girth. is expressed by figure 1 and (for infaney) figure 2. It shows that at birth chest-girth is about two-thirds of stature and diminishes in the male to the age of 1's years: thereafter, on the arerage, it rises to complete maturity.

s. Build declines temporarily during the first month of life, owing to the physiologieal diffieulties attending adjustment to new conditions. It declines temporarily, again. at about $s$ months. probably due to the cutting of the incisor teeth. 
9. The heavy build of the infant corresponds to that of the shortlegged anthropoids. The long-legred, siender-build stage of the boy of 12 years persists in the Nilotic negroes and many low-grarle feebleminded.

10. In adult life the changes in build vary with families. In those characterized by slender build there is typically little change. In those characterized by fleshy build there is typically progressive increase in weight to 50 years. In some families weight fluctuates greatly at different periods of adult life. In general, though with numerous exceptions, a fleshy adult build is foreshadowed in plump build in chilclhood.

11. Mass studies on adult build give a polygon of distribution which is skew, the mode being toward the slenderer end of the polygon. There is evidence of more than one mode, and hence that there are two or more types of build. For purposes of description five elasses of build are recognized-very slender, slender, medium, fleshy, and very fleshy.

12. The diseases associated with very slender and slender build are: tubereulosis, pneumonia. "nerrousness," melancholia. The diseases associated with very fleshy or fleshy build are: diabetes, nephritis and dropsy, apoplexy, and arterio-sclerosis and paralysis accompanying it; also numerous diseases of the alimentary tract.

13. Fleshy parents have, on the average, in our data, larger families than slender parents.

14. Regression toward mediocrity is less striking in the offspring of slender than of fleshy parents, suggesting that fleshy parents carry not only genes for fleshiness but also for slenderness, while slender parents more rarely carry genes for fleshiness.

15. The offspring of two fleshy parents are twice as variable as those of slender parents.

16. The hypothesis is indicated that genetically build is controlled by multiple factors, with fleshiness tending slightly to dominate over slenderness.

17. There is a marked tendeney for persons of similar build (or with potentialities for such) to intermarry. Dissimilar builds are selected against.

18. Two slender parents of slender stock have rarely any progeny whose index of build exceeds 2.2, or just above the upper limit of the slender group. In general, the progeny of slender parents are relatively slightly variable.

19. The slender parents are apparently of two kinds: those carrying only one kind of factor for fleshy build and the other two such gametic factors. The progeny of the former are very slightly variable; those of the latter more variable. 
20. By comparing coefficients of variability instead of indices, and by making allowance for the greater range of the fleshy class than the slender class, it still appears that the progeny of fleshy parents are relatively and per unit range more variable than the progeny of slender parents. Absolutely the offspring of the fleshy parents are, as stated, twice as variable as of slender parents.

21. The matings of slender parents and fleshy parents of fleshy stock yield a variable progeny, such as is typically found in the $F_{1}$ generation when multiple factors are concerned. The variability is between that of the progeny of slender matings and that of the progeny of fleshy matings.

22. The $F_{1}$ generation has not a mode of build that is intermediate between that of the parental stocks, but one that is about the same as of the fleshy matings. This is evidence of partial dominance of fleshiness.

23. The mating of two heterozygous $\left(F_{1}\right)$ parents produces, in general, an exceptionally variable progeny. This is one of the strongest evidences of the presence of genetical factors in build.

24. Many, if not most, parents of medium build belong to biotypes with 1 or 2 independent factors for build. Consequently the progeny of medium $\times$ medium matings is often strikingly invariable.

25. The "back-cross" of a heterozygous parent with a slender parent, on the one hand, or with a fleshy parent of fleshy stock, on the other, gives a variable progeny, whose mode is shifted toward fleshiness; but which shows a tendency to fall again into the slender (or fleshy) and medium-fleshy grandparental types.

26. Tariations in build are not to be accounted for merely by variations in intake and out-go of calories, but also by the endogenous factors that determine the "economy of nutrition" or the cost in energy of adding an additional kilogram of weight to the body. The factors involved in producing differences' in these respects are hereditary factors.

27. The hereditary factors probably work through the intermediacy of special organs that influence metabolism, notably the endocrine glands. The latter thus intermediate between the chromosomal constitution, on the one hand, and control of metabolic processes, on the other.

28. The number of factors involved in very fleshy build is, in some cases at least, three independent ones. But the number is probably not the same in all biotypes. Probably in some there is only one, in others four or more.

29. The factors probably influence the functioning of the thyroid, pituitary, and perhaps other glands. 


\section{APPENDIX.}

I-XV. Tables of mating: and progeny based on the orgeinal famly histories.

XVI. Ineliees of build, weight $\div(\text { statures })^{2}$, for weights from 100 to 225 pound: and 45.4 to $102 \mathrm{~kg}$.; statures from is to $7 \mathrm{~s}$ inches and 140 to $19 \mathrm{~s}$ cm.

XVII. Equivalent values of index of build by four different systems of ratios between weight and stature, English systen.

XVIII. To transmute the English system of index of buitd to the mestire sytem.

\section{ABBREVIATIONS.}

In top line of tables: F, father; M, mother; FF, father's father; FM, father' mother, etc.

In body of tables: ca, cancer; E, epilepsy; F, fleshy; hif, heart failure; I, insane; M-D, mania-depressive insanity; M, medium buik, $S$, slentlor; su, suicide; $t$, tuberculosis; V, very (slender, etc.); yg, young; tor d, died; * refers to special families not included in the construction of figure 7 , or tables 11 and 12 .

\section{TABLE I.- Tery slender $\times$ very slender malings and their progeny.}

This mating is not represented in our data. This table is nevertheless indicated and numbered in order to secure the proper ordinal position of the following tables.

TABLE II.-Slender $\times$ very slenter matings and their progeny.

\begin{tabular}{|c|c|c|c|c|c|c|c|c|c|c|}
\hline $\begin{array}{l}\text { File } \\
\text { ref. }\end{array}$ & $\begin{array}{l}\text { Male } \\
\text { children. }\end{array}$ & $\begin{array}{l}\text { Female } \\
\text { children. }\end{array}$ & F. & FF, & F\I. & $\begin{array}{l}\text { Father's } \\
\text { sibs. }\end{array}$ & M. & $M F$. & MML. & $\begin{array}{l}\text { Mother's } \\
\text { sibs. }\end{array}$ \\
\hline 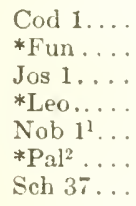 & $\begin{array}{l}26 \\
29 \\
39 \\
V S \\
25 \\
\ldots \ldots \\
3127\end{array}$ & 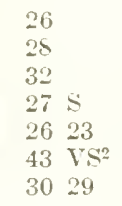 & $\begin{array}{l}29 \\
27 \\
24 \\
V S \\
26 \\
8 \\
29\end{array}$ & $\begin{array}{l}35 \\
27 \\
\cdots \\
M \\
M \\
29\end{array}$ & $\begin{array}{l}33 \\
29 \\
\ldots \\
\ldots \\
\mathrm{M} \\
\mathrm{F} \\
33 \pm\end{array}$ & $\begin{array}{l}26 \quad 27 \quad 29 \\
\ldots \ldots \ldots \\
\ldots \ldots \ldots \\
s_{F} \\
\ldots \ldots \ldots\end{array}$ & $\begin{array}{l}25 \\
25 \\
27 \\
8 \\
24 \\
15 \\
25\end{array}$ & $\begin{array}{l}30 \\
32 \\
\ldots \\
\ldots \\
M \\
M \\
27 \pm\end{array}$ & $\begin{array}{l}30 \\
27 \\
\ldots \\
\cdots \\
M \\
M \\
29 t\end{array}$ & 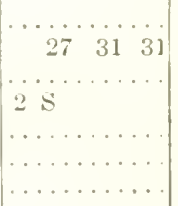 \\
\hline $\begin{array}{l}\text { families w } \\
\text { Number of }\end{array}$ & $\begin{array}{l}\text { ith*) } 26.13 \\
\text { natings: } 4\end{array}$ & $+3 *=7$ & & $\begin{array}{l}\mathrm{Cl} \\
\mathrm{Pr}\end{array}$ & $\begin{array}{l}\text { ssific: } \\
\text { porti }\end{array}$ & $\begin{array}{l}\text { tion of prog } \\
\text { nal frequen }\end{array}$ & $n y$. & mill & & $\begin{array}{rrrr} & s & M & F \\
4 & 12 & 2 & 2 \\
0 & 600 & 100 & 100\end{array}$ \\
\hline
\end{tabular}

Total number of progeny: $11+9 *=20$

${ }^{1}$ Four adolescents are all below standard weight but 1 , who is 5 pounclis above. ${ }^{2}$ An $_{\text {invulid. }}$

TABLE III.-Very slender $\times$ medium matings and their progeny.

\begin{tabular}{|c|c|c|c|c|c|c|c|c|c|}
\hline $\begin{array}{l}\text { File } \\
\text { ref. }\end{array}$ & $\begin{array}{l}\text { Male } \\
\text { children. }\end{array}$ & $\begin{array}{l}\text { Female } \\
\text { children. }\end{array}$ & F. & $\mathrm{FF}$. & $F M$ & $\begin{array}{l}\text { Father's } \\
\text { sibs. }\end{array}$ & $M F$. & MM. & $\begin{array}{l}\text { Mother's } \\
\text { sibs. }\end{array}$ \\
\hline $\begin{array}{l}\text { Ach } 2 \ldots \\
\text { Bic } 1^{1} \ldots \\
\text { Gay } 3 \ldots \\
\text { Gru } 1^{2} \ldots \\
\text { Hil } 8^{2} \ldots \\
\text { Ise } 2 \ldots \\
\text { Mil A... } \\
\text { Wit } 24 \ldots\end{array}$ & $\begin{array}{lllll}\cdots & \ldots & \ldots & \ldots \\
32 & & & \\
\cdots & \cdots & \ldots & \\
34 & & & \\
28 & 36 & 34 & 33 & 32 \\
43 & 37 & & & \\
33 & 29 \mathrm{t} & & \end{array}$ & $\begin{array}{llll}27 & 33 & 31 & \\
29 & 33 & 32 & \\
36 & & & \\
30 & 33 & & \\
31 & & & \\
31 & 30 & & \\
33 & 22 & 31 & 42 \\
26 & & & \end{array}$ & $\begin{array}{l}32 \\
34 \\
35 \\
31 \\
34 \\
31 \\
36 \\
33\end{array}$ & $\begin{array}{l}32 \\
29 \\
\cdots \\
\mathrm{MI} \\
\cdots \\
26 \\
39 \\
26\end{array}$ & $\begin{array}{l}33 \\
35 \\
t \\
M \\
33 \\
31 \\
28 \\
M\end{array}$ & 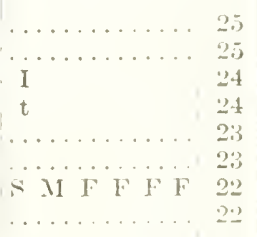 & $\begin{array}{l}32 \\
M \\
M \\
M \\
31 \\
35 \\
M\end{array}$ & $\begin{array}{l}27 \\
58 \\
5 \\
5 \\
28 \\
27 \\
30 \\
t\end{array}$ & $\begin{array}{l}\cdots \ldots \ldots \\
t, t, t, t \\
\cdots \ldots \ldots \\
\cdots \cdots \\
\cdots \cdots \cdots \\
\cdots \cdots \cdots \\
t, t\end{array}$ \\
\hline $\begin{array}{l}\text { Average } \\
\text { Total nur } \\
\text { Total nur }\end{array}$ & $\begin{array}{l}\text { uild of parents, } 2 \delta \\
\text { ber of matings, } \delta \\
\text { ber of progeny, } 2\end{array}$ & $\begin{array}{l}\text { Clas } \\
\text { Pro }\end{array}$ & $\begin{array}{l}\text { ificat } \\
\text { ortio }\end{array}$ & $\begin{array}{l}\text { ion of } \\
\text { ial fre }\end{array}$ & $\begin{array}{l}\text { proge } \\
\text { quency }\end{array}$ & per mille...... & $\stackrel{i}{i}$ & $\begin{array}{r}11 \\
17 \\
007\end{array}$ & $\begin{array}{c}\mathrm{F} \\
3 \\
107\end{array}$ \\
\hline
\end{tabular}

IF died, 39 years, pulmonary tuberculosis. Minble to tuberculosis of thruat and lunge.

- Female, 13 years, has already the build of her next older sistcr (33?).

F died, 39 years, tuberculosis.

- FM died, tuberculosis. MI insane and tuberculous in middle life: died, 51 years 
TABLE IV.- Very slender $\times$ fleshy matings and their progeny.

\begin{tabular}{|c|c|c|c|c|c|c|c|c|c|c|}
\hline $\begin{array}{l}\text { File } \\
\text { ref. }\end{array}$ & $\begin{array}{l}\text { Male } \\
\text { children. }\end{array}$ & $\begin{array}{l}\text { Female } \\
\text { children. }\end{array}$ & $\mathrm{F}$. & FF. & FMI. & $\begin{array}{l}\text { Father's } \\
\text { sibs. }\end{array}$ & M. & MF. & MII. & $\begin{array}{l}\text { Mother's } \\
\text { sibs. }\end{array}$ \\
\hline $\begin{array}{l}\text { Hol A... } \\
\text { Iut } 1^{1} \ldots \\
\text { Law A... } \\
\text { Olm A... } \\
\text { Wat } 52 . .\end{array}$ & 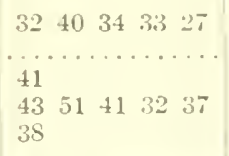 & $\begin{array}{llll}46 & 34 & 25 & 29 \\
35 & & & \\
30 & 28 & 35 \\
40 & & & \\
27 & 33 & 32 & 33\end{array}$ & $\begin{array}{l}39 \\
43 \\
43 \\
38 \\
37\end{array}$ & $\begin{array}{l}M 1 \\
34 \\
38\end{array}$ & $\begin{array}{l}3 \\
34 \\
34\end{array}$ & $\begin{array}{l}\ldots \ldots \ldots \\
\ldots \ldots \ldots \\
\mathrm{F}^{\prime} \cdots \cdots \\
\ldots \ldots \ldots\end{array}$ & $\begin{array}{l}23 \\
24 \\
24 \\
24 \\
25\end{array}$ & $\begin{array}{l}\mathrm{S} \\
35 \\
34 \\
\ldots\end{array}$ & $\begin{array}{c}\ddot{M} \\
\cdots \\
28 \\
\mathrm{~s}\end{array}$ & $\begin{array}{l}F M S M F \\
M F \\
4 S\end{array}$ \\
\hline $\begin{array}{l}\text { Average } \\
\text { Number } \\
\text { Total nur }\end{array}$ & $\begin{array}{l}\text { uild of parents, } 32 \text {. } \\
\text { f matings, } 5 \\
\text { ber of progeny, } 25\end{array}$ & $\begin{array}{l}\text { Clas: } \\
\text { Prop }\end{array}$ & $\begin{array}{l}\text { fieati } \\
\text { rtion }\end{array}$ & $\begin{array}{l}\text { on of } \\
\text { al fre }\end{array}$ & $\begin{array}{l}\text { srogen } \\
\text { uency }\end{array}$ & per mille. & . & $\begin{array}{cc}15 \\
1 \\
40\end{array}$ & $\begin{array}{lr}\text { S } & \text { MI } \\
5 & 10 \\
00 & 400\end{array}$ & $\begin{array}{ccc}\mathrm{I} & \mathrm{F} & \mathrm{VF} \\
0 & 7 & 2 \\
0 & 280 & 80\end{array}$ \\
\hline
\end{tabular}

1 Tendency to tuberculosis on maternal side.

2FF had one sister who had at least three F children. Apparently there is an F strain on Father's side. MF had two sibs who were large and tall. MMI had both $\mathrm{S}$ and $\mathrm{F}$ close relatives; one sister was $\mathrm{S}$.

TABLE I- - Fery slender $\times$ very fleshy matings and their progeny. There is only one example of this mating described at page 97 .

T'IBLF VI.-Slender $\times$ slender matings and their progeny.

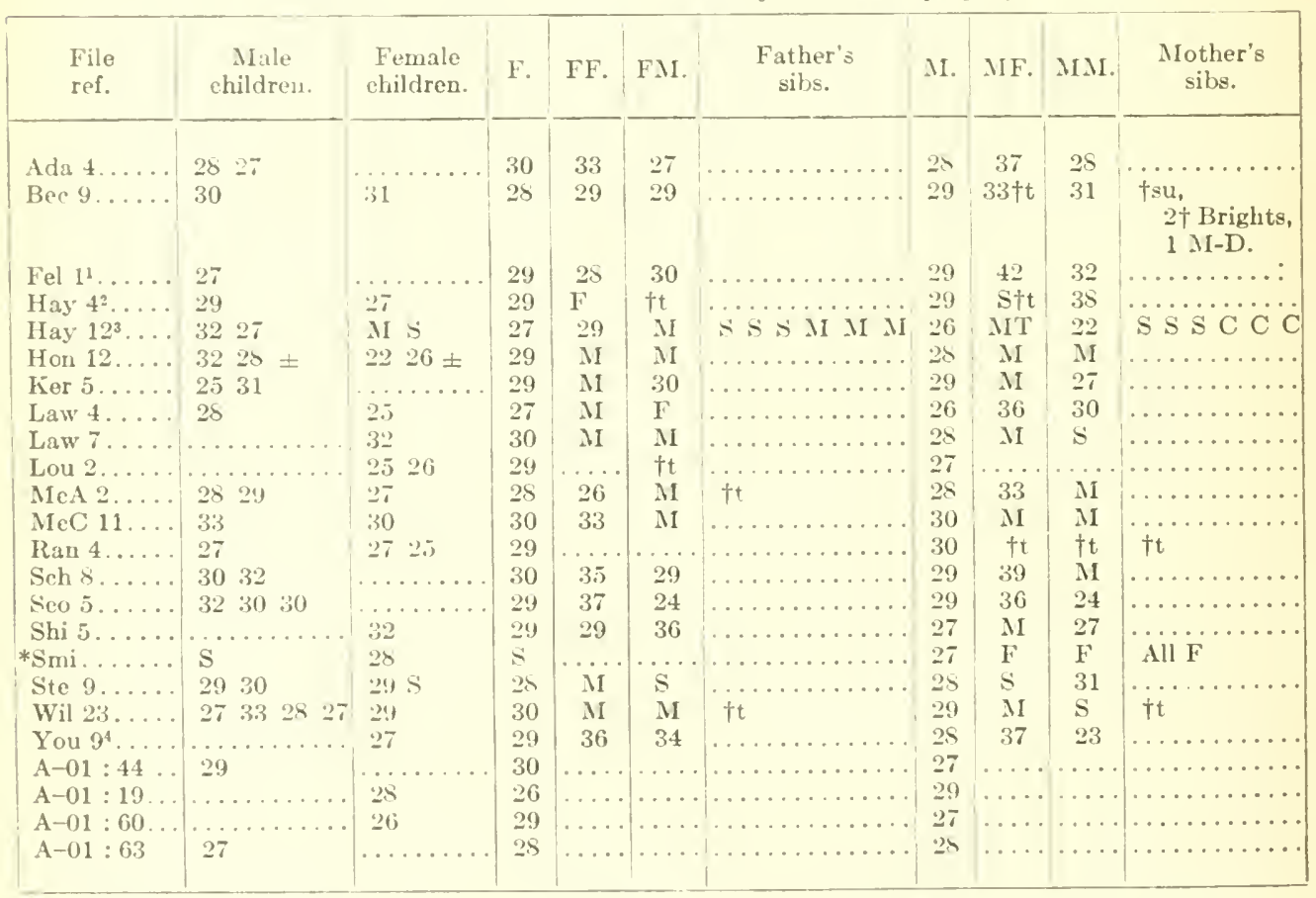

Average build of parents (exeluding family with *), 27.87

Number of matings, $23+1 *=24$

Total number of progeny, $47+2 *+2$ non-quantitative $=51$

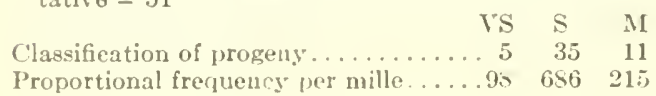

${ }^{2}$ FFF, build 36 ; FFM, build 27 ; FMF, build 28 . 23 adolescent children are $\mathbf{S}$.

- $\mathrm{N}$ 's sib (F) has one $\mathrm{F}$ and one $\mathrm{M}$ child.

- F's weight may have been reduced by bronchial trouble. 
TABLE VII.-Slender $\times$ medium matings and their progeny.

\begin{tabular}{|c|c|c|c|c|c|c|c|c|c|c|}
\hline $\begin{array}{l}\text { File } \\
\text { ref. }\end{array}$ & $\begin{array}{c}\text { Male } \\
\text { children. }\end{array}$ & $\begin{array}{c}\text { Female } \\
\text { children. }\end{array}$ & $F$. & FF. & F11. & $\begin{array}{l}\text { Father's } \\
\text { sibs. }\end{array}$ & M. & MIF. & MM. & $\begin{array}{l}\text { Mother's } \\
\text { silus. }\end{array}$ \\
\hline Alv A. & $\begin{array}{lll}36 & 32 & 30\end{array}$ & 4028 & 29 & 34 & & 3829 & 31 & 31 & 50 & $\begin{array}{llll}39 & 39 & 41\end{array}$ \\
\hline & $\begin{array}{lll}43 & 38 & 33\end{array}$ & 4232 & 36 & MI & M & en & 30 & $\mathrm{~F}$ & $\mathrm{~F}$ & 58 \\
\hline Atw 2 .. & 33 & 28 & 26 & 27 & 33 & & 35 & 30 & M & $1 \mathrm{~F} 3 \mathrm{~S}$ \\
\hline Bal $3 . .$. & 32 & 3233 & 29 & 32 & 33 & & 36 & 38 & 24 & 10 di \\
\hline Bak $8^{1}$. & 3433 & & $27^{1}$ & & & & 32 & & & \\
\hline Bes $1^{2} \ldots$ & $33 \quad 3535$ & 31 & 30 & 32 & 27 & & 36 & 31 & 31 & $3 \mathrm{~F}$ \\
\hline Bla 11. & $4033 \quad 3535$ & 39 & 33 & 31 & 34 & $3+\mathrm{t}, 2 \mathrm{~F}$ is & 30 & 43 & 30 & $\left\{\begin{array}{c}\mathrm{SSS} S \mathrm{M} \\
\mathrm{M} \mathrm{F}\end{array}\right.$ \\
\hline Blo $3 .$. & 35 & 30 & 32 & $\mathrm{~S}$ & M & & 28 & M & M & \\
\hline Bou 3.. & $37 \quad 34$ & 35 & 35 & 32 & $M$ & & 29 & M & 32 & \\
\hline Bou $4 .$. & $32 \quad 32$ & $3 \pm$ & 30 & 32 & $\mathrm{~s}$ & & 31 & 32 & 31 & \\
\hline Blu 2... & 31 & & 30 & $\mathrm{~s}$ & $\mathrm{~F}$ & & 34 & 38 & $\mathrm{~F}$ & 342733 \\
\hline Bra $4 \ldots$ & 33 & & 35 & 41 & $M$ & & 28 & M & M & \\
\hline Bri $2 \ldots$ & $\begin{array}{llll}35 & 33 & 33 & 31\end{array}$ & $\left\{\begin{array}{cccc}28 & 30 & 30 & 30 \\
33 & \end{array}\right\}$ & 32 & 32 & 31 & $\ldots$ & 26 & 32 & 30 & \\
\hline Bro 36. & 4132 & 30 & 35 & 39 & 38 & $\ldots \ldots \ldots$ & 27 & 36 & 50 & \\
\hline Bru A... & 31 & $\left\{\begin{array}{cccc}33 & 32 & 31 & 29 \\
28 & 3\end{array}\right\}$ & 34 & s & M & 31 & 26 & $\mathrm{~s}$ & $\mathrm{~s}$ & 30 \\
\hline Bru 2.. & 31 & $\begin{array}{llll} & 28 & 28 \\
35 & 32 & 34 & 28\end{array}$ & 30 & MI & & & 33 & $\mathrm{~s}$ & MI & \\
\hline & & 292628 & 30 & 29 & 33 & & 3 & 34 & 32 & \\
\hline Cla 1. & 313734 & 3629 & 30 & & & & 31 & 34 & 32 & \\
\hline Cob $1 .$. & 33 & $\begin{array}{llll}27 & 33 & 31 & 31\end{array}$ & 31 & 33 & 29 & & 28 & 35 & 31 & \\
\hline Col 19. & 40 & 33 & 3.5 & MI & $\mathrm{s}$ & & & M & $M$ & \\
\hline Clo 2 & 3132 & 30 & 32 & Mi & $\mathrm{s}$ & & 29 & & & \\
\hline Com 2. & 3532 & & 30 & 29 & 29 & & 32 & M & MI & \\
\hline $\operatorname{Cos} 2^{3} \ldots$ & & 31 & 34 & MI & $\mathrm{s}$ & & 26 & $\mathrm{~s}$ & $\mathrm{~F}$ & \\
\hline Cra & 31 & & 33 & 29 & 28 & & 8 & 29 & 49 & \\
\hline Cru $2^{4} \ldots$ & & 36 & 34 & 36 & 28 & & 28 & & 32 & \\
\hline Dew $1 \ldots$ & 413335 & 31 & 33 & $\ldots$ & ... & & 29 & 34 & 32 & \\
\hline $\operatorname{Dic} A^{5}$. & $42 * 3231$ & 2929 & 35 & .. & . & & 28 & 33 & 45 & $\left\{\begin{array}{cccc}28 & 28 & 31 & 29 \\
31 & 30 & 28 & 29\end{array}\right.$ \\
\hline Dic $3^{6} \ldots$ & 4534 & $26 \quad 34 \quad 27 \quad 33$ & 35 & 36 & $\mathrm{~S}$ & & 29 & 35 & 33 & \\
\hline & 3035 & 30 & 35 & & & $\mathrm{VF}$ & 27 & 31 & 38 & VF \\
\hline Dow $7 \ldots$ & ....... & 3032 & 28 & 31 & 29 & & 4 & 34 & 28 & \\
\hline & & 28 & 33 & 3 & 32 & & & $s$ & s & \\
\hline Dun A.. & 4438 & 31 & 35 & 35 & 34 & 38 & 26 & 33 & 33 & 2729 \\
\hline Eps & 31 & & 33 & 37 & 31 & & & & 38 & $\ldots \ldots \ldots$ \\
\hline & 33 & 31 & 33 & 35 & 49 & & 28 & MI & 3 & \\
\hline Fin & $43 \quad 383$ & & 30 & 34 & 31 & & & 38 & 33 & \\
\hline & 363430 & $33 \quad 32$ & 32 & 36 & 32 & & 6 & 31 & 34 & \\
\hline Fol & & 31 & 30 & & & & 36 & & & \\
\hline For & $36 \quad 38$ & & 28 & 30 & & & & & & \\
\hline & 39 & $\begin{array}{llll}44 & 43 & 42\end{array}$ & 34 & & & & 30 & & & \\
\hline Goo 6. . & & 2828 & 31 & 32 & 32 & & 29 & & & \\
\hline Gra 3.. & 33 & & 31 & 35 & 33 & & 26 & 37 & 35 & \\
\hline $\mathrm{Hal} \mathrm{B}^{8}$. & 32 & 31 & 31 & 39 & 47 & $\left\{\begin{array}{cccc}50 & 47 & 40 & 38 \\
36 & \end{array}\right.$ & 29 & .. & $\cdots$ & $\left\{\begin{array}{r}342929 * \\
27 *\end{array}\right.$ \\
\hline Har $35^{9}$. & 36 & & 27 & $\mathrm{M}$ & & & 35 & 27 & 34 & \\
\hline Haw $5^{10}$. & $\begin{array}{lll}40 & 31 & 32\end{array}$ & 333138 & 30 & 31 & 27 & & 34 & 40 & 30 & \\
\hline Hei $4 \ldots$ & 38 & & 34 & 39 & $M I$ & & 28 & & 39 & \\
\hline Hod $3 \ldots$ & $\begin{array}{llll}37 & 30 & 35 & 37\end{array}$ & $\left\{\begin{array}{cccc}36 & 34 & 34 & 28 \\
35 & 4 & \end{array}\right\}$ & 34 & 35 & 23 & $\ldots \ldots \ldots$ & 30 & 36 & 30 & \\
\hline Hor $7 \ldots$ & $\ldots \ldots \ldots$ & & 30 & MI & 33 & & 33 & 36 & 36 & \\
\hline & 3037 & 3133 & 34 & 34 & & $3 \dagger$ t. $1 \dagger \mathrm{ca}$ & 30 & 31 & 26 & \\
\hline & 37 & 31 & 34 & & & & 29 & & & \\
\hline Hos $3 .$. & 35 & 35 & 30 & 42 & $\mathrm{~F}$ & & 32 & 37 & 37 & \\
\hline Hox 2. & $\left\{\begin{array}{llll}S & M & M & M\end{array}\right.$ & 43 & 31 & M & M & & 28 & S & $\mathrm{F}$ & \\
\hline & $\begin{array}{lll} & & \\
33 & 33 & 34\end{array}$ & & 30 & 36 & 36 & & 31 & & 34 & \\
\hline & 3332 & & 34 & 35 & 36 & & 30 & $M$ & $\mathrm{~S}$ & \\
\hline & & 32 & 30 & $M$ & S & & 32 & M & $\mathrm{S}$ & \\
\hline Jon $15 \ldots$ & $35 \quad 38$ & & 34 & 43 & MI & & 29 & 36 & $M$ & \\
\hline
\end{tabular}


TAluE VIl.-Slender $\times$ medium matings and their progeriy-Continued.

\begin{tabular}{|c|c|c|c|c|c|c|c|c|c|c|}
\hline $\begin{array}{l}\text { File } \\
\text { ref. }\end{array}$ & $\begin{array}{c}\text { Male } \\
\text { children. }\end{array}$ & & F. & $F F$. & $F M$. & & M. & $M F$. & MMI. & $\begin{array}{l}\text { Mother's } \\
\text { sibs. }\end{array}$ \\
\hline 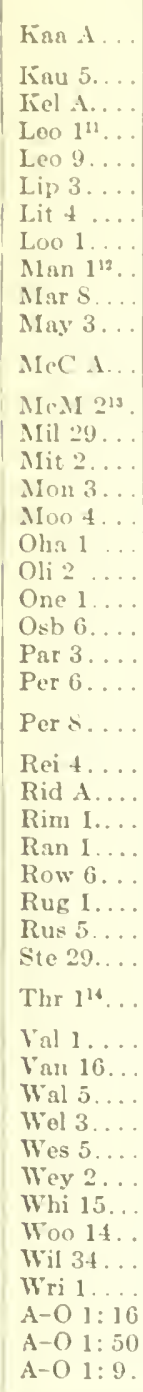 & 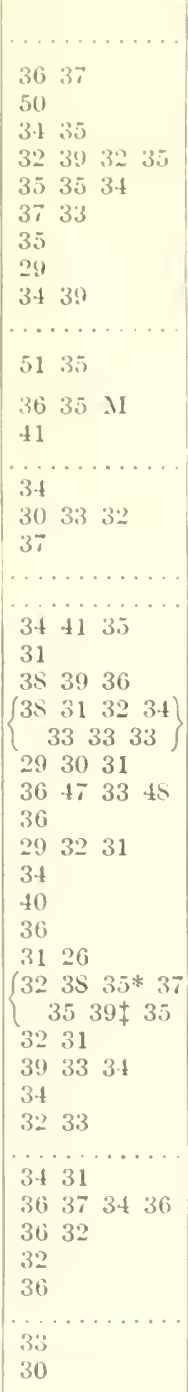 & 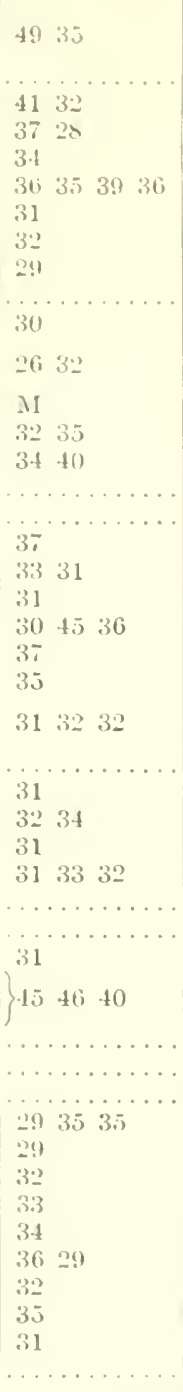 & $\begin{array}{l}35 \\
34 \\
30 \\
3511 \\
32 \\
35 \\
27 \\
34 \\
2812 \\
27 \\
31 \\
28 \\
31 \\
31 \\
32 \\
34 \\
31 \\
33 \\
32 \\
30 \\
34 \\
35 \\
29\end{array}$ & $\begin{array}{l}35 \\
34 \\
\cdots \\
\mathrm{T} \\
\ldots \\
31 \\
\mathrm{MI} \\
\ldots \\
41 \\
32 \\
\ldots\end{array}$ & $\begin{array}{c}\ldots \\
M \\
M \\
35 \\
31 \\
40 \\
\ldots \\
29 \\
M \\
\ldots \\
32 \\
38 \\
\ldots \\
32 \\
36 \\
41 \\
33 \\
40 \\
25 \\
31 \\
M \\
\Sigma \\
35 \\
5 \\
29 \\
M \\
\ldots \\
37 \\
32 \\
M \\
\ldots \\
\ldots \\
\ldots\end{array}$ & 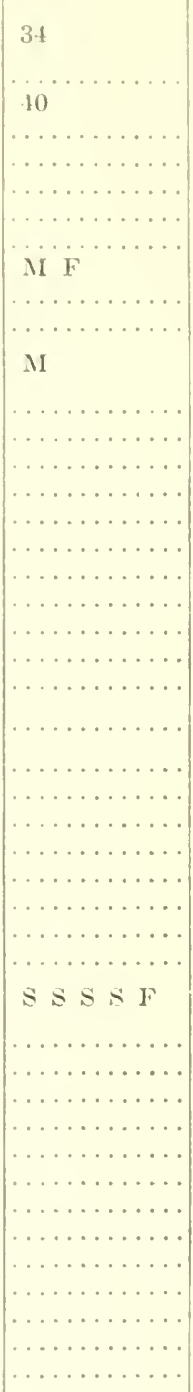 & $\begin{array}{l}25 \\
29 \\
33 \\
28 \\
30 \\
30 \\
35 \\
30 \\
31 \\
34 \\
29 \\
32 \\
27 \\
29 \\
24 \\
27 \\
26 \\
29 \\
29 \\
31 \\
28 \\
23 \\
34\end{array}$ & $\begin{array}{c}37 \\
M \\
M \\
3 . \\
30 \\
I \\
28 \\
M \\
35 \\
\mathrm{I} \\
30 \\
33 \\
\mathrm{M} \\
\mathrm{S} \\
34 \\
\mathrm{MI} \\
\ldots \\
39 \\
34 \\
4 \mathrm{I} \\
\mathrm{S} \\
\mathrm{S} \\
34 \\
\ldots \\
32 \\
24 \\
33 \\
\ldots \\
35 \\
\mathrm{~S} \\
\mathrm{MI} \\
30 \\
\mathrm{MI} \\
35 \\
\ldots \\
31 \\
\mathrm{MI} \\
\ldots \\
\ldots \\
\ldots\end{array}$ & 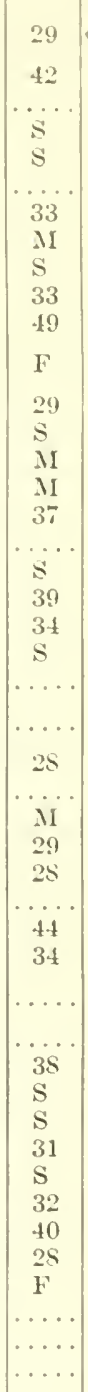 & 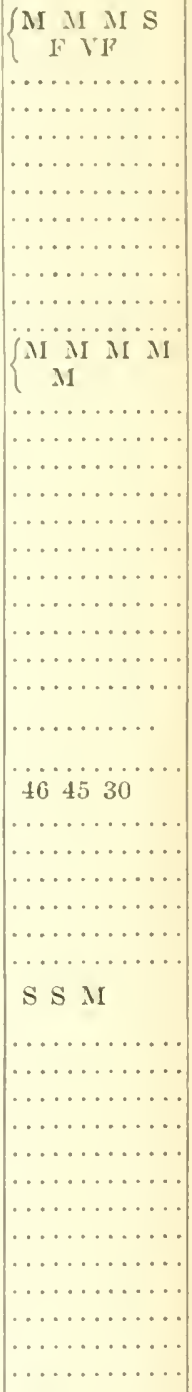 \\
\hline $\begin{array}{l}\text { Average } 1 \\
\text { Number } \\
\text { Total pro } \\
\text { 1 In middle } \\
\text { 2 adolesce } \\
\text { ' Medium f } \\
\text { 3 adolesce } \\
\text { 'MF'S sibs } \\
\text { eighed } 160 t \\
\text { espeetively } \\
\text { II beeame V } \\
\text { - MM redu }\end{array}$ & $\begin{array}{l}\text { nt children; build } \\
\text { ather earries } S \text { gan } \\
\text { ut children who ar } \\
\text { 4d. } 96 \text { years; } 5 \\
175 \text { pounds, wom } \\
9 \text { to } 71 \text { inebes; } 65 \\
\text { F after } 36 \text { years; } \\
\text { ced in build by old }\end{array}$ & $\begin{array}{l}79 \text { and } 36 \text {. } \\
\text { netes; } 2 \text { adolescen } \\
\text { e slender. } \\
\text { others at over } 65 \\
\text { en } 125 \text { to } 145 \text { poun } \\
\text { to } 66 \text { inches. } \\
\text { gained build } 51 \\
\text { gge. }\end{array}$ & $\begin{array}{l}\text { I S chil } \\
\text { yenrs: } \\
\text { ds. II } \\
\text { I. II fo }\end{array}$ & $\begin{array}{l}\text { ldren. } \\
\text { men } \\
\text { Ieight } \\
\text { amily } \\
\text { vears. }\end{array}$ & $\begin{array}{c}\text { Clas } \\
\text { Prot } \\
\text { of tu } \\
103 \\
112 \\
12 \\
16 \\
\text { daug? }\end{array}$ & $\begin{array}{l}\text { IF had } 3 \text { sibs diec } \\
\text { berculosis. } \\
3 \text { children died you } \\
2 \text { sibs and a nephe } \\
\text { Sib died of tubercu } \\
\text { MF and MM were } \\
\text { Many F relatives } \\
\text { hter, build } 45 \text {; } \$ \text { hs }\end{array}$ & $\begin{array}{l}\text { d of to } \\
\text { ung. } \\
\text { w die } \\
\text { ulosis. }\end{array}$ & $\mathrm{r}$ mil & $\begin{array}{l}\mathrm{S} \\
49 \\
15 \%\end{array}$ & 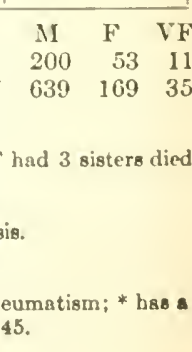 \\
\hline
\end{tabular}


TABLE VIII.-Slender $\times$ fleshy matings urul theor promgeny.

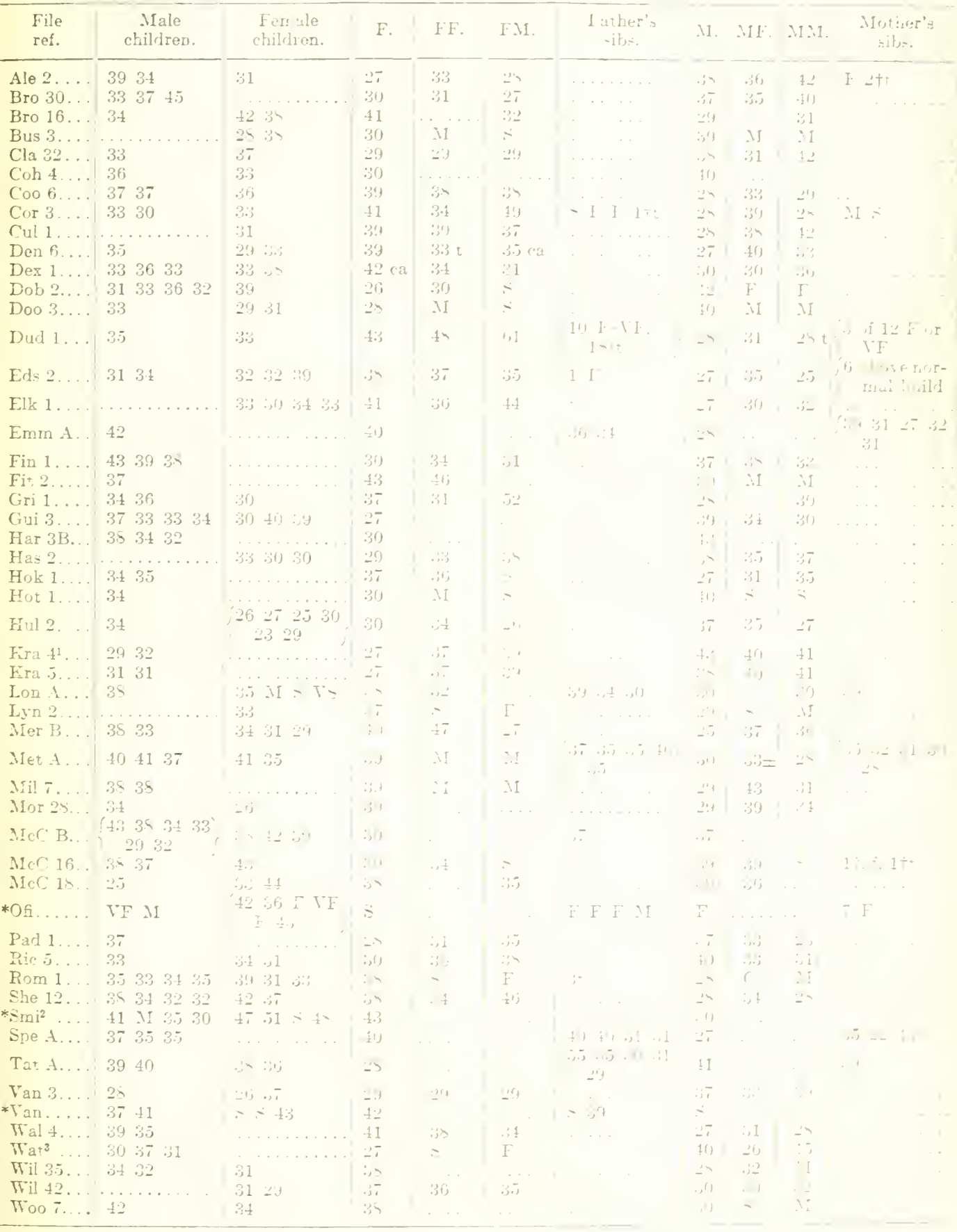

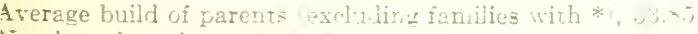

Number of mating $493-3 \%=3 \%$.

Total No. of progeny, 15 - $-21 *-3$ non-gulantits i, e $=1 \%$.

1 Kra 4, by first wife; Iira 5, by secon 1 wi:e.

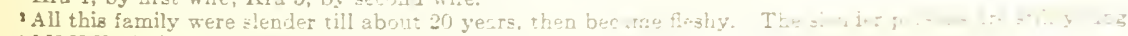

3MMM build 36; MMM 30; MFM 27; MFF 33 
APPENDIX.

TABLE IX.-Slender $\times$ tery fleshy matings and their progeny.

\begin{tabular}{|c|c|c|c|c|c|c|c|c|c|c|}
\hline $\begin{array}{l}\text { File } \\
\text { rof. }\end{array}$ & $\begin{array}{l}\text { Male } \\
\text { children. }\end{array}$ & $\begin{array}{l}\text { Fernale } \\
\text { children. }\end{array}$ & F. & $\mathrm{FF}$. & FM. & $\begin{array}{l}\text { Father's } \\
\text { sibs. }\end{array}$ & M. & $M I F$. & $\mathbf{M M}$ & $\begin{array}{l}\text { Mother's } \\
\text { sibs. }\end{array}$ \\
\hline Arn $51 \ldots$ & 32 & 38 & 44 & 31 & 4.8 & $\ldots$ & 26 & 33 & 25 & \\
\hline Ban $2^{2} \ldots$ & 3939 & & 49 & 42 & 31 & $\mathrm{t} t$ & 26 & $M T$ & $\mathrm{~F}$ & $5 \mathrm{~F}$ \\
\hline Ben $8 \ldots$ & 40 & 32 & 28 & 38 & 26 & $\ldots$ & 45 & 39 & 32 & $\ldots \ldots \ldots \ldots \ldots$ \\
\hline Bon A... & 44 & & 51 & 40 & $\ldots \ldots$ & 40 & 26 & 35 & $\ldots \ldots$ & $292728 \quad 28$ \\
\hline *Bun..... & 4433 & 25.532 & 57 & & & & 26 & $\ldots \ldots$ & $\ldots$. & $\ldots \ldots \ldots \ldots$ \\
\hline Cle $5 . .$. & 303935 & 33 & 30 & 34 & 34 & & 54 & 27 & 32 & $3 \mathrm{~F}$ \\
\hline${ }^{*} \mathrm{Coo} . . . .$. & $\ldots \ldots \ldots \ldots$ & 4834 & 29 & $\ldots$ & $\ldots \ldots$ & F F S S & 49 & $\ldots$ & 49 & 4840 \\
\hline Fen $1 \ldots$ & $\begin{array}{llll}38 & 33 & 30 & 32\end{array}$ & & 44 & $\ldots \ldots$ & $\ldots \ldots$ & $\ldots \ldots \ldots$ & 27 & $\ldots$ & $\ldots \ldots$ & $\ldots \ldots \ldots$ \\
\hline Har $15^{3} \ldots$ & $39 \quad 33 \quad 34$ & $40(t) 37$ & 30 & 41 & 28 & $t$ & 49 & 35 & 49 & \\
\hline Hor $9 \ldots$ & $\ldots \ldots \ldots \ldots$ & $31(t) 36$ & 44 & 44 & 24 & $\ldots \ldots$ & 29 & S & MI & \\
\hline How 84.. & 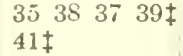 & $\ldots \ldots \ldots$ & 30 & 37 & 27 & $t \mathrm{t} \mathrm{t}$ & 51 & 40 & 46 & \\
\hline Kro 3. & 42 & & 29 & 34 & 42 & & 46 & 38 & 28 & \\
\hline *Leo..... . . & 45 & $51 \mathrm{~S} \mathrm{~S} 46 \mathrm{~F}$ & $\mathrm{~S}$ & $\ldots$. & $\ldots$ & $\ldots \ldots \ldots \ldots$ & 51 & $S$ & 51 & 4546 \\
\hline Tea A... & 463129 & 3132 & 49 & & & $\ldots \ldots \ldots \ldots$ & 27 & . & $\ldots$. & .......... \\
\hline
\end{tabular}

Average build of parents (excluding families with *), 37.91

Number of matings, $11+3^{*}=14$.

Total number of progeny $34+12=46$.
S M F VF Proportional freq. per mille.. $152 \quad 370 \quad 326 \quad 152$

1 M dicd, 46 years, tuberculosis; M's sib died of hardening of lungs; MF tuberculosis; MM tuberculosis, but recovered.

2M underwent senile degeneration after menopause.

"MM had "delicate lungs."

- $\$$ Twins. 
TABLE X.-Medium $\times$ medium matings and their progeny.

\begin{tabular}{|c|c|c|c|c|c|c|c|c|c|c|}
\hline $\begin{array}{l}\text { File } \\
\text { ref. }\end{array}$ & $\begin{array}{l}\text { Male } \\
\text { children. }\end{array}$ & $\begin{array}{l}\text { Female } \\
\text { children. }\end{array}$ & F. & FF. & FMI. & $\begin{array}{l}\text { Father's } \\
\text { sibs. }\end{array}$ & M. & $M F$ & MII. & $\begin{array}{l}\text { Mother's } \\
\text { sibs. }\end{array}$ \\
\hline Abe $1 \ldots$ & 34 & 332934 & 32 & $M$ & $M I$ & & 34 & MI & $\mathrm{S}$ & \\
\hline All A.... & 3729 & & 35 & 32 & 32 & & 32 & & 30 & \\
\hline Aus $3 \ldots$ & 35 & 33 & 32 & 32 & 31 & 39 & 31 & 34 & 28 & $t$ \\
\hline Bac $1 \ldots$ & $\ldots \ldots \ldots$ & 36 & 32 & $\mathrm{~S}$ & M & $\ldots \ldots \ldots \ldots \ldots$ & 36 & MI & $M$ & $\ldots \ldots$ \\
\hline Bar $10 \ldots$ & $32 \quad 32 \quad 30$ & & 31 & 35 & M & $\ldots \ldots \ldots \ldots \ldots$ & 33 & & & $\ldots \ldots \ldots \ldots$ \\
\hline Bat $2 \ldots$ & $33 \quad 32 \quad 35$ & 33 & 31 & M & $\mathrm{S}$ & $\ldots \ldots \ldots \ldots \ldots$ & 32 & 29 & $31 \mathrm{t}$ & $\ldots \ldots \ldots \ldots$ \\
\hline Bea $7 \ldots$ & 3432 & 3231 & 32 & 31 & 28 & $\ldots \ldots \ldots \ldots \ldots$ & 34 & 36 & 31 & $\ldots \ldots \ldots \ldots$ \\
\hline Bec 6... & 32 & $\ldots \ldots$ & 31 & 39 & 39 & $\ldots \ldots \ldots \ldots \ldots$ & 34 & 35 & 36 & $\ldots \ldots \ldots \ldots$ \\
\hline Bet $3 . .$. & & 3636 & 34 & 31 & 24 & $\ldots \ldots \ldots \ldots \ldots$ & 35 & 38 & 43 & $\ldots \ldots \ldots \ldots$ \\
\hline Bis 5.... & 35 & $\ldots \ldots$ & 32 & 39 & 28 & $\ldots \ldots \ldots \ldots \ldots$ & 31 & 38 & 36 & $\ldots \ldots \ldots \ldots$ \\
\hline Bow 3... & 33 & 3232 & 32 & MI & M & $\ldots \ldots \ldots \ldots$ & 33 & $M$ & M & $\ldots \ldots \ldots \ldots$ \\
\hline Bra $10 \ldots$ & 40 & 383936 & $35 \pm$ & $35 \pm$ & $3 E \pm$ & $\ldots \ldots \ldots \ldots$ & 34 & 35 & 32 & \\
\hline Bro $18 \ldots$ & 323634 & $\ldots \ldots \ldots \ldots$ & 33 & $31 \mathrm{t}$ & 36 & $\ldots \ldots \ldots \ldots \ldots$ & 33 & $M$ & $(\mathrm{t})$ & $\ldots \ldots \ldots$ \\
\hline Cas $4 \ldots$. & $43 \quad 4134$ & 373234 & 34 & 39 & $29 t$ & $\ldots \ldots \ldots \ldots$ & 34 & 43 & 27 & \\
\hline Chr 2... & 3236 & 32 & 32 & 33 & 32 & $\ldots \ldots \ldots \ldots \ldots$ & $33 \pm$ & 37 & 34 & \\
\hline Cla $29 \ldots$ & $\ddot{38} 3 \bar{s}_{36}$ & 36 & 33 & $\cdots$ & $\ldots$ & $\ldots \ldots \ldots$ & 33 & $\ldots$ & $\cdots$ & \\
\hline Coo 5. & $\left\{\begin{array}{cccc}38 & 35 & 36 & 31 \\
36 & 37 & 33\end{array}\right\}$ & 37413638 & 32 & (t) & 37 & $\ldots$ & 36 & 34 & 37 & \\
\hline Dex $2 \ldots$ & 33 & 33 & 34 & 35 & 30 & $\cdots \ldots \ldots \ldots$ & 36 & 33 & 31 & $t, t$ \\
\hline Dic $4 \ldots$ & 323133 & 29 & 31 & $M$ & $F$ & $\ldots \ldots \ldots \ldots$ & 32 & 32 & 29 & $\ldots \ldots \ldots \ldots$ \\
\hline Dra $1 \ldots$ & $\because \cdots \cdots \cdots$ & 3631 & 32 & 35 & 29 & $\ldots \ldots \ldots \ldots$ & 34 & $34 \mathrm{t}$ & 32 & $\ldots \ldots \ldots \ldots$ \\
\hline Eat $A$. & $\left\{\begin{array}{cccc}34 & 36 & 35 & 36 \\
38 & 38\end{array}\right\}$ & 4233 & 35 & $\cdots$ & $\ldots$ & $\begin{array}{llll}33 & 35 & 42 & 30\end{array}$ & 32 & 36 & 33 & $\begin{array}{llll}36 & 39 & 41 & 33\end{array}$ \\
\hline Fie $2 \ldots$ & 33 & 35 & 36 & 35 & 36 & $\ldots \ldots \ldots \ldots$ & 32 & 37 & 32 & 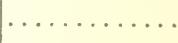 \\
\hline Fis $2^{3} \ldots$ & 35 & $\left\{\begin{array}{cccc}37 & 37 & 40 & 33 \\
39 & 37\end{array}\right\}$ & 36 & $M I$ & M & $\ldots \ldots \ldots \ldots$ & 32 & $M$ & $\cdots$ & ….... \\
\hline Fra $3 \mathrm{~A} \ldots$ & 3535 & $\ldots \ldots \ldots \ldots$ & 33 & $\mathrm{~s}$ & $\mathrm{~S}$ &. & 35 & M & $39 \pm$ & $\ldots$ \\
\hline Fri 3. & 31 & & 32 & M & $\mathrm{S}$ & $\ldots \ldots \ldots \ldots$ & 35 & 38 & 35 & $\ldots \ldots \ldots$ \\
\hline Gil 15... & 4239 & 39 & 35 & $31 \pm$ & $33 \pm$ & $\ldots \ldots \ldots \ldots$ & $33 \mathrm{t}$ & 39 & 39 & $\ldots \ldots \ldots \ldots$ \\
\hline God 2.... & 30 & $\left\{\begin{array}{cccc}27 & 31 & 31 & 31 \\
30 & & \end{array}\right\}$ & 34 & 34 & $28 \mathrm{t}$ & $\ldots \ldots \ldots \ldots$ & 31 & $M I$ & $M$ & $\ldots \ldots$ \\
\hline Gol 4.. & & 3230 & 31 & 31 & 29 & $\cdots$ & 32 & 41 & 30 & $\ldots \ldots$ \\
\hline Gor $7 \ldots$ & 34 & $\ldots \ldots \ldots \ldots \ldots$ & 3.5 & $M$ & S & $\ldots \ldots \ldots \ldots$ & 32 & $M$ & $M$ & $\ldots \ldots$ \\
\hline Hal $16^{2} \ldots$ & 39 & 37 & $3: 3$ & F & S & $\ldots \ldots$ & 34 & $M$ & $\mathrm{~S}$ & $\ldots \ldots$ \\
\hline Haw 6. & $\left\{\begin{array}{cccc}35 & 32 & 35 & 29 \\
30 & & \end{array}\right\}$ & $29 \quad 2927 \quad 33$ & 33 & S & $\mathrm{S}$ & $\ldots \ldots \ldots$ & 31 & 31 & 29 & \\
\hline Haw $7 . .$. & 36 & & 33 & 31 & 34 & $\ldots \ldots \ldots \ldots$ & 31 & 42 & 39 & $\ldots \ldots \ldots \ldots$ \\
\hline Hen $6 . .$. & 3536 & 4235 & 32 & $M$ & $M$ & $\ldots \ldots \ldots \ldots \ldots$ & 31 & $M$ & $\mathrm{~S}$ & $\ldots \ldots \ldots \ldots$ \\
\hline Hod $1 \ldots$ & $3 S$ & 39 & 33 & 31 & 24 & $\ldots \ldots \ldots \ldots$ & 31 & 30 & 29 & $\ldots \ldots \ldots \ldots$ \\
\hline Hop 5... & $\begin{array}{lll}35 & 35 & 27\end{array}$ & 31 & 35 & \pm 1 & 31 & $\ldots \ldots \ldots \ldots$ & 35 & 31 & 32 & $\ldots \ldots \ldots \ldots$ \\
\hline Hut $4 \ldots$ & 33 & 39 & 32 & $30 \pm$ & F & $\ldots \ldots \ldots \ldots$ & 32 & $M$ & $M$ & $\ldots \ldots \ldots$ \\
\hline Ill $1 \ldots$ & $\begin{array}{llll}39 & 35 & 34 & 33\end{array}$ & $\begin{array}{llll}35 & 38 & 37 & 37\end{array}$ & 34 & 32 & 33 & $\ldots \ldots \ldots \ldots$ & 33 & 32 & 31 & $\ldots \ldots \ldots \ldots$ \\
\hline Joh $1^{3} \ldots$ & 36 & & 35 & $M^{3}$ & F & $\ldots \ldots \ldots \ldots$ & 33 & M & s & $\ldots \ldots \ldots$ \\
\hline Jon $20 \ldots$ & 37 & $\ldots \ldots \ldots \ldots$ & 36 & 36 & 40 & $\ldots \ldots \ldots \ldots$ & 31 & 32 & 31 & $\ldots \ldots \ldots$ \\
\hline Jor $1 \ldots .$. & 3641 & $\begin{array}{lll}38 & 32\end{array}$ & 35 & $\cdots \cdots$ & $\cdots \cdots$ & $\cdots$ & 36 & $\cdots$ & $\cdots$ & $\cdots$ \\
\hline Kel 4a... & $3432 \mathrm{~S}$ & $\left\{\begin{array}{c}M(t) M M \\
31\end{array}\right\}$ & 36 & 34 & S & $\ldots \ldots \ldots \ldots$ & 31 & $3 \cdot 1$ & $\mathrm{~F}$ & $\ldots \ldots \ldots$ \\
\hline Kim $1 \ldots$ & 293535 & $\ldots \ldots \ldots \ldots \ldots$ & 35 & & & & 31 & & & $\cdots$ \\
\hline $\begin{array}{l}\text { Lan } 8 \ldots . . \\
\text { Lau } 2 \ldots\end{array}$ & 30 & 25 & 37 & 40 & 40 & $\ldots \ldots \ldots$ & 35 & 34 & 25 & $\cdots \cdots$ \\
\hline $\begin{array}{l}\text { Lau } 2 . . . . \\
\text { Lev } 2\end{array}$ & 36 & $\ldots \ldots \ldots \ldots$ & 35 & $S$ & $\cdots$ & $\ldots \ldots \ldots \ldots \ldots$ & 31 & MI & $\mathrm{MI}$ & $\cdots \cdots$ \\
\hline $\begin{array}{l}\text { Lev } 2 \\
\text { Lex } 1 . . .\end{array}$ & 3430 & $\begin{array}{l}3639 \\
37\end{array}$ & $\begin{array}{l}34 \\
33\end{array}$ & 34 & $\begin{array}{l}35 \\
37\end{array}$ & $\ldots \ldots \ldots$ & $\begin{array}{l}32 \\
32\end{array}$ & $\begin{array}{c}37 \pm \\
30\end{array}$ & $\begin{array}{c}51 \pm \\
33\end{array}$ & $\begin{array}{llll}34 & 35 & 36\end{array}$ \\
\hline Llo 4 & $\begin{array}{l}7630 \quad 36 \\
34\end{array}$ & & $\begin{array}{l}35 \\
32\end{array}$ & $\ddot{M I}$ & $\begin{array}{l}36 \\
\text { S }\end{array}$ & & 33 & $\cdots$ & $\ldots \ldots$ & $\ldots \ldots \ldots \ldots \ldots$ \\
\hline Loe A.... & 46383836 & 56 & 36 & & & 27 & 35 & & & $\ldots \ldots \ldots \ldots$ \\
\hline Mar 22... & $\begin{array}{llll}33 & 36 & 32 & 31\end{array}$ & 4036 & 33 & MI & $M$ & & 32 & s & S & $\ldots \ldots \ldots \ldots \ldots$ \\
\hline Mas $3 . .$. & $\ldots \ldots \ldots \ldots$ & 3434 & 35 & MI & $M$ & & 32 & MI & MI & $\ldots \ldots \ldots$ \\
\hline Mat $13 . .$. & 37 & $\begin{array}{lll}36 & 35 & 37\end{array}$ & 34 & 36 & $3 s$ & & 35 & 35 & 48 & \\
\hline Mer $8 \ldots$ & & $\left\{\begin{array}{cccc}41 & 36 & 40 & 37 \\
33 & & \end{array}\right\}$ & 35 & $M t$ & $\mathrm{~s}$ & $\mathrm{E}$ & 34 & s & MI & $\ldots$ \\
\hline
\end{tabular}


TABLE X.-Medium $\times$ medium matings and their progeny-Continued.

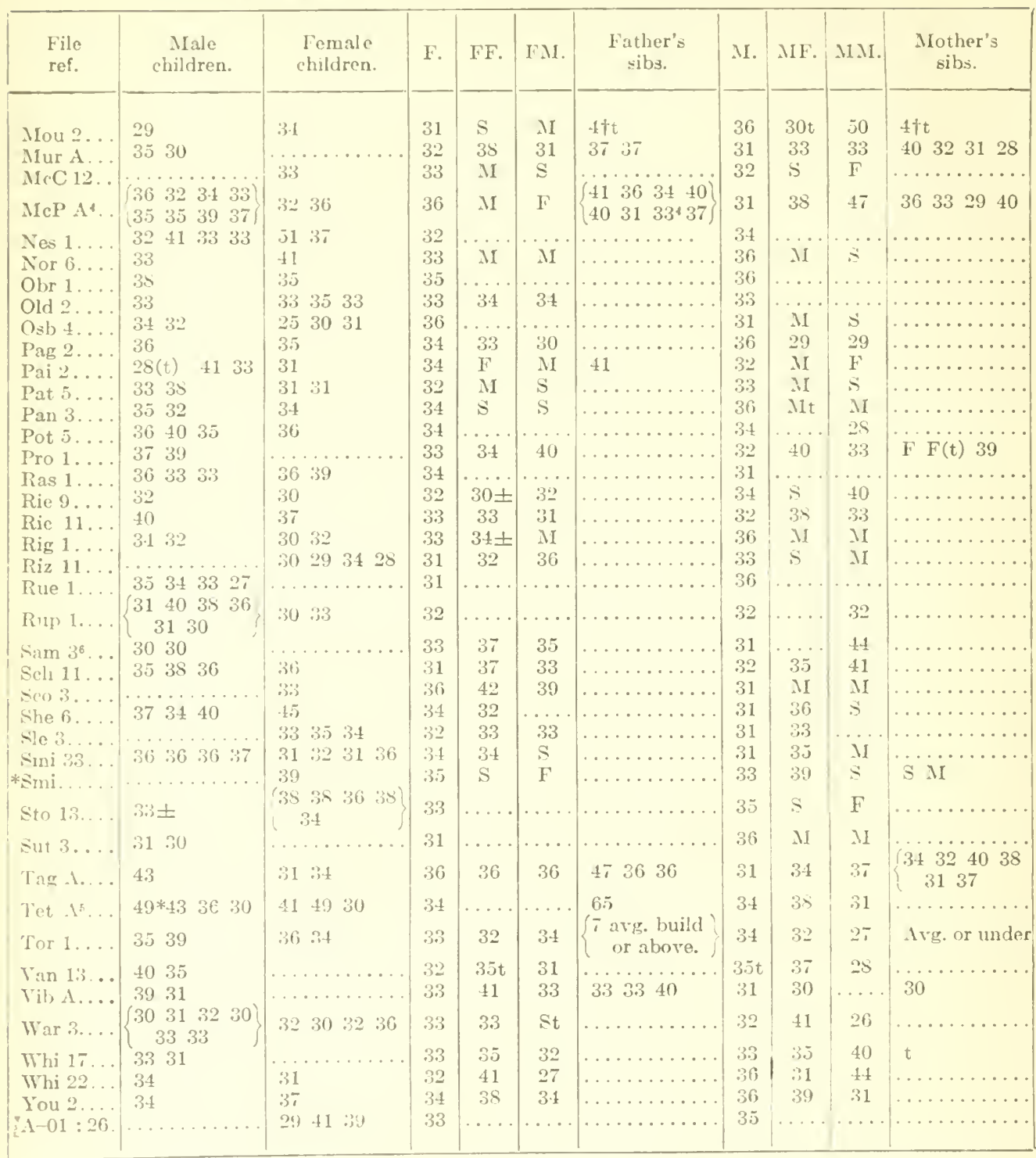

Average builu of parents (exrluding family with *), 33.23. Number of matings, $92+1 *=93$.

Total No. of progeny, $327+1 *+4$ non-riuantitative $=332$. $\mathrm{VS} \& \mathrm{M} \mathrm{F}$ VT

Classifuation of progeny..........2 $40 \begin{array}{cccc}201 & 82 & 7\end{array}$

Proportional frequoney per mille....6 $121 \quad 605 \quad 247 \quad 21$
MI and MF were first cousins. : FF and FMI were first cousins.

s Weak lungs.

4 Spinal trouble.

* * has undersized wife and 2 children; male, build 49: female, build 46 .

- $\mathrm{I}$ and $\mathrm{F}$ were first cousins. 
TABLE XI.-Medinm $\times$ fleshy matings and ther progeny.

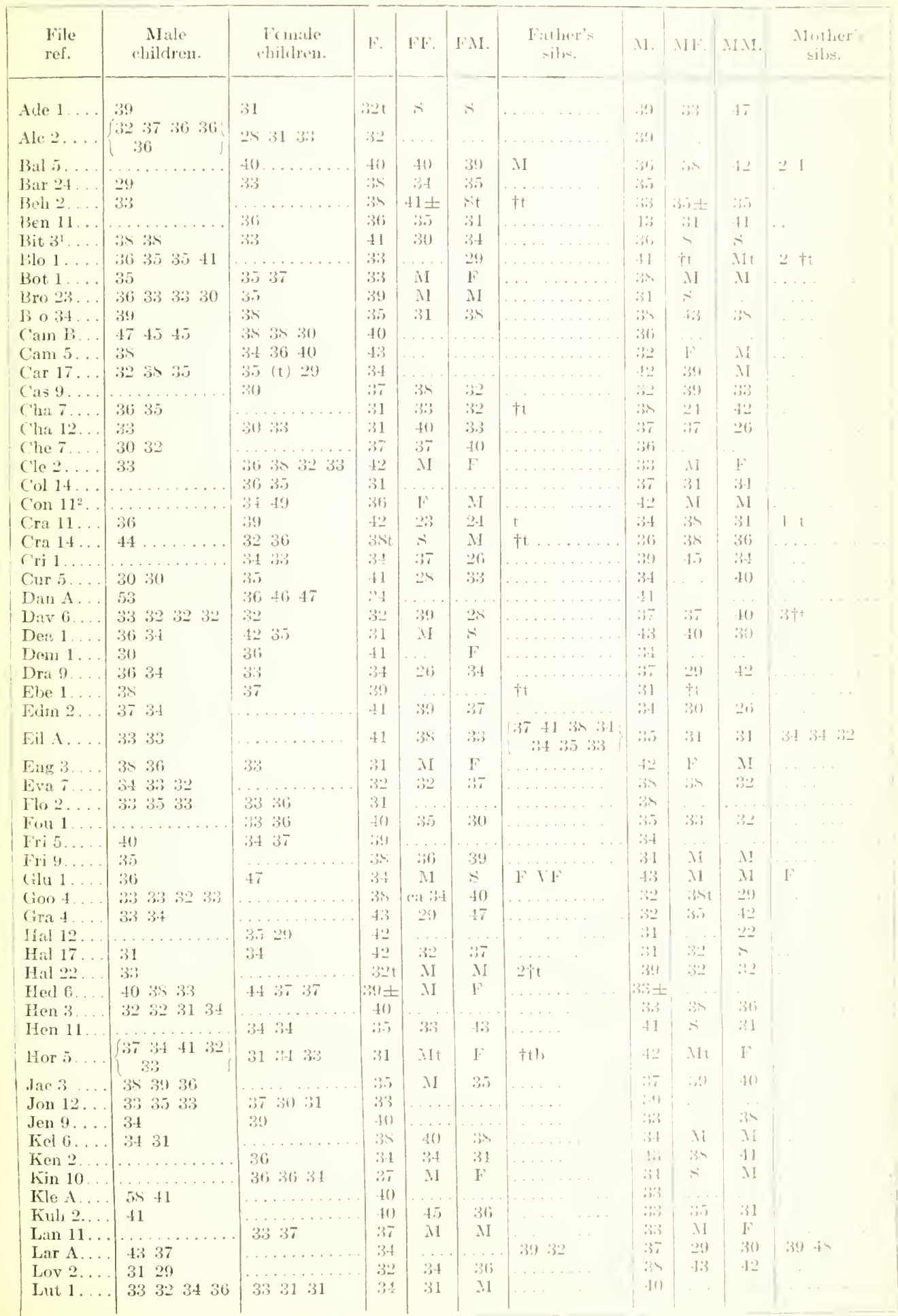


TABLE XI.-Medium $\times$ fleshy matings and their progeny-Continued.

\begin{tabular}{|c|c|c|c|c|c|c|c|c|c|c|}
\hline $\begin{array}{l}\text { File } \\
\text { ref. }\end{array}$ & $\begin{array}{l}\text { Male } \\
\text { children. }\end{array}$ & $\begin{array}{l}\text { Fomiale } \\
\text { chiltren. }\end{array}$ & F. & FF. & FMI. & $\begin{array}{l}\text { Father's } \\
\text { silss. }\end{array}$ & $\mathrm{M}$ & MF. & $\mathrm{MM}$. & $\begin{array}{l}\text { Mother's } \\
\text { sibs. }\end{array}$ \\
\hline Met 1 . & 40 & 36 & 34 & & & & 39 & & & \\
\hline er 4 . & 37 & & & 40 & $\mathrm{~S}$ & $\ldots \ldots \ldots \ldots$ & 34 & 39 & 14 & tt \\
\hline $5 \ldots$ & 36 & 3436 & 3 & $M$ & S & 4 wesk & 32 & MI & S & \\
\hline Mil 11. & $34 \quad 32 \quad 34$ & \$0 32 & 32 & & & $\ldots \ldots \ldots \ldots \ldots$ & 43 & & & \\
\hline Mil 23. & 37 & 31 & 35 & 30 & 37 & & 3.3 & 40 & 26 & \\
\hline Mor A... & 42 & $42+1+4329$ & 34 & 43 & $3 \cdot 4$ & $\left\{\begin{array}{cccc}50 & 44 & 39 & 39 \\
39 & & & \end{array}\right\}$ & 35 & 32 & 31 & $32 \quad 30 \quad 32$ \\
\hline $\begin{array}{l}\text { Mor } 16 \ldots \\
\text { Moy } 1 \ldots\end{array}$ & $\begin{array}{l}37 \\
37\end{array}$ & & 36 & $M$ & $M I$ & $\ldots \ldots \ldots$ & 37 & 31 & 50 & †t \\
\hline 1000 & $1936=5$ & 3 & 42 & $\Pi I$ & si & $\left\{\begin{array}{lllll}46 & 42 & 37 & 36\end{array}\right.$ & 34 & 5 & II & $\int 343437 \quad 40$ \\
\hline Mye : & 423654 & $3: 33335$ & 43 & 37 & 37 & $\left\{\begin{array}{c}10 \\
3127\end{array}\right\}$ & 34 & 35 & 30 & $\left\{\begin{array}{l}3230 \\
3230\end{array}\right.$ \\
\hline Mye $1 \ldots$ & 3234 & $32 \quad 35 \quad 32 \quad 33$ & 43 & 42 & 35 & $\ldots \ldots \ldots \ldots$ & 32 & 36 & 33 & $\cdots \cdots$ \\
\hline $\begin{array}{l}\operatorname{McF} 2 \ldots \\
\operatorname{Ic\lambda I} \ldots\end{array}$ & 323936 & $\begin{array}{l}39 \\
26 \\
262\end{array}$ & $\begin{array}{l}39 \\
39\end{array}$ & 28 & $\ddot{F}$ & & $\begin{array}{l}32 \\
36\end{array}$ & $\begin{array}{l}35 \\
\text { II }\end{array}$ & 27 & $\cdots \cdots$ \\
\hline New $10 \ldots$ & 3241 & $\ldots \ldots \ldots$ & 3 & S & $M I$ & & 37 & $\because$ & 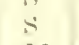 & $\ldots \ldots$ \\
\hline $2 \ldots$ & 3535 & 3233 & 40 & S & $\mathrm{F}$ & $3 \dagger t$ & $3: 2$ & $M$ & $M$ & $4+\mathrm{t}$ \\
\hline Nol B... & 4138 & $38: 28$ & 3.1 & & & 27 & 37 & & & 3134 \\
\hline Ofi. & & 27.97 & 33 & 8 & $\mathrm{VF}$ & $6 \mathrm{~F} \quad \mathrm{VF} \ldots$. & 42 & $S$ & $\mathrm{~F}$ & 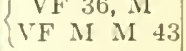 \\
\hline Olo $1 \ldots$ & 3431 & & 35 & $s$ & II & & 37 & M & $M$ & $\ldots \ldots \ldots \ldots \ldots$ \\
\hline Pap $1 \ldots$ & $32 \quad 34$ & & & $\because$ & 36 & $\ldots \ldots \ldots \ldots$ & 31 & 32 & $3 i$ & $\ldots \ldots \ldots \ldots$ \\
\hline Pec $6 \ldots$ & $\ldots \ldots \ldots \ldots$ & 44 & 31 & 37 & 27 & $\ldots \ldots \ldots \ldots$ & $4: 3$ & 39 & 25 & $\because \cdots$ \\
\hline Phi A.... & 3753478 & $\cdots$ & $3:$ & 32 & 34 & $463830 \quad 35$ & 39 & 42 & 44 & 5451 \\
\hline Pot $4 \ldots$ & 3538 & 35 & $3:$ & 35 & 28 & $\ldots \ldots \ldots \ldots$ & 39 & 29 & 43 & $\ldots \ldots \ldots \ldots$ \\
\hline Pri $6^{3} \ldots$ & 36 & $3: 3$ & & 35 & 28 & $\ldots \ldots \ldots \ldots$ & $333 t$ & 30 & 30 & $\ldots \ldots$ \\
\hline Pro $2 . .$. & $\ldots \ldots$ & 36 & & $M$ & $\mathrm{~F}$ & $\ldots \ldots \ldots$ & 33 & $M$ & $M$ & $\ldots \ldots$ \\
\hline $2 \ldots$ & 3442 & $\ldots \ldots$ & $\because 3$ & $3 \pi$ & 34 & $\ldots \ldots \ldots$ & 30 & 36 & 30 & $\ldots \ldots$ \\
\hline . & 32 & & 3 & 32 & 38 & $\ldots \ldots \ldots$ & 40 & 40 & 41 & $\ldots \ldots$ \\
\hline ob $12 \ldots$ & 4035 & 39 & 3 & 32 & 28 & $\ldots \ldots \ldots$ & 39 & 46 & 34 & $\ldots \ldots \ldots$ \\
\hline Roo 3 & $3 \overline{3}$ & $29: 37$ & 33 & $2 S$ & 46 & $\ldots$ & 40 & 34 & 31 & \\
\hline $\operatorname{Rog} A \ldots$ & $\left(\begin{array}{ccc}42 & 39 & 34 \\
32 & 32\end{array}\right.$ & 30 & 33 & 36 & 28 & $30 \quad 29$ & 35 & 34 & 34 & $\left\{\begin{array}{c}36.36 \\
36 \quad 30\end{array}\right.$ \\
\hline $\begin{array}{l}\text { Ryd } 1 \ldots \\
\operatorname{Sar} 24 \ldots\end{array}$ & $\begin{array}{l}3534 \\
32\end{array}$ & 353582 & $\begin{array}{l}36 \\
34\end{array}$ & NI & & & $\begin{array}{l}39 \\
49\end{array}$ & 32 & & \\
\hline Sau A. . & $\begin{array}{llll}43 & 30 & 41 & 31\end{array}$ & & 41 & & & $364: 3$ & 3.4 & 41 & So & $\left\{\begin{array}{llll}54 & 30 & 39 & 31\end{array}\right.$ \\
\hline $\operatorname{sen} 12$. & 37 & & 34 & 31 & & & 40 & 30 & 3.5 & ) 32.32 \\
\hline sey $1 \ldots$ & 33 & $.30 \quad 30$ & 37 & $\mathrm{~s}$ & $\mathrm{~F}$ & & $3: 3$ & 41 & M & \\
\hline sid $1 \ldots$ & 32 & $: 3131$ & 36 & & & $\left\{\begin{array}{cccc}36 & 36 & 36 & 32 \\
30 & \end{array}\right\}$ & 35 & 33 & $M$ & \\
\hline$S \operatorname{mi} 20$. & 33 & 40 & 37 & & & $\ldots \ldots \ldots \ldots$ & 33 & & & \\
\hline & 41 & & $3 !$ & 37 & $29 \mathrm{t}$ & & 32 & 34 & 37 & \\
\hline Spi & 3533 & $\therefore \leq 2850$ & 34 & 31 & 39 & $\ldots \ldots$ & 37 & M & M & $2 \mathrm{~F}$ \\
\hline $7^{5} \ldots$ & $37 \S 37837$ & $30 \quad 3033: 3$ & 34 & 35 & 29 & $\ldots \ldots$ & $4: 3$ & 37 & $4 t$ & \\
\hline & $36^{\circ} 35$ & 30 & 40 & 34 & 28 & & 32 & 38 & 34 & $\ldots \ldots \ldots$ \\
\hline & $\ldots \ldots \ldots$ & 36 & 37 & 34 & 23 & & 32 & 35 & 32 & \\
\hline & 30 & 32 & 38 & 36 & 28 & & 31 & $M I$ & 31 & \\
\hline$\ldots$ & 384241 & 3332 & 39 & 39 & 23 & & 32 & 37 & 30 & VF \\
\hline $\mathrm{Ya}$ & 35 & 36 & 34 & 32 & 25 & & 35 & 35 & 42 & $\ldots \ldots$ \\
\hline $\operatorname{Van} 12$. & $\ldots$ & $39 \quad 36 \quad 32$ & 42 & $3: 3$ & 38 & & 36 & $\cdots \cdots$ & $\cdots \cdots$ & $\ldots \ldots$ \\
\hline A... & $35 \quad 40: 37 \quad 34$ & 303532 & 31 & & & & 4.3 & 32 & 44 & \\
\hline Wak $1 \ldots$ & & 293233 & $3: 3$ & S & $M$ & & $41)$ & is & $M$ & \\
\hline $\begin{array}{l}\text { Wan } 2 . \\
\text { Wil } 10 .\end{array}$ & $\begin{array}{l}34 \mathrm{M} 35 \mathrm{M} \\
40\end{array}$ & $\ldots \cdots \cdots$ & 37 & $\cdots \cdots$ & $\mathbf{F}$ & & 3.5 & $\ldots$ & $F$ & All nervous \\
\hline & $\left\{\begin{array}{llll}40 & 36 & 41 & 35\end{array}\right\}$ & $3 ! 1$ & 11 & $\cdots$ & $\cdots$ & & 34 & & $\cdots$ & $\ldots \ldots \ldots \ldots$ \\
\hline Wil $22^{7}$ & $\left\{\begin{array}{l}32 \\
-\end{array}\right\}$ & 34 & 32 & MI & II & & $3 !)$ & $M$ & $M$ & \\
\hline $\begin{array}{l}\text { Win } 7 . \\
\text { Woo } 8 .\end{array}$ & $\begin{array}{l}3535 \\
33\end{array}$ & $\begin{array}{l}34 \quad 1034 \\
40\end{array}$ & 41 & $\mathrm{~s}$ & 11 & 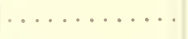 & $3: 5$ & s & $M I$ & \\
\hline Wri $3 \ldots$ & 3432 & $\begin{array}{l}40 \\
31\end{array}$ & $\begin{array}{l}32 \\
39\end{array}$ & $\begin{array}{l}38 \\
M\end{array}$ & $\begin{array}{l}38 \\
M\end{array}$ & & 34 & $\begin{array}{l}40) \\
M\end{array}$ & $\begin{array}{l}47 \\
M I\end{array}$ & \\
\hline You A.. & 35 & & 43 & $\ldots$ & $\ldots$ & 34 & 36 & $\cdots \cdots$ & 37 & $\left\{\begin{array}{cccc}40 & 36 & 33 & 37 \\
40\end{array}\right.$ \\
\hline Zec 1. & 32 & & 41 & $M I$ & $\mathrm{~s}$ & & 34 & 36 & 33 & $\ldots \ldots \ldots$ \\
\hline
\end{tabular}

Average build of parents (cxcluding family with *), 36.45 . Number of matings, $11 t+1 *=11 \overline{5}$.

Total number of progeny, $340+2^{*}+4$ non-quantitative $=346$. $\mathrm{S}$ M $\mathrm{F}$ VF

Classification of progeny.
IMF and MM were first cousins. $2 \mathrm{~F}$ and $M$ were first cousins.

$\checkmark F F$ and FMl were first cousins.

- $\mathrm{F}$ and $\mathrm{M}$ were first cousins.

s $\$$ and $\$$ were twins.

( $\mathrm{F}$ and $\mathrm{M}$ were first cousins. 
APPENDIX.

TABLE XII.-Medium $\times$ very fleshy matings and their progeny.

\begin{tabular}{|c|c|c|c|c|c|c|c|c|c|c|}
\hline $\begin{array}{l}\text { File } \\
\text { ref. }\end{array}$ & $\begin{array}{c}\text { Male } \\
\text { children. }\end{array}$ & $\begin{array}{l}\text { Female } \\
\text { children. }\end{array}$ & F. & FF. & FM. & $\begin{array}{l}\text { Father's } \\
\text { sibs. }\end{array}$ & $M$. & MIF. & MM. & $\begin{array}{l}\text { Mother's } \\
\text { sibs. }\end{array}$ \\
\hline Ada $7 .$. & 40 & & 48 & M & $\mathrm{S}$ & & 32 & M & $M$ & \\
\hline Arm 5 . & $\begin{array}{llll}31 & 32 & & \end{array}$ & 34 & 49 & 42 & 44 & $\cdots$ & 31 & 35 & 32 & \\
\hline Arm 6. & $\left\{\begin{array}{cccc}35 & 39 & 39 & 40 \\
33 & & \end{array}\right\}$ & 38 & 36 & 35 & M & & 48 & M & M & \\
\hline Bau 1. & 30 & 30 & 33 & & & & $5: 3$ & 32 & 40 & \\
\hline Bei 1 & $\begin{array}{lll}32 & 35 \\
79 & 103 & 45\end{array}$ & 2932 & 45 & s & M & & 35 & $\mathrm{~F}$ & 36 & \\
\hline Ber A.. & $\left\{\begin{array}{c}910340 \\
5039\end{array}\right.$ & 4139 & 52 & … & $\cdots$ & $\left(\begin{array}{llll}32 & 32 & 32 & 34\end{array}\right)$ & 34 & & & $\begin{array}{llll}46 & 46\end{array}$ \\
\hline Bow A... & $42 \quad 3539$ & 324531 & 32 & 41 & 26 & $\left\{\begin{array}{llll}33 & 33 & 40 & 33 \\
43 & & & \end{array}\right\}$ & 45 & 41 & 26 & $\left\{\begin{array}{lllll}32 & 32 & 40 & 27\end{array}\right.$ \\
\hline Cam 7. & $\begin{array}{lll}38 & 25 & 27\end{array}$ & & 51 & 42 & 45 & . & $31 \mathrm{t}$ & 36 & 47 & \\
\hline Can $2 .$. & $\ldots \ldots$ & $\left\{\begin{array}{c}33 t 3339 \\
43\end{array}\right.$ & 35 & $\mathrm{~S}$ & $\mathrm{~s}$ & $\ldots \ldots \ldots$ & 50 & M & S & \\
\hline Dre 3. & 3540 & & 36 & & & & 44 & & & \\
\hline $\begin{array}{l}\text { Dun } \\
\text { Fog } A\end{array}$ & $\begin{array}{l}37 \\
39\end{array} 40$ & $\begin{array}{llll}37 & 43 & 34 & 38\end{array}$ & 57 & 41 & 38 & 4635 & $32 \mathrm{t}$ & 35 & 37 & $2 \dagger \mathrm{t}$ \\
\hline & 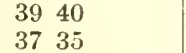 & $4935 \quad 34$ & $\begin{array}{l}47 \\
35\end{array}$ & S & 42 & 4638 & $\begin{array}{l}31 \\
49\end{array}$ & 39 & & 463753 \\
\hline $\begin{array}{l}\text { Gif } 2, \ldots . \\
\text { Hay } 9 \ldots\end{array}$ & $\begin{array}{l}3735 \\
39\end{array}$ & $\begin{array}{l}34 \\
32\end{array}$ & $\begin{array}{l}30 \\
36\end{array}$ & 5 & $M$ & ${ }^{\cdots} \ldots \ldots \ldots \ldots$ & $\begin{array}{l}49 \\
45\end{array}$ & $\begin{array}{l}M \\
35\end{array}$ & $\begin{array}{l}M \\
28\end{array}$ & ……... \\
\hline Hoa & 3344 & 2529 & 36 & & & 25 & 45 & & & \\
\hline Hor 6 & 3438 & 34 & 44 & $\mathrm{~S}$ & 25 & $\ldots \ldots \ldots$ & 34 & $29 \mathrm{t}$ & $M$ & ... \\
\hline Ing $3 .$. & $\begin{array}{llll}39 & & & \\
45 & 35 & 33 & 33\end{array}$ & 3231 & 45 & 32 & 53 & $\ldots \ldots \ldots$ & 31 & $35 \mathrm{t}$ & 37 & \\
\hline Mer A. & $\left\{\begin{array}{cccc}45 & 35 & 33 & 33 \\
29 & & \end{array}\right\}$ & 344530 & 45 & $\cdots$ & $\cdots$ & $37 \quad 48 \quad 46$ & 36 & & $\cdots$ & \\
\hline McG 5. & & 35 & 51 & $M$ & F & $\ldots \ldots \ldots$ & 31 & $M$ & M & \\
\hline & 35 & 31 & & 31 & 30 & & 44 & 35 & $29 \mathrm{t}$ & \\
\hline Ole 2 & $\begin{array}{l}37 \\
45\end{array}$ & 3343434 & $\begin{array}{l}45 \\
46\end{array}$ & $M$ & $\mathrm{~F}$ & & 34 & M & $\mathbf{F}$ & \\
\hline & $\begin{array}{l}4539 \\
34 \quad 37\end{array}$ & $\begin{array}{lllll}34 & 46 & 34 & \\
31 & 36 & 37 & 37\end{array}$ & $\begin{array}{l}40 \\
33\end{array}$ & $\begin{array}{l}F \\
36\end{array}$ & M & $\ldots \ldots \cdots \cdots$ & $\begin{array}{l}32 \\
46\end{array}$ & $\begin{array}{l}\mathrm{Ft} \\
\mathrm{M}\end{array}$ & $\begin{array}{l}\mathrm{S} \\
43\end{array}$ & an. \\
\hline Ric 2 & & & 34 & 39 & 31 & & 46 & 33 & 42 & \\
\hline & $46 \quad 40 \quad 46$ & 525048 & 33 & & 33 & & 54 & 55 & & ......... \\
\hline $\begin{array}{l}\text { Sch } 26 . . \\
\text { Sey } 1\end{array}$ & $\begin{array}{lllll}31 & 36 & 32 & \ldots\end{array}$ & 3336 & 53 & M & $\mathrm{S}$ & (ack & 36 & $M$ & M & \\
\hline War $16 \ldots$ & 3538 & 3232 & $\begin{array}{l}46 \\
32\end{array}$ & $\begin{array}{l}37 \\
M\end{array}$ & $\begin{array}{l}39 \\
\mathrm{~s}\end{array}$ & & $\begin{array}{l}34 \\
44\end{array}$ & $\begin{array}{l}33 \\
\mathrm{~F}\end{array}$ & $\mathrm{~S}^{3.3}$ & ...... \\
\hline Wey A... & $4543 \quad 37$ & 353741 & 45 & 38 & 30 & $\left\{\begin{array}{cccc}32 & 33 & 30 & 30 \\
32 & 44 & 37\end{array}\right\}$ & 35 & 33 & ... & $32 \quad 3037$ \\
\hline Win $6 \ldots$ & 34 & $3 \overline{5}$ & 47 & $M$ & 42 & $\ldots \ldots \ldots \ldots$ & 35 & 35 & $\mathrm{~s}$ & $\ldots \ldots \ldots$ \\
\hline
\end{tabular}

Average build of parents, 40.68 Number of matings 30 .

Total number of progeny, 112 .
VS S M F VF

Classification of progeny........... $2 \begin{array}{ccccc}7 & 50 & 36 & 17\end{array}$

Proportional frequency per mille...... 18 63 446321152 
TABLe XIII. - Fleshy $\times$ fleshy matings and their progeny.

\begin{tabular}{|c|c|c|c|c|c|c|c|c|c|c|}
\hline $\begin{array}{l}\text { File } \\
\text { ref. }\end{array}$ & $\begin{array}{c}\text { Malo } \\
\text { chilturen. }\end{array}$ & $\begin{array}{l}\text { Female } \\
\text { rhildren. }\end{array}$ & F. & FF. & FAI & $\begin{array}{l}\text { l'ather's } \\
\text { sibs. }\end{array}$ & MI. & $M F$. & Mal. & $\begin{array}{l}\text { Mother's } \\
\text { sibs. }\end{array}$ \\
\hline Ben 9. & $37 \quad 3536$ & $3135 \quad 34 \quad 34$ & 37 & 33 & 32 & & 39 & 39 & 29 & \\
\hline Beh A. & $\left\{\begin{array}{cccc}43 & 37 & 32 & 31 \\
29 & 47 & 31\end{array}\right\}$ & $3 n$ & -10 & 43 & 39 & $40: 3945$ & 40 & 37 & 30 & $\left\{\begin{array}{l}\mathrm{VF} \text { VF } 40 \\
27 \quad 35\end{array}\right.$ \\
\hline Bur 14 . & 34 & 34 & 39 & 37 & $M$ & & 39 & ... & 38 & \\
\hline Isur 21. & 3136 & 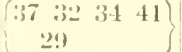 & 37 & 30 & 40 & & 37 & $3 j$ & $\mathrm{M}$ & \\
\hline I3ut 2. & 40 & 36 & 42 & 36 & 39 & & 11 & $: 33$ & 39 & \\
\hline Cat $1 \ldots$ & 33 政 34 & $42+10$ & 38 & 32 & 38 & & 35 & $41)$ & 40 & $1 \dagger t$ \\
\hline Cla 12. & 3s & $43 \quad 35 \quad 35$ & 37 & 36 & 31 & & 37 & 38 & 31 & 9 \\
\hline $\begin{array}{l}\text { Dar } 7 \ldots \\
\text { Dol } 3 . . .\end{array}$ & $\begin{array}{l}34 \\
33336,36\end{array}$ & $\begin{array}{l}47: 6411 \\
32: 34\end{array}$ & $\begin{array}{l}37 \\
40\end{array}$ & $\begin{array}{l}12 \\
36\end{array}$ & & & $\begin{array}{l}4 \div 2 \\
40\end{array}$ & $\begin{array}{l}3 \pi \\
37\end{array}$ & $\begin{array}{l}42 \\
41\end{array}$ & $\begin{array}{l}2 \mathrm{t} \\
\ldots \ldots\end{array}$ \\
\hline Elm $A$. & +232 & $\left\{\begin{array}{cccc}38 & 34 & 36 & 36\end{array}\right\}$ & 37 & ... & 40 & & 40 & 32 & 30 & \\
\hline Fea 2. & $3233: 30$ & $30^{-3}$ & 43 & 33 & 34 & & 37 & 36 & 36 & \\
\hline For A. & $39 \quad 3932$ & 52492829 & 36 & 33 & 29 & $\left\{\begin{array}{cccc}29 & 29 & 27 & 25 \\
27 & 28 & 27\end{array}\right\}$ & 39 & 30 & 35 & $\left\{\begin{array}{cccc}32 & 31 & 32 & 30 \\
54 & 25 & 30\end{array}\right.$ \\
\hline Hor 1. & 353.5 & $\ldots \ldots \ldots$ & 37 & $\mathrm{M}$ & $\therefore$ & $\ldots . . . \ldots . . . .$. & 43 & 47 & $\mathrm{~s}$ & $\ldots \ldots \ldots$ \\
\hline Hod A. & $\left\{\begin{array}{cccc}51 & 29 & 42 & 47 \\
42 & 47 & 43\end{array}\right\}$ & $: 312949$ & 42 & & & 41494136 & 38 & & 37 & \\
\hline $\operatorname{Jam} A \ldots$ & 153434 & $43+11$ & 39 & & & $\ldots \ldots \ldots$ & $3 s$ & & & \\
\hline Jen & & 123436 & 43 & M & $\therefore$ & $\left(\begin{array}{llll}36 & 31 & 43 & 44\end{array}\right)$ & $3 x$ & MI & $M$ & \\
\hline Jon $11 c^{1}$ & $37 \quad 3937$ & $\left\{\begin{array}{rrrr}37 & 40 & 37 & 40 \\
44^{1} & 355^{1} & 42\end{array}\right\}$ & 39 & 29 & 49 & $\left\{\begin{array}{llll}34 & 33 & 33 & 38 \\
39 & & & \end{array}\right\}$ & 39 & $3 \bar{\imath}$ & 42 & $\left\{\begin{array}{c}36 \quad 3437 \\
34 \quad 37\end{array}\right.$ \\
\hline Lin A & 51 & 29 & $: 37$ & 37 & 37 & 293637 & 40 & 43 & 37 & 35 \\
\hline Lic 2 & & & 40 & $M$ & MI & $\ldots \ldots \ldots \ldots \ldots$ & 40 & 30 & 41 & \\
\hline $\begin{array}{l}\text { Lin } 8 \ldots \\
\text { N1:ar } 20 \ldots\end{array}$ & $\begin{array}{l}36: 36 \\
36\end{array}$ & 30 & 38 & $\begin{array}{l}M I \\
36\end{array}$ & 26 & $\ldots \ldots \ldots \ldots \ldots$ & 43 & 8 & $\mathrm{MI}$ & \\
\hline$M\left(W_{2} 2\right.$. & $39+136 \quad 25$ & 14 & 10 & 36 & 2.1 & $\ldots \ldots \ldots \ldots$ & 37 & 33 & 37 & \\
\hline Sel $5 .$. & $\left\{\begin{array}{cccc}37 & 38 & 35 & 35 \\
35 & & \end{array}\right\}$ & 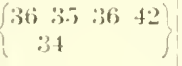 & 39 & 34 & 31 & $\ldots \ldots \ldots$ & 42 & 3.1 & 34 & \\
\hline$*[:: 1]^{2} \ldots$ & $M \mathrm{MI}$ & $61+$ & +13 & $\mathrm{~F}^{2}$ & $M^{2}$ & $\left\{\begin{array}{cccc}41 & 40 & 28 & 43 \\
52 & & \end{array}\right\}$ & $40+$ & & & \\
\hline I'ie 1 & 1040 & 4340 & 39 & $\mathrm{~F}$ & M & $\ldots \ldots \ldots \ldots \ldots$ & 43 & M & F & \\
\hline I'it 1 & 列 & $\left\{\begin{array}{cccc}37 & 29 & 37 & 30 \\
29 & 9 & 30\end{array}\right\}$ & 43 & S & $\mathrm{F}$ & $F s$ & $: 9$ & 150 & s & $t_{t}$ \\
\hline Rat 1 .. & 4541 & $\begin{array}{l}3740 \\
42\end{array}$ & 38 & M & M & 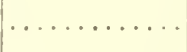 & 39 & $M$ & M & \\
\hline Smi 10. & & $36 \quad 33 \quad 35 \quad 35$ & 39 & $\begin{array}{l}36 \\
36\end{array}$ & 37 & & $\begin{array}{l}31 \\
43\end{array}$ & $\begin{array}{l}31 \\
36\end{array}$ & $\begin{array}{l}43 \\
37\end{array}$ & \\
\hline Syr $1 \ldots$ & 35 & & 37 & $\mathrm{~F}$ & $M$ & & 39 & M & M & \\
\hline Tel $1 \ldots$ & $47: 36: 36$ & & $: 39$ & MI & MI & & 38 & $M$ & $M$ & \\
\hline Thr 1a... & 433838 & 424241 & 38 & 39 & M & 5 brothers MI & 40 & .. & $\cdots$ & \\
\hline Thr $2 \ldots$ & $53 \quad 30 \quad 38$ & 144444 & 89 & 27 & 34 & $\left\{\begin{array}{llll}39 & 37 & 46 & 50 \\
35 & 50 & 35 & 35\end{array}\right\}$ & 39 & 38 & 38 & \\
\hline Wil $15^{3}$. & 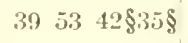 & 35.34 & 12 & 40 & 27 & $\ldots \ldots \ldots \ldots \ldots$ & 37 & MI & 31 & \\
\hline
\end{tabular}

Average build of pareuts (exeluding fauily with *), 39.21 .

Number of matings, $33+1^{*}=3.4$.

Tot:al number of progeny, $1.56+3^{*}=159$.

S $M$ F VF

Classifica'ion of progeny..........15 62 61 21

Proportional frequeney per mille......9.1 390 3\$. 132
1 Feeble-minded.

' FF's sibs fleshy; FM's sibs are M.

\& and \& are twins. 
TABLE XIV.-Fleshy $\times$ rery fleshy matings and their progen .

\begin{tabular}{|c|c|c|c|c|c|c|c|c|c|c|}
\hline $\begin{array}{l}\text { File } \\
\text { ref. }\end{array}$ & $\begin{array}{l}\text { Male } \\
\text { children. }\end{array}$ & $\begin{array}{l}\text { Fcnale } \\
\text { children. }\end{array}$ & F. & FF. & FMI. & $\begin{array}{l}\text { Father's } \\
\text { sibs. }\end{array}$ & M. & MH. & $M M$. & $\begin{array}{l}\text { Mother's } \\
\text { sibs. }\end{array}$ \\
\hline *Ber ${ }^{1} \ldots$ & $\left\{\begin{array}{c}1003850 \\
84^{1} 34\end{array}\right\}$ & $3+443$ & 50 & & & Sis & 39 & & & $4 \varsigma: 30$ \\
\hline $\begin{array}{l}\text { Bol } 1^{2} \ldots \\
\text { Bro } 10\end{array}$ & 39 & $\cdots_{3} \ldots \ldots, \cdots, \cdots$ & 10 & 31 & $2 x$ & $\ldots \ldots \ldots \ldots$ & 45 & 36 & 10 & \\
\hline Cen $2 \ldots$ & $33 \quad 39$ & $\begin{array}{l}3930 \quad 32 \\
33\end{array}$ & 41 & $M$ & $\mathrm{MI}$ & $\begin{array}{l}\cdots \\
\cdots\end{array}$ & 47 & MI & $\begin{array}{l}70 \\
\mathrm{MI}\end{array}$ & \\
\hline $\mathrm{Cla} 16 \ldots$ & 3633 & & 39 & 36 & 27 & $27: 36$ & 4ij & 39 & 45 & 42 \\
\hline Cla $25 \ldots$ & & 34 & 38 & 45 & & & 39 & 30 & & \\
\hline Dan B.. & 3232 & 5131 & 40 & $M$ & $\mathrm{MI}$ & $\triangle S \leq S$ & 51 & $M 1$ & $\mathrm{~S}$ & S S S is F \\
\hline Ebe 2 . & $\ldots \ldots \ldots \ldots \ldots$ & 3736 & 41 & M & $M$ & & 15 & $\therefore$ & M & \\
\hline Ekh $1 \ldots$ & $\begin{array}{llll}41 & 46 & 45 & 43\end{array}$ & $\ldots \ldots$ & 50 & 36 & 50 & $51 \quad 5245$ & $3 s$ & & & $\ldots \ldots$ \\
\hline Elm B. & $\ldots \ldots \ldots \ldots$ & & 38 & & $\cdots$ & & 14 & 39 & 29 & \\
\hline${ }^{*} \mathrm{Faz}{ }^{3} \ldots$ & $\mathrm{VF}^{3}$ & 514 & 39 & $F$ & $\ldots$ & $F F F F$ & 57 & $F \ddagger$ & $\mathrm{F}$ & $5 \pi$ \\
\hline Fio 3 . & $\left\{\begin{array}{cccc}39 & 42 & 39 & 42 \\
40 & & \end{array}\right\}$ & 3736 & $3 \pi$ & 42 & 42 & $\ldots \ldots \ldots \ldots$ & 49 & 37 & $3 i ;$ & $\ldots$ \\
\hline Gil A. & 5339 & 47 & $3 s$ & 34 & 28 & $\ldots$ & 46 & & & \\
\hline Gou A... & 4035 & 4832 & 37 & & & $\ldots \ldots \ldots \ldots \ldots$ & .54 & 37 & $\therefore 0$ & $\mathrm{~F} F$ \\
\hline Gre $74 \ldots$ & 4237 38 & $\ldots \ldots \ldots \ldots \ldots$ & $3 s$ & $\mathrm{~F}$ & M & $\ldots \ldots \ldots \ldots \ldots$ & 14 & M & MI & $\ldots \ldots \ldots$ \\
\hline Gug $1 \ldots$ & $\begin{array}{llll}43 & 33 & 33 & 34\end{array}$ & $\ldots \ldots \ldots \ldots$ & 44 & & & $\ldots \ldots \ldots \ldots \ldots$ & 36 & & 29 & $\ldots \ldots \ldots$ \\
\hline Hal $8 \ldots$ & $36 \quad 3533$ & man $\cdots$ & $3 s$ & 11 & 8.5 & $\ldots \ldots$ & 10 & 37 & 26 & $\ldots \ldots \ldots \ldots$ \\
\hline Lou 4. & $\ldots \ldots \ldots \ldots$ & $\left\{\begin{array}{c}4134 \\
36\end{array}\right\}$ & 37 & 32 & 32 & & 48 & 46 & 29 & \\
\hline *Lyn. & $\left\{\begin{array}{cccc}F & \text { MI } & 31 & 35 \\
39 & 46 & \end{array}\right\}$ & 34 & 38 & & & F & 50 & & & $(3 \overline{5} 34+3537$ \\
\hline MeL A... & $43 \quad 35 \quad 46 \quad 32$ & $\left\{\begin{array}{llll}45 & 30 & 42 & 38 \\
45 & 30 & 31 & 31\end{array}\right\}$ & $3 S$ & 39 & 36 & $\left\{\begin{array}{llll}36 & 37 & 39 & 37 \\
3 \pi & 40 & 45 & 44\end{array}\right\}$ & 14 & 3.1 & $4 i$ & $\left\{\begin{array}{llll}35 & 35 & 40 & 43 \\
45 & & & \end{array}\right.$ \\
\hline *Mor. . . . . & 37 & $\left\{\begin{array}{l}S 5246 \mathrm{~F} \\
\text { VS }\end{array}\right.$ & $V F$ & $\mathrm{~S}$ & $\mathrm{~F}$ & 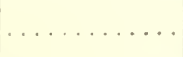 & 39 & $F$ & $F$ & All $F$ \\
\hline Moo 11. & & 4735 & 40 & 29 & 69 & $\ldots \ldots$ & 47 & 30 & 36 & \\
\hline Nic $5 . .$. & 38 & 53 & 41 & $F$ & $\mathrm{~F}$ & $\ldots \ldots \ldots \ldots$ & 45 & 35 & & ${ }_{3 \mathrm{~F}} \mathrm{y} \cdots \cdots$ \\
\hline Oel A.... & $\begin{array}{llll}42 & 35 & 33 \\
30 & 35 & 4\end{array}$ & $\begin{array}{l}38 \\
27\end{array}$ & $\begin{array}{l}38 \\
46\end{array}$ & $\cdots_{46}$ & 35 & $\cdots \cdots \cdots \cdots$ & $\begin{array}{l}\frac{14}{24} \\
39\end{array}$ & 33 & 31 & $\begin{array}{l}3 \mathrm{~F} \\
\ldots \ldots\end{array}$ \\
\hline Per A. & 585044 & 44 & 51 & $\ldots$. & 34 & 434241 & 43 & 3.5 & 30 & $\left\{\begin{array}{cccc}37 & 37 & 32 & 34 \\
34 & & \end{array}\right.$ \\
\hline Pon 1... & 38 & 4233 & 45 & & & $\ldots \ldots$ & 37 & $M$ & $S(t)$ & $\ldots \ldots \ldots \ldots$ \\
\hline *Rec... & $\ldots \ldots \ldots$ & 53 & $\mathrm{~F}$ & & 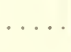 & & 57 & 40 & 100 & $\left\{\begin{array}{l}5.3 .34 \\
\mathrm{~V} F\end{array}\right.$ \\
\hline *Rec... & $\left\{\begin{array}{c}53.34 \mathrm{VF} \\
40\end{array}\right\}$ & 5735 & 40 & S & $\cdots$ & F $F$ & 100 & . & $\ldots \ldots$ & $F F S$ \\
\hline Rei $7 \ldots$ & 3134 & 30 & 44 & 72 & M & $\ldots \ldots$ & 37 & 72 & $M$ & \\
\hline$* \operatorname{Rid}^{5} \ldots$ & S 47 & $\left\{\begin{array}{c}4049 \sqrt{V F} \\
F \text { S }\end{array}\right.$ & 56 & $S^{5}$ & $\mathbf{F}$ & F & $\mathrm{F}$ & & $\cdots$ & $\left\{\begin{array}{c}111 \mathrm{t} \\
41\end{array}\right.$ \\
\hline Saw A... & 48 & 43 & 40 & 39 & - & 51 & 39 & $\cdots$ & $\cdots$ & $\begin{array}{ll}\ldots \ldots & \ldots\end{array}$ \\
\hline Sch B... & $\ldots \ldots \ldots \ldots$ & 45 & 42 & & $\cdots$ & $\cdots$ & 52 & 32 & 38 & $\left\{\begin{array}{l}30 \pm 2-52-50 \\
35\end{array}\right.$ \\
\hline $\begin{array}{l}\text { Ste } 18 \ldots \\
\text { Voi } 1^{6} \ldots\end{array}$ & $\begin{array}{l}3443 \\
\ldots \ldots\end{array}$ & $\begin{array}{l}36 \quad 35 \\
31\end{array}$ & $\begin{array}{l}43 \\
54\end{array}$ & $\begin{array}{l}37 \\
\text { MI }\end{array}$ & $\begin{array}{l}29 \\
\mathrm{~F}\end{array}$ & $\begin{array}{l}42 \\
\ldots\end{array}$ & $\begin{array}{l}50 \\
3 \mathrm{~s}\end{array}$ & $\begin{array}{l}39 \\
\mathrm{~S}\end{array}$ & $\frac{27}{\mathrm{~F}}$ & $\begin{array}{l}t \\
t(t)\end{array}$ \\
\hline *Wen'.... & 513535 & $\left\{\begin{array}{cccc}44 & 32 & 32 & 32 \\
31 & & \end{array}\right\}$ & 46 & $46^{7}$ & MI & & 37 & $M$ & $M$ & $\mathrm{FF}$ \\
\hline *Whe... & F 3646 & & 40 & 44 & 49 & & 52 & & $\cdots$ & $5442 F S$ \\
\hline Yan $2,3$. & 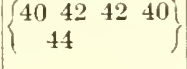 & 423335 & 52 & & & & 40 & & & \\
\hline
\end{tabular}

Average build of parents (excluding families with *), 42.49 . Total number of matings, $29+9^{*}=3 \mathrm{~S}$.

Total number of progeny, $100+46 *=146$.

islender as a child.

All show history of change (increase) of weight.

3 V till 17 years; now thin; $\dagger M F$ sibs F F F.

- Five children died in infancy.
VS S M F VF

Classification of progeny...... $17 \begin{array}{llll}7 & 52 & 51 & 35\end{array}$ Proportional frequency per mille. $7 \quad 48 \quad 356 \quad 3419 \quad 240$

Had a fleshy sister.

- Mother has 4 small nervous sisters.

i Had a brother 46 , sister 43 . 
TABLE XV.-Very fleshy $\times$ very fleshy matings and their progeny (using adjusted indices).

\begin{tabular}{|c|c|c|c|c|c|c|c|c|c|c|}
\hline $\begin{array}{l}\text { File } \\
\text { ref. }\end{array}$ & $\begin{array}{l}\text { Male } \\
\text { children. }\end{array}$ & $\begin{array}{l}\text { Female } \\
\text { children. }\end{array}$ & F. & FF. & FM. & $\begin{array}{c}\text { Futher's } \\
\text { silss. }\end{array}$ & $M$. & $M F$. & MM. & $\begin{array}{l}\text { Mother's } \\
\text { sibs. }\end{array}$ \\
\hline Bow B... & 503745 & 474042 & 45 & 45 & 38 & $\ldots \ldots$ & $4 S$ & 36 & 23 & $\left\{\begin{array}{c}35353538 \\
50\end{array}\right.$ \\
\hline Bow 2 . & 323244 & 3134 & 45 & 34 & 57 & $\left\{\begin{array}{cccc}47 & 44 & 52 & 49 \\
52 & & \end{array}\right\}$ & 48 & 41 & 32 & t 323638 \\
\hline Bry A. . & 473233 & 39 & 45 & $\ldots$ & 43 & $4638 \quad 49$ & 46 & 31 & $\ldots$. & $\ldots$. \\
\hline Cat 3. & $\left\{\begin{array}{cccc}36 & 39 & 47 & 34 \\
35 & & & \end{array}\right\}$ & 36 & 44 & 39 & 35 & $\ldots \ldots \ldots \ldots$ & 51 & 42 & 49 & \\
\hline Dal A... & 45405046 & 3432 & 49 & 48 & & $\left\{\begin{array}{cccc}34 & 31 & 30 & 47 \\
35 & 38 & 29\end{array}\right\}$ & 53 & 64 & & \\
\hline Dud A... & 5131 & $\ldots \ldots$ & 49 & $\cdots \ldots$ & & 33 & 51 & $\cdots$ & $\cdots$ & \\
\hline smi $36 \ldots$ & & & 46 & $36 \mathrm{t}$ & $34 \mathrm{t}$ & $\cdots$ & 44 & 46 & 40 & \\
\hline
\end{tabular}

Average build of parents, 47.45 .

Number of matings, 7 .

Total number of progeny, 30 .
Classification of progeny........ $14 \quad 6 \quad 10$

Proportional frequency per mille. . 467 200333 
TABLE XVI.-Indices of buill, weight $\div$ stature $^{2}$, for weights from 100 to 235 pounds and 45.4 to $102 \mathrm{~kg}$. and statures from 55 to 78 inches and 140 to $198 \mathrm{~cm}$. Decimals omitted.

[Reduction from English to metric systcm effected by the factor 0. 70308.]

\begin{tabular}{|c|c|c|c|c|c|c|c|c|c|c|c|c|c|c|c|}
\hline \multicolumn{2}{|c|}{ Weight $\left\{\begin{array}{l}\text { Pounds..... } \\
\text { Decigr..... }\end{array}\right.$} & $\begin{array}{r}100 \\
4536\end{array}$ & $\begin{array}{r}105 \\
4763\end{array}$ & $\begin{array}{r}110 \\
4990\end{array}$ & $\begin{array}{r}115 \\
5216\end{array}$ & $\begin{array}{r}120 \\
5443\end{array}$ & $\begin{array}{r}125 \\
5670\end{array}$ & $\begin{array}{r}130 \\
5 \$ 97\end{array}$ & $\begin{array}{r}135 \\
6124\end{array}$ & $\begin{array}{r}140 \\
6350\end{array}$ & $\begin{array}{r}145 \\
6576\end{array}$ & $\begin{array}{r}150 \\
680.1\end{array}$ & $\begin{array}{r}155 \\
7031\end{array}$ & $\begin{array}{r}160 \\
7259\end{array}$ & $\begin{array}{r}165 \\
7484\end{array}$ \\
\hline Stature & Stat. ${ }^{2}$ & & & & & & & & & & & & & & \\
\hline $5 j \mathrm{in.}$. & 3025 & 3306 & 3471 & 3636 & 3802 & 3967 & 4132 & $429 \mathrm{~s}$ & 4463 & 4628 & 4793 & 4959 & 5124 & 5289 & 5455 \\
\hline & 1952 & 2324 & 2440 & 2557 & 2673 & 2789 & 2905 & 3021 & 3138 & 3254 & 3370 & 3486 & 3603 & 3719 & 3835 \\
\hline 56 in $\ldots$. & 3136 & 3189 & 3348 & 3507 & 3667 & 3827 & 3986 & 4145 & 4305 & 4464 & 4624 & 4783 & 4943 & 5102 & 5261 \\
\hline $1422 \mathrm{~mm} \ldots$ & 2023 & 2242 & $235-4$ & 2466 & 2578 & 2690 & 2802 & 2915 & 3027 & 3139 & 3251 & 336 & 3475 & 3587 & 3699 \\
\hline 57 in...... & 3249 & $307 \mathrm{~s}$ & 3232 & 3386 & 3540 & 3693 & $3 S 47$ & 1001 & 4155 & 4309 & 4463 & 4617 & 4771 & 4925 & 5078 \\
\hline $1448 \mathrm{~mm}$. & 2096 & 2164 & 2272 & 2380 & 2.459 & 2597 & 2705 & $2 S 13$ & 2921 & 3030 & 3138 & 3246 & 3354 & 3462 & 3571 \\
\hline $.58 \mathrm{in} . . .$. & 3364 & 2973 & 3121 & 3270 & 3419 & 3567 & 3716 & 3564 & 4) 13 & 416 & 4310 & 4459 & 1608 & 4756 & 4905 \\
\hline $1473 \mathrm{~mm}$. & 2170 & 2090 & 2195 & 2299 & 2404 & 2508 & 2613 & 2717 & $2 \$ 21$ & 2926 & 3031 & 3135 & 3240 & 3344 & $34: 49$ \\
\hline 59 in . . . . & 3481 & 2873 & 3016 & 3160 & 3304 & 3417 & 3591 & 3735 & 3978 & 4022 & 4165 & 4309 & 4453 & 4596 & 4740 \\
\hline $1499 \mathrm{~mm}$. & 2246 & 2020 & 2121 & 2222 & 2323 & 2424 & 2525 & 2626 & 2727 & 2825 & 2929 & 3030 & 3131 & 3232 & 3333 \\
\hline $60 \mathrm{kn}$. & 3600 & 2778 & 2917 & 3056 & 3194 & 3333 & 3472 & 3611 & 3750 & 3988 & 4028 & 4167 & 4306 & 4444 & 4583 \\
\hline $1524 \mathrm{~m}$ & 2323 & 1953 & 2051 & 2145 & 2246 & 2343 & 2441 & 2539 & 2637 & 2734 & 2832 & 293 & 3027 & 3125 & 3222 \\
\hline 61 in & 3721 & 2687 & 2522 & 2956 & 3091 & 3225 & 3359 & 3404 & 3628 & 3762 & 3897 & 4031 & 4166 & 4300 & 4131 \\
\hline $1549 \mathrm{~mm}$ & 2401 & 1590 & 1984 & 2078 & 2173 & 2267 & 2362 & 2456 & 2551 & 2645 & $27+0$ & 2834 & 2929 & 3023 & 3118 \\
\hline 62 in & 3844 & 2601 & 2732 & 2862 & 2992 & 3122 & 3252 & $33 \$ 2$ & 3512 & 3642 & 3772 & 3902 & 4032 & 4162 & 4292 \\
\hline $1575 \mathrm{~mm}$ & 2.480 & 1529 & 1920 & 2012 & 2103 & 2195 & 2286 & $237 \mathrm{~s}$ & 2469 & 2561 & 2652 & 2744 & 2835 & 2926 & 3018 \\
\hline 63 in ... & 3660 & 2520 & 2646 & 2771 & 2897 & 3023 & 3149 & 3275 & 3401 & 352 & 36.53 & 377 & 3905 & 1031 & 4157 \\
\hline $1600 \mathrm{~mm}$ & 2561 & 1771 & 1860 & 1943 & 2037 & 2126 & 2214 & 2303 & 2391 & 2480 & 2569 & 2657 & 2746 & 2831 & 2923 \\
\hline 64 in . . . & 4096 & 2441 & 2563 & 2686 & $2.50 \mathrm{~s}$ & 2930 & 30.52 & 3174 & 3296 & 341 & 3540 & 366 & 3781 & 3906 & 4028 \\
\hline $1626 \mathrm{mrn}$. . & 2643 & 1716 & 1802 & $18 s 8$ & 1974 & 2060 & 2146 & 2231 & 2317 & 2403 & $24 \times 9$ & 2575 & 1 & 2746 & 2832 \\
\hline $65 \mathrm{in} . \ldots \ldots$ & 4225 & 2367 & 2485 & 2604 & 2722 & 2840 & 2959 & 3077 & 3195 & 3314 & 3432 & 3550 & 3669 & 3787 & $3: 105$ \\
\hline $1651 \mathrm{~mm} .$. & 2726 & 1664 & 1747 & 1831 & 1914 & 1997 & 2050 & 2163 & 2247 & & 241 & & & 2 & 2745 \\
\hline 66 in & 4356 & 2296 & 2410 & 2525 & 2640 & 2755 & 2570 & 2984 & 3099 & 3214 & 3329 & 3443 & $355 \mathrm{~s}$ & $36 \pi 3$ & 3788 \\
\hline $1676 \mathrm{~mm}$. & $2 \varepsilon 10$ & 1614 & 1695 & 1775 & 1856 & 1937 & 2018 & 2098 & 2179 & 226 & 2340 & 242 & 2502 & 2583 & 2663 \\
\hline & $448 ?$ & 2228 & 2339 & 2450 & 2562 & 2673 & 278.5 & 2896 & 3007 & 311 & 3230 & 33 & 34 & 3564 & 3676 \\
\hline $1702 \mathrm{~mm}$. & 2896 & 15 tit & 16.45 & 1723 & 1801 & $1 \triangleleft 79$ & $195 \mathrm{x}$ & 2026 & 2114 & 2193 & 2271 & 231 & 2428 & 2506 & 2584 \\
\hline & 4624 & 2163 & 2271 & 2379 & 2457 & 2595 & 2703 & $2 \$ 11$ & 2920 & 30 & 3136 & & & & $356 \mathrm{~s}$ \\
\hline $1727 \mathrm{~mm}$. & 2983 & 1521 & 1597 & 1673 & 1749 & 182.5 & 1901 & 1977 & 2053 & 2129 & 2205 & 2281 & 2357 & 2433 & 2509 \\
\hline 69 in. . . . & 4761 & 2100 & 2205 & 2310 & 2415 & 2520 & 2625 & 2731 & 2936 & 29.1 & 3046 & 315 & 56 & 3361 & 3466 \\
\hline $1733 \mathrm{~mm}$ & $30 \pi 2$ & 1477 & 1551 & 1624 & 1698 & 1772 & 1845 & 1920 & 1994 & 20 & 21 & 22 & 22 & 2363 & 2436 \\
\hline $70 \mathrm{in} . . .$. & 4900 & 2041 & 2143 & 2245 & 2347 & 2419 & 2551 & 2653 & 2755 & 2857 & 2959 & 306 & 3163 & 3265 & 3367 \\
\hline $1778 \mathrm{~mm}$. & 3161 & 1435 & 1507 & $157 \mathrm{~S}$ & 1650 & 1722 & 1793 & 1.56 .5 & 1937 & 201 & $20 \$ 1$ & 2152 & & & 2365 \\
\hline 71 in. & 5041 & 1984 & 2083 & 2152 & 2281 & 2380 & $24 \$ 0$ & 2579 & 2679 & 2778 & 2876 & 2976 & 3075 & 3174 & 3273 \\
\hline $1803 \mathrm{~mm}$. . & 3252 & 1395 & 1464 & 1534 & 160.4 & 167.4 & 1743 & 1813 & 1.593 & 195 & 2022 & 20 & & 2232 & 2301 \\
\hline 72 in... & 5184 & 1929 & 2025 & 2122 & 2218 & 2315 & 2411 & 2508 & 2604 & 27 & 2797 & $28 !$ & 2990 & 3086 & 3183 \\
\hline $1.529 \mathrm{~mm}$ & 3345 & 1356 & 1424 & 1492 & 1560 & 1627 & 1695 & 1763 & 1831 & 189 & 1967 & 2034 & 2102 & 2170 & $223 \mathrm{~s}$ \\
\hline & 5329 & 1577 & 1970 & 2064 & 2158 & 2252 & 2346 & 2139 & 2533 & 26. & 2721 & & 29 & & 3096 \\
\hline $1854 \mathrm{~mm}$. & 3438 & 1319 & 1385 & 1451 & 1517 & $15 \$ 3$ & 1649 & 1715 & 1781 & 181 & 1913 & 197 & 2045 & 2111 & 2177 \\
\hline 74 in.... & 5476 & 1826 & 1917 & 2029 & 2100 & 2191 & 2283 & 2374 & 2465 & 255 & 2648 & 2739 & 2831 & 2922 & 3013 \\
\hline $1850 \mathrm{~mm}$. & 3533 & 1254 & 1318 & $1+12$ & 1477 & 1541 & 1605 & 1669 & 1733 & $17 \mathrm{~s}$ & 1 sti2 & 192 & 1990 & 2054 & 2118 \\
\hline 75 in..... & 5625 & 1778 & 1867 & 1956 & 2044 & 2133 & 2222 & 2311 & 2.490 & 2459 & 2578 & 2667 & 2756 & 2844 & 2933 \\
\hline $1905 \mathrm{~mm}$. . & 3629 & 1250 & 1312 & 1375 & 1437 & 1500 & 1562 & 1625 & 1687 & 1750 & 1812 & 187 & 1937 & 2000 & 2062 \\
\hline & 5776 & 1731 & $181 \mathrm{~s}$ & 1904 & 1991 & $207 \mathrm{~S}$ & 2164 & 2251 & 2337 & 2424 & 2510 & 2597 & 2681 & 2770 & 2557 \\
\hline $1930 \mathrm{~mm}$. & 3726 & 1217 & 1278 & 1339 & 1400 & 1461 & 1522 & 1582 & 1643 & 1704 & 1765 & 1826 & 1887 & 1928 & $200 \mathrm{~S}$ \\
\hline & 5929 & 1687 & 1771 & 1855 & 1940 & 2024 & 2108 & 2193 & 2277 & 2361 & 2446 & 2530 & 2614 & 2697 & 2783 \\
\hline $1956 \mathrm{~mm}$. & 3525 & 1186 & 1245 & 1304 & 1364 & 1423 & 1482 & 1541 & 1601 & 1660 & 1719 & 1779 & 1835 & 1897 & 1957 \\
\hline & 6054 & $16 \pm 4$ & 1726 & 1808 & 1890 & 1972 & 2055 & 2137 & 2219 & 2301 & 2383 & 2465 & 2548 & 2630 & 2712 \\
\hline $1981 \mathrm{~mm}$. & 3925 & 1156 & 1213 & 1271 & 1329 & 1387 & 1445 & 1502 & 1.560 & 1618 & 1676 & 1733 & 1791 & 1519 & 1907 \\
\hline
\end{tabular}


TABLE AVI.-Inliees of build, weight $\div$ slature? , for weights from 100 to s2:5 pounds and 4.5 .4 to $102 \mathrm{~kg}$. and statures from 55 to is inches and 140 to $195 \mathrm{~cm}$.-Continued.

[1Redurtion of index from Winglish to metric systein effected by the factor 0.70308.]

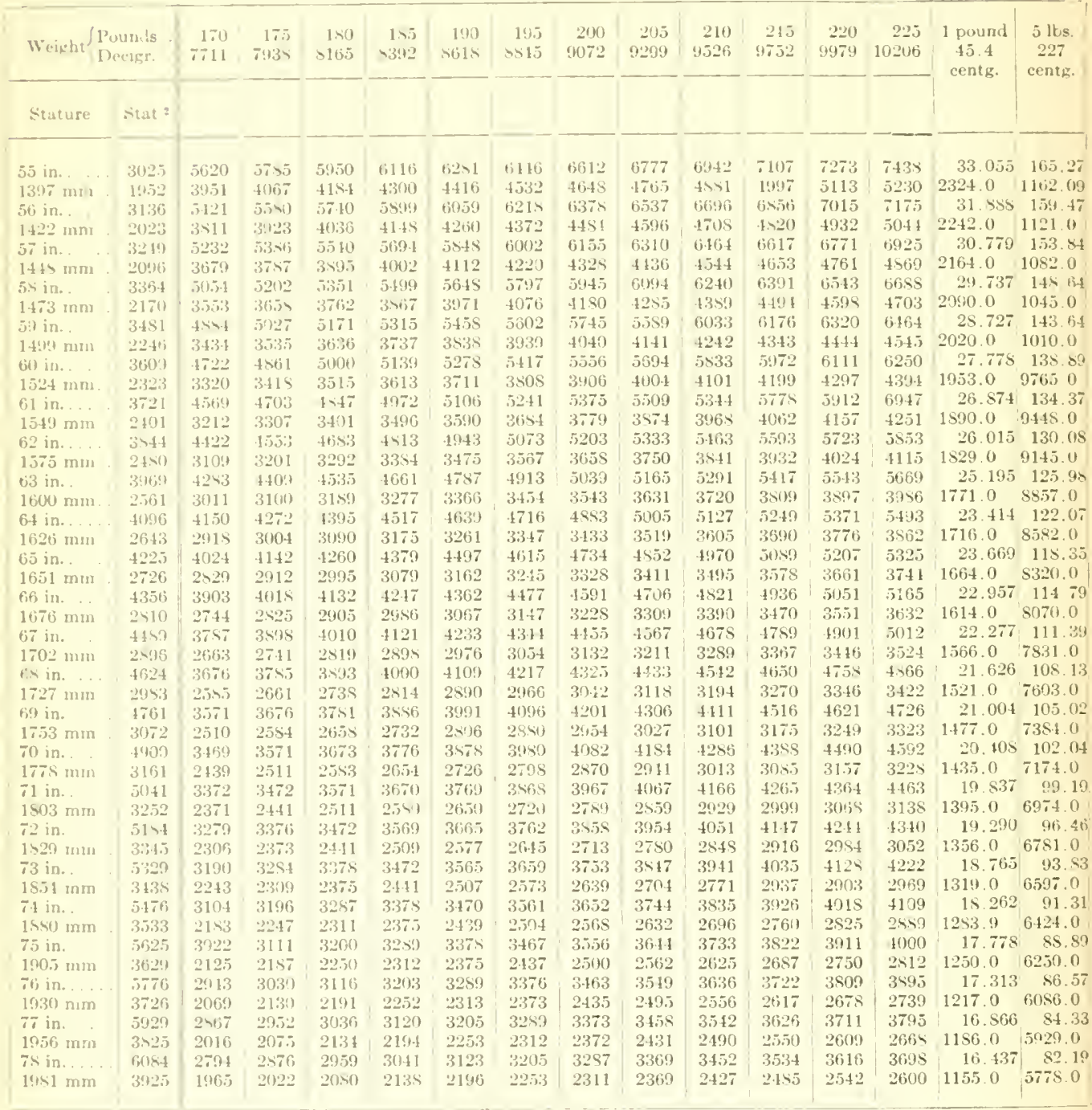


TABLE XVII.-Equivalent values of index of build by four different systems of ratios between weight and

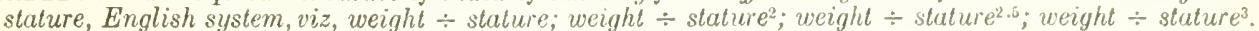

Decimals omitted.

\begin{tabular}{|c|c|c|c|c|c|c|c|c|c|c|c|c|c|c|c|}
\hline $\begin{array}{l}\text { Power of } \\
\text { stature. }\end{array}$ & Stature. & 100 & 105 & 110 & 115 & 120 & 125 & 130 & 135 & 140 & 1.15 & 150 & 155 & 160 & 165 \\
\hline 55 & 55 & 1819 & 1609 & 2000 & 2091 & 2182 & 2273 & 2364 & 2455 & 2545 & 2636 & 2727 & 2818 & 2909 & 3000 \\
\hline $55^{2}$ & 3025 & 3306 & 3471 & 3636 & 3802 & 3967 & 4132 & 4298 & 4463 & 1628 & 4793 & 4959 & $51: 2$ & 5259 & 5455 \\
\hline $55^{2.6}$ & 22434 & 4458 & 4650 & 4903 & 5126 & 5349 & 5572 & 5795 & 6015 & 6210 & 6163 & 66586 & 69909 & 7132 & 7355 \\
\hline $55^{3}$ & 166375 & 6011 & 6311 & 6612 & 6912 & 7213 & 7513 & 7811 & 8114 & 8415 & 8715 & 9016 & 9316 & 9617 & $9 y 17$ \\
\hline 56 & 56 & 1786 & 1875 & 1964 & 2054 & 2143 & 2232 & 2321 & 2411 & 2500 & 25.59 & 2679 & 2768 & 2857 & 2946 \\
\hline $5 b^{2}$ & 3136 & 3189 & 3345 & 3507 & 3667 & $3 \$ 27$ & 3986 & 4145 & 4305 & 4.464 & 4624 & 4783 & 4943 & 5102 & 5261 \\
\hline $56^{2.8}$ & 23468 & 4261 & 4474 & 4687 & 4900 & 5113 & 5327 & 5540 & 5753 & $54+66$ & 6179 & 6392 & 6605 & 6818 & 7031 \\
\hline $56^{8}$ & 175616 & 5694 & 5979 & 6264 & 6548 & 6833 & 7118 & 7403 & 7657 & 7972 & 8257 & 5541 & $\operatorname{sis} 26^{\circ}$ & 9111 & 9396 \\
\hline 57 & 57 & 1754 & 1842 & 1930 & 2018 & 2105 & 2193 & 2281 & 2368 & 2456 & 2511 & $24: 3: 32$ & 2719 & 2507 & 2895 \\
\hline $57^{2}$ & 3249 & 3078 & 3232 & 3356 & 3540 & 3693 & 3847 & 4001 & 4155 & 4309 & 4463 & .1617 & 4771 & 4925 & 5078 \\
\hline $57^{2.5}$ & 24529 & 4077 & 4281 & 4485 & $468 \mathrm{~S}$ & $4 \$ 92$ & 5096 & 5300 & 5504 & 5708 & 5911 & 6115 & 6319 & 6523 & 6727 \\
\hline $57^{3}$ & 185193 & 5400 & 5670 & 5940 & 6210 & 6150 & 6750 & 7020 & 7290 & 7560 & 7530 & 8100 & $\$ 370$ & 8640 & 8910 \\
\hline 53 & 58 & 1724 & 1810 & $1 S 97$ & 1983 & 2069 & 2155 & 2241 & 2328 & 2414 & 2500 & 2.566 & 2672 & 2759 & 2515 \\
\hline $58^{2}$ & 3364 & 2973 & 3121 & 3270 & 3419 & 3567 & 3716 & 3564 & 4013 & 4162 & 4310 & 4453 & $460 \mathrm{~s}$ & 4756 & 4905 \\
\hline 582.8 & 25619 & 3903 & 4099 & +293 & 4159 & $46 \Omega 4$ & 1879 & $50 \div 4$ & 5269 & 5465 & 5660 & 5.55 & 60.50 & 6245 & 6440 \\
\hline $58^{3}$ & 195112 & 5125 & 5352 & 5638 & 5894 & 6150 & 6407 & 6663 & 6919 & 7175 & 7432 & 7658 & $79 \cdot 14$ & $\$ 200$ & $\$ 157$ \\
\hline 59 & 59 & 1645 & 1780 & 1864 & 1949 & 2034 & 2119 & 2203 & 2285 & 2373 & 2458 & 2.542 & 2627 & 2712 & 2797 \\
\hline $59^{2}$ & 3481 & 2873 & 3016 & 3160 & 3304 & 3447 & 3591 & 3735 & 3578 & $402: 2$ & 116.5 & 4309 & 4453 & 4506 & 4740 \\
\hline $59^{2.5}$ & 26738 & 3740 & 3927 & 4114 & 4301 & $44 \times 5$ & 4675 & $4 \div 62$ & 5049 & 5236 & 5423 & 5610 & 5797 & $5 y 5 t$ & 6171 \\
\hline $59^{3}$ & 205379 & 4569 & 5113 & 53507 & 5599 & 5843 & 60osti & 6330 & 6573 & 6517 & 7060 & 7304 & $75 \frac{1}{2} \%$ & 7791 & 8034 \\
\hline 60 & 60 & 1667 & 1750 & 1833 & 1917 & 2000 & 2083 & 2167 & 2250 & 2333 & $2+17$ & 2500 & $25 \$ 3$ & 2667 & 2750 \\
\hline $60^{2}$ & 3600 & 2778 & 2917 & 3056 & 3191 & $333: 3$ & 3472 & 3611 & 3750 & $3 \mathrm{~s} s \mathrm{~s}$ & 4028 & 4167 & 4306 & 1441 & 4583 \\
\hline $60^{2.8}$ & 27585 & $35 \$ 6$ & 3765 & 3945 & 4124 & 4303 & 4483 & 4662 & 4841 & 5021 & 5200 & $\tilde{3} 379$ & 5559 & 5738 & 5917 \\
\hline $60^{3}$ & 216000 & 4630 & 4861 & 5093 & 5324 & 5556 & $57 \$ 7$ & 6019 & 6250 & 6452 & 6.30 & $6+44$ & 7176 & 7407 & 7639 \\
\hline 61 & 61 & 1639 & 1721 & $1 \$ 03$ & 1585 & 1967 & 2049 & 2131 & 2213 & 2295 & 2377 & 2453 & 2541 & 2623 & 2705 \\
\hline $61^{2}$ & 3721 & 2687 & 2822 & 2956 & 3091 & 3225 & 3359 & 3494 & 3625 & 3762 & 3897 & 4031 & 4166 & 4300 & 4434 \\
\hline $61^{2}$ & 29062 & 3411 & 3613 & 3785 & 3957 & 4129 & 4301 & 4473 & 464.5 & $4 \$ 17$ & $49 \times 4$ & .5161 & 5333 & 5506 & 5673 \\
\hline $61^{3}$ & $2269 \$ 1$ & 4406 & 4626 & 4816 & 5067 & 5287 & 5507 & 5727 & $594 \mathrm{~s}$ & 6165 & G3s: & 6609 & 6529 & 7049 & 7269 \\
\hline 62 & 62 & 1613 & 1694 & 1774 & 1855 & 1935 & 2016 & 2097 & 2177 & 2255 & 2339 & 2419 & 2500 & 2581 & 2661 \\
\hline $62^{2}$ & 3844 & 2601 & 2732 & 2862 & 2992 & 3122 & 3252 & 3382 & 3512 & 3642 & 3772 & 3902 & 4032 & 4162 & 4292 \\
\hline 622.5 & $3026 s$ & 3304 & 3469 & 3634 & 3799 & 3965 & 4130 & $\frac{1}{2} 295$ & 4.160 & $46: 25$ & 4721 & 49.56 & 5121 & $52 \times 6$ & 5451 \\
\hline $62^{3}$ & 238828 & $419 t$ & 4406 & 4616 & 4825 & 5035 & 5245 & 5455 & 5665 & 58.4 & 6084 & 6294 & 6504 & 6713 & 6923 \\
\hline 63 & 63 & 1587 & 1667 & 1746 & 1825 & 1905 & 1984 & 2063 & 2143 & 2222 & 2302 & 2381 & 2160 & 2540 & 2619 \\
\hline $63^{2}$ & 3969 & 2520 & 2646 & 2771 & $2 \$ 97$ & 3023 & 3140 & 3275 & 3401 & 3527 & 3653 & 3759 & 3905 & 4031 & 4157 \\
\hline $63^{2.5}$ & 31503 & 3174 & 3533 & 3492 & 3651 & 3500 & 396.5 & 4123 & 4285 & 4444 & 4603 & 4762 & 4920 & 5079 & 5238 \\
\hline $63^{3}$ & 250047 & 3994 & 4199 & 4399 & 4509 & 4799 & 4999 & 5199 & 5399 & .5599 & 5759 & 5999 & 6199 & 6399 & 6599 \\
\hline 61 & 64 & 1563 & 1641 & 1719 & 1797 & 1875 & 1953 & 2031 & 2109 & 2158 & 2266 & $23+4$ & 2122 & 2500 & 2578 \\
\hline $64^{2}$ & 4096 & $2 \pm 11$ & 2563 & 2686 & $2 S O S$ & 2930 & 3052 & 3174 & 3296 & $311 \mathrm{~s}$ & 3540 & 3602 & 3784 & 3906 & 4028 \\
\hline $64^{2.8}$ & $3276 \mathrm{~s}$ & 3052 & 3204 & 3357 & 3510 & 3662 & 3815 & 3907 & 4120 & 4273 & 4425 & 4578 & 4730 & 4853 & 5035 \\
\hline $64^{3}$ & 262144 & $3 \$ 15$ & 4005 & +196 & 4387 & 4578 & 4768 & 4959 & 5150 & $5: 3+1$ & 5531 & 5722 & 5913 & 6104 & $b \cdot 234$ \\
\hline 65 & 65 & 1538 & 1615 & 1692 & 1769 & 1846 & 1923 & 2000 & 2077 & 2154 & 2231 & 2305 & 2365 & 2462 & 2538 \\
\hline $65^{2}$ & 4225 & 2367 & 2455 & 2604 & 2722 & 2840 & 2959 & 3077 & 3195 & 3314 & 3432 & 3550 & 3669 & 3787 & 3905 \\
\hline $65^{2.6}$ & 34063 & 2936 & $30 \$ 3$ & 3229 & 3376 & 3523 & 3670 & 3817 & 3963 & 4110 & $425 \%$ & 4404 & 45.50 & 4697 & 4841 \\
\hline $65^{3}$ & 274625 & 3641 & 3823 & 4005 & 41 SS & 4370 & 4552 & 4734 & 4916 & $50 ! 98$ & $52 \diamond 0$ & 5462 & 5644 & $5 \times 26$ & 6008 \\
\hline 66 & 66 & 1515 & 1591 & 1667 & $17+2$ & 1818 & 1594 & 1970 & 2045 & 2121 & 2197 & 2273 & 2345 & 2424 & 2500 \\
\hline $66^{2}$ & 4356 & $22 \div 6$ & 2410 & 2525 & 2640 & 2755 & 2570 & 2984 & 3099 & 3214 & 3320 & 3443 & 3555 & 3673 & 3788 \\
\hline $66^{2}, 5$ & 35388 & $2 \times 26$ & 2967 & 3108 & 3250 & 3391 & 3532 & 3674 & 3815 & 3956 & 4097 & 4239 & $4: 5>0$ & 4521 & 4663 \\
\hline $66^{3}$ & 287496 & 3475 & 3652 & 5326 & 4000 & 1174 & $434 \mathrm{~s}$ & 4522 & 4696 & 1870 & 5044 & $521 \mathrm{~S}$ & $5: 341$ & 5565 & $5 \longdiv { 7 3 9 }$ \\
\hline 67 & 67 & 1493 & 1567 & $16+2$ & 1716 & 1791 & 1806 & 1940 & 2015 & 2090 & 2164 & 2239 & 2.313 & 2388 & 2463 \\
\hline $67^{2}$ & 4459 & 2228 & 2339 & 2450 & 2562 & 2673 & 2785 & 2896 & 3007 & 3119 & 3230 & 3342 & 34.53 & 3564 & 3676 \\
\hline $67^{2} .5$ & 36744 & 2722 & 2858 & 2994 & 3130 & 3266 & 3.102 & 3535 & 3674 & 3510 & 3916 & 4052 & 4215 & 4355 & 1491 \\
\hline $8 \pi^{3}$ & 300763 & 3325 & 3491 & 3657 & 3824 & 3950 & 4156 & 4322 & 4459 & 4655 & $4 \backslash 21$ & $4 ! 157$ & 5154 & $5: 320$ & 5486 \\
\hline 68 & is & 1471 & 1514 & 1618 & 1691 & 1765 & $183 \mathrm{~S}$ & 1912 & 1985 & 2059 & 2132 & 2206 & 2279 & 2353 & 2426 \\
\hline $68 ?$ & 4624 & 2163 & 2271 & 2379 & 2487 & 2595 & 2703 & 2811 & 2920 & 3025 & $313 n^{7}$ & 3241 & 3352 & 3460 & 3568 \\
\hline $68^{2} .5$ & 38130 & 2623 & 2754 & 2855 & 3016 & 3117 & 3278 & 3409 & 3511 & 3672 & $3 \times 03$ & 3434 & 41165 & \pm 156 & 4327 \\
\hline $6 S^{3}$ & 314432 & 3150 & 3339 & 3498 & 3657 & $3 S 16$ & 3975 & 4134 & 4294 & 4453 & $41 ; 12$ & 47.7 & $4: 40$ & 5049 & 5248 \\
\hline 69 & 69 & 1449 & 1522 & 15.94 & 1667 & 1739 & 1812 & $18 S 4$ & 1957 & 2029 & 2101 & 217.1 & $2 \cdot 246$ & 2319 & 2391 \\
\hline $69^{2}$ & 4761 & 2100 & 2205 & 2310 & 2415 & 2520 & 2625 & 2731 & 2536 & $29+1$ & 30.46 & 3151 & 3256 & 3361 & 3466 \\
\hline 892,6 & 39095 & 2558 & 2086 & $2 \$ 14$ & 28.12 & 3069 & 3197 & 3325 & 3454 & 3581 & 3709 & 3837 & $3 !) 65$ & 40993 & 4221 \\
\hline $69^{3}$ & 325509 & 3044 & 3196 & 3349 & 3501 & 3653 & 3805 & 3357 & 4110 & 4262 & 1414 & 4.766 & 4 tis & $45-1$ & 5023 \\
\hline 70 & 70 & 1429 & 1500 & 1571 & 1643 & 1714 & 1786 & 1557 & 1929 & 2000 & 2071 & 2143 & 2214 & 2256 & 2357 \\
\hline $70^{2}$ & 4900 & 2041 & 2143 & 2245 & 2347 & 2449 & 2551 & 2653 & 2755 & 2857 & 2959 & 3061 & 3163 & 3265 & 3367 \\
\hline $70^{2.6}$ & 40996 & 2439 & 2561 & 2683 & 2805 & 2927 & 3049 & 3171 & 3293 & $3+15$ & 3537 & 3659 & 3781 & 3903 & 4025 \\
\hline $70^{8}$ & 343000 & 2916 & 3061 & 3207 & 3353 & $3+99$ & 3644 & 3790 & 3936 & 40.82 & 4227 & 4373 & 4519 & 4665 & 4811 \\
\hline 71 & 71 & 1408 & 1479 & 1549 & 1620 & 1690 & 1761 & 1831 & 1901 & 1972 & 2042 & 2113 & $21 ; 3$ & 2254 & 2324 \\
\hline $71^{2}$ & 5041 & 1984 & 2083 & 2182 & 2281 & 2380 & 2480 & 2579 & 2675 & 2777 & $2>76$ & 2976 & 3075 & 3174 & 3273 \\
\hline 712.6 & 42476 & 2354 & 2472 & 2590 & 2707 & $2 \times 25$ & 2943 & 3061 & $317 \mathrm{~s}$ & 3296 & $3 \pm 14$ & 3531 & 3649 & 3767 & 3885 \\
\hline $71^{3}$ & 357911 & 2794 & 2934 & 3074 & 3213 & 3353 & 3493 & 3632 & $3 \pi 90$ & 3936 & -1051 & 4191 & 4331 & 1470 & 4610 \\
\hline
\end{tabular}


APPENDIX.

TABLE XVII.-Equivalent values of index of build by four different systems of ratios between weight and stature

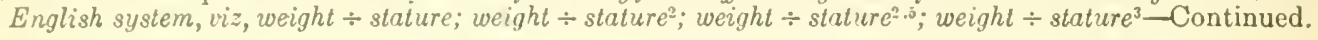

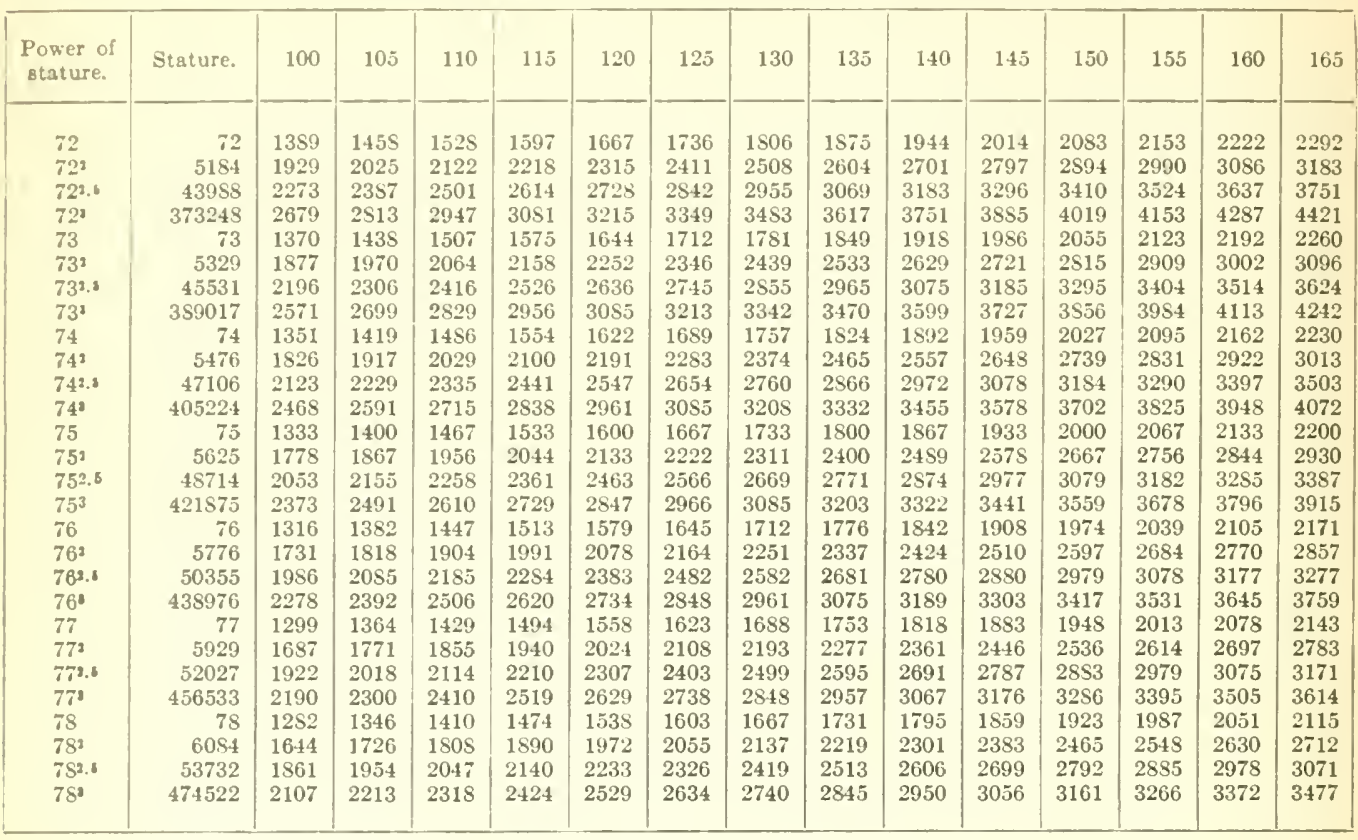


TABLE XVII.-Equivalent values of index of build by four different systerns of ratios between weight and stature, English system, viz, weight $\div$ stature; weight $\div$ stature $^{2}$; weight $\div$ stature ${ }^{2.5} ;$ weight $\div$ stature s. Continued. $^{3}$.

\begin{tabular}{|c|c|c|c|c|c|c|c|c|c|c|c|c|c|c|c|}
\hline $\begin{array}{c}\text { Power of } \\
\text { stature. }\end{array}$ & Stature. & 170 & 175 & 180 & 185 & 190 & 195 & 200 & 205 & 210 & 215 & 220 & 225 & $1 \mathrm{lb}$. & 5 lbs. \\
\hline 55 & 55 & 3091 & 3182 & 3273 & 3364 & 3455 & 3545 & 3636 & 3727 & 3818 & 3909 & 4000 & 4091 & 18.18 & 90.91 \\
\hline $55^{2}$ & 3025 & 5620 & 5785 & 5950 & 6116 & 6281 & 6446 & 6612 & 6777 & 6942 & 7107 & 7273 & 7438 & 33.055 & 165.27 \\
\hline $55^{2.8}$ & 22434 & 7578 & 7801 & 8024 & $\$ 246$ & 8469 & 8692 & 8915 & 9138 & 9361 & 9587 & 9807 & 10029 & 44.575 & 222.88 \\
\hline $55^{8}$ & 166375 & 10218 & 10518 & 10819 & 11195 & 11420 & 11720 & 12021 & 12322 & 12622 & 12923 & 13223 & 13524 & 60.105 & 300.53 \\
\hline 56 & 56 & 3036 & 3125 & 3214 & 3304 & 3393 & 3482 & 3571 & 3661 & 3750 & 3839 & 3929 & 4018 & 17.857 & 89.29 \\
\hline $56^{2}$ & 3136 & 5421 & 5580 & 5740 & 5899 & 6059 & 6218 & 6378 & 6537 & 6696 & 6856 & 7015 & 7175 & 31.888 & 165.27 \\
\hline $56^{2.3}$ & 23468 & 7214 & 7457 & 7670 & 7883 & 8096 & 8309 & 8522 & 8735 & $\$ 947$ & 9161 & 9375 & 9588 & 42.612 & 213.06 \\
\hline $56^{2}$ & 175616 & 9680 & 9965 & 10250 & 10534 & 10819 & 11104 & 11389 & 11673 & 11958 & 12243 & 12527 & 12812 & 56.942 & 284.71 \\
\hline 57 & 57 & 2982 & 3070 & 3158 & 3246 & 3333 & 3421 & 3509 & 3596 & 3684 & 3772 & 3860 & 3947 & 17.544 & 87.72 \\
\hline $57^{2}$ & 3249 & 5232 & 5386 & 5540 & 5694 & 5848 & 6002 & 6155 & 6310 & 6464 & 6617 & 6771 & 6925 & 30.779 & 153.89 \\
\hline 572.6 & 24529 & 6931 & 7134 & 7338 & 7542 & 7746 & 7950 & 8154 & 8357 & 8561 & 8765 & 8969 & 9173 & 40.768 & 203.84 \\
\hline $57^{2}$ & 185193 & 9180 & 9450 & 9720 & 9990 & 10260 & 10530 & 10800 & 11070 & 11340 & 11610 & 11880 & 12150 & 53.998 & 269.99 \\
\hline 58 & 58 & 2931 & 3017 & 3103 & 3190 & 3276 & 3362 & 3448 & 3534 & 3621 & 3707 & 3793 & 3879 & 17.241 & 86.21 \\
\hline $58^{2}$ & 3364 & 5054 & 5202 & 5351 & 5499 & 5648 & 5797 & 5945 & 6014 & 6243 & 6391 & 6543 & 6688 & 29.737 & 148.64 \\
\hline $58^{2,3}$ & 25619 & 6636 & 6831 & 7026 & 7221 & 7416 & 7611 & 7807 & 8002 & 8197 & 8392 & 8587 & 8782 & 39.033 & 195.16 \\
\hline $58^{3}$ & 195112 & 8713 & 8969 & 9226 & 9482 & 9738 & 9994 & 10251 & 10507 & 10763 & 11019 & 11276 & 11532 & 51.253 & 256.26 \\
\hline 59 & 59 & 2881 & 2966 & 3051 & 3136 & 3220 & 3305 & 3390 & 3475 & 3559 & 3644 & 3729 & 3814 & 16.949 & 84.75 \\
\hline $59^{2}$ & 3481 & 4884 & 5027 & 5171 & 5315 & 5458 & 5602 & 5745 & 5589 & 6033 & 6176 & 6320 & 6464 & 28.727 & 143.64 \\
\hline $59^{2.5}$ & 26738 & 6358 & 6545 & 6732 & 6919 & 7106 & 7293 & 7480 & 7667 & 7854 & 8041 & 8228 & 8415 & 37.400 & 187.00 \\
\hline $59^{3}$ & 205379 & 8277 & 8521 & 8764 & 9008 & 9251 & 9495 & 9738 & 9982 & 10225 & 10469 & 10712 & 10955 & 48.691 & 243.45 \\
\hline 60 & 60 & 2833 & 2917 & 3000 & 3083 & 3167 & 3250 & 3333 & 3417 & 3500 & 3583 & 3667 & 3750 & 16.667 & 83.33 \\
\hline $60^{2}$ & 3600 & 4722 & 4861 & 5000 & 5139 & 5278 & 5417 & 5556 & 5694 & 5833 & 5972 & 6111 & 6250 & 27.778 & 138.89 \\
\hline $60^{2.6}$ & 27885 & 6096 & 6276 & 6455 & 6634 & 6814 & 6993 & 7172 & 7352 & 7531 & 7710 & 7890 & 8069 & 35.861 & 179.31 \\
\hline $60^{\circ}$ & 216000 & 7871 & 8102 & $\$ 333$ & 8565 & 8796 & 9028 & 9259 & 9491 & 9722 & 9954 & 10185 & 10416 & 46.296 & 231.48 \\
\hline 61 & 61 & 2787 & 2869 & 2951 & 3033 & 3115 & 3197 & 3279 & 3361 & 3443 & 3525 & 3607 & 3689 & 16.393 & 81.97 \\
\hline $61^{2}$ & 3721 & 4569 & 4703 & 4837 & 4972 & 5106 & 5241 & 5375 & 5509 & 5644 & 5778 & 5912 & 6047 & 26.874 & 134.37 \\
\hline $61^{2.5}$ & 29062 & 5850 & 6022 & 6194 & 6366 & $6 \overline{3} 38$ & 6710 & 6882 & 7054 & 7226 & $739 \mathrm{~s}$ & 7570 & 7742 & 34.409 & 172.05 \\
\hline $61^{8}$ & 226981 & 7490 & 7710 & 7930 & 8151 & 8371 & 8591 & 8811 & 9032 & 9252 & 9472 & 9692 & 9913 & 44.057 & 220.28 \\
\hline 62 & 62 & 2742 & 2823 & 2903 & 2984 & 3065 & 3145 & 3226 & 3306 & 3387 & 3468 & 3548 & 3629 & 16.129 & 80.65 \\
\hline $62^{2}$ & 3844 & 4422 & 4553 & 4683 & 4813 & 4943 & 5073 & 5203 & 5333 & 5463 & 5593 & 5723 & $5 \$ 53$ & 26.015 & 130.08 \\
\hline $62^{2.5}$ & 30268 & 5617 & 5782 & 5947 & 6112 & 6277 & 64.13 & 6608 & 6773 & 6938 & 7103 & 7269 & 7434 & 33.039 & 165.19 \\
\hline $62^{3}$ & 238828 & 7133 & 7343 & 7553 & 7762 & 7972 & 8182 & 8392 & 8602 & 8811 & 9021 & 9231 & 9441 & 41.959 & 209.80 \\
\hline 63 & 63 & 2698 & 2778 & 2857 & 2937 & 3016 & 3095 & 3175 & 3254 & 3333 & 3413 & 3492 & 3571 & 15.873 & 79.37 \\
\hline $63^{2}$ & 3969 & 4283 & 4409 & 4535 & 4661 & 4787 & 4913 & 5039 & 5165 & 5291 & 5417 & 5543 & 5669 & 25.195 & 125.98 \\
\hline $63^{2.5}$ & 31503 & 5396 & 5555 & 5714 & $5 S 73$ & 6031 & 6190 & 6349 & 6507 & 6666 & 6825 & 6984 & 7142 & 31.743 & 158.72 \\
\hline $63^{3}$ & 250047 & 6799 & 6999 & 7199 & 7399 & 7599 & 7799 & 7999 & 8199 & 8399 & 8598 & 8798 & 8998 & 39.993 & 199.96 \\
\hline 64 & 64 & 2656 & 2734 & 2813 & 2891 & 2969 & 3047 & 3125 & 3203 & $32 \$ 1$ & 3359 & 3438 & 3516 & 15.625 & 78.13 \\
\hline $64^{2}$ & 4096 & 4150 & 4272 & 4395 & 4517 & 4639 & 4761 & 4883 & 5005 & 5127 & 5249 & 5371 & 5493 & 24.414 & 122.07 \\
\hline $64^{2.5}$ & 32768 & 5188 & 5341 & 5493 & 5646 & 5798 & 5951 & 6104 & 6256 & 6409 & 6561 & 6714 & 6867 & $30.51 \mathrm{~s}$ & 152.59 \\
\hline $64^{2}$ & 262144 & 6485 & 6676 & 6867 & 7057 & 7248 & 7439 & 7629 & 7820 & 8011 & 8202 & 8392 & 8583 & 38.147 & 190.74 \\
\hline 65 & 65 & 2615 & 2692 & 2769 & 2846 & 2923 & 3000 & 3077 & 3154 & 3231 & $330 \mathrm{~s}$ & 3385 & 3462 & 15.354 & ;6.92 \\
\hline $65^{2}$ & 4225 & 4024 & 4142 & 4260 & 4379 & 4497 & 4615 & 4734 & $4 S 52$ & 4970 & 5089 & 5207 & 5325 & 23.669 & 118.35 \\
\hline $65^{2.8}$ & 34063 & 4991 & 5138 & 5284 & 5431 & 5578 & 5725 & 5872 & 6018 & 6165 & 6312 & 6459 & 6605 & 29.358 & 146.79 \\
\hline $65^{8}$ & 274625 & 6190 & 6372 & 6554 & 6735 & 6919 & 7101 & 7283 & 7465 & 7647 & 7829 & 8011 & 8193 & 36.413 & 182.07 \\
\hline 66 & 66 & 2576 & 2652 & 2727 & 2803 & 2879 & 2955 & 3030 & 3106 & 3182 & 3258 & 3333 & 3409 & 15.152 & 75.76 \\
\hline $66^{2}$ & 4356 & 3903 & 4017 & 4132 & 4247 & 4362 & 4477 & 4591 & 4706 & 4821 & 4936 & 5051 & 5165 & 22.957 & 114.79 \\
\hline $66^{2.5}$ & 35388 & 4804 & 4945 & 5086 & 5228 & 5369 & 5510 & 5652 & 5793 & 5934 & 6076 & 6217 & 6358 & $2 \mathrm{~S} .258$ & 141.29 \\
\hline $66^{3}$ & 287496 & 5913 & 6087 & 6261 & 6435 & 6609 & 6783 & 6957 & 7131 & 7305 & 7478 & 7652 & 7826 & 34.783 & 173.92 \\
\hline 67 & 67 & 2537 & 2612 & 2687 & 2761 & 2836 & 2910 & 2985 & 3060 & 3134 & 3209 & 3284 & 3358 & 14.925 & 74.63 \\
\hline $67^{2}$ & $\mathbf{4 4 8 9}$ & 3787 & 3898 & 4010 & 4121 & 4233 & 4344 & 4455 & 4567 & 4678 & 4789 & 4901 & 5012 & 22.277 & 111.39 \\
\hline $67^{2.5}$ & 36744 & 4623 & 4763 & 4899 & 5035 & 5171 & 5307 & 5443 & 5579 & 5715 & 5851 & 5987 & 6123 & 27.215 & 136.08 \\
\hline $67^{8}$ & 300763 & 5652 & 5819 & 5985 & 6151 & 6317 & 6484 & 6650 & 6816 & 6982 & 7149 & 7315 & 7481 & 33.249 & 166.24 \\
\hline 68 & 68 & 2500 & 2574 & 2647 & 2721 & 2794 & 2868 & 2941 & 3015 & 3088 & 3162 & 3235 & 3309 & 14.706 & 73.53 \\
\hline $68^{2}$ & 4624 & 3676 & 3785 & 3893 & 4000 & 4109 & 4217 & 4325 & 4433 & 4542 & 4650 & 4758 & $4 \$ 66$ & 21.626 & 108.13 \\
\hline $68^{2.5}$ & 38130 & 4458 & 4590 & 4721 & 4852 & 4983 & 5114 & 5245 & 5376 & 5507 & 5639 & 5770 & 5901 & 26.226 & 131.29 \\
\hline $68^{2}$ & 314432 & 5407 & 5566 & 5725 & 5884 & 6043 & 6202 & 6361 & 6520 & 6679 & 6838 & 6997 & 7156 & 31.803 & 159.02 \\
\hline 69 & 69 & 2464 & 2536 & 2609 & 2681 & 2754 & 2826 & 2899 & 2971 & 3043 & 3116 & 3188 & 3261 & 14.493 & 72.46 \\
\hline $69^{2}$ & 4761 & 3571 & 3676 & 3781 & 3886 & 3991 & 4096 & 4201 & 4306 & 4411 & 4516 & 4621 & 4726 & 21.004 & 105.02 \\
\hline $69^{2.5}$ & 39095 & 4345 & 4476 & 4604 & 4372 & $4 S 60$ & 4988 & 5116 & 5244 & 5372 & 5499 & 5627 & 4744 & 25.787 & 127.89 \\
\hline $69^{8}$ & $32 \$ 509$ & 5175 & 5327 & 5479 & 5632 & 5784 & 5936 & 6088 & 6240 & 6393 & 6545 & 6697 & & 30.441 & 152.20 \\
\hline 70 & 70 & 2429 & 2500 & 2571 & 2643 & 2714 & 2786 & 2857 & 2929 & 3000 & 3071 & 3143 & 3214 & 14.286 & 71.43 \\
\hline $70^{2}$ & 4900 & 3469 & 3571 & 3673 & 3776 & 3578 & 3980 & 4082 & 4184 & 4286 & 4388 & 4490 & 4592 & 20.408 & 102.04 \\
\hline $70^{2 \cdot 5}$ & 40996 & 4145 & 4269 & 4391 & 4513 & 4635 & 4757 & 4879 & 5001 & 5112 & 5214 & 5366 & 5488 & 24.392 & 121.96 \\
\hline $70^{*}$ & 343000 & 4956 & 5102 & 5248 & 5394 & 5539 & 5685 & $5 \bigcirc 31$ & 5977 & 6122 & 6268 & 6414 & 6560 & 29.155 & 145.77 \\
\hline 71 & 71 & 2394 & 2465 & 2535 & 2606 & 2676 & 2746 & 2817 & 2887 & 2958 & 3028 & 3099 & 3169 & 14.085 & 70.42 \\
\hline $71^{2}$ & 5041 & 3372 & 3472 & 3571 & 3670 & 3769 & 3868 & 3967 & 4067 & 4166 & 4265 & 4364 & 4463 & 19.837 & 99.19 \\
\hline $71^{2.5}$ & 42476 & 4002 & 4120 & 4238 & 4355 & 4473 & 4591 & 4709 & 4826 & 4944 & 5062 & 5179 & 5297 & 23.543 & 117.71 \\
\hline $71^{3}$ & 357911 & 4750 & 4889 & 5029 & 5169 & 5309 & 5448 & 5588 & 5728 & 5867 & 6007 & 6147 & 6286 & 27.940 & 139.70 \\
\hline
\end{tabular}


TABLE XV11.-Equivalent values of inlex of build by four different systems of ratios between weight and stature, English system, riz, weight $\div$ stalure: weight $\div$ stature $^{2} ;$ weight $\div$ stature $^{2.5} ;$ weight $\div$ stature $^{3}$-Continued.

\begin{tabular}{|c|c|c|c|c|c|c|c|c|c|c|c|c|c|c|c|}
\hline $\begin{array}{l}\text { Power of } \\
\text { stature. }\end{array}$ & Stature. & 1.0 & 175 & ISO & 155 & 190 & $19 \overline{5}$ & 200 & 205 & 210 & 215 & 220 & 225 & $1 \mathrm{lb}$. & 5 lbs. \\
\hline 72 & 72 & 2301 & 2431 & 2500 & 2569 & 2639 & 2708 & 2778 & 2547 & 2917 & 2986 & 3056 & 3125 & 13. 559 & 69.44 \\
\hline $72:$ & 518.1 & 3279 & 3376 & 3472 & 3569 & 3665 & 3762 & $355 s$ & 39.54 & 4051 & 4147 & 42.44 & 4310 & 19.290 & 96.46 \\
\hline 722.6 & 43050 & 3565 & $397 \mathrm{~s}$ & 4092 & 1206 & 4319 & 4.133 & 45.17 & 4560 & 4774 & 4889 & 5001 & 5115 & 22.734 & 113.67 \\
\hline $72^{3}$ & 373245 & 4555 & $16 \$ 9$ & 4523 & 1957 & 5091 & .5224 & $53 \pi 5$ & 5492 & 5626 & 5760 & $5 S 94$ & 6028 & 26.792 & 133.96 \\
\hline 73 & 73 & 2329 & 2397 & 2466 & 2534 & 2603 & 2671 & 2740 & $250 s$ & 2877 & 2945 & 3014 & 3052 & 13.698 & 68.49 \\
\hline $73:$ & $53: 29$ & 3190 & $3: 284$ & 3378 & 3472 & 3565 & 3659 & .753 & 3847 & $39 \cdot 41$ & .1935 & 4128 & 4222 & 18.765 & 93.83 \\
\hline $73^{2.6}$ & 45531 & 3731 & $35.1-1$ & 3953 & 4063 & 4174 & 4253 & 4393 & 4.502 & 4612 & 4722 & 1532 & 4942 & 21.963 & 109.82 \\
\hline $73^{3}$ & 359017 & 4370 & 4199 & 4627 & 4756 & 4384 & $51) 13$ & 5141 & 5270 & 5398 & 5527 & 5655 & 5784 & 25.706 & 128.53 \\
\hline $7 \pm$ & $7 \cdot 1$ & 2297 & 2365 & 2432 & 2500 & 2565 & 2635 & 270.3 & 2770 & $2 S 3 S$ & 2905 & 2973 & 3011 & 13.514 & 67.57 \\
\hline $7 t^{2}$ & 5476 & 3104 & 3196 & 3287 & 3378 & 3470 & 3561 & 35.52 & 3714 & $3 \$ 35$ & 3326 & 4018 & 4109 & 18.262 & 91.31 \\
\hline $74^{3.6}$ & 47106 & 3609 & 3715 & $3 \$ 21$ & 3927 & 4033 & 11.40 & 1246 & 4352 & 44iss & 4564 & 4670 & 4776 & 21.229 & 106.14 \\
\hline $74^{3}$ & 405224 & 4195 & 4319 & 4.1 .12 & 4565 & 4659 & 4812 & 4936 & 5059 & 5182 & 5306 & 5129 & 55533 & 21.678 & 123.39 \\
\hline 75 & 75 & 2267 & 2333 & 2400 & $246 \vec{\imath}$ & 2533 & 2600 & 2607 & 2733 & 2800 & $2 \times 67$ & 2933 & 3000 & 13.333 & 66.67 \\
\hline $75=$ & $5 \leftarrow 25$ & 3022 & 3111 & 3200 & 3259 & $337 \mathrm{~s}$ & $346 \pi$ & 3556 & $36 \cdot 14$ & $3 \pi 33$ & $3 \times 22$ & 3911 & 4000 & 17.778 & 88.89 \\
\hline $75^{2.6}$ & 45.14 & 3490 & 3592 & 3695 & $3 \pi 98$ & 3900 & 4003 & 4106 & 4208 & 4311 & 4414 & 4516 & 4619 & $20.52 \mathrm{~S}$ & 102.64 \\
\hline $75^{1}$ & $4: 1975$ & 4034 & 4152 & 4271 & .4390 & $150 \mathrm{~S}$ & 4627 & 4746 & 4564 & $49 S 3$ & 5101 & 5220 & 5339 & 23.727 & 118.64 \\
\hline 76 & 76 & 2237 & 2303 & 2368 & 2431 & 2500 & 2566 & 2632 & 2697 & 2763 & 2829 & 2895 & 2961 & 13.158 & 65.79 \\
\hline $76:$ & 5776 & 2943 & 3030 & 3116 & 3203 & $32 \$ 9$ & 3376 & 3463 & 3549 & 3636 & 3722 & 3509 & 3895 & 17.313 & 86.57 \\
\hline $76^{3.1}$ & 50355 & 3376 & 3475 & 3575 & 3674 & 3773 & 3873 & 3972 & 4071 & 4170 & 4270 & 4369 & $446 \mathrm{~S}$ & 19.860 & 99.29 \\
\hline $76^{3}$ & 438976 & 3873 & 3987 & 4101 & 4214 & $432 \mathrm{~S}$ & $44 \cdot 12$ & $45 \overline{6} 6$ & 4670 & 4784 & 4898 & 5012 & 5126 & 22.780 & 113.90 \\
\hline 77 & 77 & $220 S$ & 2273 & $233 \mathrm{~S}$ & 2.103 & $216 \mathrm{~S}$ & 2532 & 2597 & 2662 & $2 \rightarrow 27$ & 2792 & $2 \$ 57$ & 2922 & 12.987 & 64.94 \\
\hline $77^{2}$ & 5929 & 2867 & 2952 & 3036 & 3120 & 3205 & 3289 & 3373 & 3458 & 3542 & 3626 & 3711 & 3795 & 16.866 & 81.33 \\
\hline $77^{2} .6$ & 52027 & 3265 & 3364 & 3460 & 3556 & 3652 & 3748 & 3841 & 3940 & 4036 & 4133 & 4229 & 4325 & 19.221 & 96.10 \\
\hline 773 & 156533 & 3724 & 3533 & 3943 & 4052 & 4162 & 4271 & 4381 & 4490 & 1600 & 1709 & 4819 & 4929 & 21.904 & 109.52 \\
\hline is & is & 2179 & 2244 & $230 \mathrm{~s}$ & 2372 & 2436 & 2500 & 2564 & 2628 & 2692 & 2756 & 2821 & 2885 & 12.821 & 64.10 \\
\hline $75:$ & 6084 & 2794 & 2576 & 2959 & 3041 & 3123 & 3205 & 3287 & 3369 & 3452 & 353.1 & 3716 & 3698 & 16.437 & 82.19 \\
\hline $78^{2.5}$ & 53732 & 3164 & 3257 & 3350 & 3443 & 35.36 & 3629 & 3722 & 3815 & 3908 & 4001 & 409.1 & 4187 & 18.611 & 93.05 \\
\hline $78^{3}$ & 474522 & $35 \$ 3$ & 3688 & 3793 & 3599 & 4004 & 4109 & 4215 & 4320 & 4126 & 4531 & 4636 & 4712 & 21.074 & 10537 \\
\hline
\end{tabular}

TABLE XVIII. - To transinute the English system of index of build to the metric system (10 units English = 0.7 unit metric).

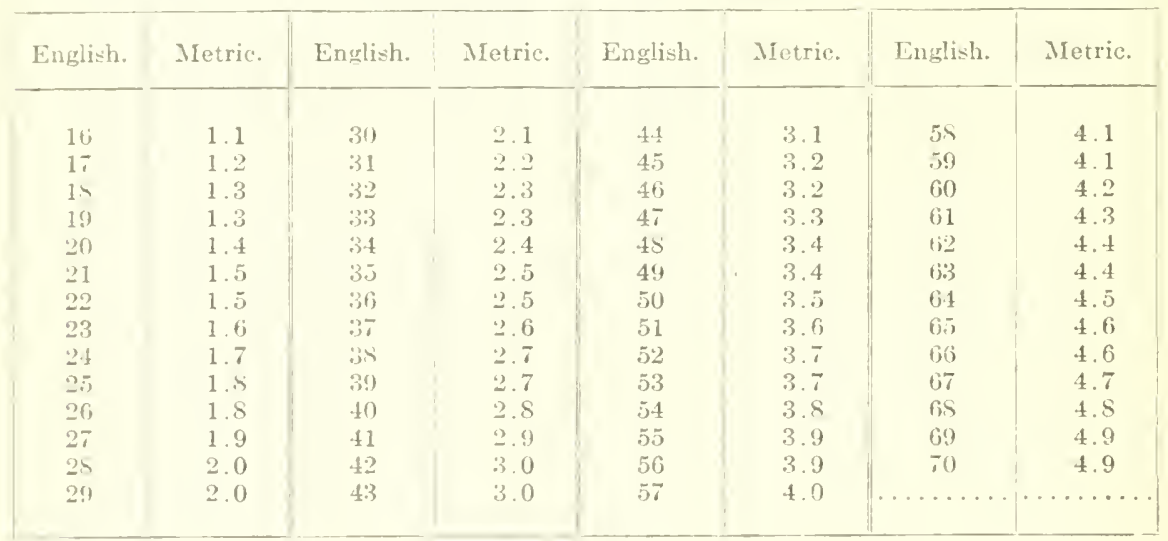




\section{LITERATURE CITED.}

Arusby, II. P., and J. A. Fries. 1911. The influence of type and of age upon the utilization of feed by cattle. U. S. Dept. Agriculture, Bureau of Animal Industry, Bulletin 12S, 245 pp., Oct.

BALDwin, B. T. 1921. The physical growth of children from birth to maturity. Lniv. Iowa Studies in Child Welfare, I (No. 1), 411 pp., June.

- BardeEn, C. R. 1920. The height-weight index of build in relation to linear and volumetric proportions, etc. Carnegie Inst. Wash. Pub. No. 272.

Barker, L. F. 1922. Endocrinology and Metabolism. 5 vols.

BECK, H. G. 1922. "Dystrophia adiposo-genitalis" in Barker's Endrocrinology and Metabolism, Vol. I, pp. 860-924.

BarRetT, A. M. 1919. Hereditary occurrence of hypothyroidism with dystrophies of the nails and hair. Arch. Neurology and Psychiatry, II, pp. 62S-637.

Benedict, F. G., and F. B. Talbot. 1915. The physiology of the new-born infant. Carnegie Inst. Wash. Pub. No. 233, 126 pp.

and F. B. TalBot. 1920. Metabolism and growth from birth to puberty. Carnegie Inst. Wash. Pub. No. 302, 213 pp.

Castle, W. E. 1922. Genetic studies of rabbits and rats. Carnegie Inst. Wash. Pub. No. 320,55 pp., 2 pls.

Chambers, Thomas King. 1850. Corpulence, or excess of fat in the human body. Also published in Lancet, I, 1850, pp. 523, 557, 581, 651, 687, 747 (page 652, table showing some inherited cases).

Crum, F. S. 1915. Anthropometric table: Male and female children from 6 to 48 months old. Newark: Prudential Ins. Co., 2 pp.

Cushing, Harver. 1912. The pituitary body and its disorders. Philadelphia, 348 pp.

Daffner, F. 1902. Das Wachstum des Mensehen: Anthropologische Studien. Leipzig: Englemann, $475 \mathrm{pp}$.

Davenport, C. B. 1915. The feebly inhibited: Inheritance of temperament. Carnegie Inst. Wash. Pub. No. 236.

1917. Inheritance of stature. Genetics, II, pp. 313-389, July. (Eugenics Record Office Bull. No. 18.)

—, and A. G. Love. 1921. Army anthropology. Medical Dept. U. S. Army in World War, Vol. XV. Statisties, Part I, Gov't Printing Office, 635 pp.

Godin, P. 1903. Recherches anthropométric sur la croissance des diverses parties du corps. Paris: Maloine, $212 \mathrm{pp}$.

Grover, J. I. 1915. Some measurements of normal children, especially of the arm and leg. Arch. Pediat., XXXII, pp. 473-486.

Gulick, A. 1922. A study of weight regulation in adult human body during overnutrition. Amer. Journal of Physiology, LX, 371-395.

Hecked, F. 1920. Grandes et petites obésités: cure radicale. Masson. $537 \mathrm{pp}$.

Hitchсоск, E., H. H. Seeley, and P. C. Phillips. 1900. The anthropometric manual of Amherst College. Amherst, $40 \mathrm{pp}$.

Hoffman, F. L. 1918. Army anthropometry and medical rejection statistics. Newark (N. J.): Prudential Press, 114 pp.

Howard, -190 s. Abnormal development in a girl. Report for Soc. Diseases of Children, VIII, pp. 54-56.

JANNEY, N. W. 1922. Hypothyroidism, in Barker's Endocrinology and Metabolism. I, pp. 379-440.

Johnson, HARry. 1906. Liberia. 2 vols. London.

Lron, I. P. 1910. Adiposis and lipomatosis. Arch. of Inter. Med. 6, 28-120.

Maranon, G., and E. Bonilla. 1920. Histoire clinique et autopsie d'un cas d'obésité mortelle. Rev. neurolog. 27, pp. 909-914.

Martin, R. 1914. Lehrbuch der Anthropologie. xvi $+1181 \mathrm{pp}$.

Medico-actuarial Mortality Investigations. Vol. I. Compiled and published by the Associaticn of Life Insurance Medical Doctors and the Actuarial Society of America. New York. 1912, 131 pp. (Build of men, p. 38. Build of women, p. 67.) 
MeEII, K. 1895. Volunmessungen des mensehlichen Körpers und siener einzelnen Theile in den verschichenen Alterstufen. Ztsch. f. Biol. 31, pj. 125-147.

Mies, J. 18s9. Utber die Masse, den Rauminhalt und die Dichte des Menschen. Virchow's .Irch. f. pith. Anat. u. Physiol., 157, $90 \mathrm{pp}$.

Niceforo, 1. 1910. Anthropologie der nichtbesitzenden Kilassen. Leipzig: Maas u. Van Suchtelen, 512 pp.

Noordex, Carl von. 1907. "Obesity" in Noorden's Metabolism and Practieal Medieine, edited by W. Hall. Vol. III, pp. 693-715. London: Heincmann.

Price, G. E. 1909. Adiposis dolorosa. Amer. Jour. Med. Sci., 137, pp). 705-715.

QUETElet, A. 1Sī0. Anthroponétrie on mesure des différentes facultés de l'homme. Brixelles.

Reitz, E. 1904. Das Waehstum der Berliner Schulkinder während den Schuljahre. Arch. f. Anthropol., No. 5.I. pp. 30-42.

Rose, F. 1907. Obésité familiale. LiEncephale, II, pp. 299-303, 1 pl.

Commd-Moxxard, R. 1892. Utber den Einfluss des Millitairdlienstes der Väter auf die körpertiche Entwicklung ihrer Nachkommenschaft. Jahrb. Kinderheilkunde XXXIII, pp. $327-350$.

Sixclair, James. 1907. History of Shorthorn Cattle. London: Vinton, S95 pp.

Stratz, C. H. 1922. Der Körper cles Kindes und seine Pflege. Stuttgart: Enke., 366 pp.

Towx, Clara HI. 1922. Analytie study of a group of five- and six-year-nld children. Univ. Iowa Studies: Studies in Child Welfare, I (No. 4), S7 pp.

UhlexntTir, E. 1922. Hormone factors in growth and development, in Barker's Endrocrinology and Metabolism I, pp. 1S1-203.

Weissenberg, S. 1911. Das Wachstum des Menschen. Stuttgart: Strecher u. Schröder, $220 \mathrm{pp}$.

Wortinngton, L. S. 157j. De l'obésité, étiologie, thérapentique, et hregiène. Paris: Martinet, $1 \mathrm{ss} \mathrm{pp}$. 
$17^{8}$ 



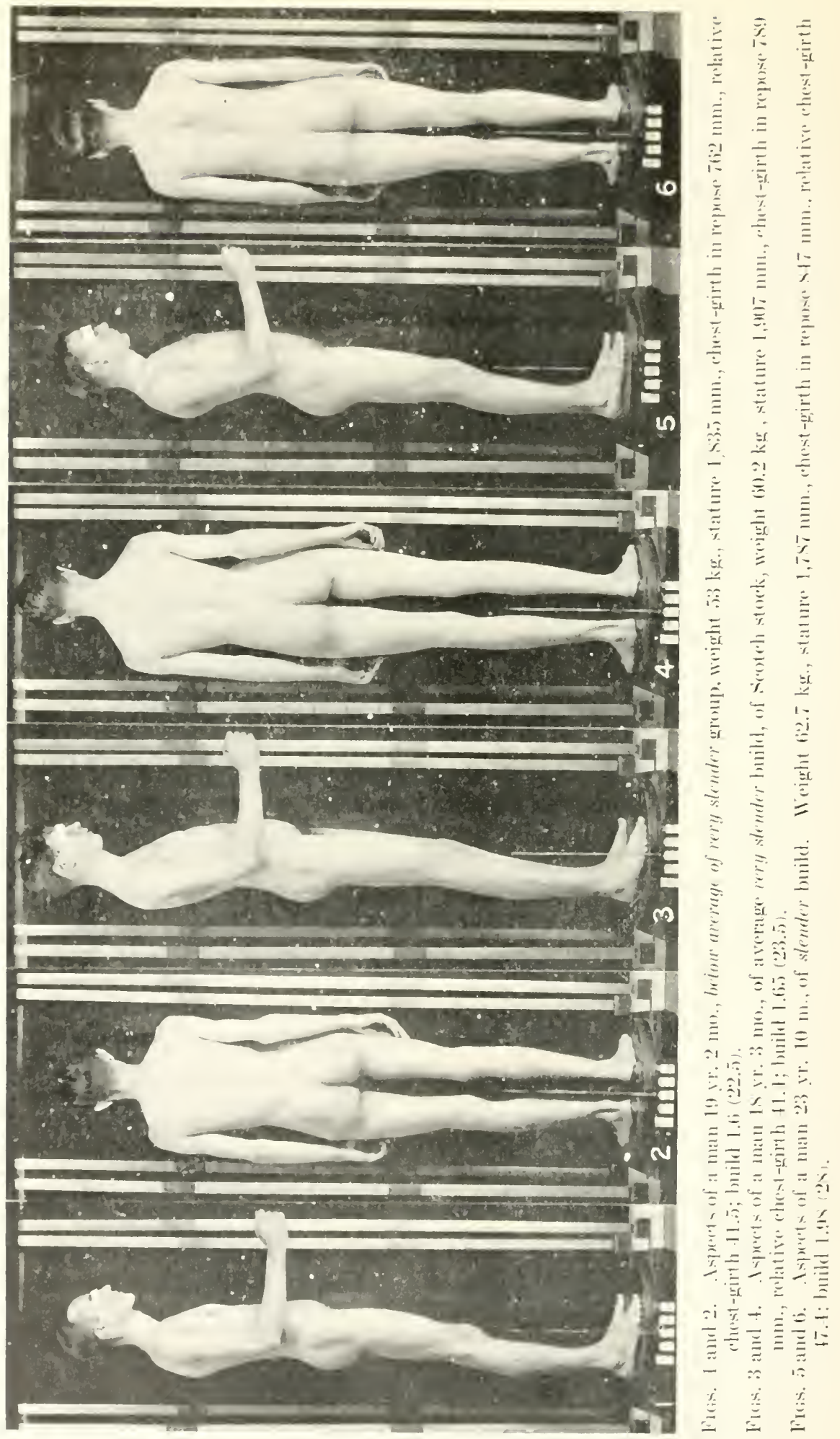




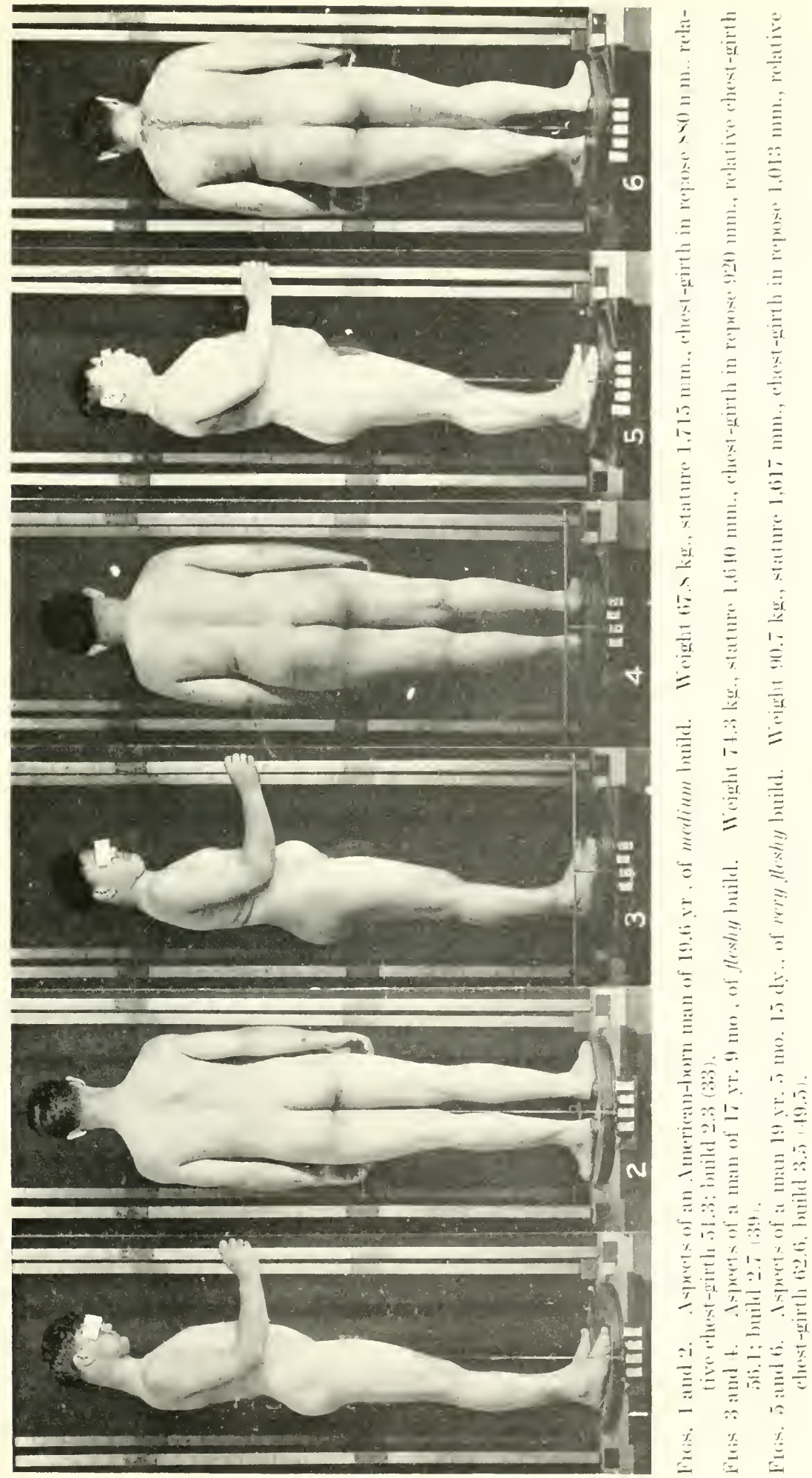




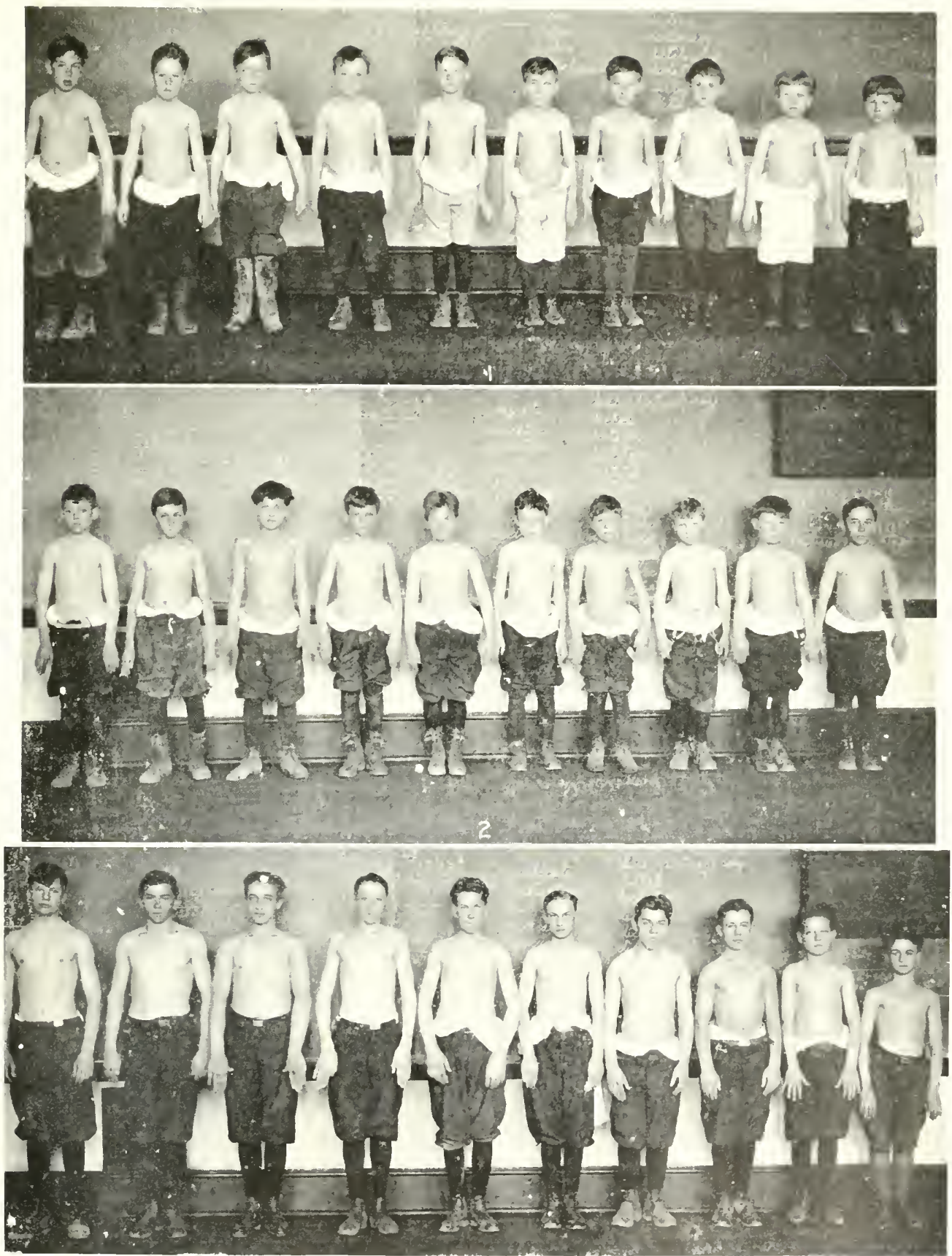

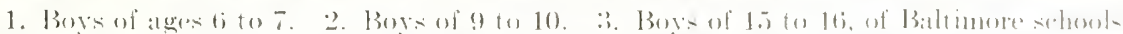

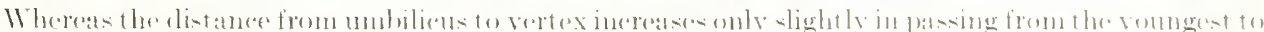

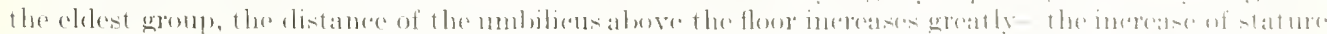

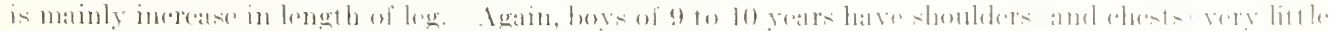

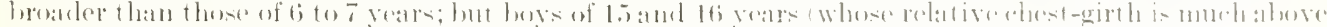

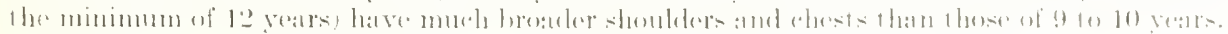





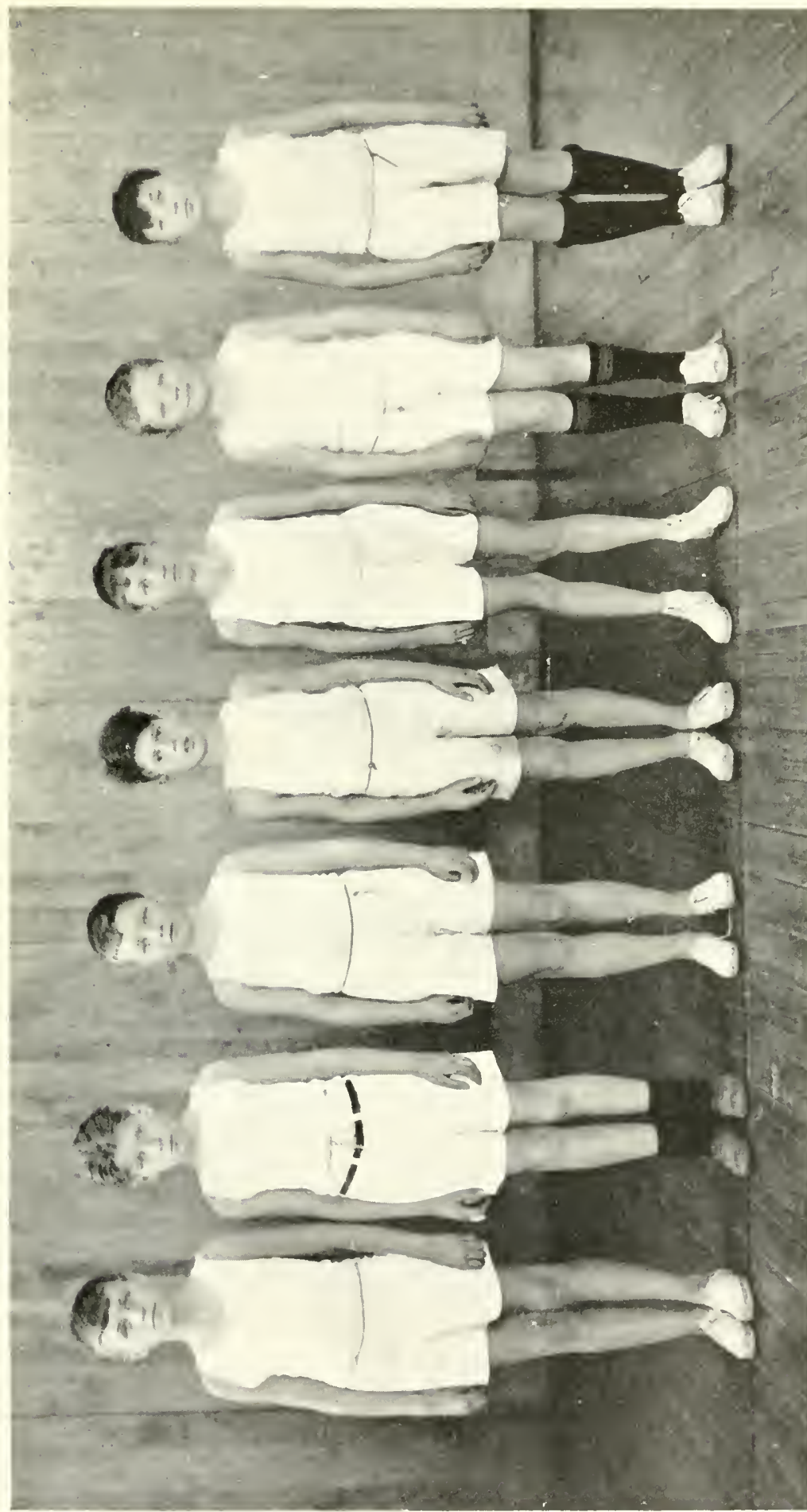

$\Xi \doteqdot$

$=0$

$\stackrel{\bar{*}}{*}+1$

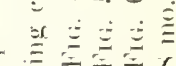

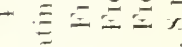

恶

$\equiv$.

$\therefore \div$ 1

六亥亥三

$\therefore \equiv=$

萟

立 $=\leqq$

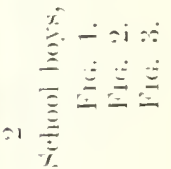





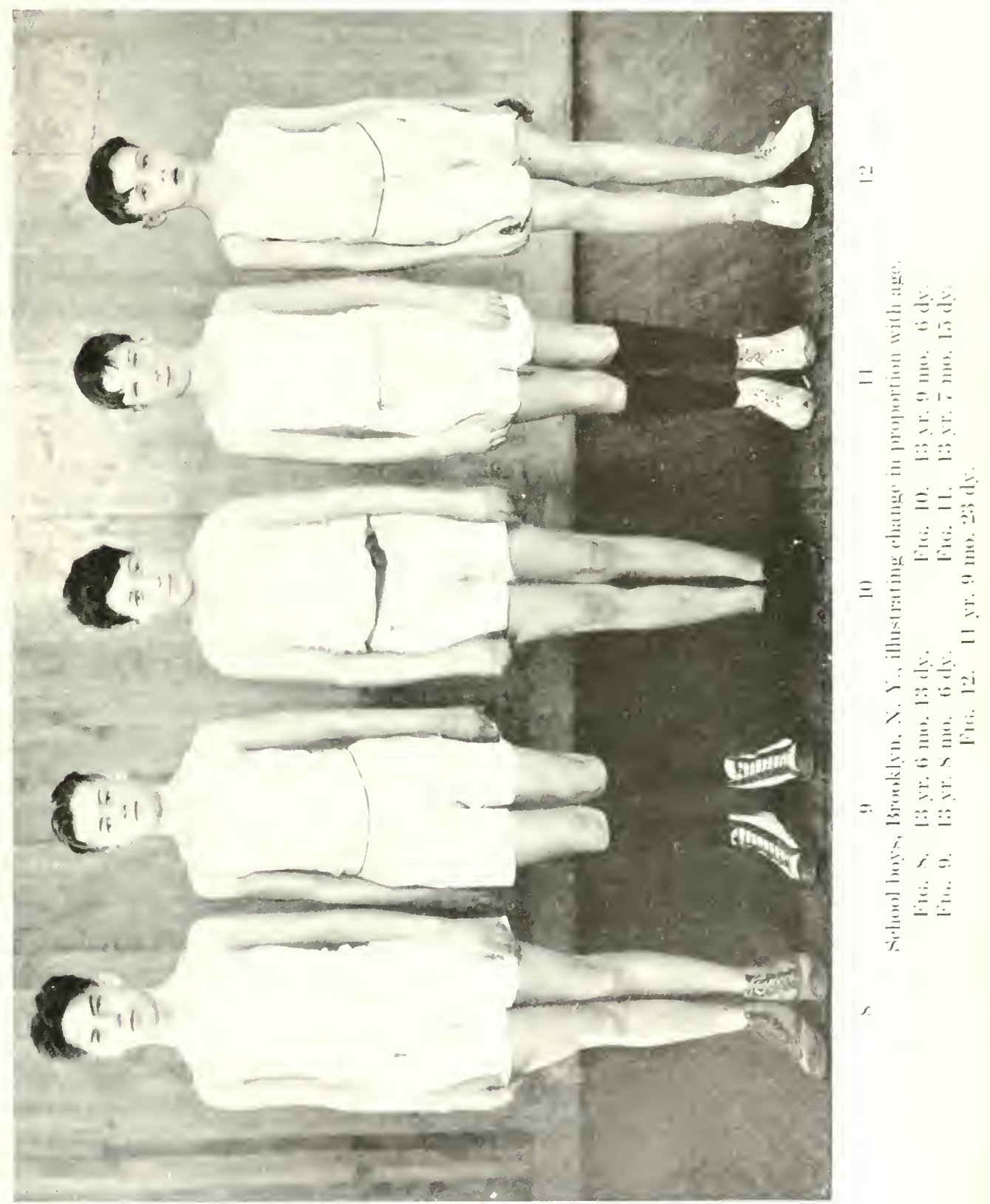





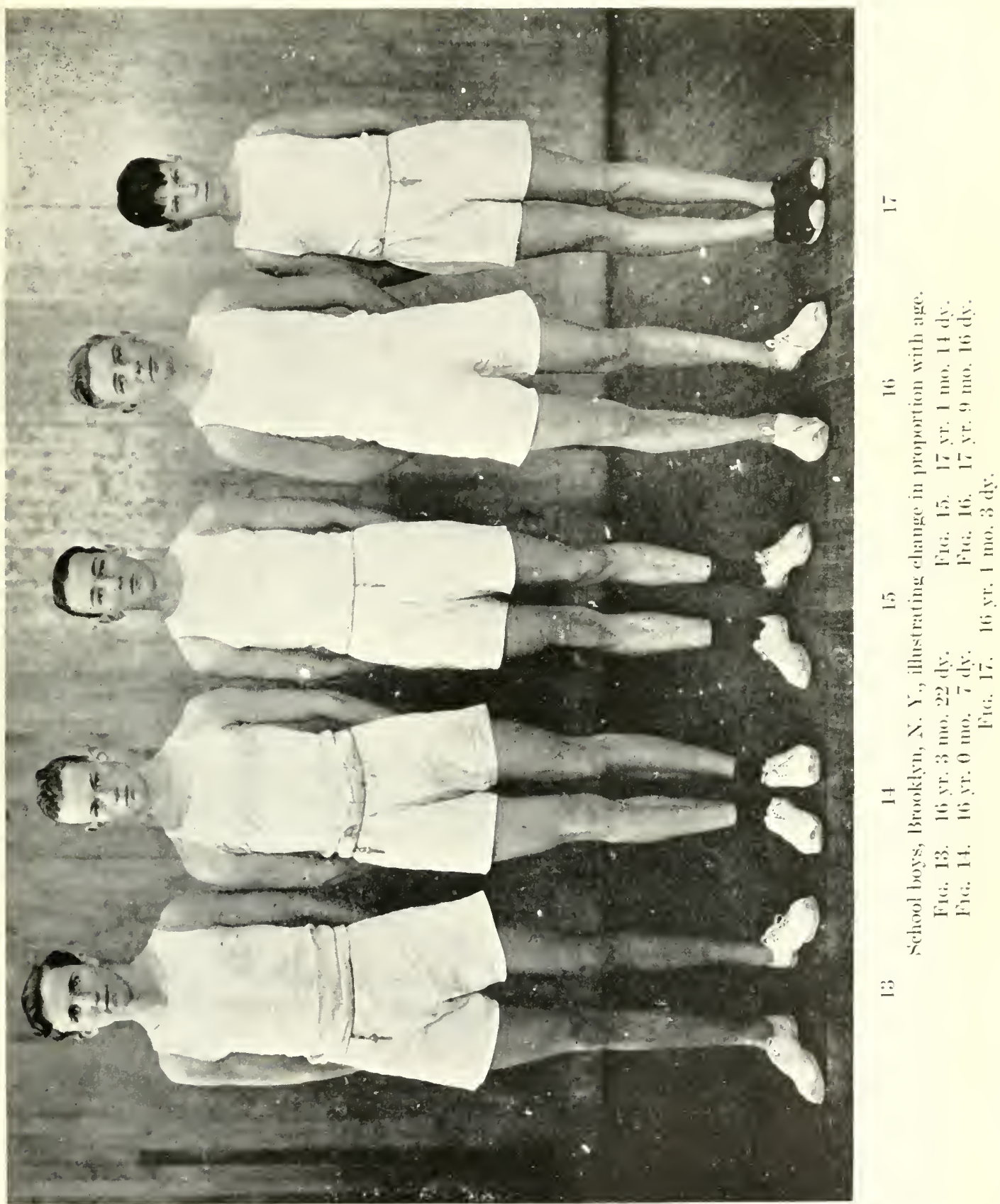




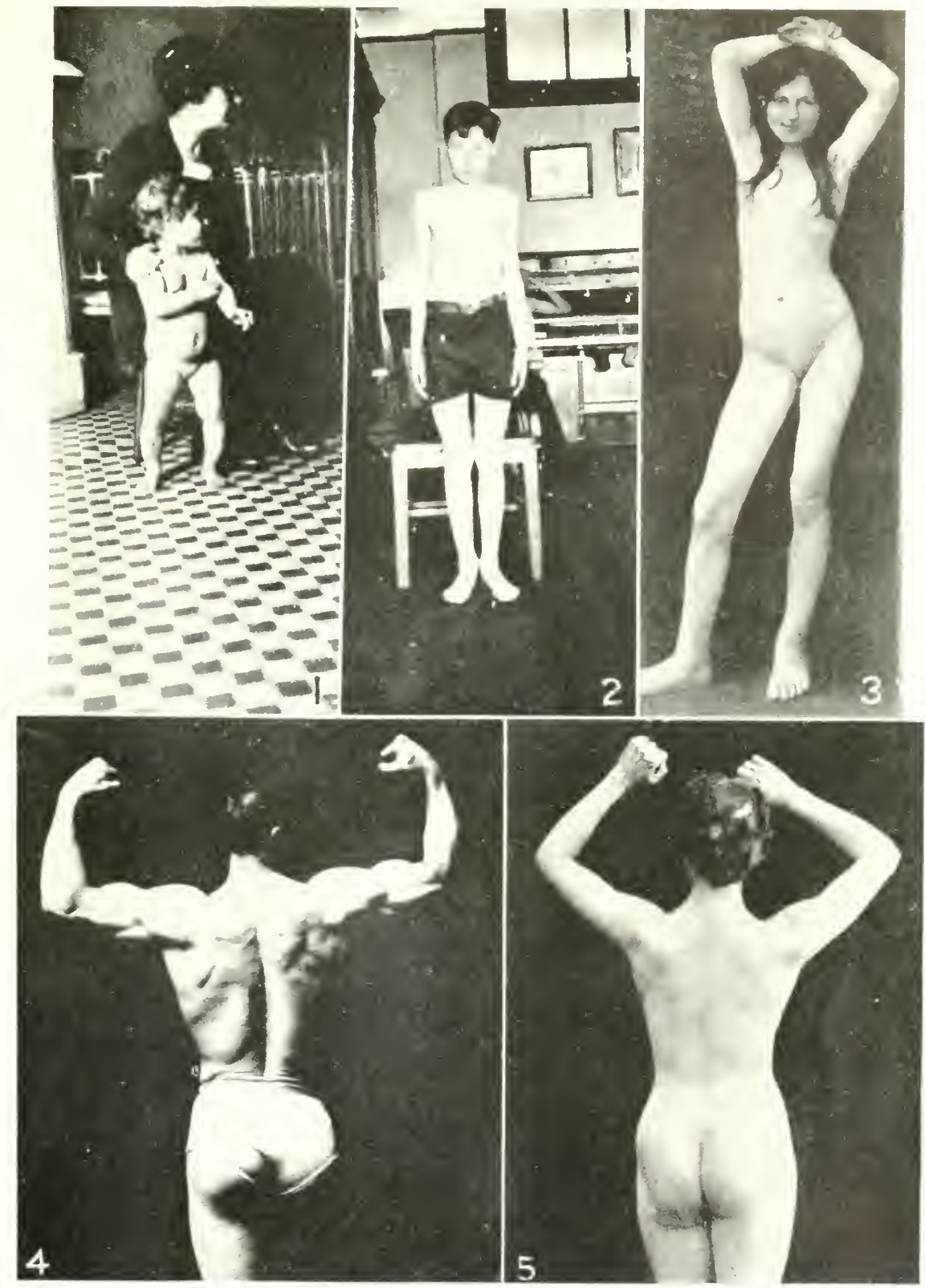

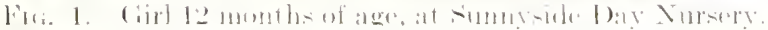

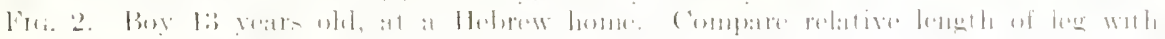
limirr !

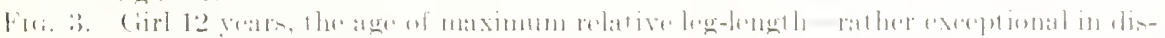

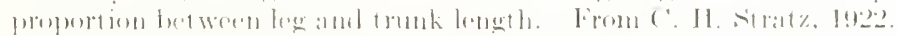

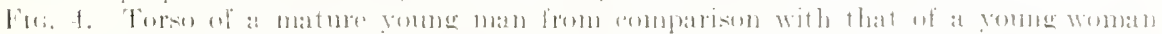

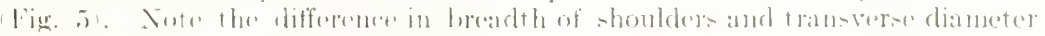

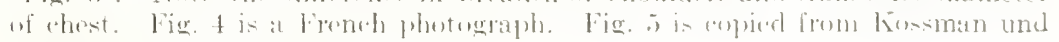
Woiss, "Mann und Wah,", 1, p. 51. 


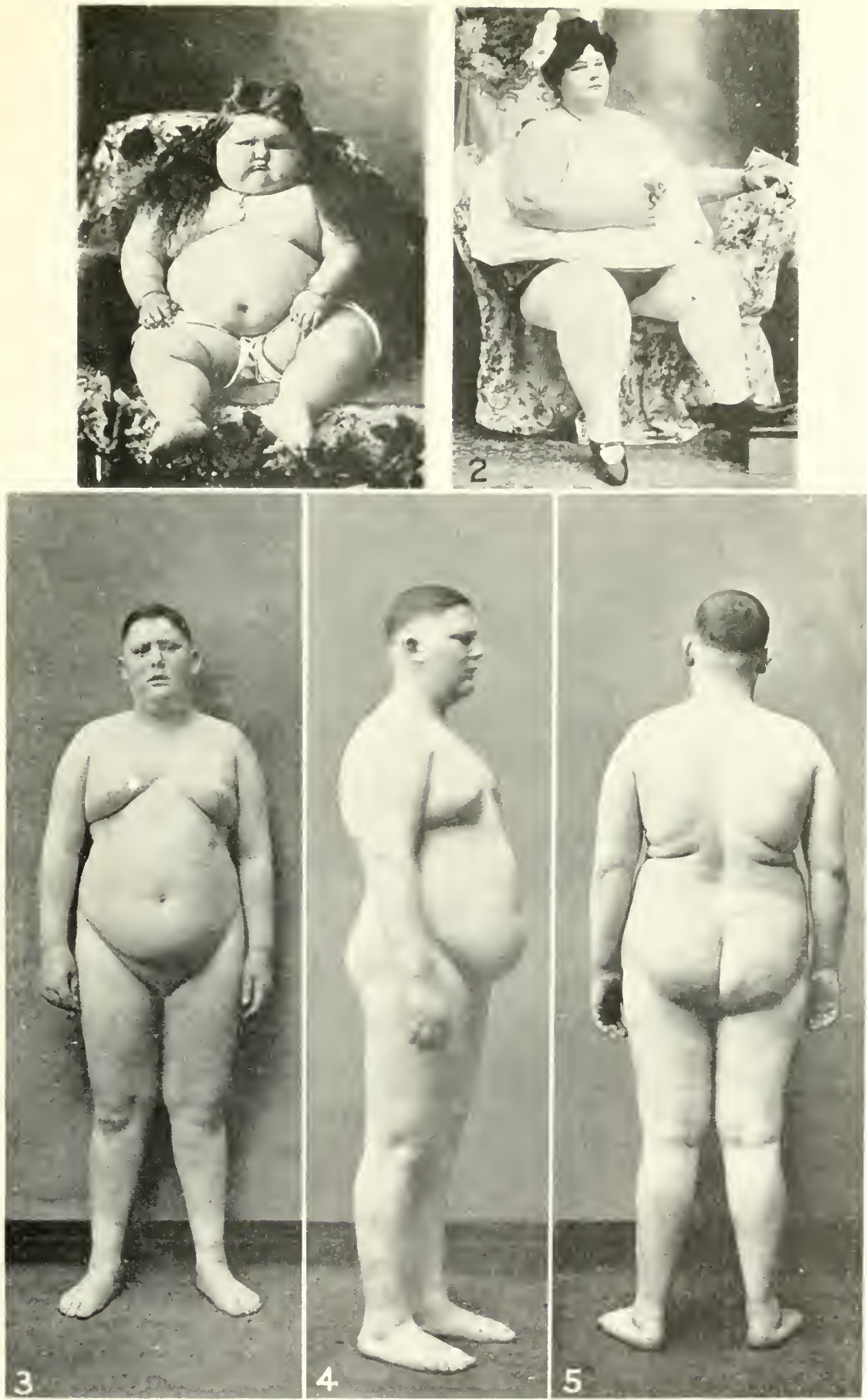

Fugis. 1 and 2. "Mliss Allen" at the age of 4 and "2s years respectively, as evidence of persistence of an early jusenile condition of build.

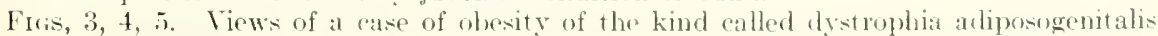
typus feminus, age th years. This wase is characterized by obesity, knock-knee, lurge breasts and mons, and modimentary genitalia (from Elangh and Ioskins in Barker: Endocrines and Metabolism I: sol). 


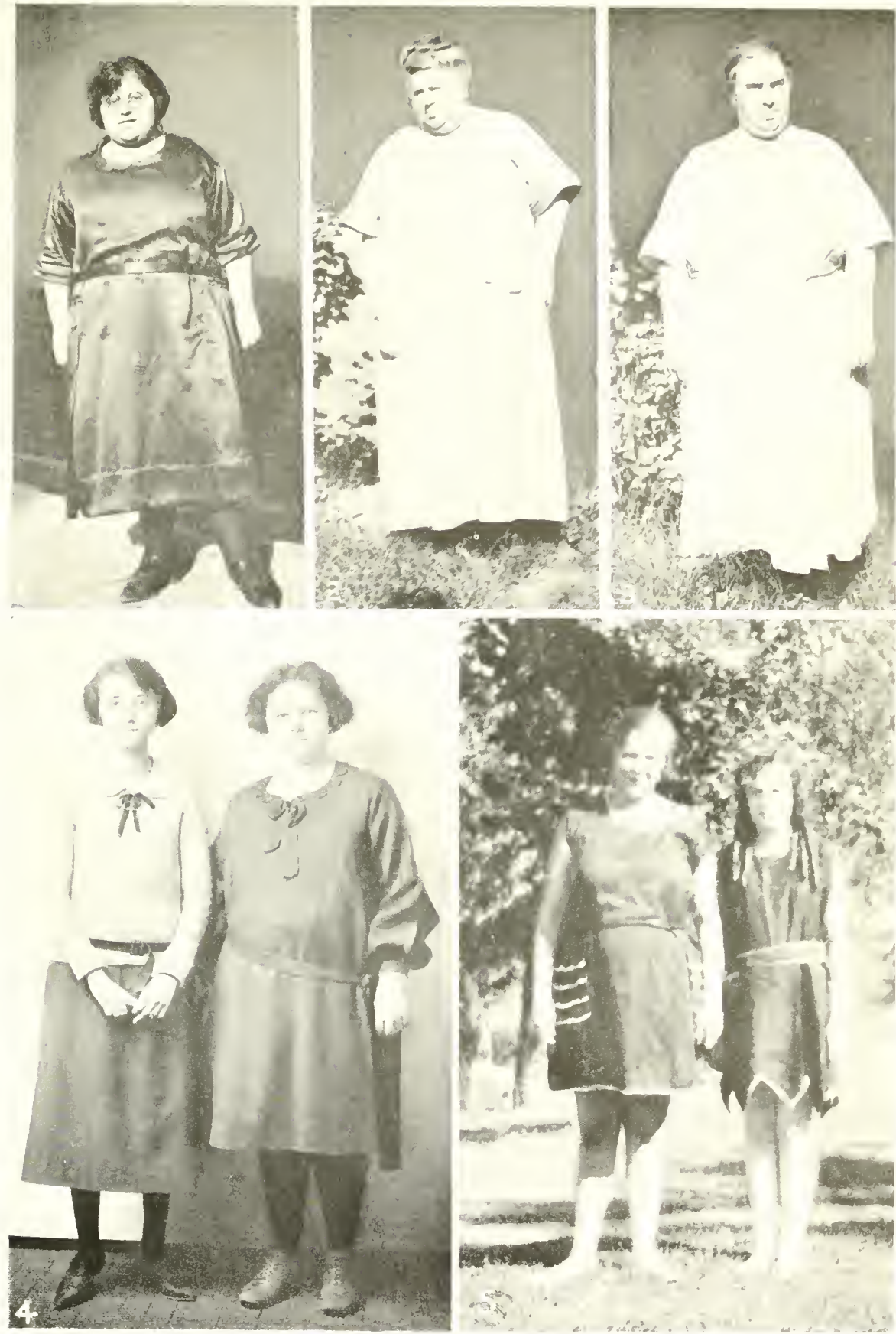

Fin. 1. Rose (), the intividual indicater in fig. 35 at 111 1.5; 1.5 yeatrs of age, stature of

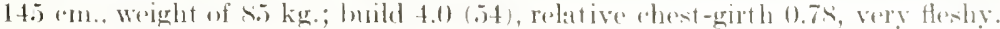

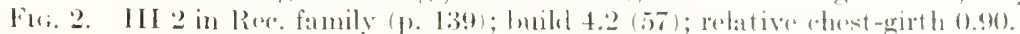

Fin. 3. Ditughter of foregoing; thild :3.7 (52).

Fin. 4. G. sisters, of Luray, Va., showing eontrats of build in two full sisters of at heterozovelus mating.

Fuc 5. The girl at the left is the thenghter in the smi. family peeligres (p). 110). The other is an unrelated friend. This daughter has the formulat at $1 . t$ years: fot

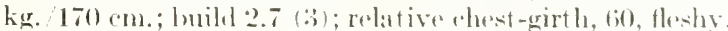



s. . 



$\mathrm{QH}$ Davenport, Charles Benediet
Body-build and its

D25 inheritance

Biotogical

1. Medical

PLEASE DO NOT REMOVE CARDS OR SLIPS FROM THIS POCKET UNIVERSITY OF TORONTO LIBRARY 
3.1.3.

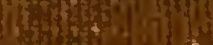

